\title{
Ethnic minority position as risk indicator for autism- spectrum and psychotic disorders
}

Citation for published version (APA):

van der Ven, E. M. A. (2016). Ethnic minority position as risk indicator for autism-spectrum and psychotic disorders. [Doctoral Thesis, Maastricht University]. https://doi.org/10.26481/dis.20160422ev

Document status and date:

Published: 01/01/2016

DOI:

10.26481/dis.20160422ev

Document Version:

Publisher's PDF, also known as Version of record

\section{Please check the document version of this publication:}

- A submitted manuscript is the version of the article upon submission and before peer-review. There can be important differences between the submitted version and the official published version of record.

People interested in the research are advised to contact the author for the final version of the publication, or visit the DOI to the publisher's website.

- The final author version and the galley proof are versions of the publication after peer review.

- The final published version features the final layout of the paper including the volume, issue and page numbers.

Link to publication

\footnotetext{
General rights rights.

- You may freely distribute the URL identifying the publication in the public portal. please follow below link for the End User Agreement:

www.umlib.nl/taverne-license

Take down policy

If you believe that this document breaches copyright please contact us at:

repository@maastrichtuniversity.nl

providing details and we will investigate your claim.
}

Copyright and moral rights for the publications made accessible in the public portal are retained by the authors and/or other copyright owners and it is a condition of accessing publications that users recognise and abide by the legal requirements associated with these

- Users may download and print one copy of any publication from the public portal for the purpose of private study or research.

- You may not further distribute the material or use it for any profit-making activity or commercial gain

If the publication is distributed under the terms of Article $25 \mathrm{fa}$ of the Dutch Copyright Act, indicated by the "Taverne" license above, 
Ethnic minority position as risk indicator for autism-spectrum and psychotic disorders 
Cover design: Rein van der Ven

ISBN: 978-94-6182-662-6

Layout and printing: Off Page

Copyright ( 2016 Els van der Ven 


\title{
Ethnic minority position as risk indicator for autism-spectrum and psychotic disorders
}

\author{
ACADEMISCH PROEFSCHRIFT \\ ter verkrijging van de graad van doctor \\ aan de Universiteit Maastricht \\ op gezag van de Rector Magnificus \\ Prof. dr. L.L.G. Soete \\ volgens het besluit van het College van Decanen \\ in het openbaar te verdedigen \\ op vrijdag 22 april 2016 om 14.00 uur \\ door \\ Elisabeth Maria Anna van der Ven \\ geboren op 29 april 1983 te Nijmegen
}




\section{Promotores}

Prof. dr. J.P. Selten

Prof. dr. J. van Os

\section{Beoordelingscommissie}

Prof. dr. T.A.M.J. van Amelsvoort (voorzitter)

Prof. dr. J. Ormel (Rijksuniversiteit Groningen)

Prof. dr. I. Myin-Germeys (KU Leuven, België)

Prof. dr. C.L. Mulder (Erasmus Universiteit Rotterdam)

The research presented in this thesis was conducted at the School for Mental Health and Neuroscience (MHeNS), Department of Psychiatry and Neuropsychology of Maastricht University, the department of Psychiatry of the Amsterdam Medical Center, and Rivierduinen Institute for Mental Health Care. 


\section{Table of contents}

$\begin{array}{lll}\text { Chapter } 1 & \text { Introduction } & 7\end{array}$

PART I The epidemiological landscape of psychiatric disorders in minority populations

Chapter 2 A meta-analysis of the risk for psychotic disorders among firstand second-generation immigrants

Chapter 3 Evidence of an excessive male-to-female ratio among North African immigrants with a psychotic disorder in Europe: a systematic review and meta-analysis

Chapter 4 Childhood bullying and the association with psychosis in non-clinical and clinical samples: a review and meta-analysis

Chapter 5 An incidence study of diagnosed autism-spectrum disorders among immigrants to the Netherlands

PART II Examining hypotheses behind the epidemiology

Chapter 6 Comparing the clinical presentation of first-episode psychosis across different migrant and ethnic minority groups in Montreal, Quebec

Chapter 7 Testing Ødegaard's selective migration hypothesis: a longitudinal cohort study of risk factors for non-affective psychotic disorders among prospective emigrants

Chapter 8 The social defeat hypothesis of schizophrenia: an update

Chapter 9 General discussion

PART III Addendum

Valorisation

Nederlandse samenvatting

List of publications

Dankwoord

Curriculum Vitae 



\section{chapter ONE}

Introduction 

"Why did this individual develop these symptoms at this time?" is the central question of epidemiology. It forms the basis of case-control studies, in which we retrospectively investigate how individuals who develop a disease and those who do not differ, and cohort studies, in which we search for risk factors that make certain individuals more susceptible for developing a disease (Rose, 1985). When a disease strikes preferentially individuals from one geographical region, sex or social class, we may identify characteristics in the vulnerable group that renders its members at increased risk (Nolen-Hoeksema, 1987). However, we should bear in mind that in our search for risk factors, we assume heterogeneity of exposures within our study population. That is, if everyone smoked 20 cigarettes per day, we would conclude with any of the aforementioned study designs, that lung cancer is a genetic disease, independent of the environment (Rose, 2001). Considering these principles of epidemiology, we sought to increase our understanding of potential causes for psychiatric disorders. We used an approach of investigating the occurrence of these disorders among minority populations, foremost migrants. These types of studies provide a unique window for assessing the influence of environmental factors on disease risk, since migrant populations experience environmental change while the genetic make-up remains stable. It therefore adds to the ongoing debate on the relative contribution of genes and environment in the onset of psychopathology.

\section{The battle between genes and environment}

Risk factors for disease are generally categorized as genetic or environmental. By comparing concordance rates for disease risk among monozygotic and dizygotic twins, we can estimate the relative contribution of genetic factors (e.g. Trisomy 21), unique environmental factors (e.g. a cerebral concussion) and shared environmental factors (e.g. parental socioeconomic status). Based on these impact figures, we can calculate a heritability index for a disease. For instance, the heritability of non-affective, psychotic disorders has been estimated at over $80 \%$ (Cardno et al. 1999). However, the interaction and correlation between risk factors is often neglected in this calculation, while in fact, these associations are common in multi-causal diseases. The interaction between a genetic and environmental factor (geneenvironment interaction) implies that the genetic factor determines the sensitivity to an environmental factor. For example, because of a specific gene mutation many Asians suffer from a deficiency of the aldehyde dehydrogenase (ALDH) enzyme, which is responsible for the oxidative metabolism of ethanol (Thomasson et al. 1991). It is associated with facial flushing, nausea, light-headedness and palpitations when alcohol is consumed. This is a type of gene-environment interaction. Consequently, individuals with this variant of the enzyme drink less alcohol, meaning that genetic factors influence the risk of exposure to an environmental factor. This is gene-environment correlation.

A serious limitation to the validity of the heritability index is that the contribution of gene-environment interactions and correlations is entirely attributed to the genetic effect (Schwartz \& Susser, 2006). Hence, a heritability index of over $80 \%$ for non-affective psychotic disorders is not completely incorrect, because the interactions and correlations cannot occur without the genetic contribution. However, the environmental exposure is also important in the activation of these processes. The heritability indices of complex diseases therefore overestimate the genetic effect. 


\section{Migrant studies and environmental risk factors}

Once the prevalence of a disease increases or decreases after migration, we can search for the nature of the (changing) exposures in the environment and for risk or protective factors in the migrant population. Comparing disease risk according to migrant generations (foreign-born versus native-born) can provide additional clues on the potential impact of the environment. For instance, studies of this kind have been instrumental in the discovery of diet and lifestyle factors in the aetiology of breast cancer. Among Asians who immigrated to the US, the incidence of breast cancer is elevated compared to the population of origin, while rates among US-born Asians approximate those of the white American population. Since the disease risk follows the migration pattern, exposure to Western society appears to influence breast cancer incidence in Asians (Ziegler et al. 1993). Research focusing strictly on ethnic background of the study population may therefore miss insights derived from generational differences in disease risk. However, there are several types of bias that need to be considered in migrant studies. First, migrants do not reflect a random representation of the general population, but a positive selection. This so-called 'healthy migrant phenomenon' implies that emigrants are a biased selection of their population of origin, because the migration process requires favourable circumstances, a certain mental and physical health status and personal qualities (Razum et al. 2000). Second, the diagnostic process may be different in the country of origin and the host society, which complicates the comparability of disease prevalence in immigrants and non-migrants. Third, numerator and denominator data are key to estimating disease incidence. Unreliable population data or differential treatment thresholds for migrants and non-migrants may distort these figures, leading to an over- or underestimation of the incidence (MacMahon \& Trichopoulos, 1996).

\section{Concepts of migration, ethnicity and (visible) minority status}

In this thesis, we use different definitions to describe and categorize migrant and ethnic minority populations. Migration denotes the highly heterogeneous process of an individual moving from one place to settle in another (Bhugra, 2004). The terms 'emigrant' and 'immigrant' are used to designate respectively a person who moves out of a place in another, and a person who moves into a place, either permanently or for a prolonged period. Here, we generally use these two terms to refer to individuals that move countries in the migration process as opposed to internal migrants who move to a different region within one country. For simplification purposes, 'migrant' is regularly used in reference to its meaning of 'immigrant'.

Most research on migrants has focused on foreign-born, i.e. first-generation, migrants who have a personal history of migration. However, we will also discuss the disease risk for the children of migrated parents, who are referred to as second-generation migrants, although they have no personal history of migration. Unlike their parent(s), secondgeneration migrants were not exposed to pre-migration factors or the often stressful migration process itself; however, they share the post-migration context and are at least partially exposed to similar post-migration stressors as their parents. Comparison of disease risk between first- and second-generation migrants may therefore provide clues 
about the potentially pathological influences of different migration phases. Ethnicity, used as a means to categorize migrant populations, highlights a sense of belonging and identification resulting from a variety of factors, such as birth region, language, diet, religion, ancestry, and physical features (Bhopal \& Rankin, 1999). We also demarcated migrant groups according to visible minority status or skin colour to investigate the impact of discrimination.

Although the topic of my thesis largely concerns ethnic minority groups, I will also touch upon the mental health of other minority groups, for instance children who are bullied. A minority group refers to the broad, sociological concept of a category of individuals, differentiated from and defined by the majority group based on one or more human characteristics.

\section{Psychotic disorder versus symptoms}

Throughout this thesis, we use the related terms of psychotic symptoms, (non-affective) psychosis or psychotic disorder, and schizophrenia. Psychotic symptoms generally refer to positive symptoms, i.e. hallucinations, delusions and disorganized behaviour. The prevalence of psychotic symptoms is about 7\% in the general population (Linscott \& van Os, 2013) and the majority (over 75\%) are transitory in nature (van Os et al. 2009). When these symptoms persist, occur for at least a week and interfere with an individual's level of functioning we speak of a psychotic disorder according to the DSM (APA, 2013). Clinicians differentiate roughly between two types of psychoses, the affective and non-affective variant. An affective psychosis is typically characterized by a depressive or manic mood state with a distorted reality testing. Often, the mood is saturated in the psychotic phenomenology; for instance, a depressed patient may be convinced that he/she deserves punishment, while a manic patient may believe he/she has special powers. Although anxiety and depression are common by-products of psychosis, non-affective psychoses occur in the absence of a major mood disorder and are often accompanied by negative symptoms, such as affective flattening, loss of initiative and social withdrawal. Schizophrenia is the diagnostic term used to signify a long-lasting (at least 6 months) non-affective psychosis.

\section{Migration and psychosis}

Driven by the influential 10-country study of the World Health Organization, which reported little variation in schizophrenia incidence in different cultures across the world (Jablensky et al. 1992), the scientific community believed for a long time that "contrary to almost any other common condition, the incidence of schizophrenia is independent of the environment and a characteristic of human populations" (Crow, 2000). This assumption of universality has been refuted by several epidemiological findings demonstrating large variation in schizophrenia incidence (McGrath, 2005; McGrath, 2007).

One of these findings comprises the increased risk of psychotic disorders among various migrant and ethnic minority groups (Bresnahan et al. 2007; Fearon et al. 2006; Veling et al. 2006). Research on the relationship between migration and psychotic disorder is not a new field of interest. Back in the 1930s, the Norwegian psychiatrist Ødegaard, demonstrated that among Norwegian immigrants in Minnesota, admission rates for schizophrenia were 
twice as high as that of native-born Americans and Norwegians in Norway (Ødegaard, 1932). He persuaded his fellow scientists that his findings were a consequence of negative selection (see paragraph 6) and the issue of migration in the aetiology of psychosis was largely disregarded thereafter.

From the 1970s, British researchers rekindled interest for the topic by discovering strikingly high incidence rates for non-affective psychotic disorder (NAPD) among African-Caribbean immigrants in the UK (Cochrane \& Bal, 1989; Harrison et al. 1988). These findings were reinforced by reports of an elevated incidence among similar and other non-Western migrant groups in Europe, including the Netherlands (Selten \& Sijben, 1994), Denmark (Cantor-Graae et al. 2003) and Sweden (Hjern et al. 2004). A first-contact incidence study from the Hague, the Netherlands, showed an increased risk among first- and secondgeneration immigrants from Morocco, Surinam and other non-Western countries (Veling et al. 2006). Evidence from a comprehensive meta-analysis demonstrated that skin colour is a significant predictor for risk variation between migrant groups. Specifically, the psychosis risk for immigrants from countries where the majority of the inhabitants are black was more than four times increased (Cantor-Graae \& Selten, 2005). Pooled relative risks for respectively first- and second-generation immigrants were 2.7 (95\% confidence interval (CI) 2.3-3.2) and 4.9 (95\% CI 1.5-13.1). However, the synthesized risk estimate for secondgeneration migrants was based on only seven migrant groups, each consisting of a relatively small number of cases, as also reflected by the wide confidence interval. Between the 1960s and 1980s, the initial waves of migrants arrived in Europe, and an accumulating number of second-generation migrants lived through their period of risk for developing psychosis. Hence, incidence data for second-generation migrants became increasingly available. If the risk elevation persists in the second generation, it would suggest that post-migration factors play a more prominent role in the aetiology of psychosis than those operating in the pre-migration phase and during the migration process itself. If migrants comprise a positive selection of the population of origin, it would further support the notion that genetic liability cannot be the sole explanation for variation in risk based on migrant status. We therefore sought to update meta-analytical data with recent migrant studies including a greater number of second-generation migrant groups to address the question whether the increased psychosis risk in immigrants persists among their children.

While a meta-analysis found that the mean weighted relative risks of schizophrenia for male and female migrants were similar (Cantor-Graae \& Selten, 2005), studies conducted in the Netherlands indicated disproportionate male-to-female ratios in psychosis risk among the Moroccan-Dutch (Veling et al. 2006). Since disorders cannot influence sex, epidemiological differences according to sex may be of particular interest allowing unidirectional explanations (Aleman et al. 2003). For example, true sex differences in psychosis risk among the Moroccan-Dutch challenge an explanation in terms of hypovitaminosis D, because this deficiency is likely to be more prevalent in Moroccan-Dutch women. We therefore examined the validity of previous studies reporting disproportionate male-to-female ratios among Moroccan-Dutch and their generalizability to North African immigrants in other European countries. 
Because autism-spectrum disorders (ASDs) and psychotic disorders show phenotypical overlap, including difficulties in social interaction and impairments in cognitive functioning, researchers have focused on identifying shared genetic risk factors. However, a study of common single nucleotide polymorphisms demonstrates a low genetic correlation between ASD and schizophrenia (0.16+/- 0.06 SE) (Cross-Disorder Group of the Psychiatric Genomics Consortium, 2013).

On the basis of conclusions derived from relatively small twin samples, ASDs have long been considered purely heritable (Bailey et al. 1995; Folstein \& Rutter, 1977). This line of research was challenged by findings from a recent study of mono- and dizygotic twin pairs with at least 1 affected twin, demonstrating only moderate heritability (37\%). In fact, in this much larger sample, the majority of the liability to autism could be explained by the shared twin environment (Hallmayer et al. 2011). The combination of evidence supporting environmental factors in the aetiology of ASDs, and similarities of the clinical picture with that of psychotic disorder, calls for the investigation of psychosis risk factors in ASDs, such as migration and ethnic minority status. Previous studies have found mixed results. While US-based reports indicated decreased or similar rates of ASD in children of an ethnic minority, studies from the UK and Scandinavia found their risk to be increased (Dealberto, 2011). In a large cohort of Swedish children, Magnusson and colleagues (2012) found that those born to migrant parents were at decreased risk of high-functioning autism (odds ratio $(\mathrm{OR})=0.5,95 \% \mathrm{CI} 0.5-0.6)$ and at increased risk for low-functioning autism $(\mathrm{OR}=1.5,95 \%$ CI 1.3-1.7). The risk magnitude was largest when parents migrated from poorer areas and when migration occurred during the pregnancy. The association between parental migration and risk for developing an ASD has never been investigated in the Netherlands. We therefore aimed to map out the incidence of ASD among children of non-migrant, Dutch, versus migrant parents.

\section{Bias and confounding}

\section{Misdiagnosis}

Critics question the association between psychotic disorder and migration, arguing that Western clinicians who are unfamiliar with their patient's culture, wrongly attribute some beliefs or phenomena to a psychotic disorder (Littlewood \& Lipsedge, 1981; Zandi et al. 2010). For instance, Zandi and colleagues (2010) emphasize that for Moroccans, hearing voices of spirits ('jinns') are common cultural expressions of distress that emerge during difficult periods in life. Indeed, the existence of supernatural forces is a mainstream belief in many cultures and magical explanatory models for psychiatric symptoms are common (Lim et al. 2014). However, the question is whether it is in the best interest of patients if these experiences are interpreted as normal cultural phenomena once they structurally start interfering with a person's life.

In several studies, efforts were made to investigate the plausibility that the increased psychosis risk can be explained by diagnostic bias. Importantly, involving relatives in the diagnostic process to enable a well-informed judgement on whether behaviour and 
expressions are compatible with a patient's ethnic background, led to the highest incidence numbers among Moroccan-Dutch (Veling et al. 2006). Ethnic blinding, i.e. assigning a diagnosis while remaining blind to a person's ethnic background, did not influence the elevated risk (Fearon et al. 2006). Another study demonstrated that there was no significant difference in the number of African-Caribbean patients diagnosed with a psychotic disorder by either a Jamaican or British psychiatrist (Hickling et al. 1999).

In two studies the diagnostic process was repeated at intervals of thirty months (Veen et al. 2004) and eighteen years (Takei et al. 1998), both showing high diagnostic stability among ethnic minority patients. This suggests that psychotic symptoms do not appear transient or insignificant in nature.

If symptomatology was indeed structurally misinterpreted among ethnic minority patients, one would expect differences in age at onset of symptoms (e.g. depressive disorders usually have a later onset than psychotic disorders) and in the nature of psychotic symptoms at baseline, contingent on an individual's ethnic background. Using a cohort of patients with a first psychotic episode in a defined catchment area in Montreal, Canada, we tested the null hypothesis of no difference in age at onset or in the nature of symptoms between the various ethnic groups.

\section{Selective migration}

Ødegaard (1932) attributed his findings of increased psychosis risk among Norwegian immigrants in the United States to selective migration. He postulated that individuals with a genetic predisposition for schizophrenia are more likely to emigrate, because they are unable to integrate in their home country, but the evidence presented was purely anecdotal. Genetic confounding has also been suggested to play a role in other psychosis risk factors, such as childhood trauma, assuming that individuals with high psychosis liability are more likely to be victimized in early life (Shakoor et al. 2015). Although most investigations to date do not support the selection hypothesis, some researchers still consider it a potential candidate for explaining higher rates of psychosis in migrants. For instance, Pedersen and colleagues (2011) found a positive association between the degree of urbanization and risk of emigration to a foreign country and concluded that Danes living abroad have a higher "environmental" predisposition for developing schizophrenia. If selective migration would indeed be responsible for the increased incidence in migrants, it would emphasize the impact of genetic liability in the association. We tested the selection hypothesis by investigating whether psychosis risk factors are more prevalent among prospective emigrants in a longitudinal study design.

\section{Confounding}

There are a number of variables that could confound the association between migrant status and risk for psychotic disorder. Differences in the age composition of migrant and non-migrant populations may lead to artefactual results. However, studies with robust denominator data and age-adjusted effect sizes also show consistently increased psychosis rates. Immigrants generally have a lower socioeconomic status (SES), as measured by a variety of variables, including income, level of employment and education. Patients with a psychotic disorder have a much lower socio-economic status than non-psychotic individuals, 
but this difference is mainly due to the consequences of having a serious mental disorder. Studies of parental SES have produced mixed results. Some studies did find a lower SES for parents of psychotic individuals (Goldberg et al. 2011; Werner et al. 2007; Wicks et al. 2005), while others did not (Byrne et al. 2004). Statistical adjustment for parental SES resulted in attenuated psychosis risk estimates among immigrants in several studies; however, it did not eliminate the entire effect (Hjern et al. 2004; Kirkbride et al. 2008). Furthermore, if poverty were a risk factor for psychosis, one would expect a very high incidence in low-income countries. However, there is no evidence of this (Saha et al. 2005).

Urbanicity, a well-established risk factor for psychosis, could act as a confounder if migrants would have an increased risk, simply, because a large proportion lives in cities. However, adjustment for urbanization of birthplace in a Danish study only caused a small reduction of psychosis risk and this effect was larger for native Danes than for immigrants (Cantor-Graae \& Pedersen, 2007). Furthermore, most incidence studies have been conducted within one town or city (London, Nottingham, The Hague, Malmø, etc.), meaning that the entire study population was exposed to an urban living environment.

Nonetheless, this does not exclude the possibility that the relationship between migration and psychosis risk is partly moderated by specific characteristics of urban dwelling. In fact, high social fragmentation and low social capital are neighbourhood characteristics predictive of many adverse health outcomes, one of which is psychosis (Kirkbride et al. 2007; Veling et al. 2014), and may be more common in the living environment of migrants. These concepts of social cohesion of the wider shared environment, measured by variables like percentage of single-person households, rental housing and population turnover, appear to be more essential than economic deprivation per se (Allardyce \& Boydell, 2006).

\section{The role of biological factors}

\section{Cannabis use}

There is strong evidence that cannabis use, especially forms with high concentrations of tetrahydrocannabinol, constitute a risk factor for psychotic disorder (Di Forti et al. 2009; Zammit et al. 2002). Cannabis was therefore considered a potential candidate to explain high psychosis rates, primarily among African-Caribbean migrants in the UK (Sharpley et al. 2001). In clinical studies to date, however, the reported prevalence of cannabis use was similar in ethnic minority patients compared to their non-migrant counterparts in the Netherlands (Veen et al. 2002; Veling et al. 2008a) and the UK (Mazzoncini et al. 2010). We should nonetheless be cautious before refuting the influence of cannabis altogether, since these studies did not eliminate the potential impact of reporting bias (Selten et al. 2002) and did not include relevant details on duration of use or age at commencement.

\section{Obstetric complications}

A meta-analysis has demonstrated a small, but significant effect of complications during pregnancy or delivery and psychosis risk in offspring (Cannon et al. 2002). However, the limited evidence suggests that African-Caribbean patients have less obstetric complications than white British patients with a psychotic disorder (Harvey et al. 1990; McKenzie et al. 2002). 
Prenatal and chronic postnatal hypovitaminosis $\mathrm{D}$ has also been proposed to affect psychosis risk in migrants, especially dark-skinned immigrants who live in cooler climates with less sunlight, the most important source for vitamin D (Dealberto, 2007; McGrath, 2011). Studies in rats have demonstrated that indeed a lack of vitamin D may alter brain structure and function, as well as dopaminergic activity (Eyles et al. 2009; Kesby et al. 2010). Although this may lend some support to the idea that hypovitaminosis D could contribute to the development of psychotic pathology, it does not match well with findings of increased psychosis incidence among immigrants moving to similar or even warmer climates, for instance, immigrants from the Former Soviet Union in Israel (Weiser et al. 2008) and Finns in Sweden (Leao et al. 2006). Along similar lines, it does not correspond with the risk pattern in the UK, where Asians have the highest rates of vitamin D deficiency and lower rates of psychosis than African-Caribbean migrant groups (Morgan et al. 2010).

\section{Viral infections}

Derived from the theory that individuals immigrating to new countries are more susceptible to certain infectious agents due to a different immune status, viral infections have also been considered as a potential risk factor (Veling \& Susser, 2011). Although there is some evidence for an association between prenatal exposure to infection, and risk for psychotic disorder in adult life (Mortensen et al. 2007; Sørensen et al. 2009), there are no findings demonstrating that viral infectious agents are more common among migrant patients (Selten et al. 2000). Furthermore, this hypothesis lacks an explanation for the increased risk among individuals that have not migrated in the perinatal period of their life. Lastly, it cannot account for higher rates in immigrants who migrated from proximal regions, for instance, Scandinavian immigrants in Denmark (Cantor-Graae et al. 2003).

\section{The role of socio-environmental factors}

\section{Ethnic identity}

One social factor that is believed to play a role at the individual level is the style of 'acculturation' - the extent to which an individual holds on to his/her ethnic identity after going through a cultural change (Berry, 2001). Findings in relation to psychosis risk have been equivocal in terms of its potential harmful or protective influence. In a case-control study by Veling and colleagues (2010), ethnic identity (i.e. subjective feelings and ideas about one's own ethnic background) was associated with psychosis risk. Specifically, cases were more likely to have an assimilated identity and less likely to have a separated identity or positive identification with one's own ethnic group, as compared to hospital controls and siblings. Findings among Black African and African-Caribbean migrants in the UK, however, demonstrated the opposite pattern: an increased odds for psychosis corresponding to higher levels of ethnic identification with the own ethnic group. Perceived discrimination mediated this association (Reininghaus et al. 2010). These contradictory findings may be the result of methodological differences, but could also suggest that the impact of a strong ethnic identity on psychosis risk may vary, depending on the interaction between the ethnic 
minority group and societal factors. In spite of these uncertainties, more research on this topic is warranted, since the growing group of second- and further generation migrants in Europe are often faced with negotiating two cultures, sometimes conflicting, throughout their development.

\section{Discrimination}

Variation in risk based on ethnic background has led to the hypothesis that discrimination plays a role in the aetiology of psychotic disorder. Prospective research with a general population sample demonstrated that perceived discrimination was, independent of its source (appearance, sexual orientation, handicap), associated with subclinical, delusional ideas (Janssen et al. 2003).

Furthermore, there was a dose-response relationship between the degree of perceived discrimination (high, medium, low and very low) of ethnic groups, as measured by reported occasions of discrimination, and the odds for having a psychotic disorder in a study conducted in The Hague. Thus, the most exposed group (Moroccan-Dutch) had the highest odds (Veling et al. 2007). This association has also been demonstrated in the AESOP study among African-Caribbean and Black African immigrants in the UK (Cooper et al. 2008). Differential incidence rates depending on the neighbourhood ethnic composition are compatible with these findings if migrants living in neighbourhoods with high own-group density are less exposed to discrimination and other forms of social exclusion.

\section{Ethnic density}

Studies set in various different countries have demonstrated that the greater the proportion of the own ethnic group in the neighbourhood, the lower the risk for psychotic disorder (Faris \& Dunham, 1939; Kirkbride et al. 2007; Veling et al. 2008b) and subclinical psychotic experiences (Das-Munshi et al. 2012). For instance, in The Hague the incidence of psychosis was highest for Turkish, Moroccan and Surinamese immigrants living in areas with low own-group ethnic density. In high-ethnic-density areas, the risk was similar to that for nonmigrant Dutch, even though the level of deprivation is highest in areas where immigrants constitute a large proportion of the population (Veling et al. 2008b). It has therefore been suggested that ethnic density, perhaps as a proxy for social cohesion, mitigates the pathogenic effects of minority stress, including discrimination and chronic strains (Veling \& Susser, 2011). The ethnic density effect has also been replicated at school level; that is, non-migrant, Swedish children attending schools with a high proportion of foreign-born children had an increased risk for developing a psychosis later in life and vice versa (Zammit et al. 2010). A Dutch investigation at symptom level found that low own-group ethnic density in the classroom composition increased feelings of paranoia among ethnic majority pupils (Eilbracht et al. 2014). The extent to which an individual occupies a minority position may therefore be more important than being part of a specific ethnic group (van Os et al. 2010).

\section{Other minority populations and the social defeat hypothesis}

Other minority populations than migrants have also been found to be at increased risk of psychotic symptoms or disorder, such as individuals with a hearing impairment (van der 
Werf et al. 2011), a sexual minority status (Gevonden et al. 2013) and adolescents with low IQ (Goldberg et al. 2011; Zammit et al. 2004).

There have also been several studies showing that early traumatic and stressful experiences are related to the development of a psychotic disorder, especially sexual and physical abuse (Read et al. 2005). However, until recently, the relationship between psychosis and being a victim of bullying, a highly prevalent type of childhood trauma, did not receive much attention. Moreover, the strength and validity of this association is largely unknown, so a systematic quantitative synthesis of the available data is needed.

A decade ago, Selten \& Cantor-Graae (2005) proposed that the association between migration and psychosis risk could be explained by exposure to social defeat, "the negative experience of being excluded from the majority group". According to this hypothesis, the long-term, subjective exposure to social defeat could lead to sensitization of the mesolimbic dopamine system, thereby increasing the risk for developing a psychotic disorder. This hypothesis is derived from findings on dopamine sensitization in neuroleptic-naïve, psychotic patients (Laruelle, 2003) and from experiments, which showed that repeatedly defeated rats exhibited an increased locomotor response to amphetamine (Covington III \& Miczek, 2001) and an increased mesocorticolimbic dopamine release when threatened with another episode of defeat (Tidey \& Miczek, 1996). The experience of chronic social defeat could therefore be the pathological component of occupying a minority position. Given the eruption of research on the influence of environmental factors in psychosis and potential underlying biological mechanisms since 2003, we updated the literature on the role of social defeat in psychosis and sought to answer the question whether the social defeat hypothesis is still compatible with the accumulating, empirical evidence. 


\section{Outline and aims of this thesis}

The aims of this thesis are twofold and are centred around the main objective of advancing our understanding of the variation in risk for psychotic disorder associated with minority status.

AIM I To examine the incidence of psychotic and autism-spectrum disorder in minority populations using different psychiatric outcome measures.

In Chapter 2, using meta-analytic methods we sought to determine the magnitude of risk for developing a psychotic disorder in first- and second-generation migrants compared to the non-migrant, reference population. We also examined intergenerational differences and explored potential moderators that play a role in risk variation. As previously discussed, sex differences may provide important clues about aetiology. In Chapter 3, we compared sex ratios for the incidence of psychotic disorder among North African immigrants in Europe to those for non-migrant Europeans and other migrant groups to Europe. We evaluate the consistency of these findings and discuss potential underlying mechanisms. Chapter 4 encompasses a review and meta-analysis of the literature on the association between psychotic disorder and another disadvantaged group - children who are victim of bullying. The purpose of Chapter 5 was to examine whether parental migration impacts a child's risk of being diagnosed with an autistic-spectrum disorder (ASD) in the Netherlands.

AIM II To test several hypotheses which have been proposed to explain the increased risk of psychotic disorder in ethnic minority populations.

Chapter 6 addresses the potential role of diagnostic bias by describing variations in clinical presentation of patients with a first psychotic episode according to ethnic background in Montreal, Canada. In Chapter 7, we test Ødegaard's selective migration hypothesis by examining whether previously identified risk factors for psychotic disorders are more prevalent among Swedish men who emigrate later in life. In Chapter 8, we will investigate whether the social defeat hypothesis can account for five major psychosis risk factors. Furthermore, we will synthesize epidemiological and experimental evidence that supports or refutes the role of social defeat in the aetiology of psychotic disorder.

Finally, in Chapter 9, I will summarize the findings of this thesis, discuss the implications, limitations, and strengths of the described studies, as well as directions for future research. 


\section{References}

1. Aleman, A., Kahn, R. S., Selten, J. P. (2003). Sex differences in the risk of schizophrenia: evidence from meta-analysis. Arch Gen Psychiatry 60, 565-571.

2. Allardyce, J., Boydell, J. (2006). Review: the wider social environment and schizophrenia. Schizophr Bull 32, 592-598.

3. APA (2013). Diagnostic and statistical manual of mental disorders, DSM-5. American Psychiatric Publishing: Arlington, VA.

4. Bailey, A., Le Couteur, A., Gottesman, I., Bolton, P., Simonoff, E., Yuzda, E., Rutter, M. (1995). Autism as a strongly genetic disorder: evidence from a British twin study. Psychol Med 25, 63-77.

5. Berry, J. W. (2001). A Psychology of Immigration. J Soc Issues 57, 615-631.

6. Bhopal, R., Rankin, J. (1999). Concepts and terminology in ethnicity, race and health: be aware of the ongoing debate. Br Dent J 186, 483-484.

7. Bhugra, D. (2004). Migration and mental health. Acta Psychiatr Scand 109, 243-258.

8. Bresnahan, M., Begg, M. D., Brown, A., Schaefer, C., Sohler, N., Insel, B., Vella, L., Susser, E. (2007). Race and risk of schizophrenia in a US birth cohort: another example of health disparity? Intl J Epidemiol $36,751-758$.

9. Byrne, M., Agerbo, E., Eaton, W. W., Mortensen, P. B. (2004). Parental socioeconomic status and risk of first admission with schizophrenia- a Danish national register based study. Soc Psychiatry Psychiatr Epidemiol 39, 87-96.

10. Cannon, M., Jones, P. B., Murray, R. M. (2002). Obstetric Complications and Schizophrenia: Historical and Meta-Analytic Review. Am J Psychiatry 159, 1080-1092.

11. Cantor-Graae, E., Pedersen, C. B. (2007). Risk of schizophrenia in second-generation immigrants: a Danish population-based cohort study. Psychol Med 37, 485-494.

12. Cantor-Graae, E., Pedersen, C. B., McNeil, T. F., Mortensen, P. B. (2003). Migration as a risk factor for schizophrenia: a Danish population-based cohort study. Br J Psychiatry 182, 117-122.

13. Cantor-Graae, E., Selten, J. P. (2005). Schizophrenia and migration: a meta- analysis and review. Am J Psychiatry 162, 12-24.

14. Cardno, A. G., Marshall, E. J., Coid, B., Macdonald, A. M., Ribchester, T. R., Davies, N. J., Venturi, P., Jones, L. A., Lewis, S. W., Sham, P. C., Gottesman, I. I., Farmer, A. E., McGuffin, P., Reveley, A. M., Murray, R. M. (1999). Heritability estimates for psychotic disorders: the Maudsley twin psychosis series. Arch Gen Psychiatry 56, 162-168.

15. Cochrane, R., Bal, S. S. (1989). Mental hospital admission rates of immigrants to England: a comparison of 1971 and 1981. Soc Psychiatry Psychiatr Epidemiol 24, 2-11.

16. Cooper, C., Morgan, C., Byrne, M., Dazzan, P., Morgan, K., Hutchinson, G., Doody, G. A., Harrison, G., Leff, J., Jones, P., Ismail, K., Murray, R., Bebbington, P., Fearon, P. (2008). Perceptions of disadvantage, ethnicity and psychosis. Br J Psychiatry 192, 185-190.

17. Covington III, H. E., Miczek, K. A. (2001). Repeated social-defeat stress, cocaine or morphine. Effects on behavioral sensitization and intravenous cocaine self-administration "binges". Psychopharmacology (Berl) 158, 388-398.

18. Cross-Disorder Group of the Psychiatric Genomics Consortium (2013). Genetic relationship between five psychiatric disorders estimated from genome-wide SNPs. Nat Genet 45, 984-994.

19. Crow, T. J. (2000). Schizophrenia as the price that homo sapiens pays for language: a resolution of the central paradox in the origin of the species. Brain Res Brain Res Rev 31, 118-129.

20. Das-Munshi, J., Becares, L., Boydell, J. E., Dewey, M. E., Morgan, C., Stansfeld, S. A., Prince, M. J. (2012). Ethnic density as a buffer for psychotic experiences: findings from a national survey (EMPIRIC). Br J Psychiatry 201, 282-290.

21. Dealberto, M. J. (2007). Why are immigrants at increased risk for psychosis? Vitamin D insufficiency, epigenetic mechanisms, or both? Med Hypotheses 68, 259-267.

22. Dealberto, M. J. (2011). Prevalence of autism according to maternal immigrant status and ethnic origin. Acta Psychiatr Scand 123, 339348. 
23. Di Forti, M., Morgan, C., Dazzan, P., Pariante, C., Mondelli, V., Marques, T. R., Handley, R., Luzi, S., Russo, M., Paparelli, A., Butt, A., Stilo, S. A., Wiffen, B., Powell, J., Murray, R. M. (2009). High-potency cannabis and the risk of psychosis. Br J Psychiatry 195, 488-491.

24. Eilbracht, L., Stevens, G. W., Wigman, J. T., van, D. S., Vollebergh, W. A. (2014). Mild psychotic experiences among ethnic minority and majority adolescents and the role of ethnic density. Soc Psychiatry Psychiatr Epidemiol 50, 1029-1037.

25. Eyles, D. W., Feron, F., Cui, X., Kesby, J. P., Harms, L. H., Ko, P., McGrath, J. J., Burne, T. H. (2009). Developmental vitamin $\mathrm{D}$ deficiency causes abnormal brain development. Psychoneuroendocrinol 34 Suppl 1, S247-S257.

26. Faris, R. E. L., Dunham,H. W. (1939). Mental disorders in urban areas: an ecological study of schizophrenia and other psychoses. Univ. Chicago Press: Oxford.

27. Fearon, P., Kirkbride, J. B., Morgan, C., Dazzan, P., Morgan, K., Lloyd, T., Hutchinson, G., Tarrant, J., Fung, W. L., Holloway, J., Mallett, R., Harrison, G., Leff, J., Jones, P. B., Murray, R. M. (2006). Incidence of schizophrenia and other psychoses in ethnic minority groups: results from the MRC AESOP Study. Psychol Med 36, 1541-1550.

28. Folstein, S., Rutter, M. (1977). Infantile autism: a genetic study of 21 twin pairs. J Child Psychol Psychiatry 18, 297-321.

29. Gevonden, M. J., Selten, J. P., MyinGermeys, I., de Graaf, R., Ten Have, M., van Dorsselaer, S., van Os, J., Veling, W. (2014). Sexual minority status and psychotic symptoms: findings from the Netherlands Mental Health Survey and Incidence Studies (NEMESIS). Psychol Med 44, 421-433.

30. Goldberg, S., Fruchter, E., Davidson, M., Reichenberg, A., Yoffe, R., Weiser, M. (2011). The relationship between risk of hospitalization for schizophrenia, SES, and cognitive functioning. Schizophr Bull 37, 664-670.

31. Hallmayer, J., Cleveland, S., Torres, A., Phillips, J., Cohen, B., Torigoe, T., Miller, J., Fedele, A., Collins, J., Smith, K. and Lotspeich, L. (2011). Genetic heritability and shared environmental factors among twin pairs with autism. Arch Gen Psychiatry 68, 1095-1102.

32. Harrison, G., Owens, D., Holton, A., Neilson, D., Boot, D. (1988). A prospective study of severe mental disorder in AfroCaribbean patients. Psychol Med 18, 643-657.

33. Harvey, I., Williams, M., McGuffin, P., Toone, B. K. (1990). The functional psychoses in Afro-Caribbeans. Br J Psychiatry 157, 515 522.

34. Hickling, F. W., McKenzie, K., Mullen, R., Murray, R. (1999). A Jamaican psychiatrist evaluates diagnoses at a London psychiatric hospital. Br J Psychiatry 175, 283-285.

35. Hjern, A., Wicks, S., Dalman, C. (2004). Socialadversity contributes to high morbidity in psychoses in immigrants--a national cohort study in two generations of Swedish residents. Psychol Med 34, 1025-1033.

36. Jablensky, A., Sartorius, N., Ernberg, G., Anker, M., Korten, A., Cooper, J. E., Day, R., Bertelsen, A. (1992). Schizophrenia: manifestations, incidence and course in different cultures. A World Health Organization ten-country study. Psychol Med Monogr Suppl 20, 1-97.

37. Janssen, I., Hanssen, M., Bak, M., Bijl, R. V., de Graaf, R., Vollebergh, W., McKenzie, K., van Os, J. (2003). Discrimination and delusional ideation. Br. J Psychiatry 182, 7176.

38. Kesby, J. P., Cui, X., O’Loan, J., McGrath, J. J., Burne, T. H., Eyles, D. W. (2010). Developmental vitamin D deficiency alters dopamine-mediated behaviors and dopamine transporter function in adult female rats. Psychopharmacology (Berl) 208, 159-168.

39. Kirkbride, J. B., Barker, D., Cowden, F., Stamps, R., Yang, M., Jones, P. B., Coid, J. W. (2008). Psychoses, ethnicity and socioeconomic status. Br J Psychiatry 193, 18-24.

40. Kirkbride, J. B., Morgan, C., Fearon, P., Dazzan, P., Murray, R. M., Jones, P. B. (2007). Neighbourhood-level effects on psychoses: re-examining the role of context. Psychol Med 37, 1413-1425.

41. Laruelle, M. (2003). Dopamine transmission in the schizophrenic brain. In Schizophrenia, (ed. S. R. Hirsch and D. Weinberger), pp. 365387. Blackwell: Oxford.

42. Leao, T. S., Sundquist, J., Frank, G., Johansson, L. M., Johansson, S. E., 
Sundquist, K. (2006). Incidence of Schizophrenia or Other Psychoses in Firstand Second-Generation Immigrants: A National Cohort Study. J Nerv Ment Dis 194, 27-33.

43. Lim, A., Hoek, H. W., Blom, J. D. (2014). The attribution of psychotic symptoms to jinn in Islamic patients. Transcult Psychiatry 52, 18-32.

44. Linscott, R. J., van Os, J. (2013). An updated and conservative systematic review and meta-analysis of epidemiological evidence on psychotic experiences in children and adults: on the pathway from proneness to persistence to dimensional expression across mental disorders. Psychol Med 43, 1133-1149.

45. Littlewood, R., Lipsedge, M. (1981). Some social and phenomenological characteristics of psychotic immigrants. Psychol Med 11, 289-302.

46. MacMahon, B. \& Trichopoulos, D. (1996). Migration. In Epidemiology: Prinicples and Methods, (ed. B. MacMahon and D. Trichopoulos), pp. 148-164. Little, Brown and Co.: London.

47. Magnusson, C., Rai, D., Goodman, A., Lundberg, M., Idring, S., Svensson, A., Koupil, I., Serlachius, E., Dalman, C. (2012). Migration and autism spectrum disorder: population-based study. Br J Psychiatry 201, 109-115.

48. Mazzoncini, R., Donoghue, K., Hart, J., Morgan, C., Doody, G. A., Dazzan, P., Jones, P. B., Morgan, K., Murray, R. M., Fearon, P. (2010). Illicit substance use and its correlates in first episode psychosis. Acta Psychiatr Scand 121, 351-358.

49. McGrath, J. (2011). Migrant status, vitamin D and risk of schizophrenia. Psychol Med 41, 892-893.

50. McGrath, J. J. (2005). Myths and plain truths about schizophrenia epidemiology--the NAPE lecture 2004. Acta Psychiatr Scand 111, 4-11.

51. McGrath, J. J. (2007). The surprisingly rich contours of schizophrenia epidemiology. Arch Gen Psychiatry 64, 14-16.

52. McKenzie, K., Jones, P., Lewis, S., Williams, M., Toone, B., Sham, P., Murray, R. M. (2002). Lower prevalence of pre-morbid neurological illness in African-Caribbean than White psychotic patients in England. Psychol Med 32, 1285-1291.
53. Morgan, C., Charalambides, M., Hutchinson, G., Murray, R. M. (2010). Migration, ethnicity, and psychosis: toward a sociodevelopmental model. Schizophr Bull 36, 655-664.

54. Mortensen, P. B., Norgaard-Pedersen, B., Waltoft, B. L., Sorensen, T. L., Hougaard, D., Torrey, E. F., Yolken, R. H. (2007). Toxoplasma gondii as a Risk Factor for EarlyOnset Schizophrenia: Analysis of Filter Paper Blood Samples Obtained at Birth. Biol Psychiatry 61, 688-693.

55. Nolen-Hoeksema, S. (1987). Sex differences in unipolar depression: evidence and theory. Psychol Bull. 101, 259-282.

56. Ødegaard, Ø. (1932). Emigration and insanity: a study of mental disease among Norwegian-born population in Minnesota. Acta Psychiatr Neurol Scand Suppl 4, 1-206.

57. Pedersen, C. B., Mortensen, P. B., CantorGraae, E. (2011). Do risk factors for schizophrenia predispose to emigration? Schizophr Res 127, 229-234.

58. Razum, O., Zeeb, H., Rohrmann, S. (2000). The 'healthy migrant effect'--not merely a fallacy of inaccurate denominator figures. Int J Epidemiol 29, 191-192.

59. Read, J., van Os, J., Morrison, A. P., Ross, C. A. (2005). Childhood trauma, psychosis and schizophrenia: a literature review with theoretical and clinical implications. Acta Psychiatr Scand 112, 330-350.

60. Reininghaus, U., Craig, T. K., Fisher, H. L., Hutchinson, G., Fearon, P., Morgan, K., Dazzan, P., Doody, G. A., Jones, P. B., Murray, R. M., Morgan, C. (2010). Ethnic identity, perceptions of disadvantage, and psychosis: findings from the AESOP study. Schizophr Res 124, 43-48.

61. Rose, G. (1985). Sick individuals and sick populations. Int J Epidemiol 14, 32-38.

62. Rose, G. (2001). Sick individuals and sick populations. Int J Epidemiol 30, 427-432.

63. Saha, S., Chant, D., Welham, J., McGrath, J. (2005). A systematic review of the prevalence of schizophrenia. PLoS. Med 2, e141.

64. Schwartz, S. \& Susser, E. S. (2006). The myth of the heritability index. In Beyond Nature and Nurture in Psychiatry, (ed. J. MacCabe, O. O’Daly, R. Murray and P. Wright), pp. 1926. Informa Healthcare: Abingdon. 
65. Selten, J. P., Bosman, I. J., de, B. D., Veen, N. D., van der Graaf, Y., Maes, R. A., Kahn, R. S. (2002). Hair analysis for cannabinoids and amphetamines in a psychosis incidence study. Eur Neuropsychopharmacol 12, 27-30.

66. Selten, J. P., Cantor-Graae, E. (2005). Social defeat: risk factor for schizophrenia? Br J Psychiatry 187, 101-102.

67. Selten, J. P., Sijben, N. (1994). First admission rates for schizophrenia in immigrants to The Netherlands. The Dutch National Register. Soc Psychiatry Psychiatr Epidemiol 29, 71-77.

68. Selten, J. P., van Vliet, K., Pleyte, W., Herzog, S., Hoek, H. W., van Loon, A. M. (2000). Borna disease virus and schizophrenia in Surinamese immigrants to the Netherlands. Med Microbiol Immunol 189, 55-57.

69. Shakoor, S., McGuire, P., Cardno, A. G., Freeman, D., Plomin, R., Ronald, A. (2015). A shared genetic propensity underlies experiences of bullying victimization in late childhood and self-rated paranoid thinking in adolescence. Schizophr Bull 41, 754-763.

70. Sharpley, M., Hutchinson, G., McKenzie, K., Murray, R. M. (2001). Understanding the excess of psychosis among the AfricanCaribbean population in England. Review of current hypotheses. Br J Psychiatry Suppl 40, s60-s68.

71. Sørensen, H., Mortensen, E. L., Reinisch, J. M., Mednick, S. A. (2009). Association Between Prenatal Exposure to Bacterial Infection and Risk of Schizophrenia. Schizophr Bull 35, 631-637.

72. Takei, N., Persaud, R., Woodruff, P., Brockington, I., Murray, R. M. (1998). First episodes of psychosis in Afro-Caribbean and White people. An 18-year follow-up population-based study. Br J Psychiatry 172, 147-153.

73. Thomasson, H. R., Edenberg, H. J., Crabb, D. W., Mai, X. L., Jerome, R. E., Li, T. K., Wang, S. P., Lin, Y. T., Lu, R. B., Yin, S. J. (1991). Alcohol and aldehyde dehydrogenase genotypes and alcoholism in Chinese men. Am J Hum Genet 48, 677-681.

74. Tidey,J. W., Miczek, K.A. (1996). Socialdefeat stress selectively alters mesocorticolimbic dopamine release: an in vivo microdialysis study. Brain Res 721, 140-149.

75. vanderWerf, M., Thewissen, V., Dominguez, M. D., Lieb, R., Wittchen, H., van Os, J. (2011). Adolescent development of psychosis as an outcome of hearing impairment: a 10-year longitudinal study. Psychol Med 41, 477-485.

76. van Os, J., Linscott, R. J., Myin-Germeys, I., Delespaul, P., Krabbendam, L. (2009). A systematic review and meta-analysis of the psychosis continuum: evidence for a psychosis proneness-persistenceimpairment model of psychotic disorder. Psychol Med 39, 179-195.

77. van Os, J., Kenis, G., Rutten, B. P. F. (2010). The environment and schizophrenia. Nature 468, 203-212.

78. Veen, N., Selten, J. P., Hoek, H. W., Feller, W., van der Graaf, Y., Kahn, R. (2002). Use of illicit substances in a psychosis incidence cohort: a comparison among different ethnic groups in the Netherlands. Acta Psychiatr Scand 105, 440-443.

79. Veen, N. D., Selten, J. P., Schols, D., Laan, W., Hoek, H. W., van der Tweel, I., Kahn, R. S. (2004). Diagnostic stability in a Dutch psychosis incidence cohort. Br. J Psychiatry $185,460-464$.

80. Veling, W., Hoek, H. W., Wiersma, D., Mackenbach, J. P. (2010). Ethnic identity and the risk of schizophrenia in ethnic minorities: a case-control study. Schizophr Bull 36, 1149-1156.

81. Veling, W., Mackenbach, J. P., van Os, J., Hoek, H. W. (2008a). Cannabis use and genetic predisposition for schizophrenia: a case-control study. Psychol Med 38, 12511256.

82. Veling, W., Selten, J. P., Susser, E., Laan, W., Mackenbach, J. P., Hoek, H. W. (2007). Discrimination and the incidence of psychotic disorders among ethnic minorities in The Netherlands. Int J Epidemiol 36, 761768.

83. Veling, W., Selten, J. P., Veen, N., Laan, W., Blom, J. D., Hoek, H. W. (2006). Incidence of schizophrenia among ethnic minorities in the Netherlands: a four-year first-contact study. Schizophr Res 86, 189-193.

84. Veling, W., Susser, E. (2011). Migration and psychotic disorders. Expert Rev Neurother 11, 65-76.

85. Veling, W., Susser, E., Selten, J. P., Hoek, H. W. (2014). Social disorganization of neighborhoods and incidence of psychotic disorders: a 7-year first-contact incidence study. Psychol Med 45, 1789-1798. 
86. Veling, W., Susser, E., van Os, J., Mackenbach, J. P., Selten, J. P., Hoek, H. W. (2008b). Ethnic density of neighborhoods and incidence of psychotic disorders among immigrants. Am J Psychiatry 165, 66-73.

87. Weiser, M., Werbeloff, N., Vishna, T., Yoffe, R., Lubin, G., Shmushkevitch, M., Davidson, M. (2008). Elaboration on immigration and risk for schizophrenia. Psychol Med 38, 11131119.

88. Werner, S., Malaspina, D., Rabinowitz, J. (2007). Socioeconomic status at birth is associated with risk of schizophrenia: population-based multilevel study. Schizophr Bull 33, 1373-1378.

89. Wicks, S., Hjern, A., Gunnell, D., Lewis, G., Dalman, C. (2005). Social adversity in childhood and the risk of developing psychosis: a national cohort study. Am J Psychiatry 162, 1652-1657.

90. Zammit, S., Lewis, G., Rasbash, J., Dalman, C., Gustafsson, J. E., Allebeck, P. (2010). Individuals, schools, and neighborhood: a multilevel longitudinal study of variation in incidence of psychotic disorders. Arch Gen Psychiatry 67, 914-922.
91. Zammit, S., Allebeck, P., Andreasson, S., Lundberg, I., Lewis, G. (2002). Self reported cannabis use as a risk factor for schizophrenia in Swedish conscripts of 1969: historical cohort study. BMJ 325, 1199.

92. Zammit, S., Allebeck, P., David, A. S., Dalman, C., Hemmingsson, T., Lundberg, I., Lewis, G. (2004). A Longitudinal Study of Premorbid IQ Score and Risk of Developing Schizophrenia, Bipolar Disorder, Severe Depression, and Other Nonaffective Psychoses. Arch Gen Psychiatry 61, 354-360.

93. Zandi, T., Havenaar, J. M., Smits, M., Limburg-Okken, A. G., van Es, H., Cahn, W., Algra, A., Kahn, R. S., van den Brink, W. (2010). First contact incidence of psychotic disorders among native Dutch and Moroccan immigrants in the Netherlands: influence of diagnostic bias. Schizophr Res 119, 27-33.

94. Ziegler, R. G., Hoover, R. N., Pike, M. C., Hildesheim, A., Nomura, A. M. Y., West, D. W., Wu-Williams, A. H., Kolonel, L. N., Horn-Ross, P. L., Rosenthal, J. F., Hyer, M. B. (1993). Migration Patterns and Breast Cancer Risk in Asian-American Women. J Natl Cancer Institute 85, 1819-1827. 




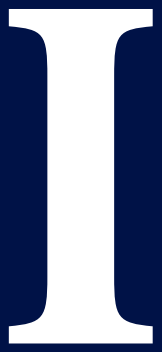

The epidemiological landscape of psychiatric disorders in minority populations 



\section{chapter TWO}

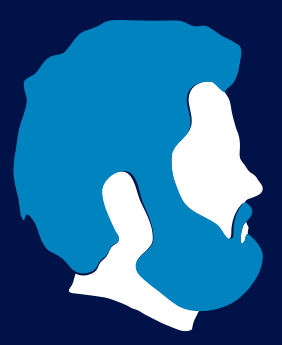

A meta-analysis of the risk for psychotic disorders among first- and second-generation immigrants

F. Bourque,

E. van der Ven,

A. Malla

Psychological Medicine (2011), 41, 897-910. 


\begin{abstract}

\section{Background}

There is increasing acceptance of migration as a risk factor for schizophrenia and related disorders; however, the magnitude of the risk among second-generation immigrants (SGIs) remains unclear. Generational differences in the incidence of psychotic disorders among migrants might improve our understanding of the relationship between migration, ethnicity and psychotic disorders. This meta-analysis aimed at determining the risk of psychotic disorders among SGIs in comparison with non-migrants and first-generation immigrants (FGIs).
\end{abstract}

\title{
Method
}

Medline, EMBASE and PsycINFO databases were searched systematically for populationbased studies on migration and psychotic disorders published between 1977 and 2008. We also contacted experts, tracked citations and screened bibliographies. All potential publications were screened by two independent reviewers in a threefold process. Studies were included in the meta-analysis if they reported incidence data, differentiated FGIs from SGIs and provided age-adjusted data. Data extraction and quality assessment were conducted for each study.

\section{Results}

Twenty-one studies met all inclusion criteria. A meta-analysis of 61 effect sizes for FGIs and 28 for SGIs yielded mean-weighted incidence rate ratios (IRRs) of 2.3 [95\% confidence interval (CI) 2.0-2.7] for FGIs and 2.1 (95\% CI 1.8-2.5) for SGIs. There was no significant risk difference between generations, but there were significant differences according to ethnoracial status and host country.

\section{Conclusions}

The increased risk of schizophrenia and related disorders among immigrants clearly persists into the second generation, suggesting that post-migration factors play a more important role than pre-migration factors or migration per se. The observed variability suggests that the risk is mediated by the social context. 


\section{Introduction}

The incidence of schizophrenia was long held to be homogeneous worldwide, leading to an emphasis on the genetic determination of the condition rather than on the contribution of social or environmental factors (Jablensky et al. 1992). This tenet has been challenged, based on reports of significant variation in incidence between and within countries according to gender, urbanicity and, in particular, migration and ethnicity (Cantor-Graae \& Selten, 2005; Fearon et al. 2006; McGrath et al. 2004).

An association between migration and schizophrenia was first described by the pioneer Ødegaard (1932), who observed an increased risk among Norwegians migrants to the USA in the early twentieth century. However, only in recent decades has an interest in migration and schizophrenia been rekindled, especially after consistent reports of high incidence rates in Caribbean migrants to the UK (Fearon et al. 2006; Harrison et al. 1997; Sharpley et al. 2001). Such elevated incidence rates were noted initially in the decades that followed large migration waves from Commonwealth countries after the Second World War. Later investigations of the incidence of schizophrenia have extended to other European countries. Increased incidence rates have been reported among Moroccan, Surinamese and Antillean migrants to The Netherlands (Selten et al. 1997; Selten \& Sijben, 1994; Veling et al. 2006), and among migrants in Denmark and Sweden (Cantor-Graae et al. 2003; Cantor-Graae \& Pedersen, 2007; Leao et al. 2006). These studies have found increased rates of schizophrenia not only among first-generation immigrants (FGIs), who have a personal history of migration, but also among the growing population of second-generation immigrants (SGIs), their children born in the host society context. It was suggested that the risk may be even higher for SGIs than for FGIs (Harrison et al. 1988). More recent studies in the UK have reported that migrants are at risk for all psychoses, and not only schizophrenia (Coid et al. 2008; Fearon et al. 2006). A meta-analysis of 18 migrant studies found that a personal or family history of migration was associated with an approximately threefold risk elevation for schizophrenia (Cantor-Graae \& Selten, 2005). Significantly higher risk estimates were observed among migrants from developing countries and among those from areas where the majority of the population is black. The authors also observed a higher risk for SGIs than FGIs; however, the meta-analysis was not adequately powered to provide a precise risk estimate, with only seven effect sizes from small second-generation samples.

Migration is now being increasingly recognized as a risk factor for schizophrenia (Selten et al. 2007; Tandon et al. 2008). Yet the relationship between migration and psychotic disorders remains unexplained. So far, biological factors, such as cannabis use or obstetric complications, have failed to account for the risk of schizophrenia among migrant groups (Fearon \& Morgan, 2006). In addition, socio-environmental factors, such as urbanicity, discrimination or socioeconomic deprivation, are now being looked upon as potential contributing factors for psychotic disorders in migrants (Cantor-Graae, 2007). It is uncertain whether SGIs have a similar or even a higher risk than FGIs. Such determination is crucial to explain the association between migration and schizophrenia, and may provide valuable clues to understanding the social determinants of psychotic disorders. Indeed, the persistence or elevation of the risk in the second generation could not be strictly explained by a selection 
hypothesis or genetic factors, and would further highlight the role of post-migration factors. It should be noted that migrant studies and generational differences have yielded significant advances in uncovering the role of environmental factors in other conditions (Lin \& Kelsey, 2000), such as breast cancer and multiple sclerosis (Ramagopalan et al. 2008).

Systematic reviews and meta-analyses provide a transparent approach to identify, abstract and critically appraise pertinent studies and integrate their results. In addition, they can widen the base of studies by addressing broader questions and exploring patterns of results from primary studies (Egger et al. 2001). The current study is a meta-analytic review of population-based studies of the incidence of schizophrenia and related disorders among FGIs and SGIs. The aims of the study were: (1) to determine whether SGIs are at increased risk for schizophrenia and related disorders in comparison with non-migrant groups; (2) to determine the magnitude of the risk among SGIs compared to that of FGIs; and (3) to investigate potential sources of variation in the risk for psychosis among immigrants. To answer these questions, we conducted a meta-analysis to provide an estimate of the risk for schizophrenia and related disorders separately for FGIs and SGIs. The methodology for this study is based on the Meta-analysis of Observational Studies in Epidemiology (MOOSE) guidelines (Stroup et al. 2000).

\section{Method}

A librarian-assisted computerized search strategy was applied to Medline, PsycINFO and EMBASE databases to identify potentially relevant articles published between January 1977 and December 2008. A highly sensitive search string was developed with database-specific medical subject headings for the 'migration', 'psychosis' and 'schizophrenia' concepts. Reference lists of relevant articles were screened to locate additional articles, including a previous extensive review of schizophrenia incidence studies (McGrath et al. 2004). Forward and backward citation tracking was completed using the Web of Science. Experts on migration and psychosis were also contacted to ensure no study had been missed.

Specific criteria for inclusion in the review were established a priori to minimize methodological variations of studies to be entered in the meta-analysis. Studies were included in the review if they were: (1) published in a peer-reviewed journal in or after 1977; (2) written in English, French, Spanish, Dutch or German; (3) population-based incidence studies (first admission or first contact) of schizophrenia, first-episode psychosis or psychotic disorders in general; (4) reporting incidence rates for $\geq 1$ migrant group and a reference group (or numerator/denominator data that enabled such computations); (5) differentiating first- from second-generation migrants; and (6) providing age-adjusted incidence data. In light of the methodological concerns affecting early migrant studies, we selected 1977 as a conservative lower publication time limit for inclusion in our study, as did Cantor-Graae \& Selten (2005). Cochrane's study was the first to rigorously account for potential demographic differences between migrant and non-migrant populations (Cochrane, 1977). Moreover, it is only in recent decades that researchers have investigated SGIs and differentiated them from foreign-born migrants. 
All retrieved citations were screened independently by two reviewers in a threefold process, and selected after consensus. Citations were first screened for relevance using broad criteria. The second screen was based on abstracts and excluded studies that clearly did not meet $\geq 1$ inclusion criteria. Full-text articles were scrutinized in the final screen. When eligible studies reported findings from overlapping populations, we selected the version of the study with the largest sample size or the longest study period.

Detailed quantitative and qualitative data were extracted independently by two reviewers. The internal validity of each study was assessed based on methodological features and potential for selection bias, information bias and confounding. Each study attained a numeric quality score, using the scale from a prior systematic review of schizophrenia incidence studies (McGrath et al. 2004). As there is no consensus on using quality scores in meta-analyses of observational studies (Stroup et al. 2000), we conducted a broad quality appraisal and classified studies into higher, average and lower quality ranges. Studies were later stratified to determine whether their quality impacted on pooled effect sizes (Pai et al. 2003). Incidence data were extracted for each FGI and SGI group identified and also for their native counterparts. Given the large differences in data reporting and the need for comparable estimates for comparison and pooling purposes, incidence rate ratios (IRRs) were selected as the index measure of effect associated with migrant status. IRRs were preferred for their optimal statistical properties and their more intuitive meaning as risk estimates (Cooper et al. 2009). Age- and sex-adjusted IRRs were extracted or computed for each migrant group identified. Gender-specific IRRs were extracted when available. Authors were contacted when necessary, to ensure accuracy and completeness of data. A descriptive synthesis of selected studies was first completed by tabulating the main study characteristics, including settings, observation periods, study populations and design features. Prior to initiating meta-analyses, the variance for each effect size was estimated using the same formula applicable to rate ratios (Borenstein, 2010; Borenstein et al. 2009a): Variance $=1 / \mathrm{N}_{\mathrm{m}}+1 / \mathrm{N}_{\mathrm{r}}$, where $\mathrm{N}_{\mathrm{m}}$ is the number of migrant cases and $\mathrm{Nr}$ is the number of reference cases. Variance estimates determine the weight of each effect size, more precise studies generally being assigned more weight. Analyses were conducted on a log scale to avoid the skewed distribution associated with IRR measures. A first analysis was conducted based on a comprehensive dataset including all available effect sizes to yield a pooled estimate of their risk for schizophrenia and related disorders in FGIs and SGIs. In an attempt to minimize heterogeneity due to methodological variation, a second analysis was conducted from the subset of studies that reported data on both migrant generations. The potential for publication bias was assessed by examination of a funnel plot displaying the standard errors of studies relative to their effect sizes, with the underlying assumption that non-publication of smaller studies would lead to an asymmetry in the expected funnel shape.

Analyses were conducted under the random-effects model, which, unlike a fixedeffects model, assumes that studies will have different true effect sizes as a result of variations in methodology or study populations (Borenstein et al. 2009b). Based on prior knowledge, it was expected that ethnicity and study countries would probably underlie 
variation across effect sizes. It also seemed unlikely that methods and populations could be regarded as equivalent across studies. A random-effects model was therefore justified a priori, presuming that true effects were distributed randomly around the mean effect size and considering two sources of variance: the within-study error and the betweenstudies variance. The latter refers to heterogeneity, which was estimated by Cochran's $\mathrm{Q}$ and $\mathrm{I}^{2}$ statistics (Borenstein et al. 2009c). First, $\mathrm{Q}_{\mathrm{W}}$ (Q within) was calculated for each analysis to determine whether heterogeneity was present across effect sizes, as suggested by a significant $p$-value. The between-category homogeneity statistic $Q_{B}$ was also used to test whether risk differences between various groups were significant.

Subgroup analyses served as the primary mode of investigating heterogeneity as they have the potential to identify relevant effect moderators, which may include substantive or methodological variables (Song et al. 2001). A possible gender effect was examined based on the available sex-specific effect sizes. We also examined the potential effect of visible minority status, based on the classification used by Statistics Canada (2008). Migrant groups were classified as either 'black', 'other' (non-black non-white) or 'white', based on the skin color of the majority population in migrants' countries of origin. An additional analysis was conducted to determine the potential effect of sociopolitical context by grouping effect sizes according to the main host countries. We also conducted a sensitivity analysis to test the robustness of findings (Egger et al. 2001). An analysis including only higher quality studies was conducted to determine whether quality impacted the summary effect sizes. Sensitivity analyses were also conducted for two potentially salient design features: case ascertainment and diagnostic categorization. Effect sizes derived from all first-contact studies were compared to those from studies based on first-admissions only. We analyzed separately the studies that used standardized DSM-IV criteria for schizophrenia and those that used ICD-8, - 9 or -10 criteria. Analyses were carried out using the Comprehensive Meta-Analysis statistical software, version 2.2 (Borenstein et al. 2005).

\section{Results}

Out of 1720 potentially relevant publications, we identified 21 population-based migrant studies (Fig. 1). We extracted 61 FGI effect sizes and 28 SGI effect sizes, providing information on 5508 and 4422 cases respectively.

Study characteristics are presented in Table 1 and their effect sizes are listed in Table 2. Among the retrieved studies, nine were conducted in the UK (Bebbington et al. 1981; Castle et al. 1991; Cochrane \& Bal, 1987; Coid et al. 2008; Dean et al. 1981; Harrison et al. 1988; Hitch \& Clegg, 1980; Rwegellera, 1977; Thomas et al. 1993), three in The Netherlands (Aleman et al. 2003; Selten et al. 1997; Selten \& Sijben, 1994; Veling et al. 2006), three in Sweden (Cantor-Graae et al. 2005; Leao et al. 2006; Zolkowska et al. 2001), two in Israel (Corcoran et al. 2009; Weiser et al. 2008), two in Denmark (Cantor-Graae et al. 2003; CantorGraae \& Pedersen, 2007), one in Australia (Krupinski \& Cochrane, 1980) and one in Canada (Smith et al. 2006). The single North American study was conducted recently but was based on hospital data from the early twentieth century (Smith et al. 2006). Despite its much earlier observation period, it met all inclusion criteria and it used methods similar to that of 


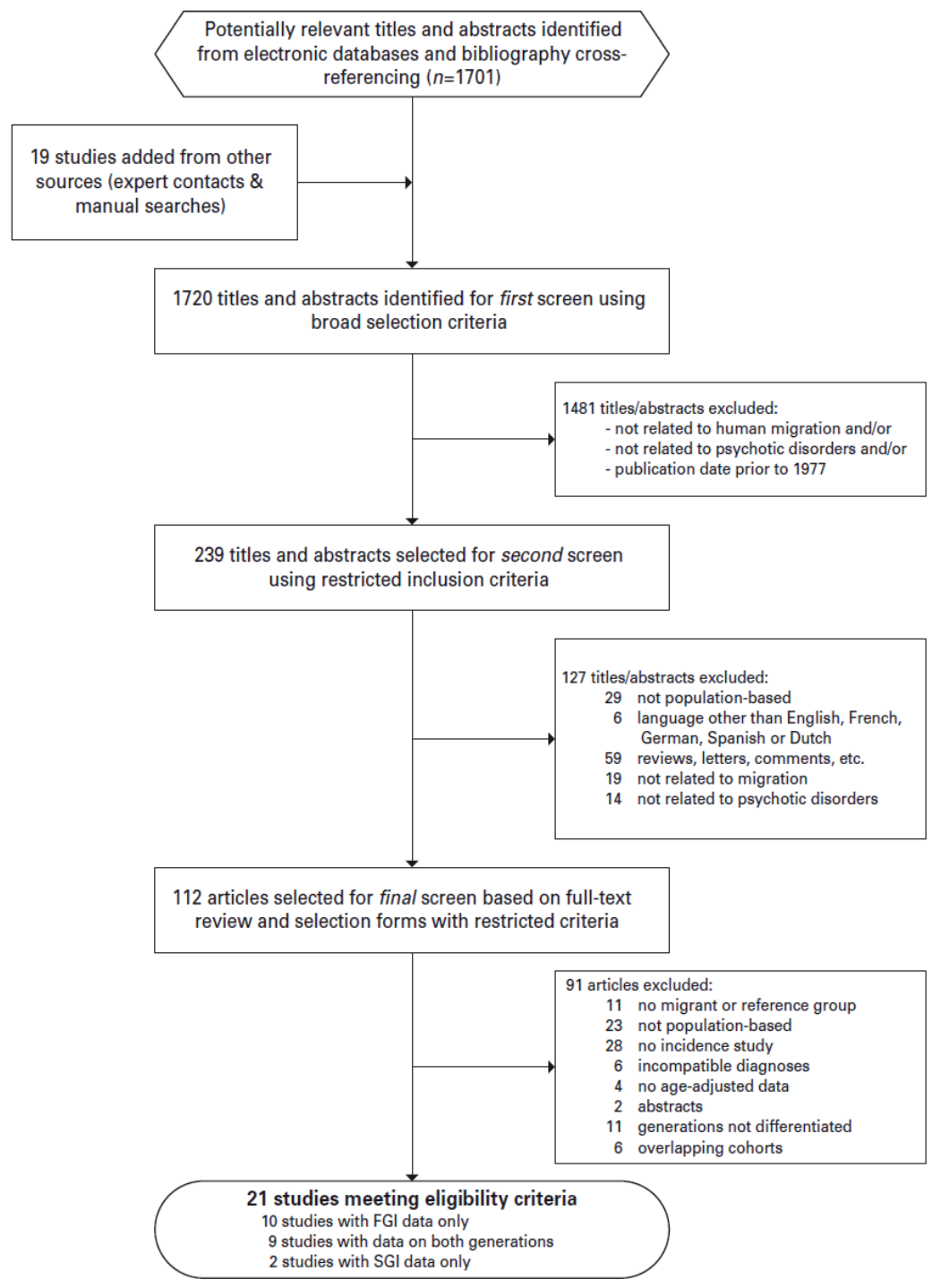

Figure 1. Study selection flow chart

contemporary studies. Almost all IRRs indicated higher risks for schizophrenia and related disorders among migrants than in their native counterpart. This held for both FGIs and SGIs (Table 2), with the exception of the Israel-based SGI cohort study (Corcoran et al. 2009).

Analyses based on the comprehensive dataset (Table 3) yielded mean-weighted IRRs estimates of 2.3 [95\% confidence interval (CI) CI 2.0-2.7] and 2.1 (95\% CI 1.8-2.5) for FGIs and SGIs respectively. The magnitude of the risk did not differ significantly between the first and the second generations, as also indicated by the non-significant $Q_{B}$ statistic. Both 


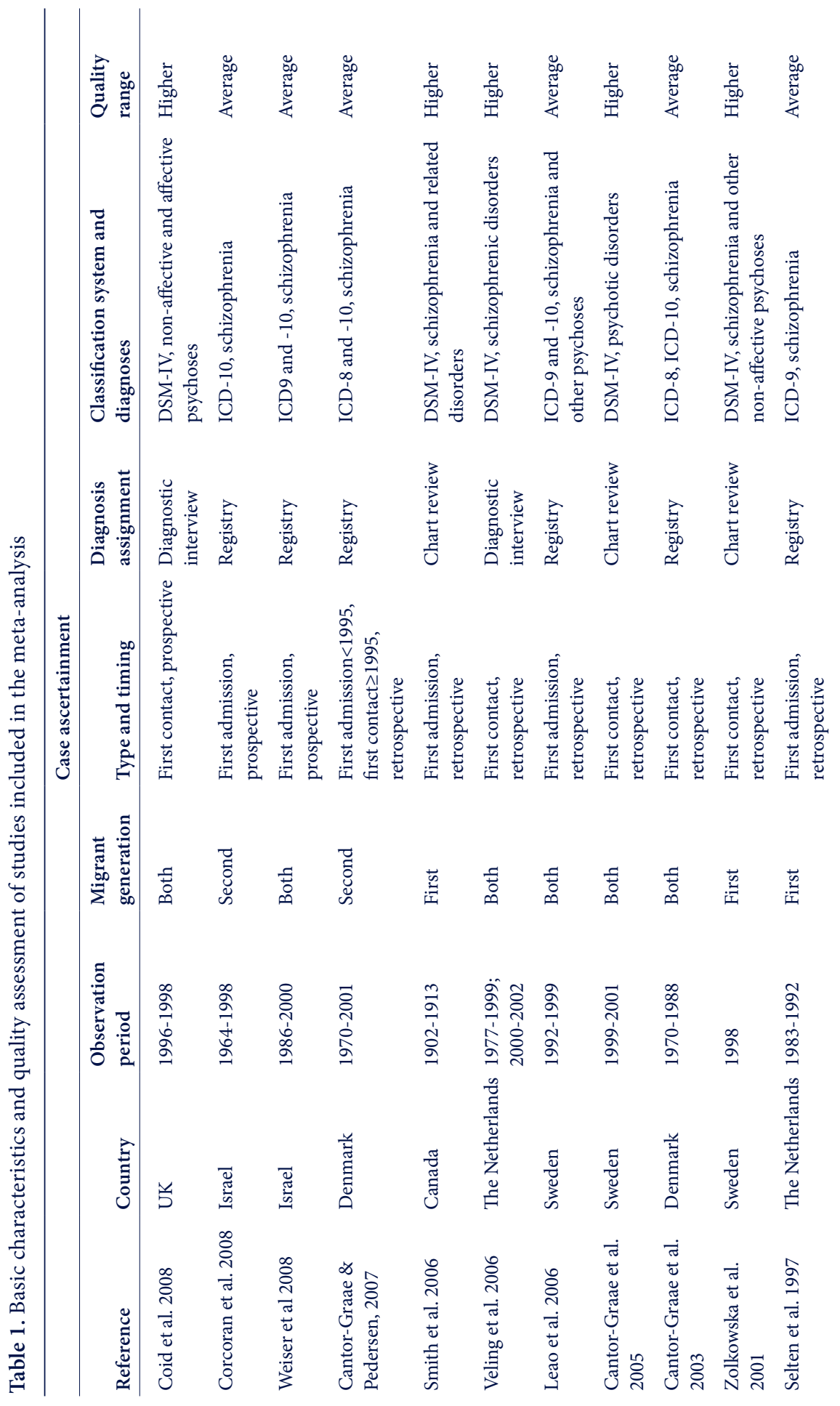




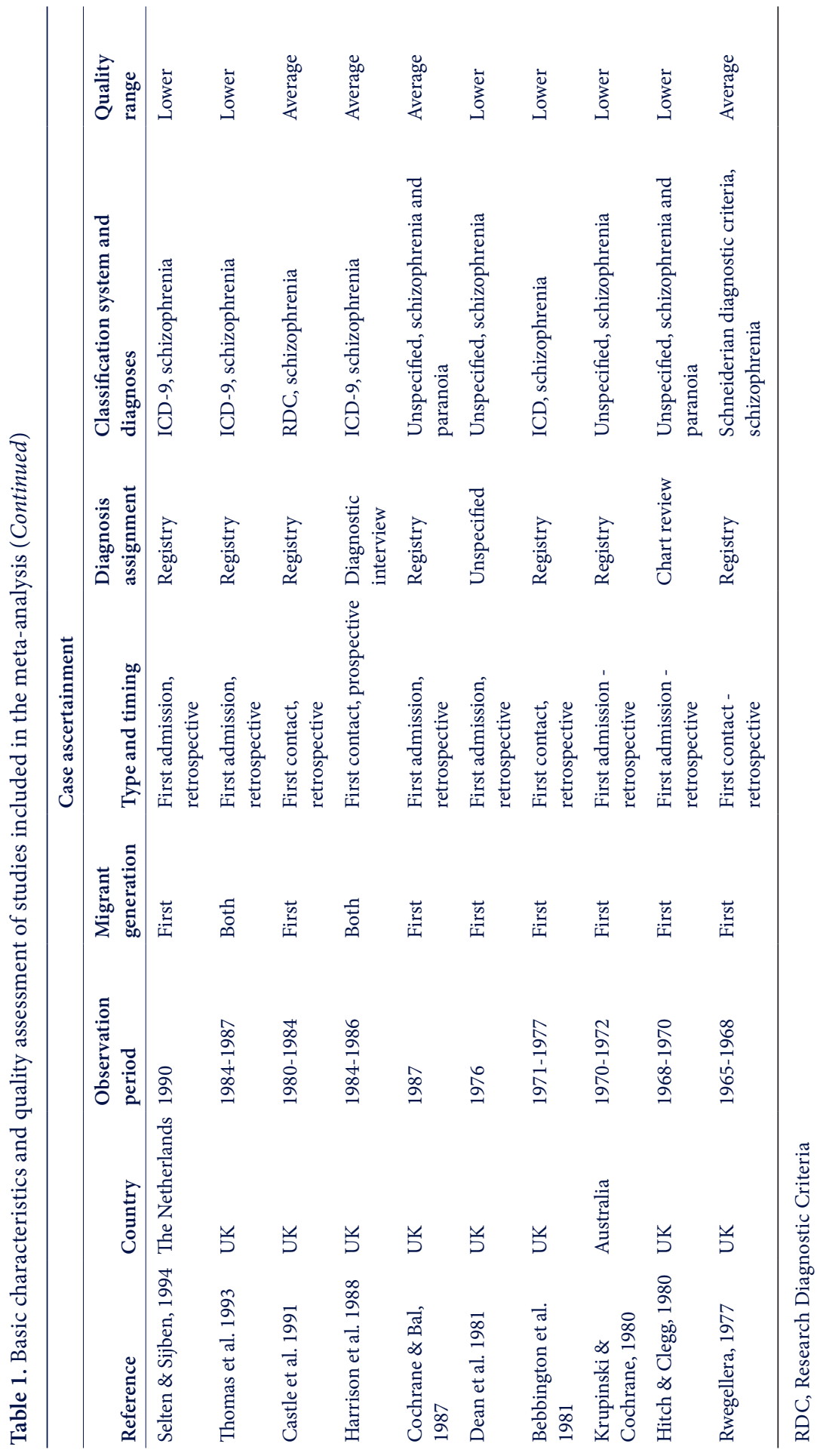


analyses were statistically significant for heterogeneity within subgroups, indicating that various migrant groups should not be regarded as coming from a homogeneous population sharing a common effect size. The second analysis based on the subset studies that reported data for both generations yielded IRRs of 2.1 (95\% CI 1.8-2.4) and 2.4 (95\% CI 2.0-2.9) for FGIs and SGIs respectively. Although much reduced in absolute value, heterogeneity remained statistically significant within both groups.

A careful exploration of heterogeneity was conducted through subgroup analyses based on the comprehensive dataset (Table 4). No significant differences were observed when comparing the risk of male versus female immigrants. However, significant between-group differences emerged when migrant groups were categorized according to the skin color of the majority of the population in their countries of origin. The mean-weighted IRR for FGIs from areas where most of the population is black was 4.0 (95\% CI 3.4-4.6) versus 1.8 (95\% CI 1.6-2.1) for groups classified as 'white' and 2.0 (95\% CI 1.6-2.5) for groups classified as 'other'. Risk estimates for migrant groups classified in the 'black' visible minority category were even higher for SGIs, with IRR 5.4 (95\% CI 3.2-8.8) versus 1.9 (95\% CI 1.2-3.0) for the 'white' category and 2.0 (95\% CI 1.0-4.0) for the 'other' category.

Table 2. Incidence rate ratios (IRRs) and analyses for each migrant group in the metaanalysis

\begin{tabular}{|c|c|c|c|c|c|c|}
\hline \multirow[b]{2}{*}{ Reference } & \multirow[b]{2}{*}{ Study group } & \multicolumn{2}{|c|}{$\begin{array}{l}\text { First-generation } \\
\text { immigrants }\end{array}$} & \multicolumn{2}{|c|}{$\begin{array}{l}\text { Second-generation } \\
\text { immigrants }\end{array}$} & \multirow[b]{2}{*}{ Analyses } \\
\hline & & $\mathrm{n}$ & IRR (95\% CI) & $\mathrm{n}$ & IRR (95\% CI) & \\
\hline \multirow{6}{*}{$\begin{array}{l}\text { Coid et al., } \\
2008\end{array}$} & Native (non-migrant) & 80 & 1.0 (reference) & 80 & 1.0 (reference) & $a, b, c, d, e, f$ \\
\hline & White British & 35 & $1.6(1.1-2.4)$ & 11 & $2.8(1.5-5.3)$ & $a, b, c, d, e, f$ \\
\hline & Black Caribbean & 11 & $2.3(1.2-4.3)$ & 55 & $4.9(3.5-6.9)$ & $a, b, c, d, e, f$ \\
\hline & Black African & 48 & $3.2(2.2-4.6)$ & 16 & $3.7(2.2-6.3)$ & $\mathrm{a}, \mathrm{b}, \mathrm{c}, \mathrm{d}, \mathrm{e}, \mathrm{f}$ \\
\hline & Asian & 64 & $1.8(1.3-2.5)$ & 20 & $1.3(0.8-2.1)$ & $a, b, c, d, e, f$ \\
\hline & Other & 15 & $1.3(0.8-2.3)$ & 5 & $1.1(0.5-2.7)$ & $a, b, c, d, f$ \\
\hline \multirow{4}{*}{$\begin{array}{l}\text { Corcoran et } \\
\text { al., } 2008\end{array}$} & Native (non-migrant) & n.a. & n.a. & 192 & 1.0 (reference) & $a, f$ \\
\hline & Father migrant & n.a. & n.a. & 85 & $0.9(0.8-1.1)$ & $\mathrm{a}, \mathrm{f}$ \\
\hline & Mother migrant & n.a. & n.a. & 81 & $1.0(0.8-1.3)$ & $a, f$ \\
\hline & Both migrant parents & n.a. & n.a. & 279 & $0.9(0.8-1.1)$ & $\mathrm{a}, \mathrm{f}$ \\
\hline \multirow{6}{*}{$\begin{array}{l}\text { Weiser et al., } \\
2007\end{array}$} & Native (non-migrant) & 46 & 1.0 (reference) & 46 & 1.0 (reference) & $a, b, d, e, f$ \\
\hline & Former SU & 196 & $1.6(1.1-2.1)$ & n.a. & n.a. & $a, b, d, e, f$ \\
\hline & Europe & 16 & $1.0(0.6-1.7)$ & n.a. & n.a. & $a, b, d, e, f$ \\
\hline & Ethiopia & 38 & $3.0(1.9-4.5)$ & n.a. & n.a. & $a, b, d, e, f$ \\
\hline & North America & 15 & $1.3(0.7-2.4)$ & n.a. & n.a. & $a, b, d, e, f$ \\
\hline & South America & 8 & $1.3(0.6-2.7)$ & n.a. & n.a. & $a, b, d, f$ \\
\hline
\end{tabular}


Table 2. Incidence rate ratios (IRRs) and analyses for each migrant group in the metaanalysis (Continued)

\begin{tabular}{|c|c|c|c|c|c|c|}
\hline \multirow[b]{2}{*}{ Reference } & \multirow[b]{2}{*}{ Study group } & \multicolumn{2}{|c|}{$\begin{array}{l}\text { First-generation } \\
\text { immigrants }\end{array}$} & \multicolumn{2}{|c|}{$\begin{array}{l}\text { Second-generation } \\
\text { immigrants }\end{array}$} & \multirow[b]{2}{*}{ Analyses } \\
\hline & & $\mathbf{n}$ & IRR (95\% CI) & $\mathrm{n}$ & IRR (95\% CI) & \\
\hline \multirow{7}{*}{$\begin{array}{l}\text { Cantor- } \\
\text { Graae et al., } \\
2007\end{array}$} & Asia \& Australia & 6 & $1.0(0.4-2.4)$ & n.a. & n.a. & $a, b, f$ \\
\hline & Africa & 5 & $1.7(0.7-4.3)$ & n.a. & n.a. & $a, b, d, e, f$ \\
\hline & 1 migrant parent & n.a. & n.a. & 187 & $1.4(1.0-2.0)$ & $a, b, f$ \\
\hline & 2 migrant parents & n.a. & n.a. & 1169 & $1.5(1.1-2.0)$ & $a, b, f$ \\
\hline & Native (non-migrant) & n.a. & n.a. & 9742 & 1.0 (reference) & $a, f$ \\
\hline & 1 migrant parent & n.a. & n.a. & 768 & $1.6(1.5-1.7)$ & $a, f$ \\
\hline & 2 migrant parents & n.a. & n.a. & 137 & $2.3(2.0-2.8)$ & $a, f$ \\
\hline \multirow{2}{*}{$\begin{array}{l}\text { Smith et al., } \\
2006\end{array}$} & Native (non-migrant) & 259 & 1.0 (reference) & n.a. & n.a. & $\mathrm{a}, \mathrm{d}, \mathrm{e}$ \\
\hline & All other & 548 & $1.5(1.3-1.8)$ & n.a. & n.a. & $\mathrm{a}, \mathrm{d}, \mathrm{e}$ \\
\hline \multirow{7}{*}{$\begin{array}{l}\text { Veling et al., } \\
2006\end{array}$} & Native (non-migrant) & 79 & 1.0 (reference) & 79 & 1.0 (reference) & $a, b, c, d, e, f$ \\
\hline & Morocco & 25 & $4.0(2.6-6.3)$ & 10 & $5.8(3.0-11.2)$ & $a, b, c, d, e, f$ \\
\hline & Surin.a.m & 28 & $2.6(1.7-4.0)$ & 15 & $2.9(1.7-5.0)$ & $a, b, c, d, e, f$ \\
\hline & Netherland Antilles & 5 & $1.9(0.8-4.7)$ & 1 & $1.4(0.2-10.0)$ & $a, b, c, d, e, f$ \\
\hline & Turkey & 11 & $1.4(0.8-2.6)$ & 6 & $2.3(1.0-5.3)$ & $a, b, c, d, e, f$ \\
\hline & Other, Non-Western & 26 & $2.2(1.4-3.4)$ & 10 & $3.5(1.8-6.8)$ & $a, b, c, f$ \\
\hline & Other, Western & 7 & $1.2(0.6-2.6)$ & 6 & $1.6(0.7-3.7)$ & $a, b, c, d, e, f$ \\
\hline \multirow{5}{*}{$\begin{array}{l}\text { Leao et al., } \\
2006\end{array}$} & Native (non-migrant) & 5407 & 1.0 (reference) & 5407 & 1.0 (reference) & $a, b, c, d, e, f$ \\
\hline & Finns & 428 & $2.2(2.0-2.4)$ & 211 & $2.3(2.0-2.7)$ & $a, b, c, d, e, f$ \\
\hline & Labor immigrants & 248 & $1.2(1.1-1.4)$ & 71 & $1.2(1.0-1.5)$ & $a, b, c, d, e, f$ \\
\hline & Refugees & 605 & $1.4(1.3-1.6)$ & 37 & $1.9(1.4-2.6)$ & $a, b, c, f$ \\
\hline & 1 migrant parent & n.a. & n.a. & 863 & $1.6(1.5-1.8)$ & $a, b, f$ \\
\hline \multirow{13}{*}{$\begin{array}{l}\text { Cantor- } \\
\text { Graae et al., } \\
2005 \\
\text { Cantor- } \\
\text { Graae et al., } \\
2003\end{array}$} & Native (non-migrant) & 10 & 1.0 (reference) & 10 & 1.0 (reference) & $a, b, f$ \\
\hline & All & 19 & $4.0(1.9-8.6)$ & 5 & $2.0(0.7-5.9)$ & $a, b, f$ \\
\hline & Native (non-migrant) & 8684 & 1.0 (reference) & 8684 & 1.0 (reference) & $a, b, d, e, f$ \\
\hline & All & 597 & $2.5(2.3-2.7)$ & 426 & $1.9(1.7-2.1)$ & $\mathrm{b}$ \\
\hline & Europe & 178 & $2.2(1.9-2.6)$ & n.a. & n.a. & $\mathrm{a}, \mathrm{d}, \mathrm{e}, \mathrm{f}$ \\
\hline & Scandinavia & 106 & $2(1.7-2.4)$ & n.a. & n.a. & $a, d, e, f$ \\
\hline & Asia & 74 & $2.3(1.8-2.9)$ & n.a. & n.a. & $\mathrm{a}, \mathrm{d}, \mathrm{e}, \mathrm{f}$ \\
\hline & Middle East & 29 & $3.8(2.6-5.4)$ & n.a. & n.a. & $a, d, e, f$ \\
\hline & Australia & 11 & $4.2(2.3-7.5)$ & n.a. & n.a. & $\mathrm{a}, \mathrm{d}, \mathrm{e}, \mathrm{f}$ \\
\hline & Africa & 41 & $3.9(2.8-5.2)$ & n.a. & n.a. & $\mathrm{a}, \mathrm{d}, \mathrm{e}, \mathrm{f}$ \\
\hline & North America & 36 & $2.1(1.5-3.0)$ & n.a. & n.a. & $\mathrm{a}, \mathrm{d}, \mathrm{e}, \mathrm{f}$ \\
\hline & South America & 15 & $2.6(1.5-4.2)$ & n.a. & n.a. & $\mathrm{a}, \mathrm{d}, \mathrm{f}$ \\
\hline & Greenland & 81 & $3.4(2.7-4.2)$ & n.a. & n.a. & $\mathrm{a}, \mathrm{d}, \mathrm{f}$ \\
\hline
\end{tabular}


Table 2. Incidence rate ratios (IRRs) and analyses for each migrant group in the metaanalysis (Continued)

\begin{tabular}{|c|c|c|c|c|c|c|}
\hline \multirow[b]{2}{*}{ Reference } & \multirow[b]{2}{*}{ Study group } & \multicolumn{2}{|c|}{$\begin{array}{l}\text { First-generation } \\
\text { immigrants }\end{array}$} & \multicolumn{2}{|c|}{$\begin{array}{l}\text { Second-generation } \\
\text { immigrants }\end{array}$} & \multirow[b]{2}{*}{ Analyses } \\
\hline & & $\mathbf{n}$ & IRR $(95 \% \mathrm{CI})$ & $\mathrm{n}$ & IRR (95\% CI) & \\
\hline & Unknown & 26 & $1.2(0.8-1.7)$ & n.a. & n.a. & $\mathrm{a}, \mathrm{f}$ \\
\hline \multirow{2}{*}{$\begin{array}{l}\text { Zolkowska } \\
\text { et al., } 2001\end{array}$} & Native (non-migrant) & 34 & 1.0 (reference) & n.a. & n.a. & $a, f$ \\
\hline & All & 22 & $1.9(1.0-3.2)$ & n.a. & n.a. & $a, f$ \\
\hline \multirow{3}{*}{$\begin{array}{l}\text { Selten et al., } \\
1997\end{array}$} & Native (non-migrant) & 10726 & 1.0 (reference) & n.a. & n.a. & $\mathrm{a}, \mathrm{c}, \mathrm{d}, \mathrm{e}, \mathrm{f}$ \\
\hline & Surinam & 697 & $3.8(3.5-4.1)$ & n.a. & n.a. & $\mathrm{a}, \mathrm{c}, \mathrm{d}, \mathrm{e}, \mathrm{f}$ \\
\hline & Netherlands Antilles & 236 & $3.9(3.4-4.4)$ & n.a. & n.a. & $\mathrm{a}, \mathrm{c}, \mathrm{d}, \mathrm{e}, \mathrm{f}$ \\
\hline \multirow{3}{*}{$\begin{array}{l}\text { Selten et al., } \\
1994\end{array}$} & Native (non-migrant) & 975 & 1.0 (reference) & n.a. & n.a. & $\mathrm{a}, \mathrm{c}, \mathrm{d}, \mathrm{e}, \mathrm{f}$ \\
\hline & Turkey & 17 & $0.9(0.6-1.5)$ & n.a. & n.a. & $a, c, d, e, f$ \\
\hline & Morocco & 39 & $3.3(2.4-4.5)$ & n.a. & n.a. & $\mathrm{a}, \mathrm{c}, \mathrm{d}, \mathrm{e}, \mathrm{f}$ \\
\hline \multirow{3}{*}{$\begin{array}{l}\text { Thomas et } \\
\text { al., } 1993\end{array}$} & Native (non-migrant) & 41 & 1.0 (reference) & 28 & 1.0 & $a, b, d, e, f$ \\
\hline & Asian & 5 & $1.6(0.6-4.0)$ & 1 & $1.0(0.1-7.4)$ & $a, b, d, e, f$ \\
\hline & Caribbean & 2 & $0.6(0.1-2.4)$ & 10 & $9.1(4.4-18.8)$ & $a, b, d, e, f$ \\
\hline \multirow{2}{*}{$\begin{array}{l}\text { Castle et al., } \\
1991\end{array}$} & Native (non-migrant) & 53 & 1.0 (reference) & 53 & 1.0 (reference) & $\mathrm{a}, \mathrm{b}, \mathrm{d}, \mathrm{e}, \mathrm{f}$ \\
\hline & Caribbean & 22 & $5.6(3.4-9.2)$ & 13 & $4.5(2.5-8.3)$ & $a, b, d, e, f$ \\
\hline \multirow{2}{*}{$\begin{array}{l}\text { Harrison et } \\
\text { al, } 1988\end{array}$} & Native (non-migrant) & 39 & 1.0 (reference) & 39 & 1.0 (reference) & $a, b, d, e, f$ \\
\hline & Caribbean & 3 & $6.7(2.1-22.8)$ & 17 & $18.0(10.2-32.9)$ & $a, b, d, e, f$ \\
\hline \multirow{5}{*}{$\begin{array}{l}\text { Cochrane et } \\
\text { al., } 1987\end{array}$} & Native (non-migrant) & 3669 & 1.0 (reference) & n.a. & n.a. & $a, c, d, e, f$ \\
\hline & Ireland & 115 & $1.6(1.4-2.0)$ & n.a. & n.a. & $\mathrm{a}, \mathrm{c}, \mathrm{d}, \mathrm{e}, \mathrm{f}$ \\
\hline & Caribbean & 108 & $3.2(2.6-3.8)$ & n.a. & n.a. & $\mathrm{a}, \mathrm{c}, \mathrm{d}, \mathrm{e}, \mathrm{f}$ \\
\hline & India & 56 & $1.3(1.0-1.8)$ & n.a. & n.a. & $a, c, d, e, f$ \\
\hline & Pakistan & 36 & $1.3(1.0-1.9)$ & n.a. & n.a. & $\mathrm{a}, \mathrm{c}, \mathrm{d}, \mathrm{e}, \mathrm{f}$ \\
\hline \multirow{6}{*}{$\begin{array}{l}\text { Dean et al., } \\
1981\end{array}$} & Native (non-migrant) & 1191 & 1.0 (reference) & n.a. & n.a. & $\mathrm{a}, \mathrm{c}, \mathrm{d}, \mathrm{e}, \mathrm{f}$ \\
\hline & India & 58 & $3.1(2.4-4.0)$ & n.a. & n.a. & $\mathrm{a}, \mathrm{c}, \mathrm{d}, \mathrm{e}, \mathrm{f}$ \\
\hline & Pakistan & 27 & $1.2(1.0-1.9)$ & n.a. & n.a. & $\mathrm{a}, \mathrm{c}, \mathrm{d}, \mathrm{e}, \mathrm{f}$ \\
\hline & Caribbean & 108 & $5.1(4.2-6.2)$ & n.a. & n.a. & $\mathrm{a}, \mathrm{c}, \mathrm{d}, \mathrm{e}, \mathrm{f}$ \\
\hline & Africa & 80 & $4.2(3.3-5.2)$ & n.a. & n.a. & $\mathrm{a}, \mathrm{c}, \mathrm{d}, \mathrm{e}, \mathrm{f}$ \\
\hline & Ireland & 96 & $2.4(1.9-2.9)$ & n.a. & n.a. & $\mathrm{a}, \mathrm{c}, \mathrm{d}, \mathrm{e}, \mathrm{f}$ \\
\hline $\begin{array}{l}\text { Bebbington } \\
\text { et al., } 1981\end{array}$ & Native (non-migrant) & 600 & 1.0 (reference) & n.a. & n.a. & $a, d, e, f$ \\
\hline
\end{tabular}


Table 2. Incidence rate ratios (IRRs) and analyses for each migrant group in the metaanalysis (Continued)

\begin{tabular}{|c|c|c|c|c|c|c|}
\hline \multirow[b]{2}{*}{ Reference } & \multirow[b]{2}{*}{ Study group } & \multicolumn{2}{|c|}{$\begin{array}{l}\text { First-generation } \\
\text { immigrants }\end{array}$} & \multicolumn{2}{|c|}{$\begin{array}{l}\text { Second-generation } \\
\text { immigrants }\end{array}$} & \multirow[b]{2}{*}{ Analyses } \\
\hline & & $\mathbf{n}$ & IRR (95\% CI) & n & IRR (95\% CI) & \\
\hline \multirow{7}{*}{$\begin{array}{l}\text { Krupinski et } \\
\text { al., } 1980\end{array}$} & Caribbean & 244 & $4.9(4.2-5.7)$ & n.a. & n.a. & $a, d, e, f$ \\
\hline & Ireland & 60 & $1.5(1.2-2.0)$ & n.a. & n.a. & $a, d, e, f$ \\
\hline & Native (non-migrant) & 1097 & 1.0 (reference) & n.a. & n.a. & $\mathrm{a}, \mathrm{c}, \mathrm{d}, \mathrm{e}$ \\
\hline & Britain & 173 & $1.1(0.9-1.3)$ & n.a. & n.a. & $\mathrm{a}, \mathrm{c}, \mathrm{d}, \mathrm{e}$ \\
\hline & Germany & 65 & $2.8(1.9-3.1)$ & n.a. & n.a. & $a, c, d, e$ \\
\hline & Italy & 126 & $1.8(1.5-2.2)$ & n.a. & n.a. & $a, c, d, e$ \\
\hline & Poland & 59 & $4.2(3.2-5.5)$ & n.a. & n.a. & $\mathrm{a}, \mathrm{c}, \mathrm{d}, \mathrm{e}$ \\
\hline \multirow{3}{*}{$\begin{array}{l}\text { Hitch et al., } \\
1980\end{array}$} & Native (non-migrant) & 123 & 1.0 (reference) & n.a. & n.a. & $\mathrm{a}, \mathrm{c}, \mathrm{f}$ \\
\hline & New Commonwealth & 41 & $3.2(2.2-4.5)$ & n.a. & n.a. & $\mathrm{a}, \mathrm{c}, \mathrm{f}$ \\
\hline & Other Foreign & 22 & $4.7(3.0-7.4)$ & n.a. & n.a. & $\mathrm{a}, \mathrm{c}, \mathrm{f}$ \\
\hline \multirow{3}{*}{$\begin{array}{l}\text { Rwegellera, } \\
1977\end{array}$} & Native (non-migrant) & 47 & 1.0 (reference) & n.a. & n.a. & $\mathrm{a}, \mathrm{d}, \mathrm{e}, \mathrm{f}$ \\
\hline & West Africa & 12 & $24.5(13.0-46.1)$ & n.a. & n.a. & a, d, e, f \\
\hline & Caribbean & 23 & $6.2(3.8-10.2)$ & n.a. & n.a. & $a, d, e, f$ \\
\hline
\end{tabular}

$\mathrm{n}$, sample size; $\mathrm{CI}$ : confidence interval; n.a.: non-applicable; a, meta-analysis from the comprehensive dataset; $\mathrm{b}$, meta-analysis from the restricted data; $c$, gender-specific analysis; d, visible minority category analysis; e, ethno-racial category analysis; $\mathrm{f}$, analysis based on host country.

All effect sizes from the comprehensive dataset were included in the urbanization, incidence type, diagnostic system and quality rating subgroup analyses.

Significant between-group heterogeneity was observed when grouping migrants according to host countries. For both generations, the highest IRRs were obtained in the UK (2.8 and 3.7 for FGIs and SGIs respectively), followed by The Netherlands (2.5 and 3.0) and Scandinavian countries (2.3 and 1.8). The lowest IRRs were observed in Israel (1.5 and 1.1). No significant between-group differences were observed when comparing urban settings to mixed rural-urban settings. The results of first-admission studies, based on hospital admission incidence rates, were compared to those of first-contact studies, based on any first contact for psychosis, whether in hospital or in the community. There was a non-significant trend towards higher risk estimates in first-contact than in first-admission studies for FGIs, with respective IRRs of 2.9 (95\% CI 2.1-4.0) and 2.2 (95\% CI 1.9-2.6). However, significant differences emerged for SGIs, for whom first-contact studies yielded a mean-weighted IRR of 3.2 (95\% CI 2.1-4.7), as opposed to 1.6 (95\% CI 1.3-1.8) in first-admission studies, with statistically significant between-group heterogeneity $\left(Q_{B}=10.6, p<0.01\right)$. 
Table 3. Main meta-analyses for first- (FGIs) and second-generation immigrants (SGIs)

\begin{tabular}{lllllllll}
\hline Dataset & Generation & $\mathbf{n}$ & IRR & LL & UL & $\mathrm{Q}_{\mathrm{W}}$ & $\mathrm{Q}_{\mathrm{B}}$ & $\mathrm{I}^{2}$ \\
\hline \multirow{2}{*}{ Comprehensive $^{\mathrm{a}}$} & First & 61 & 2.3 & 2.0 & 2.7 & $1071^{*}$ & & 94.4 \\
& Second & 28 & 2.1 & 1.8 & 2.5 & $302^{*}$ & & 91.1 \\
& & & & & & & 0.97 & \\
\multirow{2}{*}{ Restricted } & First & 36 & 2.1 & 1.8 & 2.4 & $253^{*}$ & & 86.2 \\
& Second & 24 & 2.4 & 2.0 & 2.9 & $191^{*}$ & & 87.9 \\
& & & & & & & 1.45 &
\end{tabular}

n, number of effect sizes; IRR, incidence ratio; LL, lower limit; UL, upper limit; $\mathrm{Q}_{\mathrm{W}}$, within-category homogeneity statistic; $Q_{B ;}$ between-category homogeneity statistic.

Levels of significance: ${ }^{*} \mathrm{p}<0.01$.

${ }^{a}$ An analysis of the distribution of effect sizes yielded median IRR estimates (with $10 \%$ to $90 \%$ quantiles) of 2.1 (1.2 to 4.7$)$ and 2.0 (1.0 to 5.2 ) for FGIs and SGIs, respectively.

There were no significant effect differences between studies with non-standardized diagnostic classifications and those based on DSM-IV or ICD-8, -9 or -10. Sensitivity analyses based on methodological quality revealed no significant differences when higher quality studies were compared with studies in mid-quality and lower quality ranges. Higher quality studies yielded slightly higher risk estimates for the second generation, with a mean IRR of 2.7 (95\% CI 1.9-3.7) for SGIs as opposed to 2.1 (95\% CI 1.7-2.5) for FGIs. The examination of generation-specific funnel plots did not reveal any asymmetry suggestive of publication bias (available from the authors on request).

\section{Conclusions}

Our review confirms that an increased risk for schizophrenia and related disorders affects not only FGIs, with a personal history of migration, but also SGIs born to one or two migrant parents in the host country. This finding held for nearly all migrant groups identified. Our relative risk estimates are comparable for both migrant generations. Our review echoes previous findings of significant heterogeneity in incidence rates of schizophrenia and of increased risk associated with migration (Cantor-Graae \& Selten, 2005; McGrath et al. 2004), but advances the literature in demonstrating the persistence of the risk in a similar magnitude in the second generation. This strongly suggests that post-migration factors are more important than pre-migration factors, such as selective migration or migration per se, in conferring an increased risk for psychotic disorders among immigrants. In addition, it may be more accurate to refer to migrant status than to migration in relation to the risk of psychosis. With 61 and 28 effect sizes for FGIs and SGIs respectively, our review could generate more precise estimates than prior reviews or individual studies. Relative risk estimates between 2 and 3 emphasize that migrant status, either FGI or SGI, cannot be disregarded as an important risk factor for psychotic disorders, with a risk magnitude within 
the same range as that associated with cannabis use, urbanicity or perinatal complications (Tandon et al. 2008).

Significant heterogeneity was observed across FGI and SGI effect sizes, indicating that these could not be regarded as random estimates of a common effect shared by all groups and that other factors contribute to differences between risk estimates. Hence, our summary findings provide overall risk estimate for FGIs and SGIs, but should not be attributed to a specific migrant group. This is similar to the effects of other risk factors estimated at the population level but that may operate differentially within subgroups.

A major concern with any primary migrant study is that of determining whether the observed incidence rates are true or not, in particular for complex conditions such as psychotic disorders. The question of potential misdiagnosis has been the object of considerable debate in the UK, in particular with regard to the Afro-Caribbean population (Bhui and Tsangarides, 2008; Sashidharan, 1993). A meta-analytic review enables us to appraise findings from primary studies in perspective and to note the remarkable consistency of increased risk across a diversity of migrant populations and host society contexts. Although the cross-cultural validity of current diagnostic categories has not been formally established (Alarcón et al. 2002), we did not observe significant differences between studies using DSM-IV, ICD-8 or -10 or non-standardized diagnostic criteria, or between higher quality studies and those with average and lower quality ratings. Some recent more rigorous investigations have used diagnoses assigned from clinical information, with blinding from any information about the ethnicity of patients (Coid et al. 2008; Fearon et al. 2006). Of note, these investigations have yielded rates even higher than those of prior studies based on chart reviews. Another important methodological issue of early migrant studies in the UK stemmed from the doubts about the reliability of the census data available, especially concerns about the possible underenumeration of the Afro-Caribbean population (Harrison et al. 1997; Van Os et al. 1996). Indeed, if the denominator underestimated the actual population for a given migrant group, this could give rise to an artificially elevated incidence rate, unlike incidence rates obtained in Scandinavian countries that are generally regarded as having very accurate census data. Some authors have sought to address this issue by applying an estimated correction factor to denominator populations (Harrison et al. 1988). However, even large uncertainties could hardly account for the five- to tenfold risk increase in some migrant groups relative to the host population. In addition, studies based on the more accurate 2001 census data still find consistently elevated risk among Caribbean migrants (Coid et al. 2008; Fearon et al. 2006).

There were significant generational differences in risk estimates among some groups, especially in Caribbean migrants in the UK (Coid et al. 2008; Harrison et al. 1988; Thomas et al. 1993) and in Moroccan migrants in The Netherlands (Veling et al. 2006). However, these generational differences were not consistent across ethnic groups and countries. Significant between-group heterogeneity emerged when effect sizes were grouped according to study settings, with the highest estimates being observed in the UK, intermediate risk estimates in The Netherlands and Scandinavian countries, and the lowest in Israel. No study revealed a protective effect associated with migrant status. The study of an Israel SGI cohort is the 


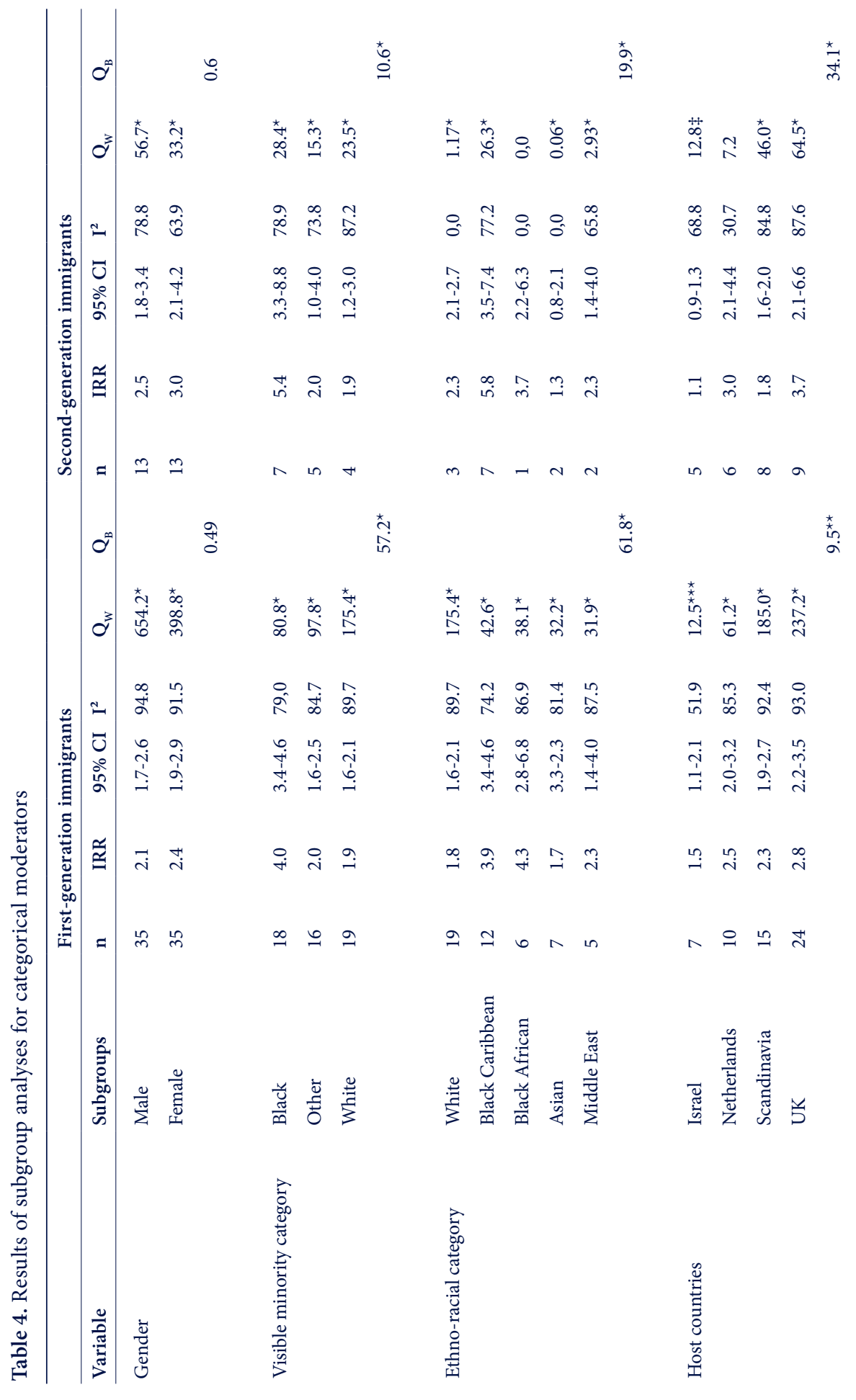




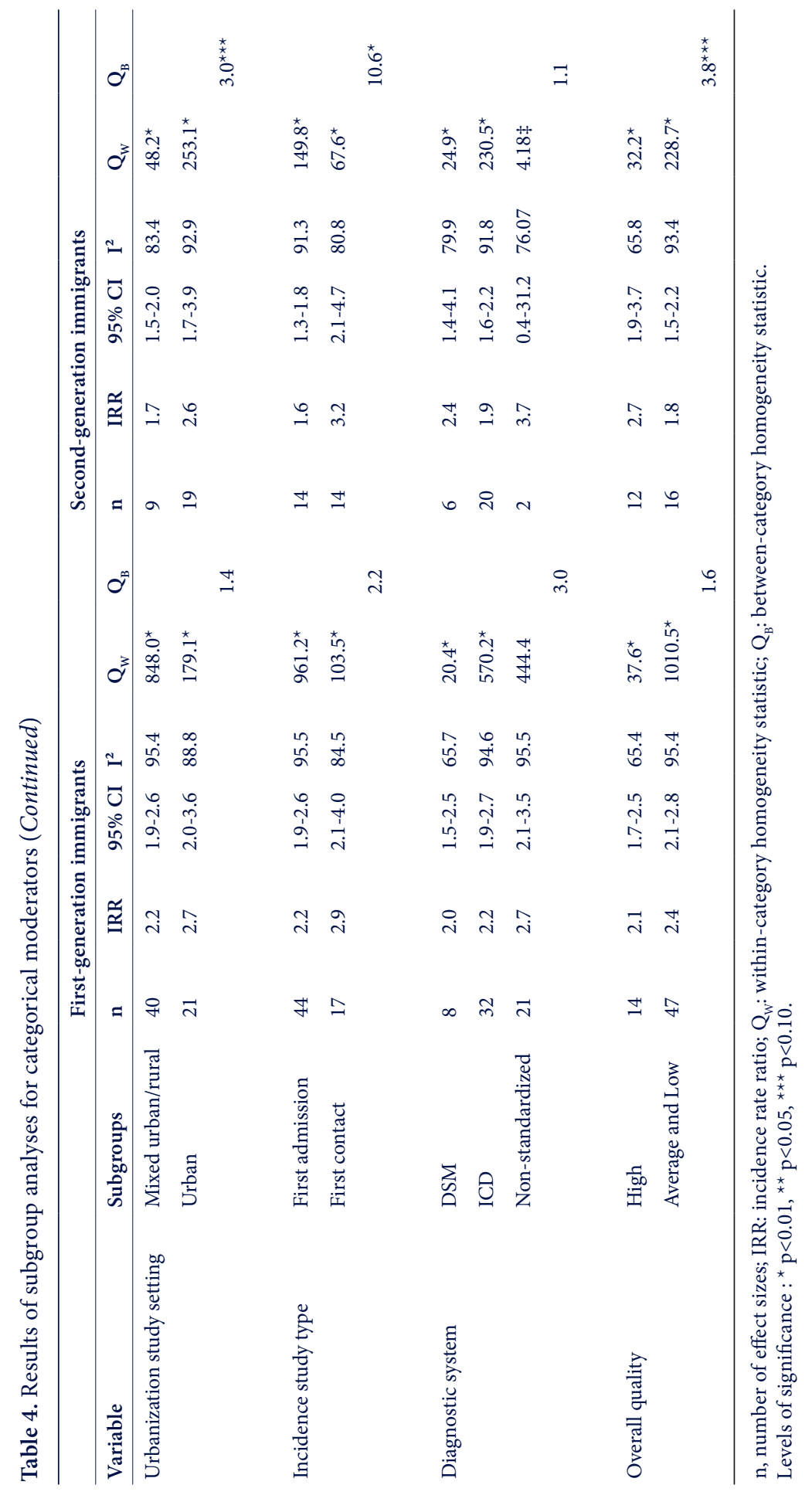


only one in our review that did not observe an association between migrant status and schizophrenia (Corcoran et al. 2009). The authors argued that this may result from the differential nature of migration to Israel. Unlike migrants to other European countries, Jewish migrants may in fact leave from a minority position in their source country to a Jewish state in which they are not perceived as 'outsiders' and are potentially less exposed to discrimination in the host society. Nonetheless, another Israel-based study found significantly elevated risk among some groups, especially among Ethiopian migrants, who may be considered most dissimilar to the majority population (Weiser et al. 2008).

Perhaps one of the most important finding of this meta-analysis is the considerable variation in the risk magnitude associated with visible minority status, with immigrants from countries where the majority population is black presenting significantly higher risk for psychosis (IRR 4.0 and 5.4 for FGIs and SGIs, respectively) than those from countries where the majority population is white (IRR 1.8 and 1.9 for FGIs and SGIs respectively) or other (IRR 2.0 in either generation). The risk of black migrants seems even higher in the second than in the first generation. A similar risk estimate (RR 4.8 without stratifying for generation) has been reported previously (Cantor-Graae \& Selten, 2005). Our findings raise questions as to what may underlie an increased risk among migrants from areas as diverse as Jamaica, Surinam or Africa. In the absence of evidence of elevated incidence rates in source countries, such findings point at the contributory role of the social environment and suggest a common exposure to adverse social experiences such as discrimination. Various lines of evidence suggest that this may be the case. The experience of discrimination in itself has been linked to an increased risk of ulterior psychotic experiences (Janssen et al. 2003). A recent Dutch investigation observed a dose-response relationship between the level of discrimination reported by an ethnic group and the risk of psychoses in that group (Veling et al. 2008a). In addition, it has now been replicated in different studies that the relative incidence of psychotic disorders among immigrants increases as they form a decreasing proportion of the population (Boydell et al. 2001; Kirkbride et al. 2007; Veling et al. 2008b). Such findings were attributed to the potential exposure to discrimination of isolated migrants and a possible buffering effect of social support in neighborhoods with higher ethnic density. If discrimination is in fact a factor contributing to the risk of psychoses among migrants, it is plausible that the experience of discrimination may vary across ethnic groups, thus contributing to a different risk load for psychosis. Such adverse social experiences may affect both migrant generations similarly.

Although visible minority status of migrant groups may be an important indicator of the risk associated with migration status, its effects seem to be context dependent. Most UK-based investigations have observed higher rates among Caribbean and Black African immigrants (Cochrane \& Bal, 1987; Coid et al. 2008; Harrison et al. 1988). However, Dutch studies have observed higher rates in Moroccan immigrants than in Surinamese and Dutch Antilleans (Selten et al. 1997; Selten \& Sijben, 1994; Veling et al. 2006). Similarly to Black immigrants in the UK, Moroccans seem to be most the most likely to experience discrimination in The Netherlands (Veling et al. 2008a). Although visible minority status may be a relevant variable, the risk observed in a given group may be better conceived as 
resulting from a dynamic interaction between migrant and ethnic minority groups and host societies. This notion is compatible with the proposed social defeat hypothesis, according to which the chronic experience of social defeat, defined as one of subordinate position or 'outsider status' in a given environment, may lead to sensitization of the mesolimbic dopamine system, and an elevated baseline risk for psychotic disorders (Selten \& CantorGraae, 2005; Selten \& Cantor-Graae, 2007).

Based on findings from the recent East London First Episode Psychosis study (Coid et al. 2008), which found higher incidence rates of psychosis in second than in first-generation Caribbean migrants, it has been argued that the observed generational differences may actually reflect different age profiles between generations rather than differences in the risk load. We observed that the ethnic groups with the highest risk estimates for psychosis tend to present an even higher risk magnitude in the second generation than in the first, which include groups such as Black Caribbean migrants in the UK and Moroccans in The Netherlands. Although underlying putative risk factors may be comparable between generations, their cumulative effect may be higher among SGIs. Unlike their parents, whose exposure to adverse social experiences probably occurred only after migration, SGIs may be exposed to similar pathogenic effects for longer periods and at an earlier more crucial phase of their development. Even among FGIs, the experience of migration and of the post-migration environment is likely to differ significantly according to age and developmental phase.

Our findings point primarily to socio-environmental determinants, but do not exclude the possibility that other environmental or biological factors may contribute to the association between migrant status and psychotic disorders. There has been no consistent evidence yet to explain the migrant status effect by substance misuse, although this may be a factor in some specific groups (Cantor-Graae \& Selten, 2005; Coid et al. 2008; Sharpley et al. 2001; Veen et al. 2002). Similar to the infectious hypothesis for the migration patterns in multiple sclerosis (Gale \& Martyn, 1995), early exposure to viruses or other infectious agents, such as toxoplasma gondii, has been associated with a later risk for psychotic disorders and suggested as a candidate for the migrant effect (Cantor-Graae \& Selten, 2005; Torrey et al. 2007). Vitamin D deficiency has been proposed as a hypothesis for the increased vulnerability for schizophrenia among dark-skinned immigrants who live in cold climates, in particular among SGIs who may have been exposed in the pre-natal period (Dealberto, 2007; McGrath, 1999). This hypothesis could partially explain the differential risk associated with visible minority status, but could scarcely account for the higher risk among lighterskinned immigrants in some contexts (e.g. Moroccans in The Netherlands) or other groups who moved to warmer climates.

To our knowledge, this contribution is the most extensive meta-analytic review of the risk for psychotic disorders among immigrants, especially for SGIs. However, there are several limitations to be considered in appraising the results of this study. First, meta-analyses represent secondary research of primary studies, and their validity is inevitably contingent on methodological quality and completeness of reporting of underlying studies. We have attempted to control for this by contacting authors and carefully assessing each study for quality. Second, as in any systematic review, studies may have been missed despite efforts to 
conduct a comprehensive and sensitive search. Third, although we could provide relatively precise estimates, some migrant groups had small sample sizes. Some studies may thus have lacked the power to demonstrate significant risk differences, in particular for SGIs. Given the relatively recent history of significant migration to Europe, it is likely that many SGIs have not yet gone through their period of risk. Finally, we provided mean-weighted estimates of the risk associated with migrant status. However, caution is needed in attributing these risk estimates to specific groups, given the significant heterogeneity of the findings.

This study adds further weight to the notion that socio-environmental factors contribute to the risk for psychosis among immigrants. Much could be learned by further exploring the factors underlying risk variations across groups and settings through comparative incidence studies using similar and rigorous methodology. Future studies of SGIs with larger sample sizes are also required, as generational differences may help to better disentangle the relationship between migration, ethnicity and psychosis, and shed further light on social causation mechanisms.

\section{Acknowledgments}

We thank the staff of the McGill Life Science Library and the Douglas Institute E. Cahn Library for their assistance in conducting the electronic searches for this review. We also thank E. Jarvis and J.-P. Selten who were contacted as experts, and the authors of the primary studies who responded to our information requests. F. Bourque also thanks C. Rousseau, E. Jarvis and N. Schmitz for their advisory role in conducting this study. F. Bourque is supported by a research training award from the Fonds de la recherche en santé Québec (FRSQ). A. Malla is supported by the Canada Research Chairs Program.

\section{References}

1. Alarcón, R. D., Bell, C. C., Kirmayer, L. J., Lin, K. M., Ustun, B., Wisner, K. L. (2002). Beyond the funhouse mirrors. A research agenda for DSM-V. American Psychiatric Association, Washington, DC, 219-281.

2. Aleman, A., Kahn, R. S., Selten, J. P. (2003). Sex differences in the risk of schizophrenia: evidence from meta-analysis. Arch Gen Psychiatry 60, 565-571.

3. Bebbington, P. E., Hurry, J., Tennant, C. (1981). Psychiatric disorders in selected immigrant groups in Camberwell. Soc Psychiatry 16, 43-51.

4. Bhui, K., Tsangarides, N. (2008). Culture and schizophrenia. Psychiatry 7, 454-457.

5. Borenstein, M. (2010). Meta-Analysis: Computing Treatment Effects and Effect Sizes. Wiley: Chichester.

6. Borenstein, M., Hedges, L., Higgins, J., Rothstein, H. (2005). Comprehensive meta- analysis version 2. Englewood, NJ: Biostat 104.

7. Borenstein, M., Hedges, L. V., Higgins, J., Rothstein, H. R. (2009a). Effect Sizes Based on Binary Data $(2 \times 2$ tables). In Introduction to meta-analysis, 33-39. Wiley Online Library: Chichester.

8. Borenstein, M., Hedges, L. V., Higgins, J., Rothstein, H. R. (2009b). Fixed Effect Versus Random Effects Models. In Introduction to meta-analysis, 77-86. Wiley Online Library: Chicester.

9. Borenstein, M., Hedges, L. V., Higgins, J., Rothstein, H. R. (2009c). Identifying and quantifying heterogeneity. In Introduction to meta-analysis, 107-125. Wiley Online Library: Chichester.

10. Boydell, J., Van Os, J., McKenzie, K., Allardyce, J., Goel, R., McCreadie, R. G., Murray, R. M. (2001). Incidence of 
schizophrenia in ethnic minorities in London: ecological study into interactions with environment. BMJ 323, 1336-1338.

11. Cantor-Graae, E., Pedersen, C. B. (2007). Risk of schizophrenia in second-generation immigrants: a Danish population-based cohort study. Psychol Med 37, 485-494.

12. Cantor-Graae, E., Pedersen, C. B., McNeil, T. F., Mortensen, P. B. (2003). Migration as a risk factor for schizophrenia: a Danish population-based cohort study. $\mathrm{Br} \mathrm{J}$ Psychiatry 182, 117-122.

13. Cantor-Graae, E., Selten, J. P. (2005). Schizophrenia and migration: a metaanalysis and review. Am J Psychiatry 162, 12-24.

14. Cantor-Graae, E. (2007). The contribution of social factors to the development of schizophrenia: a review of recent findings. Can J Psychiatry 52, 277.

15. Cantor-Graae, E., Zolkowska, K., McNeil, T. F. (2005). Increased risk of psychotic disorder among immigrants in Malmo: a 3-year firstcontact study. Psychol Med 35, 1155-1163.

16. Castle, D., Wessely, S., Der, G., Murray, R. M. (1991). The incidence of operationally defined schizophrenia in Camberwell, 196584. Br J Psychiatry 159, 790-794.

17. Cochrane, R. (1977). Mental illness in immigrants to England and Wales: an analysis of mental hospital admissions, 1971. Soc Psychiatry 12, 25-35.

18. Cochrane, R., Bal, S. S. (1987). Migration and schizophrenia: an examination of five hypotheses. Soc Psychiatry 22, 181-191.

19. Coid, J. W., Kirkbride, J. B., Barker, D., Cowden, F., Stamps, R., Yang, M., Jones, P. B. (2008). Raised incidence rates of all psychoses among migrant groups: findings from the East London first episode psychosis study. Arch Gen Psychiatry 65, 1250-1258.

20. Cooper, H., Hedges, L. V., Valentine, J. C. (2009). The handbook of research synthesis and meta-analysis. Russell Sage Foundation.

21. Corcoran, C., Perrin, M., Harlap, S., Deutsch, L., Fennig, S., Manor, O., Nahon, D., Kimhy, D., Malaspina, D., Susser, E. (2009). Incidence of schizophrenia among second-generation immigrants in the Jerusalem perinatal cohort. Schizophr Bull 35, 596-602.
22. Dealberto, M. J. (2007). Why are immigrants at increased risk for psychosis? Vitamin D insufficiency, epigenetic mechanisms, or both? Med Hypotheses 68, 259-267.

23. Dean, G., Walsh, D., Downing, H., Shelley, E. (1981). First admissions of native-born and immigrants to psychiatric hospitals in South-East England 1976. Br J Psychiatry 139, 506-512.

24. Egger, M., Smith, G. D., Altman, D. (2001). Systematic reviews in health care: metaanalysis in context. BMJ Books: London.

25. Fearon, P., Kirkbride, J. B., Morgan, C., Dazzan, P., Morgan, K., Lloyd, T., Hutchinson, G., Tarrant, J., Fung, W. L., Holloway, J., Mallett, R., Harrison, G., Leff, J., Jones, P. B., Murray, R. M. (2006). Incidence of schizophrenia and other psychoses in ethnic minority groups: results from the MRC AESOP Study. Psychol Med 36, 1541-1550.

26. Fearon, P., Morgan, C. (2006).Environmental factors in schizophrenia: the role of migrant studies. Schizophr Bull 32, 405-408.

27. Gale, C. R., Martyn, C. N. (1995). Migrant studies in multiple sclerosis. Progress in Neurobiol 47, 425-448.

28. Harrison, G., Glazebrook, C., Brewin, J., Cantwell, R., Dalkin, Fox, R., Jones, P., Medley, I. (1997). Increased incidence of psychotic disorders in migrants from the Caribbean to the United Kingdom. Psychol Med 27, 799-806.

29. Harrison, G., Owens, D., Holton, A., Neilson, D., Boot, D. (1988). A prospective study of severe mental disorder in AfroCaribbean patients. Psychol Med 18, 643-657.

30. Hitch, P. J., Clegg, P. (1980). Modes of referral of overseas immigrant and native-born first admissions to psychiatric hospital. Social Science, Medicine. Part A: Med Psychol Med Sociol 14, 369-374.

31. Jablensky, A., Sartorius, N., Ernberg, G., Anker, M., Korten, A., Cooper, J. E., Day, R., Bertelsen, A. (1992). Schizophrenia: manifestations, incidence and course in different cultures. A World Health Organization ten-country study. Psychol Med Monogr Suppl 20, 1-97.

32. Janssen, I., Hanssen, M., Bak, M., Bijl, R. V., de, G. R., Vollebergh, W., McKenzie, K., van Os, J. (2003). Discrimination and delusional ideation. Br J Psychiatry 182, 71-76. 
33. Kirkbride, J. B., Morgan, C., Fearon, P., Dazzan, P., Murray, R. M., Jones, P. B. (2007). Neighbourhood-level effects on psychoses: re-examining the role of context. Psychol Med. 37, 1413-1425.

34. Krupinski, J., Cochrane, R. (1980). Migration and mental health - a comparative study. J Int Studies 1, 49-57.

35. Leao, T. S., Sundquist, J., Frank, G., Johansson, L. M., Johansson, S. E., Sundquist, K. (2006). Incidence of Schizophrenia or Other Psychoses in Firstand Second-Generation Immigrants: A National Cohort Study. J Nerv Ment Dis 194, 27-33.

36. Lin, S. S., Kelsey, J. L. (2000). Use of race and ethnicity in epidemiologic research: concepts, methodological issues, and suggestions for research. Epidemiol Rev 22, 187-202.

37. McGrath, J. (1999). Hypothesis: is low prenatal vitamin D a risk-modifying factor for schizophrenia? Schizophr Res 40, 173177.

38. McGrath, J., Saha, S., Welham, J., El Saadi, O., MacCauley, C., Chant, D. (2004). A systematic review of the incidence of schizophrenia: the distribution of rates and the influence of sex, urbanicity, migrant status and methodology. BMC Medicine 2, 13.

39. Ødegaard, Ø. (1932). Emigration and insanity: a study of mental disease among Norwegian-born population in Minnesota. Acta Psychiatr Neurol Scand Suppl 4, 1-206.

40. Pai, M., McCulloch, M., Gorman, J. D., Pai, N., Enanoria, W., Kennedy, G., Tharyan, P., Colford Jr, J. M. (2003). Systematic reviews and meta-analyses: an illustrated, step-bystep guide. Natl Med J India 17, 86-95.

41. Ramagopalan, S. V., Dyment, D. A., Ebers, G. C. (2008). Genetic epidemiology: the use of old and new tools for multiple sclerosis. Trends Neurosci 31, 645-652.

42. Rwegellera, G. G. (1977). Psychiatric morbidity among West Africans and West Indians living in London. Psychol Med 7, 317-329.

43. Sashidharan, S. P. (1993). Afro-Caribbeans and schizophrenia: the ethnic vulnerability hypothesis re-examined. Int Rev Psychiatry 5, 129-144.
44. Selten, J. P., Cantor-Graae, E. (2005). Social defeat: risk factor for schizophrenia? Br J Psychiatry 187, 101-102.

45. Selten, J. P., Cantor-Graae, E. (2007) Hypothesis: social defeat is a risk factor for schizophrenia? Br J Psychiatry Suppl 51, s912.

46. Selten, J. P., Sijben, N. (1994). First admission rates for schizophrenia in immigrants to The Netherlands. The Dutch National Register. Soc Psychiatry Psychiatr Epidemiol 29, 71-77.

47. Selten, J. P., Slaets, J. P., Kahn, R. S. (1997). Schizophrenia in Surinamese and Dutch Antillean immigrants to The Netherlands: evidence of an increased incidence. Psychol Med 27, 807-811.

48. Selten, J. P., Cantor-Graae, E., Kahn, R. S. (2007). Migration and schizophrenia. Curr Opin Psychiatry 20, 111-115.

49. Sharpley, M., Hutchinson, G., McKenzie, K., Murray, R. M. (2001). Understanding the excess of psychosis among the AfricanCaribbean population in England. Review of current hypotheses. Br J Psychiatry Suppl 40, s60-s68.

50. Smith, G. N., Boydell, J., Murray, R. M., Flynn, S., McKay, K., Sherwood, M., Honer, W. G. (2006). The incidence of schizophrenia in European immigrants to Canada. Schizophr Res 87, 205-211.

51. Song, F., Sheldon, T. A., Sutton, A. J., Abrams, K. R., Jones, D. R. (2001). Methods for exploring heterogeneity in meta-analysis. Evaluation, the Health Professions 24, 126151.

52. Statistics Canada (2008). Visible minority population and population group reference guide, 2006 census.

53. Stroup, D. F., Berlin, J. A., Morton, S. C., Olkin, I., Williamson, G. D., Rennie, D., Moher, D., Becker, B. J., Sipe, T. A., Thacker, S. B. (2000). Meta-analysis of observational studies in epidemiology: a proposal for reporting. Meta-analysis Of Observational Studies in Epidemiology (MOOSE) group. JAMA 283, 2008-2012.

54. Tandon, R., Keshavan, M. S., Nasrallah, H. A. (2008). Schizophrenia, just the facts what we know in 2008. 2. Epidemiology and etiology. Schizophrenia Res 102, 1-18.

55. Thomas, C. S., Stone, K., Osborn, M., Thomas, P. F., Fisher, M. (1993). Psychiatric morbidity and compulsory admission among 
UK-born Europeans, Afro-Caribbeans and Asians in central Manchester. Br J Psychiatry 163, 91-99.

56. Torrey, E. F., Bartko, J. J., Lun, Z. R., Yolken, R. H. (2007). Antibodies to Toxoplasma gondii in patients with schizophrenia: a meta-analysis. Schizophr Bull 33, 729-736.

57. Van Os, J., Castle, D. J., Takei, N., Der, G., Murray, R. M. (1996). Psychotic illness in ethnic minorities: clarification from the 1991 census. Psychol Med 26, 203-208.

58. Veen, N., Selten, J. P., Hoek, H. W., Feller, W., van der Graaf, Y., Kahn, R. (2002). Use of illicit substances in a psychosis incidence cohort: a comparison among different ethnic groups in the Netherlands. Acta Psychiatr Scand 105, 440-443.

59. Veling, W., Hoek, H. W., Mackenbach, J. P. (2008a). Perceived discrimination and the risk of schizophrenia in ethnic minorities: a case-control study. Soc Psychiatry Psychiatr Epidemiol 43, 953-959.
60. Veling, W., Selten, J. P., Veen, N., Laan, W., Blom, J. D., Hoek, H. W. (2006). Incidence of schizophrenia among ethnic minorities in the Netherlands: a four-year first-contact study. Schizophr Res 86, 189-193.

61. Veling, W., Susser, E., van Os, J., Mackenbach, J. P., Selten, J. P., Hoek, H. W. (2008b). Ethnic density of neighborhoods and incidence of psychotic disorders among immigrants. Am J Psychiatry 165, 66-73.

62. Weiser, M., Werbeloff, N., Vishna, T., Yoffe, R., Lubin, G., Shmushkevitch, M., Davidson, M. (2008). Elaboration on immigration and risk for schizophrenia. Psychol Med 38, 1113 1119.

63. Zolkowska, K., Cantor-Graae, E., McNeil, T. F. (2001). Increased rates of psychosis among immigrants to Sweden: is migration a risk factor for psychosis? Psychol Med 31, 669-678. 



\section{chapter THREE}

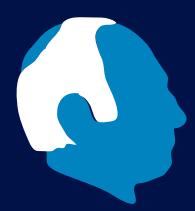

Evidence of an excessive male-to-female ratio among North African immigrants with a psychotic disorder in Europe: a systematic review and meta-analysis

E. van der Ven,

W. Veling,

A. Tortelli,

I. Tarricone,

D. Berardi,

F. Bourque,

J.P. Selten 


\section{Abstract}

\section{Purpose}

Epidemiological studies in the Netherlands have reported an excessive male-to-female risk for non-affective psychotic disorder (NAPD) among immigrants from Morocco. We examined the validity of these findings and their generalizability to immigrants from the Maghreb (Mauritania, Morocco, Algeria, Tunisia and Libya) in other European countries.

\section{Methods}

Systematic review and meta-analysis. Medline, PsychINFO and EMBASE databases were searched for publications in the period from January 1970 through April 2014. We included incidence and prevalence studies of non-affective psychotic disorder (NAPD) among migrants from the Maghreb in Europe and studies of subclinical psychotic symptoms (SPS) in representative samples. A meta-analysis was performed on the subgroup of incidence studies.

\section{Results}

Five incidence and three prevalence studies of NAPD, and two prevalence studies of SPS, conducted in the Netherlands, Belgium, France and Italy met our inclusion criteria. Across all research designs, the risks of NAPD and SPS were consistently increased among male, not female immigrants from the Maghreb. The meta-analysis of incidence studies of NAPD yielded male-to-female risk ratios of 5.1 (95\% confidence interval (CI) 3.1-8.4) for migrants from the Maghreb, 2.0 (95\% CI 1.6-2.5) for other migrant groups, and 1.8 (95\% CI 1.3-2.5) for non-migrant Europeans.

\section{Conclusions}

The marked male-to-female ratio in psychosis risk among migrants from the Maghreb appears a valid finding, foremost among the Moroccan-Dutch. The small number of studies limits the strength of conclusions that can be drawn about countries other than the Netherlands. Achievement-expectation mismatch, social marginalization and an increased prevalence of illicit drug use are possible explanations. 


\section{Introduction}

There is consistent evidence for an increased incidence of non-affective psychotic disorders (NAPD) among various migrant and ethnic minority populations (Bourque et al. 2011; Fearon et al. 2006). Since the underlying mechanisms remain incompletely understood, an in-depth examination of sources of variation in risk between non-migrant and migrant groups may shed light on candidate explanatory factors.

Meta-analytic evidence has not revealed significant differences in the incidence of NAPD between male and female immigrants with pooled relative risks of 2.5 (95\% confidence interval (CI) 2.0-3.2) and 2.4 (95\% CI 1.8-3.1), respectively (Cantor-Graae \& Selten, 2005). However, this does not preclude a sex difference in any particular ethnic minority group. In fact, there have been several studies reporting an excessive risk of schizophrenia for first-and second-generation male immigrants from Morocco to the Netherlands and not for their female counterparts (Selten et al. 2012; Selten \& Sijben, 1994; Veling et al. 2006). Since this phenomenon has not been observed in other immigrant groups with an Islamic background (Coid et al. 2008; Veling et al. 2006) or in migrants from other low- or middle-income countries (Fearon et al. 2006), we investigated whether excessive male-to-female ratios in psychosis risk are specific to immigrants in Europe originating from North African countries with a predominantly Berber culture, i.e., Mauritania, Morocco, Algeria, Tunisia and Libya (hereafter: "the Maghreb").

Thus, the aims of this study are (i) to compare sex ratios for the incidence of nonaffective psychotic disorders (NAPD) among first- and second-generation immigrants from the Maghreb in Europe to those for non-migrant Europeans and other migrant groups in the same investigations, using meta-analytic methods, (ii) to evaluate the validity and consistency of these findings in prevalence studies of NAPD and subclinical psychotic symptoms (SPS), and (iii) to discuss possible explanations.

\section{Methods}

\section{Search strategy}

We performed a systematic search of Medline, PsychINFO and EMBASE databases to identify potentially relevant publications appearing between January 1970 and April 2014 using the following search themes: ("North African*”; "Maghreb"; "Libya*”; Algeria*”; "Tunisia*”; "Morocc", "Berber", "Arab") combined with psychosis-related search terms ("psychosis"; "paranoi*"; "psychotic*”; "schizo*”; "hallucinat*; "delusion"; "depersonalization"; "derealisation"; "djinn"; "evil eye”; "grandios*; "magic"; "PLE”; "PLS”) and search terms related to research design ("prevalen*”; inciden*”; "occurrence”). Bibliographies from identified publications were cross-referenced. We used a cut-off publication year of 1970, because older studies did not account for potential age differences between migrant and non-migrant populations (Bourque et al. 2011).

\section{Inclusion and exclusion criteria}

Reports were eligible if the following inclusion criteria were met: (a) the report is an incidence or prevalence study of SPS or NAPD among representative samples of immigrants from the 
Maghreb in Europe and a non-migrant, reference population from the respective European country; (b) use of standardized instruments or criteria to assess or classify clinical diagnoses or symptoms; (c) publication in a peer-reviewed, English-, Dutch-, or French-language, indexed scientific journal; (d) sex-specific figures were reported or provided by the authors upon request. Immigrants were defined as such if they (first-generation) had been born abroad or at least one parent (second-generation).

\section{Procedure}

Two researchers assessed eligibility independently following a three-stage process. First, all study titles were screened for relevancy to SPS and NAPD and migration of individuals from the Maghreb to Europe. If one or both deemed a title eligible, it was kept for the next phase. Second, abstracts were screened for eligibility based on all inclusion criteria. In case of doubt, studies were kept for final screening. In the last stage, full-text articles were screened and eligibility assessed. At each stage consensus on eligibility was met between two researchers (EV and JPS)(see Figure 1).

\section{Group by \\ Visible minority status}

Non-migrant

Overall

North-African
Study name

veling
zandi
selten
tarricone
tortelli
veling
zandi
selten
tarricone
tortelli

Figure 1. Forest plot for the meta-analysis examining sex ratios for non-affective psychotic disorder in non-migrant, European study populations versus migrants from the Maghreb (i.e., Mauritania, Morocco, Algeria, Tunisia and Libya) in Europe.

If numerators and denominators by sex were reported or made available by authors, we calculated age-adjusted sex ratios for the incidence of NAPD for each migrant group (at least one of which from the Maghreb) and for each group of non-migrant Europeans using Poisson regression. For each migrant group, we extracted or calculated sex-specific age-adjusted incidence risk ratios (IRRs) for risk of NAPD or SPS using non-migrants of the relevant European country as the reference population. 


\section{Meta-analysis}

We performed a meta-analysis on incidence studies of NAPD. This was not possible for the small number of prevalence studies. In case of two studies reporting on overlapping populations, we selected the study with the largest study sample (Veling et al. 2006; Veling et al. 2011). Since the denominators for Algerian, Tunisian, Mauritanian and Lybian individuals in the study by Veling and colleagues (2011) could not be retrieved, it was not possible to compute an incidence rate for the entire group of immigrants from the Maghreb, but only for Moroccans. However, it is unlikely that this had a major impact on the results, since it applied to only 4 other migrants from the Maghreb ( 3 men and 1 woman of Tunisian origin), representing less than $5 \%$ of the total group of migrants from 'other non-Western countries'. To enable inclusion of one study that reported an absence of female Moroccan cases (Zandi et al. 2010), we added a hypothetical " 1 " instead of " 0 " as a numerator.

In order to use the same method of variance estimation across incidence studies, we calculated the variance for each effect size as follows: $V=1 / N_{m}+1 / N_{r}$, where $N_{m}$ is the number of migrant cases and $\mathrm{N}_{\mathrm{r}}$ the number of reference cases. For the meta-analysis of sex ratios the variance was calculated using the same formula attuned to cases by sex: $V=1 / \mathrm{N}_{\mathrm{m}}+1 / \mathrm{N}_{\mathrm{f}}$, where $\mathrm{N}_{\mathrm{m}}$ is the number of male cases and $\mathrm{N}_{\mathrm{f}}$ the number of female cases (Borenstein, 2010). Since the distribution of effect sizes was skewed, we conducted analyses on a log scale.

The initial meta-analysis included sex ratios of risk for NAPD within each ethnic group (migrants and non-migrants). For the purpose of analysis based on region of origin, migrants and non-migrants of different studies were divided according to six groups: non-migrants, migrants from the Maghreb, Sub-Saharan Africa, South or Central-America, Asia, and Western countries (from Europe, the United States, Canada, Australia or New Zealand). Since most studies were carried out in the Netherlands, we conducted a separate analysis on sex ratios for risk of NAPD among native Dutch and migrants from the Maghreb in the Netherlands.

To examine the consistency of findings, we also performed a meta-analysis on sexspecific incidence risk ratios (IRRs) for risk of NAPD among migrants compared to their native European counterparts. Computation of summary effects was carried out under a random-effects-model, because we cannot assume that the true effect sizes are identical across migrant and ethnic groups. We carried out heterogeneity analysis using the $\mathrm{Q}$ and $\mathrm{I}^{2}$ statistics to examine the amount of observed variance accounted for by true heterogeneity rather than by sampling error (Higgins et al. 2003). By examination of the symmetry of the funnel plot, we assessed the potential for publication bias in each analysis.

\section{Results}

The electronic search yielded 1,160 studies, 14 of which met all inclusion criteria. One additional study was retrieved through regular updates of the literature search (Adriaanse et al. 2015). We excluded five studies, because these concerned a convenience sample (van der Stelt et al. 2013) or samples consisting of youth offenders (Vinkers et al. 2013) or compulsory admissions only (de Wit et al. 2012; Mulder et al. 2006; van der Post et al. 2012).

The ten included studies consisted of five incidence and three prevalence studies of psychotic disorder, and two prevalence studies of subclinical psychotic symptoms (see table 1). These were conducted in Belgium $(n=1)$, France $(n=1)$, Italy $(n=1)$ and the Netherlands $(n=7)$. 


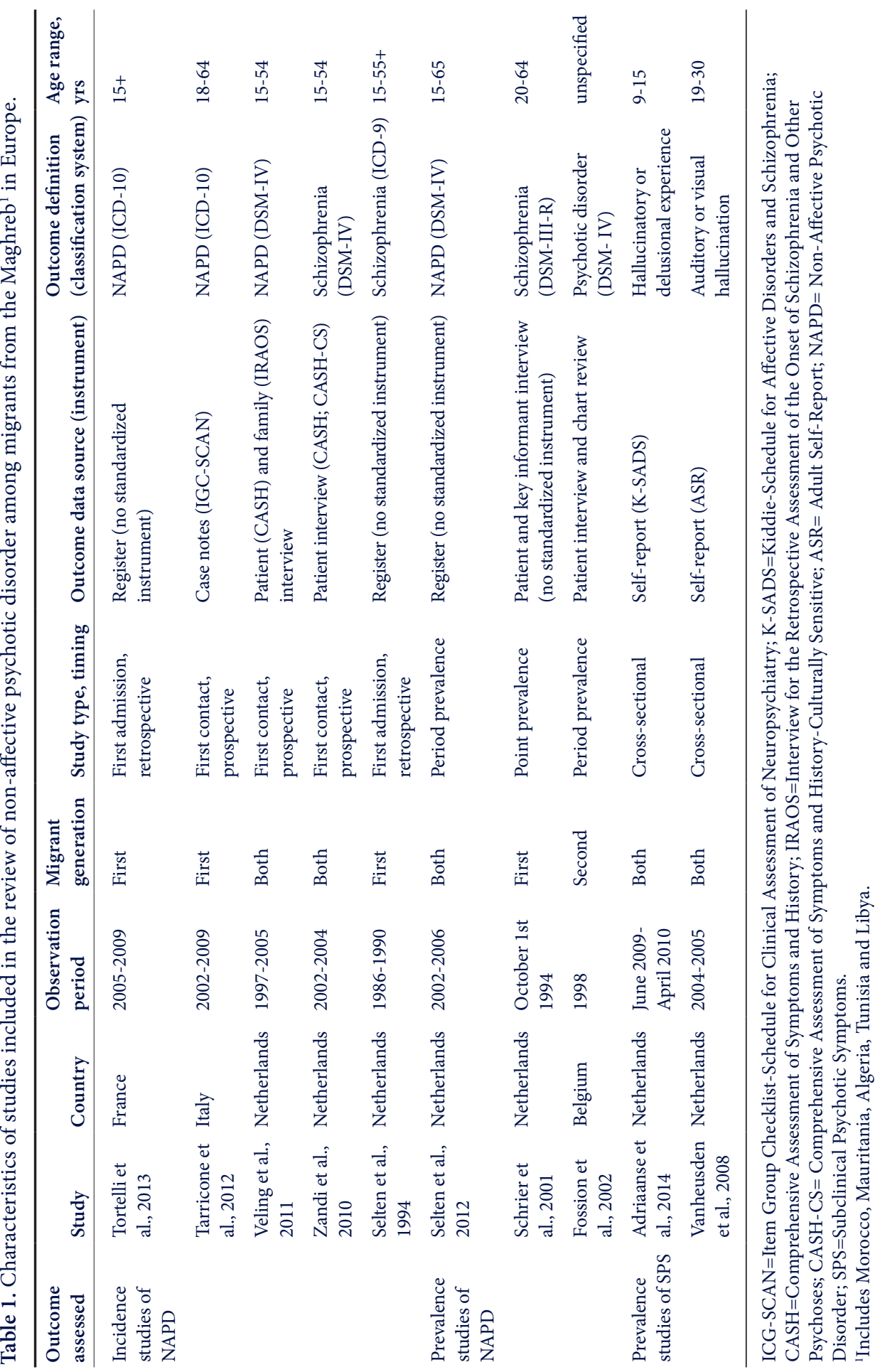




\section{Incidence studies of psychotic disorder}

Of the incidence studies, three used first-contact, prospective designs (Tarricone et al. 2012; Veling et al. 2011; Zandi et al. 2010) and two a first hospital admission, retrospective design (Selten and Sijben, 1994; Tortelli et al. 2014). Sample sizes of migrants from the Maghreb with NAPD varied from 4 to 70 patients per study. Incidence rates for NAPD among male and female migrant groups compared to their non-migrant counterparts, as well as corresponding sex ratios are depicted in table 2 .

Across all studies, except for one (Zandi et al. 2010), men from the Maghreb had a significantly higher risk than their European counterparts. In contrast, incidence rates of NAPD in women from the Maghreb were, with one exception (Veling et al. 2011), similar to those of non-migrant women in Europe.

Table 2. Sex-specific incidence risk ratios (IRRs) of non-affective psychotic disorder (NAPD) for migrant groups versus non-migrant Europeans and sex ratios of risk for NAPD within each ethnic group, based on incidence studies of NAPD among migrants from the Maghreb ${ }^{1}$ in Europe.

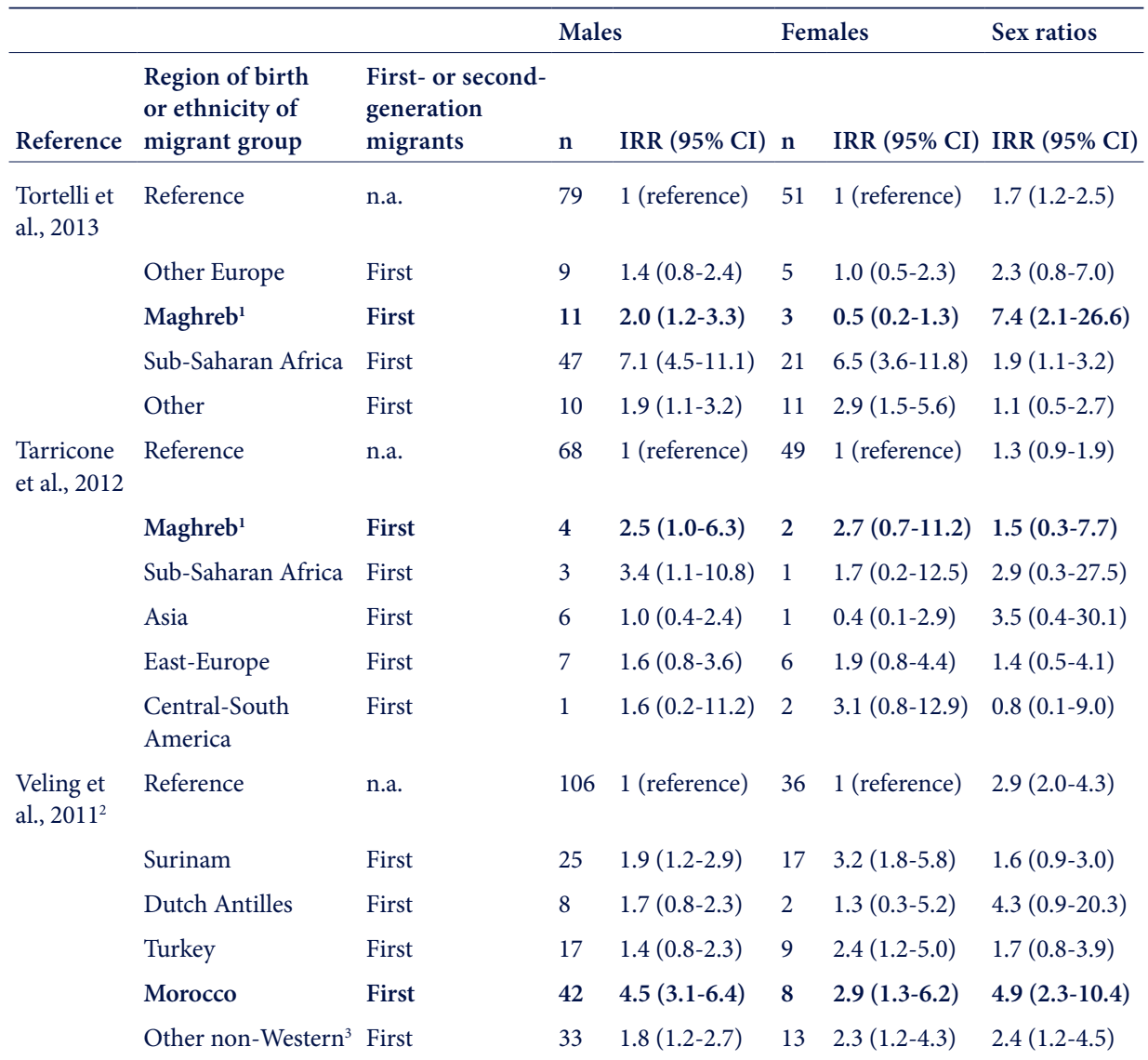


Table 2. Sex-specific incidence risk ratios (IRRs) of non-affective psychotic disorder (NAPD) for migrant groups versus non-migrant Europeans and sex ratios of risk for NAPD within each ethnic group, based on incidence studies of NAPD among migrants from the Maghreb ${ }^{1}$ in Europe. (Continued)

\begin{tabular}{|c|c|c|c|c|c|c|c|}
\hline \multirow[b]{2}{*}{ Reference } & \multirow[b]{2}{*}{$\begin{array}{l}\text { Region of birth } \\
\text { or ethnicity of } \\
\text { migrant group }\end{array}$} & \multicolumn{3}{|c|}{ Males } & \multicolumn{2}{|c|}{ Females } & \multirow{2}{*}{$\begin{array}{l}\text { Sex ratios } \\
\text { IRR }(95 \% \mathrm{CI})\end{array}$} \\
\hline & & $\begin{array}{l}\text { First- or second- } \\
\text { generation } \\
\text { migrants }\end{array}$ & $\mathrm{n}$ & IRR (95\% CI) & $\mathrm{n}$ & IRR $(95 \% \mathrm{CI})$ & \\
\hline & Other Western & First & 10 & $1.1(0.6-2.1)$ & 5 & $1.4(0.6-3.5)$ & $2.3(0.8-6.6)$ \\
\hline & Surinam & Second & 20 & $1.8(1.1-2.9)$ & 10 & $3.2(1.6-6.7)$ & $2.0(0.9-4.3)$ \\
\hline & Dutch Antilles & Second & 3 & $2.3(0.7-7.1)$ & 0 & n.a. & n.a. \\
\hline & Turkey & Second & 9 & $1.6(0.8-3.2)$ & 2 & $1.3(0.3-5.5)$ & $4.5(1.0-20.9)$ \\
\hline & Morocco & Second & 18 & $4.2(2.5-7.1)$ & 2 & $1.8(0.4-5.0)$ & $9.4(2.2-40.3)$ \\
\hline & Other non-Western ${ }^{3}$ & Second & 13 & $1.5(0.8-2.7)$ & 6 & $2.4(1.0-5.9)$ & $2.2(0.8-5.7)$ \\
\hline & Other Western & Second & 7 & $1.2(0.5-2.5)$ & 3 & $1.5(0.5-5.0)$ & $2.3(0.6-8.9)$ \\
\hline \multirow{2}{*}{$\begin{array}{l}\text { Zandi et } \\
\text { al., } 2010\end{array}$} & Reference & n.a. & 11 & 1 (reference) & 11 & 1 (reference) & $1.1(0.5-2.4)$ \\
\hline & Morocco & First & 4 & $1.6(0.4-4.2)$ & $1^{*}$ & $1.0(0.1-7.4)^{* *}$ & $3.6(0.4-32.3)^{* *}$ \\
\hline \multirow{5}{*}{$\begin{array}{l}\text { Selten et } \\
\text { al., } 1994\end{array}$} & Reference & n.a. & 1149 & 1 (reference) & 737 & 1 (reference) & $1.6(1.5-1.8)$ \\
\hline & Turkey & First & 15 & $0.8(0.5-1.4)$ & 4 & $0.5(0.2-1.3)$ & $3.3(1.1-9.8)$ \\
\hline & Morocco & First & 37 & $2.8(2.0-3.8)$ & 6 & $1.1(0.5-2.4)$ & $4.9(2.1-11.6)$ \\
\hline & Dutch Antilles & First & 26 & $4.4(3.0-6.6)$ & 8 & $2.3(1.1-4.6)$ & $3.4(1.6-7.6)$ \\
\hline & Surinam & First & 95 & $5.6(4.5-6.8)$ & 35 & $4.7(3.3-6.6)$ & $1.9(1.3-2.9)$ \\
\hline
\end{tabular}

IRR=incidence Risk Ratio; $\mathrm{CI}=$ confidence interval; n.a.=non-applicable

${ }^{1}$ Includes Morocco, Mauritania, Algeria, Tunisia and Libya.

${ }^{2}$ In the meta-analysis data for both generations combined by ethnic group were entered.

${ }^{3}$ Also includes immigrants from the North African countries, Algeria, Tunisia and Libya.

*For the purpose of the meta-analysis the actual numerator of "0" was replaced by a hypothetical " 1 ".

**Based on a hypothetical numerator of " 1 ".

\section{Meta-analysis}

The results of the meta-analysis are detailed in Table 3. The analysis, including all 20 effect sizes, yielded mean weighted sex ratios of 1.8 (95\% CI 1.3-2.5) and 2.4 (95\% CI 1.9-2.9) for the European reference population and all migrant groups, respectively. However, when classified according to region of origin, we found a significantly higher male-to-female ratio for migrants from the Maghreb (IRR=5.1, 95\% CI 3.1-8.4). In contrast, the pooled risk estimates for migrants from other regions of origin, obtained from the same investigations, were similar to those for non-migrant Europeans. The analysis for immigrants from the Maghreb in the Netherlands, including only individuals of Moroccan origin, yielded mean sex ratios of 1.8 (95\% CI 1.1-3.2) for the Dutch and 5.3 (95\% CI 3.0-9.5) for the Moroccan-Dutch. 


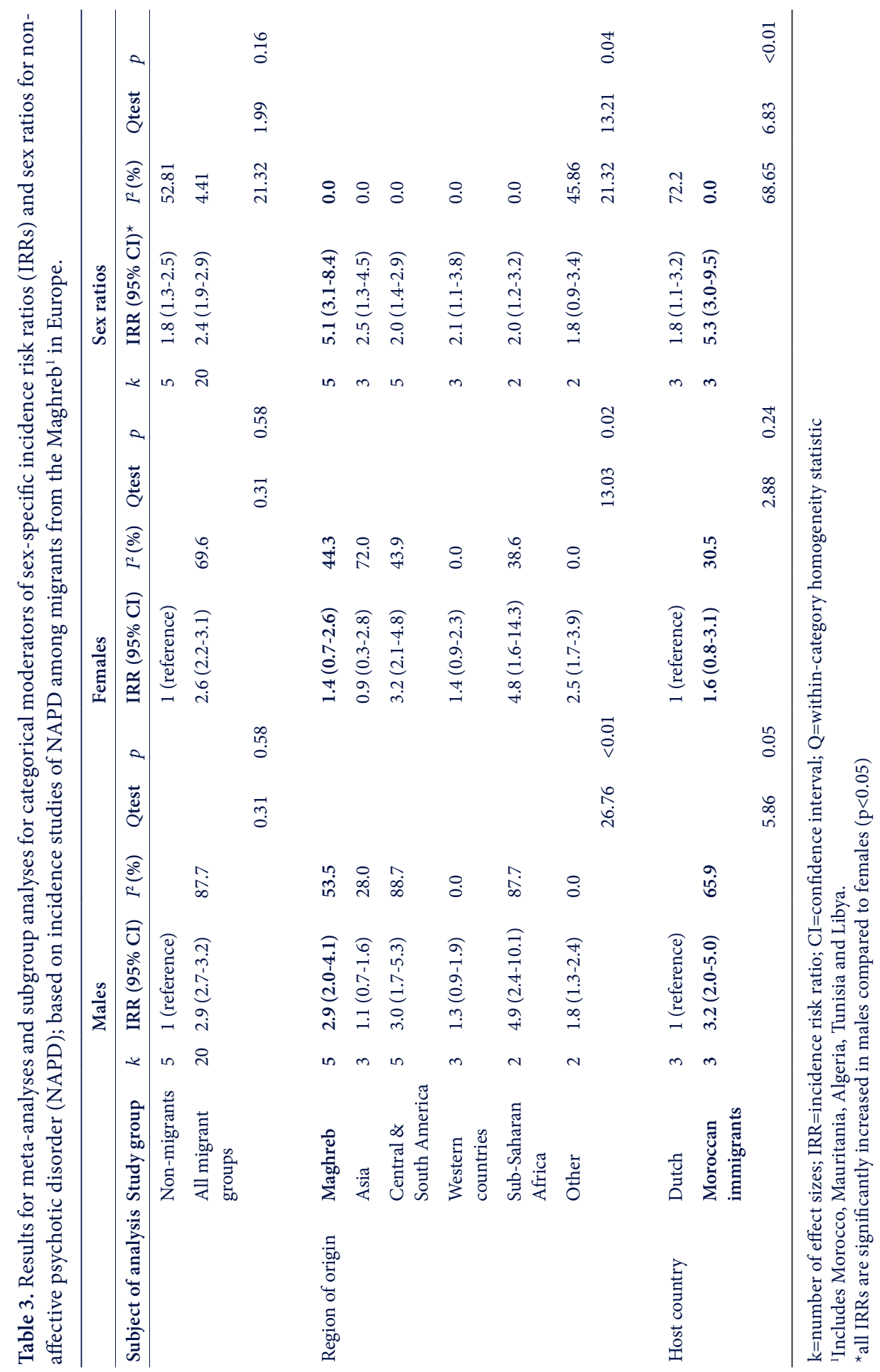

3

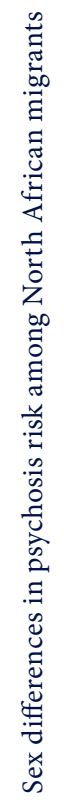


Sensitivity analyses of sex-specific IRRs revealed a similar pattern with a significant increase in the mean weighted risk for men from the Maghreb (IRR=2.9, 95\% CI 2.0-4.1), but not for their female counterparts (IRR=1.6, 95\% CI 0.7-2.6). Risk estimates for migrants from other regions, compared to Europeans, were either increased in both sexes or in none of the sexes. Figure 1 plots the log sex ratios for European and immigrants from the Maghreb

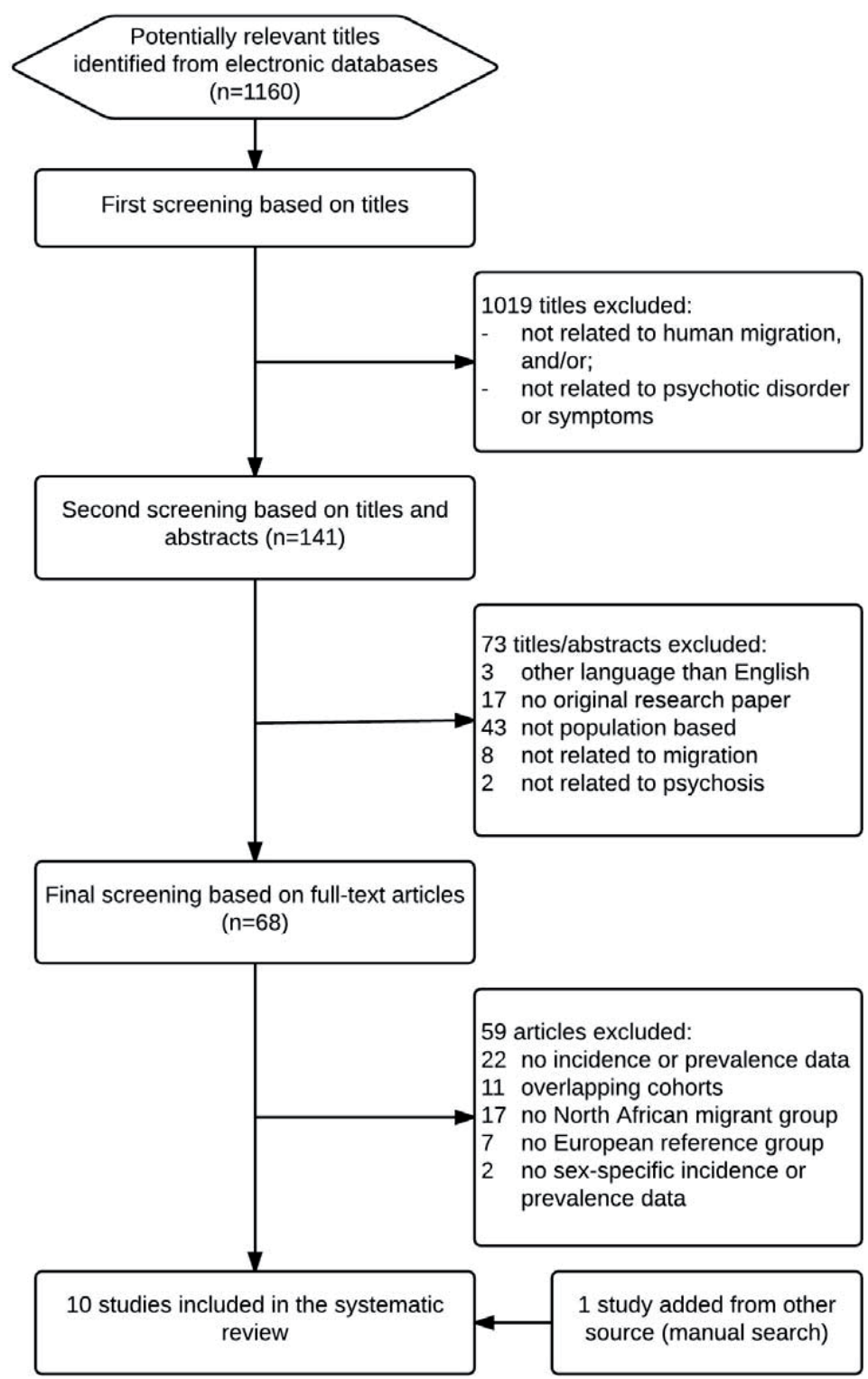

Figure 1. Flow chart of study selection 
of each study that were entered into the analysis. The funnel plot (not shown, available on request) did not suggest any evidence of publication bias. There was low observed heterogeneity across sex ratios grouped according to region of origin $\left(I^{2}=0 \%\right)$, except for migrants classified as 'Other' $\left(I^{2}=45.9 \%\right)$ or non-migrant Europeans $\left(I^{2}=52.8 \%\right)$.

Analyses of sex-specific IRRs yielded higher heterogeneity test statistics (see table 3), indicating that a larger percentage of the total variation in those incidence risk estimates is due to true heterogeneity rather than chance (Higgins et al. 2003).

\section{Prevalence studies of NAPD and SPS}

The three prevalence studies of NAPD showed significantly increased risks for MoroccanDutch males, not for females (see Table 4). Remarkably, the point prevalence study conducted in Rotterdam reported a complete absence of Moroccan-Dutch female cases of schizophrenia, as opposed to 23 cases among Moroccan-Dutch males (Schrier et al. 2001). A cross-sectional survey study of all Belgian and second-generation Moroccan patients first admitted to hospital during the year 1998, reported that Moroccan-Belgian males had a significantly increased odds for a diagnosis of psychotic disorder compared to age- and sex-matched Belgian patients $(\mathrm{OR}=4.0,95 \% \mathrm{CI} 1.9-8.5)$, while this was not the case for Moroccan-Belgian females ( $\mathrm{OR}=1.9,95 \%$ 0.7-5.4)(Fossion et al. 2002).

Table 4. Sex-specific odds ratios of non-affective psychotic disorder (NAPD) and subclinical psychotic symptoms (SPS) for migrant groups versus non-migrant Europeans, derived from prevalence studies among migrants from the Maghreb ${ }^{1}$ in Europe.

\begin{tabular}{|c|c|c|c|c|c|c|c|}
\hline & & & & Male & & Fem & \\
\hline Study type & Study & $\begin{array}{l}\text { Region of birth } \\
\text { or ethnicity of } \\
\text { migrant group }\end{array}$ & $\begin{array}{l}\text { First- or second- } \\
\text { generation } \\
\text { migrants }\end{array}$ & n & OR $(95 \% \mathrm{CI})$ & $\mathbf{n}$ & OR $(95 \% \mathrm{CI})$ \\
\hline \multirow{13}{*}{$\begin{array}{l}\text { Prevalence } \\
\text { studies of } \\
\text { NAPD }\end{array}$} & $\begin{array}{l}\text { Selten et al., } \\
2012^{2}\end{array}$ & Reference & n.a. & 364 & 1 (reference) & 283 & 1 (reference) \\
\hline & & Turkey & First & 28 & $1.6(1.1-2.4)$ & 14 & $1.2(0.7-2.0)$ \\
\hline & & Morocco & First & 106 & $3.1(2.5-3.9)$ & 22 & $1.1(0.7-1.7)$ \\
\hline & & Surinam & First & 46 & $4.4(3.3-6.0)$ & 24 & $2.7(1.8-4.0)$ \\
\hline & & Dutch Antilles & First & 9 & $3.0(1.6-5.8)$ & 6 & $2.6(1.2-5.9)$ \\
\hline & & Western Europe & First & 4 & $0.6(0.2-1.6)$ & 4 & $0.8(0.3-2.2)$ \\
\hline & & Turkey & Second & 18 & $4.5(2.7-7.3)$ & 4 & $2.7(1.0-7.4)$ \\
\hline & & Morocco & Second & 17 & $3.4(2.0-5.6)$ & 4 & $2.2(0.8-6.0)$ \\
\hline & & Surinam & Second & 13 & $3.8(2.2-6.6)$ & 11 & $6.4(3.5-11.8)$ \\
\hline & & Dutch Antilles & Second & 3 & $2.6(0.8-8.2)$ & 1 & $1.7(0.2-12.3)$ \\
\hline & & Western Europe & Second & 13 & $1.3(0.7-2.3)$ & 4 & $0.5(0.2-1.3)$ \\
\hline & $\begin{array}{l}\text { Schrier et } \\
\text { al., } 2001\end{array}$ & Reference & n.a. & 292 & 1 (reference) & 173 & 1 (reference) \\
\hline & & Surinam & First & 75 & $2.7(2.0-3.5)$ & 38 & $2.3(1.6-3.4)$ \\
\hline
\end{tabular}


Table 4. Sex-specific odds ratios of non-affective psychotic disorder (NAPD) and subclinical psychotic symptoms (SPS) for migrant groups versus non-migrant Europeans, derived from prevalence studies among migrants from the Maghreb ${ }^{1}$ in Europe. (Continued)

3

\begin{tabular}{|c|c|c|c|c|c|c|c|}
\hline \multirow[b]{2}{*}{ Study type } & \multirow[b]{2}{*}{ Study } & \multirow[b]{2}{*}{$\begin{array}{l}\text { Region of birth } \\
\text { or ethnicity of } \\
\text { migrant group }\end{array}$} & \multicolumn{3}{|c|}{ Males } & \multicolumn{2}{|c|}{ Females } \\
\hline & & & $\begin{array}{l}\text { First- or second- } \\
\text { generation } \\
\text { migrants }\end{array}$ & n & OR $(95 \% \mathrm{CI})$ & $\mathbf{n}$ & OR $(95 \% \mathrm{CI})$ \\
\hline & & Dutch Antilles & First & 9 & $1.3(0.7-2.6)$ & 8 & $3.1(1.5-6.4)$ \\
\hline & & Turkey & First & 17 & $1.0(0.6-1.7)$ & 4 & $1.3(0.5-3.6)$ \\
\hline & & Morocco & First & 23 & $1.9(1.2-3.0)$ & 0 & n.a. \\
\hline & & Cape Verde & First & 4 & $0.7(0.3-2.0)$ & 8 & $2.1(1.0-4.4)$ \\
\hline & & Other & First & 34 & $0.9(0.6-1.3)$ & 28 & $1.2(0.8-1.8)$ \\
\hline & $\begin{array}{l}\text { Fossion et } \\
\text { al., } 2002\end{array}$ & Reference & n.a. & 12 & 1 (reference) & 7 & 1 (reference) \\
\hline & & Morocco & Second & 34 & $4.0(1.9-8.5)$ & 12 & $1.9(0.7-5.4)$ \\
\hline \multirow{12}{*}{$\begin{array}{l}\text { Prevalence } \\
\text { studies of } \\
\text { SPS }\end{array}$} & $\begin{array}{l}\text { Adriaanse } \\
\text { et al., } 2014\end{array}$ & Reference & n.a. & 15 & 1 (reference) & 7 & 1 (reference) \\
\hline & & Morocco & Both & 25 & $3.3(1.7-6.5)$ & 13 & $2.6(1.0-6.7)$ \\
\hline & & Turkey & Both & 12 & $3.4(1.5-7.6)$ & 0 & n.a. \\
\hline & & Other LMIC & Both & 9 & $2.2(0.9-5.2)$ & 6 & $3.3(1.1-10.2)$ \\
\hline & & Other HIC & Both & 3 & $2.2(0.6-7.9)$ & 3 & $3.6(0.9-14.9)$ \\
\hline & $\begin{array}{l}\text { Vanheusden } \\
\text { et al., } 2008\end{array}$ & Reference & Both & 23 & 1 (reference) & 21 & 1 (reference) \\
\hline & & Turkey & Both & 4 & $2.7(0.9-8.2)$ & 11 & $\begin{array}{l}13.4(6.0- \\
30.3)\end{array}$ \\
\hline & & Morocco & Both & 7 & $8.6(3.4-21.9)$ & 1 & $1.2(0.2-8.9)$ \\
\hline & & Surinam & Both & 6 & $3.4(1.3-8.7)$ & 3 & $1.3(0.4-4.6)$ \\
\hline & & Indonesia & Both & 1 & $1.4(0.2-10.4)$ & 5 & $6.8(2.4-19.3)$ \\
\hline & & $\begin{array}{l}\text { Other non- } \\
\text { Western }\end{array}$ & Both & 4 & $4.2(1.4-12.8)$ & 4 & $3.0(0.3-10.5)$ \\
\hline & & Western & Both & 2 & $1.0(0.2-4.4)$ & 0 & na \\
\hline
\end{tabular}

$\mathrm{OR}=$ odds ratio; $\mathrm{CI}=$ confidence interval; $\mathrm{LMIC}=$ low- and middle-income countries; $\mathrm{HIC}$ =high-income countries.

${ }^{1}$ Includes Morocco, Mauritania, Algeria, Tunisia and Libya.

${ }^{2}$ Effect sizes reflect risk ratios

Studies of psychotic symptoms in non-help-seeking samples comprised two crosssectional surveys, one of self-reported auditory and visual hallucinations among young adults ( $\mathrm{n}=2258)$ (Vanheusden et al. 2008) and the other on psychotic-like experiences (PLE) with high impact in 9- to 16-year-old schoolchildren $(n=1411)$ (Adriaanse et al. 2015) of different ethnic backgrounds in the Netherlands. 
The former study showed that Moroccan-Dutch males were more likely to report hallucinations than Dutch males ( $\mathrm{OR}=8.4,95 \%$ CI 3.3-21.2), while these proportions were similar for Moroccan and Dutch females (3.0\% and $2.4 \%$, respectively).

Among schoolchildren the prevalence rates of PLE with impact were increased in both Moroccan boys (OR=3.3, 95\% CI 1.7-6.5) and girls (OR=2.6, 95\% CI 1.0-4.0) compared to their Dutch peers. Interestingly, however, among the 13-16 year olds, the presence of PLE with impact was more common in Moroccan boys compared to girls (10.3\% and $2.9 \%$, respectively), while these proportions were similar in the age group of children between 9 and 12 years old. Turkish boys also disclosed significantly more PLEs than girls, while the opposite applied to youth from other low-to-middle-income countries.

\section{Discussion}

We found evidence of a very high male-to-female ratio for the incidence of NAPD among immigrants from the Maghreb in Europe, foremost among the Moroccan-Dutch. In this ethnic group, a consistent sex difference in the prevalence of NAPD and SPS emerged from age 13 years onwards. No excessive sex difference in risk was consistently observed in nonmigrant Europeans or in other migrant groups.

\section{Strengths and limitations}

To our knowledge, this is the first systematic review of sex differences in psychosis risk among specific migrant populations. The moderating effect of sex on the psychosis risk for migrants from the Maghreb emerged consistently across various types of research designs, including different end-points on the psychosis continuum. This strengthens the validity of the observed relationship (Kelleher \& Cannon, 2011). Several limitations need to be taken into account in the interpretation of its findings. The amount of studies was limited and the number of migrant cases in each study was small. Some studies may thus have lacked the power to demonstrate significant risk differences. The large majority of findings applied to Moroccan immigrants in the Netherlands. Although a similar risk pattern emerged in studies of immigrants from the Maghreb in Belgium and France (not Italy), the generalizability of these findings to migrant groups from the Maghreb in Europe is limited. We therefore discuss our findings primarily in light of the Moroccan-Dutch context.

\section{The potential role of bias}

One could argue that Moroccan-Dutch women with NAPD do not enter mental health care services or that Dutch psychiatrists do not recognize psychotic symptoms in this particular group, but there is no evidence in support of this. Findings from the Dutch National Survey of General Practice (2000-2002) demonstrate that Moroccan women are three times more likely to contact outpatient mental health care services for any psychiatric problem compared to Moroccan men (Gerritsen \& Deville, 2009). In addition, the worldwide reported female excess in the treated prevalence of unipolar depressive disorder has also been found among Moroccan-Dutch women, implying that they do find their way to mental health services (Selten et al. 2012). In an effort to test whether Moroccan-Dutch women with psychosis are 
overlooked by treatment-based epidemiological studies, Selten et al. (2008) interviewed relatives of Moroccan-Dutch patients with NAPD about the presence of these disorders in the siblings of the patients and found a large number of cases among the brothers $(\mathrm{N}=14)$, not among their sisters $(\mathrm{N}=1)$.

Bias in numerator data of Moroccan immigrants in registry studies (Selten et al. 2012; Selten \& Sijben, 1994) may exist, because many individuals born in Morocco during the period 1950-1970 did not know their exact date of birth and were assigned an arbitrary one (January or July $1^{\text {st }}$ ) upon arrival in the Netherlands. Since patients are anonymously selected for analysis using their date of birth, country of birth and sex, many Moroccanborn individuals could not be distinguished and were counted as one, leading to an underestimation of the incidence among first-generation, Moroccan immigrants. With reference to the study of the Utrecht registry, consequences were less significant, because the registry disposed of postal codes (Selten et al. 2012).

Zandi et al. (2010) proposed that the reported increase of schizophrenia among Moroccan immigrants in the Netherlands is caused by misinterpretation of culturally appropriate experiences leading to wrong diagnoses. However, based on a culturally sensitive diagnostic instrument (CASH-CS), they also found a male preponderance of psychotic disorder among Moroccan immigrants.

\section{Sex difference in country of origin?}

It is important to consider the possibility that an excessive sex difference may already be present in the country of origin. The large cross-national, WHO study on psychotic symptoms in the general population does not support this idea and revealed a similar prevalence of psychotic symptoms (17\% versus $19 \%$ ) and disorder (0.5\% versus $0.7 \%$ ) in respectively males and females in Morocco (Nuevo et al. 2012). This is in line with meta-analytic evidence of a significant sex difference in the risk of schizophrenia in high-income, not low-income countries (Aleman et al. 2003).

\section{Possible explanations}

The excessive male-to-female psychosis risk among primarily the Moroccan-Dutch is a surprising finding for which we have no ready explanation. Interestingly, a Dutch register study on the risk of a first treatment for drug abuse reported an increased risk for Moroccan men (vs. Dutch men) and a decreased risk for Moroccan women (vs. Dutch women) in both hospital- and out-patient settings (Selten et al. 2007). Such a pattern was not observed in any other ethnic minority group. Although the association between ethnic minority stress and drug use may be bi-directional, this raises the possibility that the sex difference in drug abuse is larger in the Moroccan-Dutch community than in other sections of the population. Nonetheless, studies of illicit drug use in the general population (Spruit, 2002; van Laar et al. 2011) or in psychotic patients (Veen et al. 2002; Veling et al. 2008) did not report higher rates for Moroccan-Dutch males.

Lahlah et al. (2013) interviewed adolescent boys and found an increased prevalence of child abuse in Moroccan compared to Dutch boys. However, it is unknown whether the prevalence of childhood trauma is disproportionally increased in boys compared to girls from the Maghreb. 
Other socio-environmental factors that could impact psychosis risk in migrants at individual level include ethnic identity, achievement-expectation mismatch and discrimination (Veling and Susser, 2011). A strong identification with one's own ethnic identity is associated with a decreased odds for psychotic disorder (Veling et al. 2010), but Moroccan-Dutch girls are generally less attached to their culture of origin than boys (Stevens et al. 2007).

Alternatively, men from the Maghreb may be more likely to experience a widening of the gap between aspirations and achievements after emigration to Europe, while this gap may become narrower for women from the Maghreb, leading to a respective drop and rise in social status. For instance, the ratio of literate females to males (aged 15-24) in Morocco is about 0.83 to 1.0 , while this gender disparity is negligible in the Netherlands (UNESCO, 2010). Also, compared to first-generation migrants the participation in higher education and the labour market has grown among second-generation, Moroccan-Dutch women, not men (Crul \& Doomernik, 2003; Gijsberts et al. 2012). The discrepancy between achievement and expectation has previously been suggested to contribute to high rates of psychosis among African Americans in Philadelphia (Kleiner \& Parker, 1963) and was associated with psychosis risk in both White British and African-Caribbean patients in the UK (Reininghaus et al. 2008).

In addition, the majority of Moroccan-Dutch boys have been charged for a crime before age 23 years (Blokland et al. 2010; Gijsberts et al. 2012). They constitute a marginalized group in the Netherlands and face intolerance by neighbourhood residents, strict supervision by police and stigmatization in the media (de Jong, 2012; Pels, 2003). Resulting feelings of dissatisfaction about Dutch society (Huijnk \& Dagevos, 2012; Ouarasse \& van de Vijver, 2005) in combination with limited parental control beyond the domestic sphere (Engbersen et al. 2007), may provide fertile ground for deviant behaviour. Although speculative, this could lead to further alienation and, ultimately, development of psychotic symptoms among a vulnerable group.

This potential mechanism ties well in with the model of social defeat, which proposes that the subjective experience of social exclusion or defeat may lead to sensitization of the mesolimbic dopamine system (or to increased baseline activity of this system) and thereby increase the risk for psychosis (Gevonden et al. 2014; Selten et al. 2013; Selten \& CantorGraae, 2005). Social defeat could be an explanation for the observed sex differences if this subjective experience is indeed more prevalent among men from the Maghreb compared to their female counterparts.

In conclusion, the large sex difference in psychosis risk among immigrants from the Maghreb in Europe appears to be a valid finding, especially among Moroccans in the Netherlands. Our results may be explained by sex differences in changes in social status, in drug abuse (Di Forti et al. 2009) or by as yet unidentified risk or protective factors that operate differentially according to sex.

\section{Acknowledgements}

We thank the researchers who kindly provided data and information regarding their relevant published studies: Dr. Eva Velthorst, Dr. Louk van der Post, Dr. Odin van der Stelt, Dr. David Vinkers, Dr. Marcia Adriaanse, Dr. Teklah Zandi, Dr. Jan van der Ende and Dr. Jaap Peen. 
We thank Prof. Driss Moussaoui, Dr. Esmah Lahlah and Prof. Jeremy Coid for providing valuable comments on the topic of this manuscript. The authors have declared that there are no conflicts of interest in relation to the subject of this study.

\section{References}

1. Adriaanse, M., van Domburgh, L., Hoek, H. W., Susser, E., Doreleijers, T. A. H., Veling, W. (2015). Prevalence, impact and cultural context of psychotic experiences among ethnic minority youth. Psychol Med 45, 637646.

2. Aleman, A., Kahn, R. S., Selten, J. P. (2003). Sex differences in the risk of schizophrenia: evidence from meta-analysis. Arch Gen Psychiatry 60, 565-571.

3. Blokland, A., Grimbergen, K., Bernasco, W., Nieuwbeerta, P. (2010). Criminaliteit en etniciteit. Tijdschr Criminol 2, 122-152.

4. Borenstein, M. (2010). Meta-Analysis: Computing Treatment Effects and Effect Sizes. Chichester.

5. Bourque, F., van der Ven, E., Malla, A. (2011). A meta-analysis of the risk for psychotic disorders among first- and secondgeneration immigrants. Psychol Med 41, 897910.

6. Cantor-Graae, E., Selten, J. P. (2005). Schizophrenia and migration: a metaanalysis and review. Am J Psychiatry 162, 12-24.

7. Coid, J. W., Kirkbride, J. B., Barker, D., Cowden, F., Stamps, R., Yang, M., Jones, P. B. (2008). Raised incidence rates of all psychoses among migrant groups: findings from the East London first episode psychosis study. Arch Gen Psychiatry 65, 1250-1258.

8. Crul, M., Doomernik, J. (2003). The Turkish and Moroccan Second Generation in the Netherlands: Divergent Trends between and Polarization within the Two Groups ${ }^{1}$. Int Migr Rev 37, 1039-1064.

9. de Jong, J. (2012). Typically Moroccan? A Group Dynamic Explanation of Nuisance and Criminal Behavior. In Youth Gangs in International Perspective, ed. F. A. Esbensen \& C. L. Maxson, pp. 225-236. Springer New York.

10. de Wit, M. A., Tuinebreijer, W. C., van Brussel, G. H., Selten, J. P. (2012). Ethnic differences in risk of acute compulsory admission in Amsterdam, 1996-2005. Soc Psychiatry Psychiatr Epidemiol 47, 111-118.

11. Di Forti, M., Morgan, C., Dazzan, P., Pariante, C., Mondelli, V., Marques, T. R., Handley, R., Luzi, S., Russo, M., Paparelli, A., Butt, A., Stilo, S. A., Wiffen, B., Powell, J., Murray, R. M. (2009). High-potency cannabis and the risk of psychosis. Br J Psychiatry 195, 488-491.

12. Engbersen, G., van der Leun, J., de Boom, J. (2007). The Fragmentation of Migration and Crime in the Netherlands. Crime Justice 35, 389-452.

13. Fearon, P., Kirkbride, J. B., Morgan, C., Dazzan, P., Morgan, K., Lloyd, T., Hutchinson, G., Tarrant, J., Fung, W. L., Holloway, J., Mallett, R., Harrison, G., Leff, J., Jones, P. B., Murray, R. M. (2006). Incidence of schizophrenia and other psychoses in ethnic minority groups: results from the MRC AESOP Study. Psychol Med 36, 1541-1550.

14. Fossion, P., Ledoux, Y., Valente, F., Servais, L., Staner, L., Pelc, I., Minner, P. (2002). Psychiatric disorders and social characteristics among second-generation Moroccan migrants in Belgium: an ageand gender-controlled study conducted in a psychiatric emergency department. Eur Psychiatry 17, 443-450.

15. Gerritsen, A. A., Deville, W. L. (2009). Gender differences in health and health care utilisation in various ethnic groups in the Netherlands: a cross-sectional study. BMC Public Health 9, 109.

16. Gevonden, M., Booij, J., van den Brink, W., Heijtel, D., Van Os, J., Selten, J. P. (2014). Increased release of dopamine in the striata of young adults with hearing impairment and its relevance for the social defeat hypothesis of schizophrenia. JAMA Psychiatry71, 13641372.

17. Gijsberts, M., Huijnk, W., Dagevos, J. (2012). Annual Integration Report 2011, pp. $102-$ 227. The Netherlands Institute for Social Research. 
18. Higgins, J. P., Thompson, S. G., Deeks, J. J., Altman, D. G. (2003). Measuring inconsistency in meta-analyses. BMJ 327, 557-560.

19. Huijnk, W., Dagevos, J. (2012). Closer together? The socio-cultural position of non-Western migrants in the Netherlands, pp. 128-144. The Netherlands Institute for Social Research.

20. Kelleher, I., Cannon, M. (2011). Psychoticlike experiences in the general population: characterizing a high-risk group for psychosis. Psychol Med 41, 1-6.

21. Kleiner, R. J., Parker, S. (1963). GoalStriving, Social Status, and Mental Disorder: A Research Review. Am Sociol Rev 28, 189203.

22. Lahlah, E., van der Knaap, L. M., Bogaerts, S. (2013). Dangerous boys or boys in danger? Examining the relationship between ethnicity, child abuse and violent offending. Eur J Criminol 10, 641-658.

23. Mulder, C. L., Koopmans, G. T., Selten, J. P. (2006). Emergency psychiatry, compulsory admissions and clinical presentation among immigrants to the Netherlands. Br J Psychiatry 188, 386-391.

24. Nuevo, R., Chatterji, S., Verdes, E., Naidoo, N., Arango, C., Ayuso-Mateos, J. L. (2012). The continuum of psychotic symptoms in the general population: a cross-national study. Schizophr Bull 38, 475-485.

25. Ouarasse, O. A., van de Vijver, F. J. R. (2005). The role of demographic variables and acculturation attitudes in predicting sociocultural and psychological adaptation in Moroccans in the Netherlands. Int J Intercult Relat 29, 251-272.

26. Pels, T. (2003). The question of respect: Socialisation and misconduct of Moroccan boys in the Netherlands. Neth J Soc Sci 39, 126-141.

27. Reininghaus, U. A., Morgan, C., Simpson, J., Dazzan, P., Morgan, K., Doody, G. A., Bhugra, D., Leff, J., Jones, P., Murray, R., Fearon, P., Craig, T. K. (2008). Unemployment, social isolation, achievement-expectation mismatch and psychosis: findings from the AESOP Study. Soc Psychiatry Psychiatr Epidemiol. 43, 743751.

28. Schrier, A.C., van de Wetering, B. J., Mulder, P. G., Selten, J. P. (2001). Point prevalence of schizophrenia in immigrant groups in Rotterdam: data from outpatient facilities. Eur Psychiatry 16, 162-166.

29. Selten, J. P., Blom, J. D., van, d. T., I, Veling, W., Leliefeld, B., Hoek, H. W. (2008). Psychosis risk for parents and siblings of Dutch and Moroccan-Dutch patients with non-affective psychotic disorder. Schizophr Res 104, 274-278.

30. Selten, J. P., Cantor-Graae, E. (2005). Social defeat: risk factor for schizophrenia? Br J Psychiatry 187, 101-102.

31. Selten, J. P., Laan, W., Kupka, R., Smeets, H. M., van, Os, J. (2012). Risk of psychiatric treatment for mood disorders and psychotic disorders among migrants and Dutch nationals in Utrecht, The Netherlands. Soc Psychiatry Psychiatr Epidemiol 47, 271-278.

32. Selten, J. P., Sijben, N. (1994). First admission rates for schizophrenia in immigrants to The Netherlands. The Dutch National Register. Soc Psychiatry Psychiatr Epidemiol 29, 71-77.

33. Selten, J. P., van der Ven, E., Rutten, B. P., Cantor-Graae, E. (2013). The social defeat hypothesis of schizophrenia: an update. Schizophr Bull 39, 1180-1186.

34. Selten, J. P., Wierdsma, A., Mulder, N., Burger, H. (2007). Treatment seeking for alcohol and drug use disorders by immigrants to the Netherlands: retrospective, populationbased, cohort study. Soc Psychiatry Psychiatr Epidemiol 42, 301-306.

35. Spruit, I. P. (2002). Cannabis 2002 Report, pp. 1-142. Ministry of Public Health, Brussels, Belgium.

36. Stevens, G. W. J. M., Vollebergh, W. A. M., Pels, T. V. M., Crijnen, A. A. M. (2007). Problem Behavior and Acculturation in Moroccan Immigrant Adolescents in the Netherlands: Effects of Gender and ParentChild Conflict. J Cross-Cult Psychol 38, 310317.

37. Tarricone, I., Mimmi, S., Paparelli, A., Rossi, E., Mori, E., Panigada, S., Carchia, G., Bandieri, V., Michetti, R., Minenna, G., Boydell, J., Morgan, C., Berardi, D. (2012). First-episode psychosis at the West Bologna Community Mental Health Centre: results of an 8-year prospective study. Psychol Med 42, 2255-2264.

38. Tortelli, A., Morgan, C., Szoke, A., Nascimento, A., Skurnik, N., de Caussade, E. M., Fain-Donabedian, E., Fridja, F., 
Henry, M., Ezembe, F., Murray, R. M. (2014). Different rates of first admissions for psychosis in migrant groups in Paris. Soc Psychiatry Psychiatr Epidemiol 49, 11031109.

39. UNESCO (2010). United Nations Educational, Scientific, and Cultural Organization, Institute for Statistics. Statistical tables.

40. van der Post, L., Visch, I., Mulder, C., Schoevers, R., Dekker, J., Beekman, A. (2012). Factors associated with higher risks of emergency compulsory admission for immigrants: a report from the ASAP study. Int J Soc Psychiatry 58, 374-380.

41. van der Stelt, O., Boubakri, D., Feltzer, M. (2013). Migration Status, Familial Risk for Mental Disorder, and Schizotypal Personality Traits. Europe's J Psychol 9, 552571.

42. van Laar, M. W., Cruts, A. A. N., van OoyenHouben, M. M. J., Meijer, R. F., Croes, E. A., Brunt, T., Ketelaars, A. P. M. (2011). NDM Annual Report 2010, Netherlands National Drug Monitor, pp. 1-275. Trimbos Instituut: Utrecht.

43. Vanheusden, K., Mulder, C. L., van der Ende, J., Selten, J. P., van Lenthe, F. J., Verhulst, F. C., Mackenbach, J. P. (2008). Associations between ethnicity and selfreported hallucinations in a population sample of young adults in The Netherlands. Psychol Med 38, 1095-1102.

44. Veen, N., Selten, J. P., Hoek, H. W., Feller, W., van der Graaf, Y., Kahn, R. (2002). Use of illicit substances in a psychosis incidence cohort: a comparison among different ethnic groups in the Netherlands. Acta Psychiatr Scand 105, 440-443.

45. Veling, W., Hoek, H. W., Selten, J. P., Susser, E. (2011). Age at migration and future risk of psychotic disorders among immigrants in the Netherlands: a 7-year incidence study. Am J Psychiatry 168, 1278-1285.

46. Veling, W., Hoek, H. W., Wiersma, D., Mackenbach, J. P. (2010). Ethnic identity and the risk of schizophrenia in ethnic minorities: a case-control study. Schizophr Bull 36, 1149-1156.

47. Veling, W., Mackenbach, J. P., van Os, J., Hoek, H. W. (2008). Cannabis use and genetic predisposition for schizophrenia: a case-control study. Psychol Med 38, 12511256.

48. Veling, W., Selten, J. P., Veen, N., Laan, W., Blom, J. D., Hoek, H. W. (2006). Incidence of schizophrenia among ethnic minorities in the Netherlands: a four-year first-contact study. Schizophr Res 86, 189-193.

49. Veling, W., Susser, E. (2011). Migration and psychotic disorders. Expert Rev Neurother 11, 65-76.

50. Vinkers, D. J., Selten, J. P., Hoek, H. W., Rinne, T. (2013). Psychotic disorders are more common in ethnic minority than in Dutch native defendants. Soc Psychiatry Psychiatr Epidemiol 48, 1399-1404.

51. Zandi, T., Havenaar, J. M., Smits, M., Limburg-Okken, A. G., van Es, H., Cahn, W., Algra, A., Kahn, R. S., van den Brink, W. (2010). First contact incidence of psychotic disorders among native Dutch and Moroccan immigrants in the Netherlands: influence of diagnostic bias. Schizophr Res 119, 27-33. 




\section{chapter FOUR}

Childhood bullying and the association with psychosis in non-clinical and clinical samples: a review and meta-analysis

D.S. van Dam,

E. van der Ven,

E.Velthorst,

J. P. Selten,

C. Morgan,

L. de Haan

Psychological Medicine (2012), 42, 2463-2474. 


\begin{abstract}
Background

Approximately 11 percent of school children are bullied on a regular basis. It has been argued that continuous exposure to stress is related to the development of psychotic symptoms. The current study therefore sought to investigate whether being bullied in childhood is related to the development of psychotic symptoms.
\end{abstract}

\title{
Method
}

A search of Pubmed, PsycINFO and EMBASE was conducted. The reference lists of included papers were searched to identify other eligible papers. On a subgroup of studies a metaanalysis was performed.

\section{Results}

We found four clinical and ten general population studies that met inclusion criteria. The results of clinical studies were mixed. However, the results of non-clinical studies provided more consistent evidence that school bullying is related to the development of non-clinical psychotic symptoms. Stronger associations were found with increased frequency and severity and longer duration of being bullied. We performed a meta-analysis on seven populationbased studies, yielding unadjusted and adjusted odds ratios (ORs) of 2.7 (CI 95\% 2.1-3.6) and 2.3 (CI 95\% 1.5-3.4), respectively.

\section{Conclusions}

Although there is some evidence of an association between bullying and psychosis in clinical samples, research is too sparse to draw any firm conclusions. However, population-based non-clinical studies support the role of bullying in development of psychotic symptoms later in life. These findings are consistent with findings of an increased risk of psychotic symptoms among those exposed to other types of abuse. 


\section{Introduction}

School bullying is a worldwide problem that affects about one-third of children and approximately $11 \%$ are bullied on a regular basis (Craig \& Harel, 2004). Bullying is defined as behaviour that takes place between individuals of the same age group and is intended to cause harm or distress (Olweus, 1996). A history of being bullied has been associated with feelings of depression and loneliness, lower levels of self-esteem, (for a review, see Hawker \& Boulton, 2000) and a lower quality of life (Wilkins-Shurmer et al. 2003; Frisén \& Bjarnelind, 2010). Moreover, school bullying has negative long-term effects on mental health (Allison et al. 2009) and is found to be predictive of psychiatric disorders later in life (Sourander et al. 2007).

Several authors suggest that being bullied can be considered a traumatic experience often resulting in responses of avoidance, intrusive thoughts, dissociative experiences and nightmares which persist for years (Mynard et al. 2000; Storch \& Esposito, 2003; Newman et al. 2005; Crosby et al. 2010).

A growing body of literature over the past decade has shown that early traumatic and stressful experiences are related to the development of psychotic symptoms later in life, across the continuum of psychosis, from non-clinical expressions of psychotic symptoms to psychotic disorder (Lardinois et al. 2011). Patients suffering from psychotic disorders have often been exposed to a traumatic experience in childhood (for reviews, see Read et al. 2005; Morgan \& Fisher, 2007; Bendall et al. 2008; Larkin \& Read, 2008). A high prevalence of trauma has also been reported in individuals at ultra-high risk of developing psychosis (Thompson et al. 2009; Bechdolf et al. 2010). In addition, general population studies have found that people with a history of childhood trauma have more non-clinical psychotic symptoms compared with people without a history of similar traumatic events (Janssen et al. 2004; Spauwen et al. 2006).

To date, the most frequently reported traumas associated with psychotic symptoms are sexual and physical abuse (e.g. Read et al. 2005; Bendall et al. 2008). The relationship between psychotic symptoms and bullying, however, has not received much attention until recently (e.g. Bebbington et al. 2004; Lataster et al. 2006). Considering the high prevalence of bullying and its putative negative consequences for mental health, it is important to investigate the possible influence of being bullied on the development of psychotic symptomatology. The presence of an association underlines the importance of specific prevention and intervention programs (Sourander et al. 2009).

The aim of this review and meta-analysis was to answer the following question: is being bullied in childhood related to the development of clinical or non-clinical psychotic symptoms? We did not include studies focusing on personality disorders or traits (e.g. schizotypical and schizoid personality disorder or traits). We aimed to provide an overview of the literature on the association between childhood bullying and psychotic symptoms and discuss the theoretical models concerning the relationship between bullying and psychosis. We focused, first, on the association between bullying and (non-clinical) psychotic symptoms in the general population, and second, on the association between bullying and psychotic symptoms in clinical samples. 


\section{Method}

\section{Search strategy}

With the aid of a clinical librarian, we conducted searches in Pubmed, PsychINFO, and EMBASE. We combined the following two sets of keywords:

1. the keyword search terms bullying OR bullied OR bully [tw] OR bullies OR violence/ psychology OR victimization [tw] or victimisation [tw] OR mobbing OR mob OR (peer group or peer rejection or peer acceptance or peer pressure) AND (adolescent OR adolescence OR child OR childhood OR children OR teen ${ }^{\star} \mathrm{OR}_{\text {boy }}{ }^{\star} \mathrm{OR}_{\text {girl }}{ }^{\star}$ ); and

2. the keyword search terms psychosis OR psychoses OR psychotic disorder OR ple [tw] or psychotic [tw] OR delusion OR Schizoaffective Disorder* OR depersonalization OR derealisation* OR paranoia or paranoid* OR illusion OR hallucination OR ("schizophrenia"[MeSH Terms] OR "schizophrenia"[All Fields] OR "schizophrenic"[All Fields]) NOT “violence/psychology”[MeSH Terms]).

Our search covered articles that were available in the databases from 1806 to November 2011 and yielded an initial total of 1238 papers. We first screened manuscript titles to examine relevance. Then the abstracts were read. In the final screen the full-text itself was read to validate inclusion. Included papers were cross-referenced to identify other potentially eligible papers (Fig. 1).

\section{Inclusion and exclusion criteria}

We included only those papers that: (1) were original research papers; (2) were published in English; (3) reported information about psychosis outcome (i.e. non-clinical psychotic symptoms or psychotic symptoms or diagnosis of psychosis or the use of antipsychotics); and (4) reported any information about being bullied as exposure variable. Since the relationship between psychotic symptoms and bullying has not received much attention until recently, we retained papers even when the term bullying was not carefully defined.

We excluded those papers in which: (1) bullying was only analyzed as a confounding variable and; (2) bullying was not analyzed separately, but was part of an overall variable (e.g. victimization). A distinction was made between non-clinical and clinical samples. Samples including individuals that had at least one contact with mental health services were defined as clinical samples. Non-clinical samples were those recruited from general populations.

\section{Meta- analysis of the non-clinical sample studies}

We carried out a meta-analysis including a subset of seven population-based studies with comparable study designs (Lataster et al. 2006; Kelleher et al. 2008; Nishida et al. 2008; Schreier et al. 2009; Arsenault et al. 2010; Mackie et al. 2010; van Nierop et al. 2011). Two studies (Morrison \& Petersen, 2003; Campbell \& Morrison, 2007) were excluded from our meta-analysis because they made use of a different study design. Instead of calculating the risk of psychotic symptoms in a bullied versus non-bullied group, these two studies investigated the association between the predisposition to hallucinations and the experience 


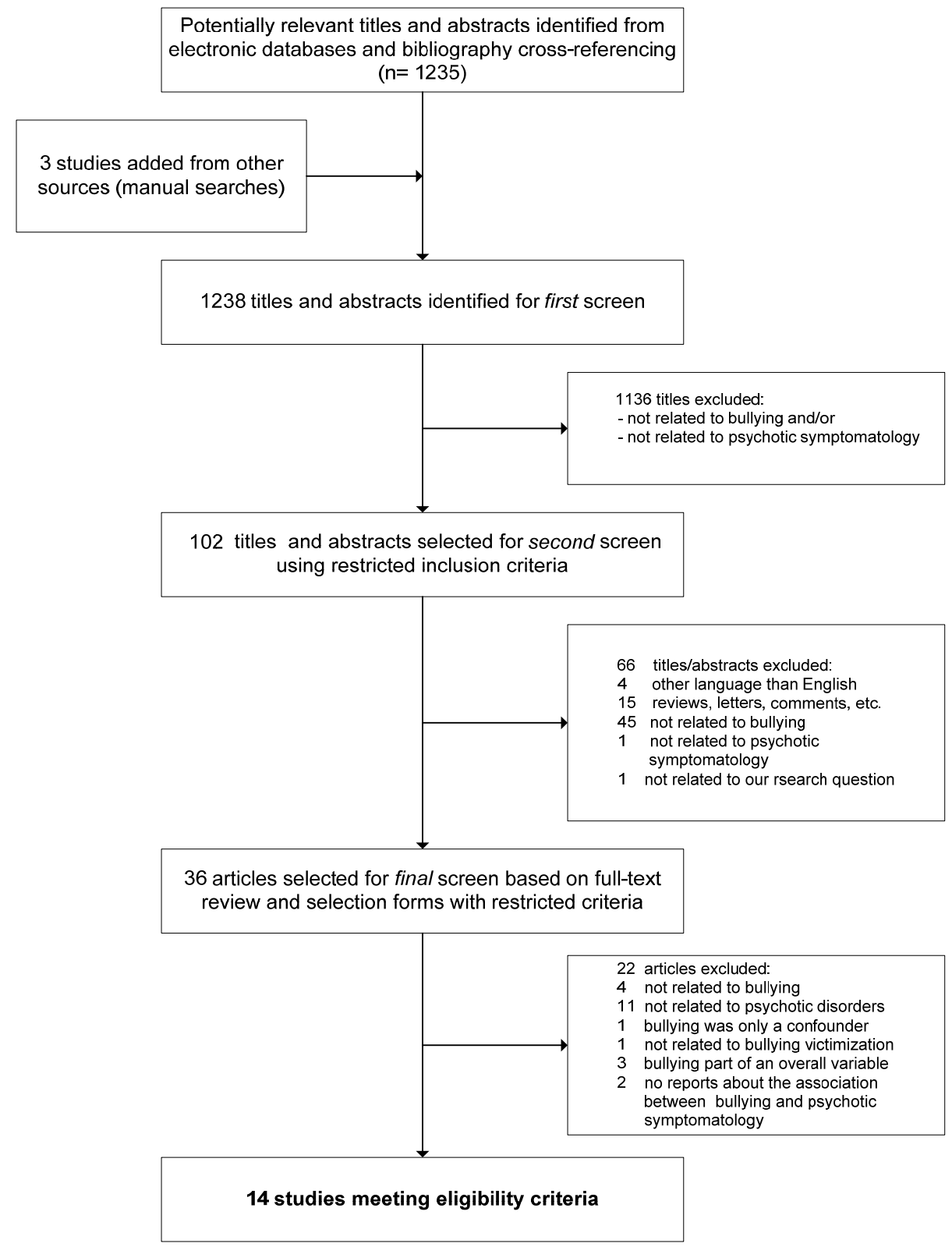

Figure 1. Selection of studies on bullying victimization and psychotic symptomatology. 
of being bullied based on questionnaire mean scores. Therefore, they do not generate any numerator and denominator data from which risk ratios could be calculated. We selected the version of the study with the largest sample size, when suitable studies reported findings from overlapping populations; for example Lataster et al. (2006) was selected as opposed to de Loore et al. (2007), both reporting on the Regional Profiles of Youth health (RPY) data. We decided not to include clinical-based sample studies in the meta-analysis, because their designs were too heterogeneous.

First, we calculated an odds ratio (OR) for every study, as well as an estimated variance by the following formula: $[(1 / a)+(1 / b)+(1 / c)+(1 / d)$ (Rosenberg et al. 2000). When studies lacked sufficient information for $2 \times 2$ contingency tables (numerators and denominators), authors were contacted to ensure accuracy and completeness of data. Analyses were conducted on a log scale to correct for the skewed distribution of effect sizes across studies. The potential for publication bias was assessed by examination of a funnel plot.

Analyses were first conducted under the fixed-effects model to examine if there was one true effect size shared by all studies. The homogeneity statistic $\mathrm{Q}$ was calculated to test whether the variability of the effect sizes is larger than would be expected from sampling error alone. Because the homogeneity statistic was significant, the analyses were afterwards conducted under the random-effects model, which assumes there are differences among the effect sizes as a result of variations in study characteristics. Analyses were performed with both unadjusted ORs and adjusted ORs. For each study we selected the OR for the most persistent and definite symptoms. Meta-analytical calculations were carried out with MetaWin 2.0 statistical software (Rosenberg, 2000).

\section{Results}

Fourteen studies met the inclusion criteria (fig. 1). The features of studies are described in Table 1.

\section{Bullying and non-clinical psychotic symptoms}

Ten studies examined the relationship between being bullied and psychotic symptoms in non-clinical samples, eight of which found a significant association (Lataster et al. 2006; Campbell \& Morrison, 2007; Kelleher et al. 2008; Nishida et al. 2008; Schreier et al. 2009; Arsenault et al. 2010; Mackie et al. 2010, van Nierop et al. 2011). The remaining two studies (Morrison \& Petersen, 2003; De Loore et al. 2007) initially found a significant effect that was diminished after adjustment for other negative life events.

In the studies that showed a significant association, bullied children had about a two-fold risk of experiencing psychotic symptoms in adolescence (Lataster et al. 2006; Nishida et al. 2008; Schreier et al. 2009; Arsenault et al. 2010; Mackie et al. 2010), or adulthood (van Nierop et al. 2011) compared to non-bullied children. One study examined the impact of frequency of being bullied (Lataster et al. 2006). In this study, the risk of developing psychotic symptoms increased in linear fashion with increases in the frequency of being bullied.

Two studies compared the relationship between a history of being bullied and transient versus more persistent psychotic symptoms. Adolescents with more persistent symptoms 


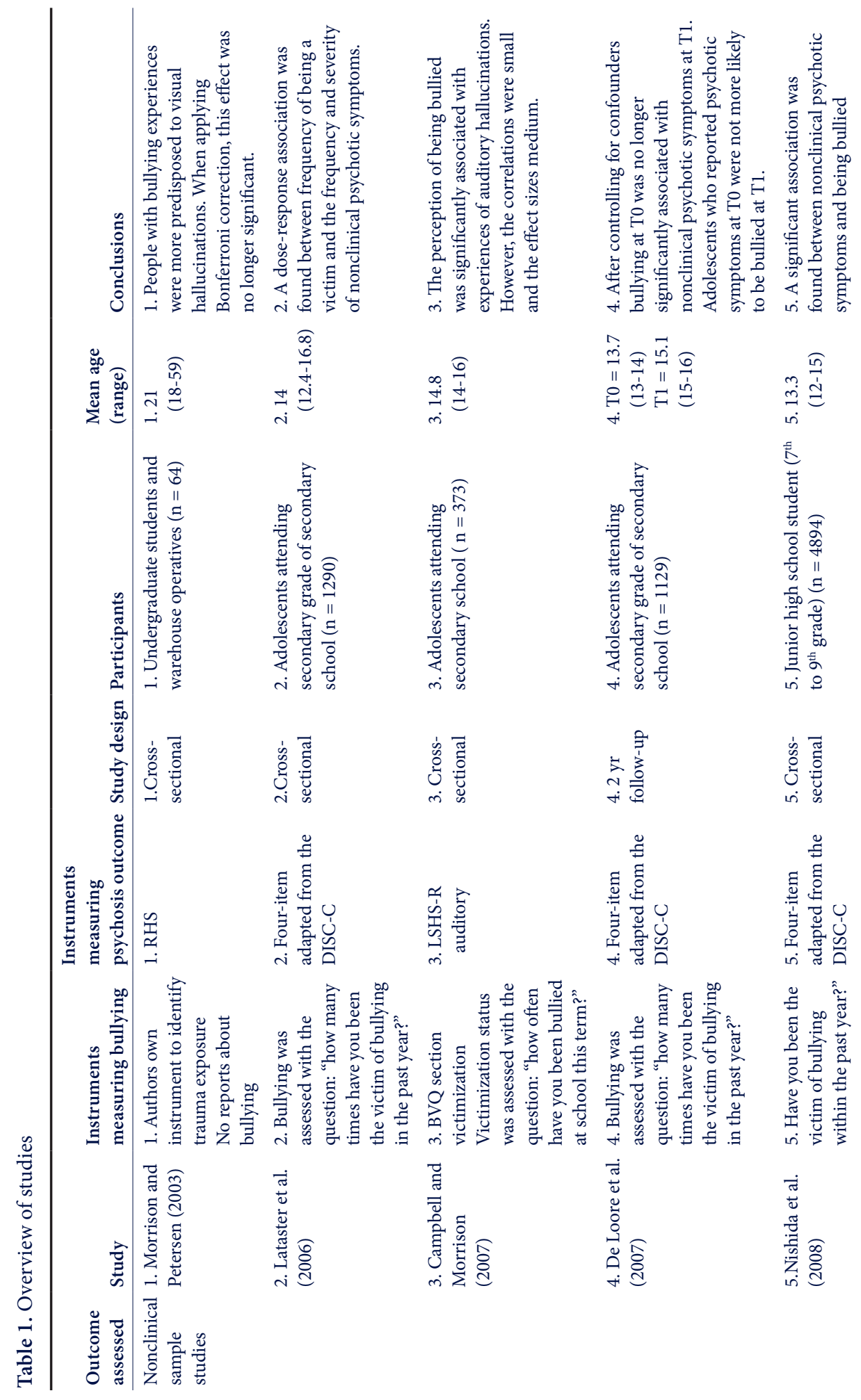




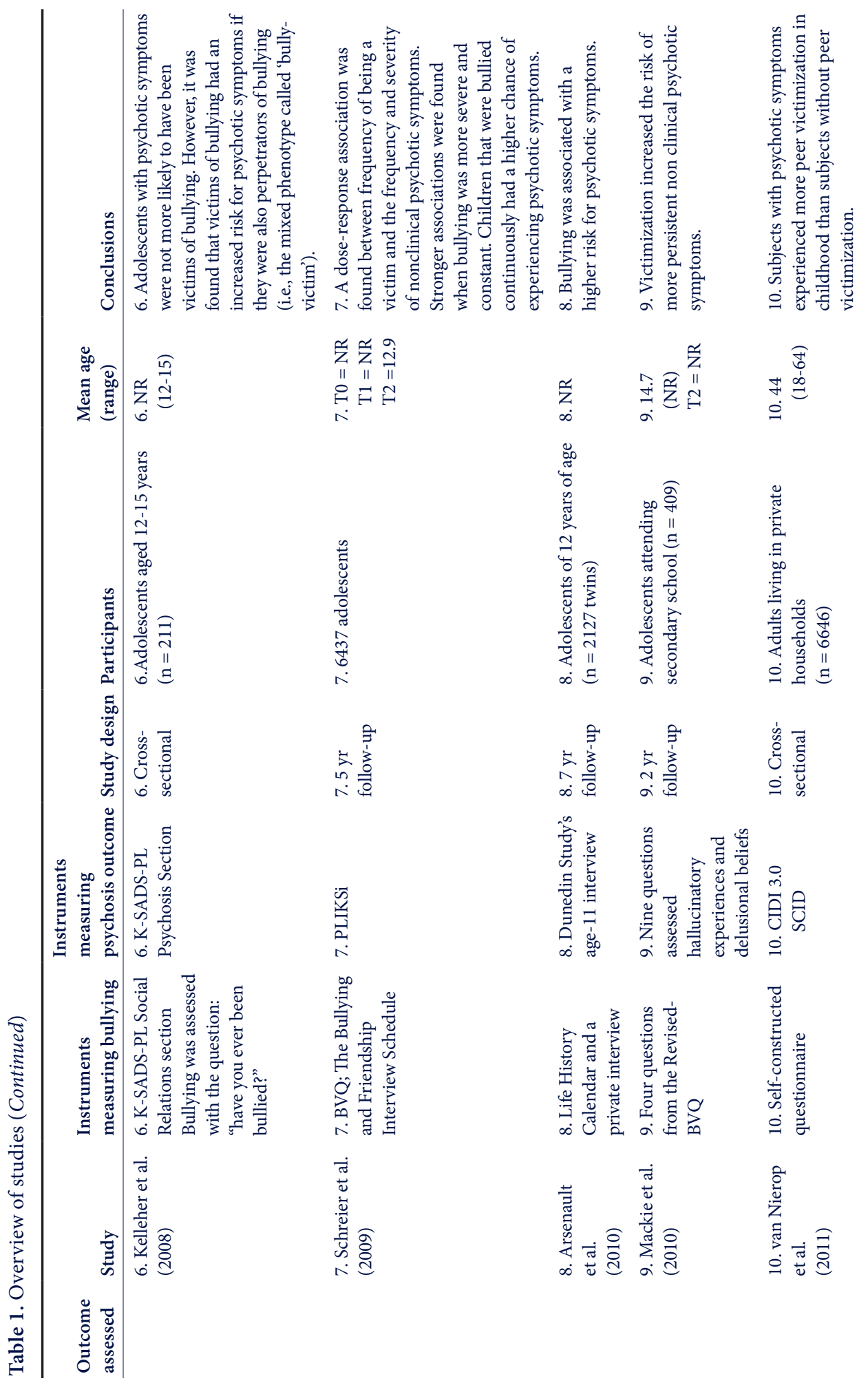




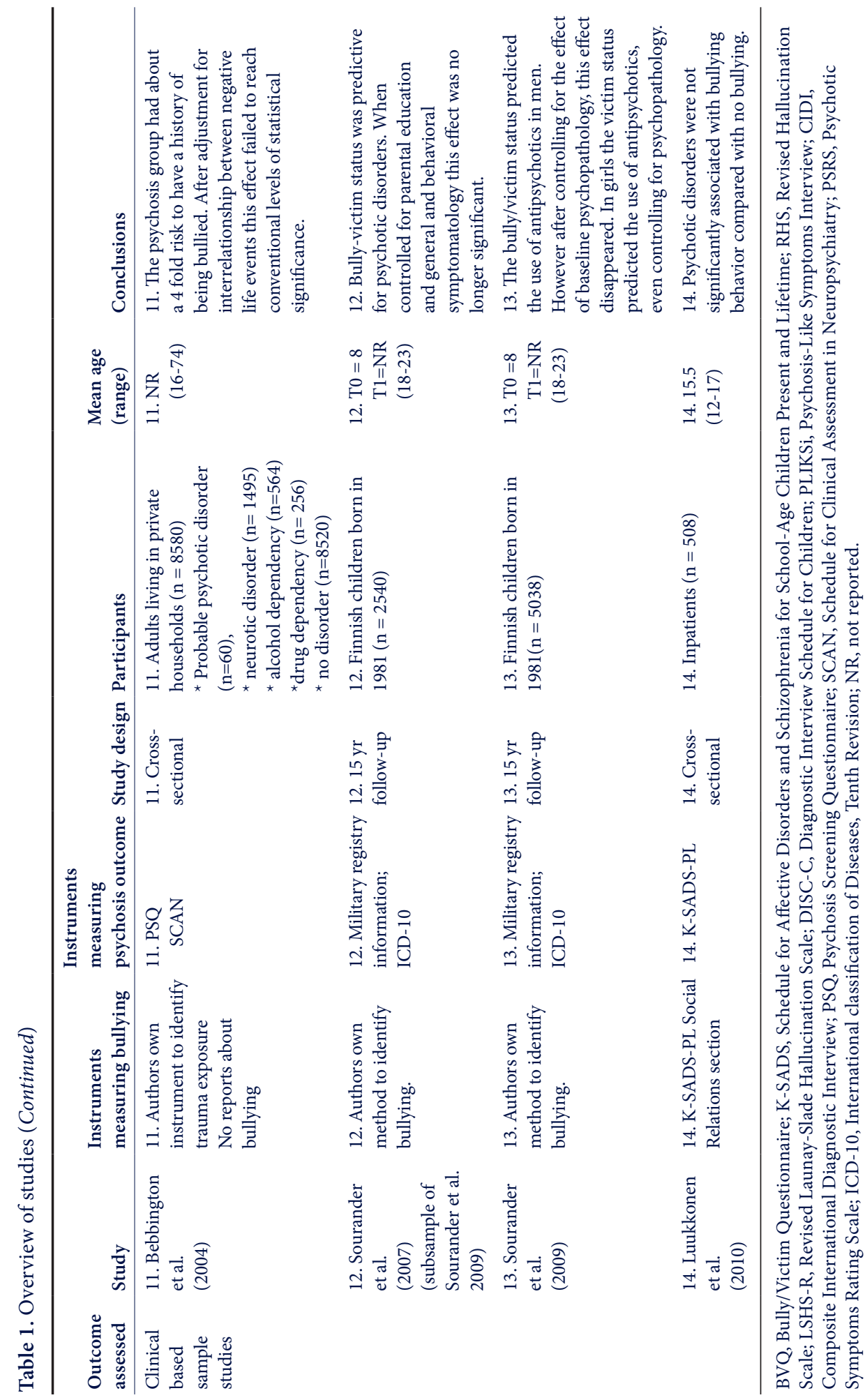

\section{4}

$n$
0
0
0
0
0
0
0
0
0
00
0
0
0
0
0
0
0
0
0
0
0 
reported having been bullied more frequently compared with adolescents with transient symptoms. Being bullied increased the odds of developing persistent symptoms by 3 to 4 times, suggesting a stronger association when longer lasting psychotic symptoms were reported (Lataster et al. 2006; Mackie et al. 2010).

Furthermore, Schreier et al. (2009) found that stronger associations were found when bullying was more severe and constant: children who experienced more than one form of bullying (overt and relational; e.g. kicking and gossiping) had approximately a two-fold increased risk of developing psychotic symptoms compared with children who experienced only one form bullying. No differences were found between overt versus relational bullying in the risk of developing psychotic symptoms. Moreover, children who reported being bullied at two time points (bullied at 8 and 10 years) had a higher chance of experiencing psychotic symptoms at a third time point (at 12 years), compared to children that were not bullied at both initial ages (Schreier et al. 2009).

Kelleher et al. (2008) found that victims of bullying had an increased risk for psychotic symptoms if they were also perpetrators of bullying (i.e. the mixed phenotype called 'bullyvictim'). Half of all 'bully-victims' reported psychotic symptoms. However, those who were purely victims of bullying did not have an increased risk of psychotic symptoms.

\section{Meta-analysis}

Our meta-analysis of seven population-based studies including unadjusted effect sizes yielded a mean-weighted OR of 2.7 (CI 95\% 2.0-3.6) for developing non-clinical psychotic symptoms for children being bullied compared to children not being bullied. The reviewed studies adjusted for various confounding variables (e.g. gender, age, and other negative life events). The analysis with adjusted ORs (six studies) yielded a mean-weighted OR of 2.3 (CI 95\% 1.5-3.4). The results of the meta-analysis are detailed in table 2. Figure 2 plots the unadjusted log ORs associated with the studies that were entered into our analysis. We show the plot of the unadjusted ORs, because it was impossible to calculate adjusted ORs for all studies. The funnel plot (not shown, available on request) was difficult to interpret due to the limited number of included studies, but did not suggest any evidence of publication bias.

Table 2. Results of the meta-analysis

\begin{tabular}{lllll}
\hline & Estimate & $95 \%$ CI & Q & P value \\
\hline Unadjusted analysis & & & & \\
Fixed-effects Model & 2.49 & $2.20-2.83$ & 19.53 & $<.005$ \\
Random-effects Model & 2.67 & $2.01-3.56$ & 7.45 & 0.28 \\
Adjsuted analysis & & & & \\
Fixed-effects Model & 1.85 & $1.59-2.14$ & 22.20 & $<.001$ \\
Random-effects Model & 2.25 & $1.49-3.40$ & 5.29 & 0.38 \\
\hline
\end{tabular}

CI, confidence interval 


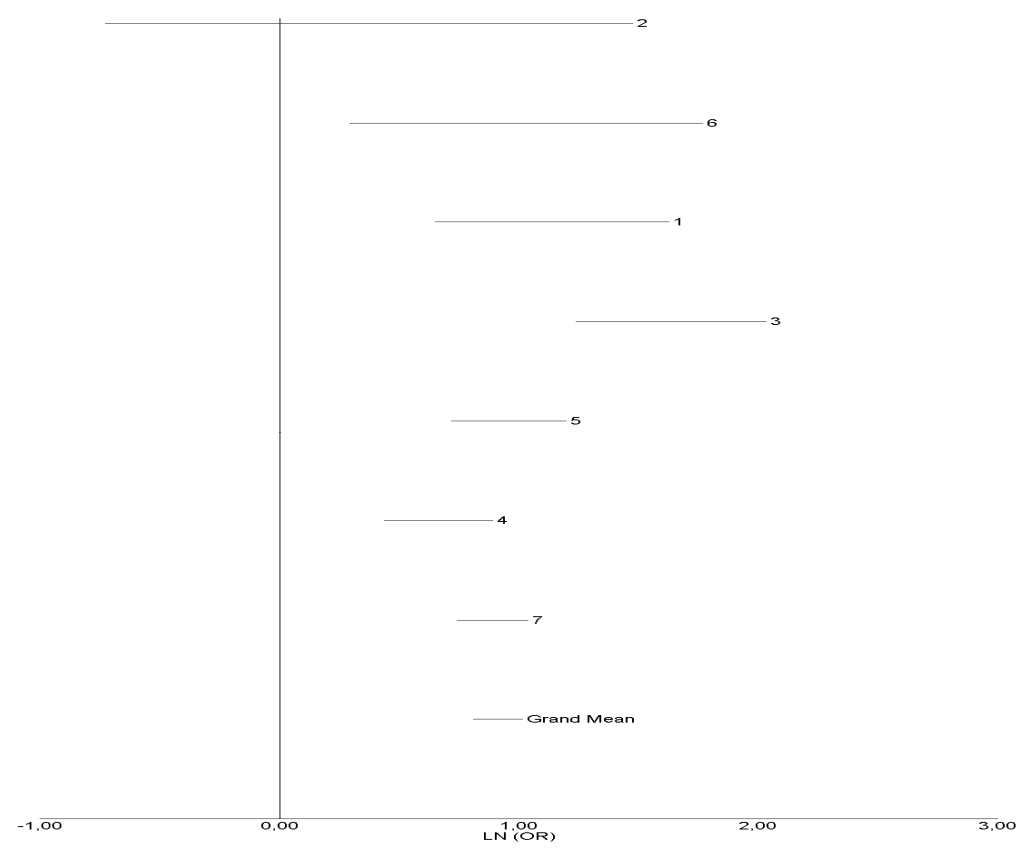

Figure 2. Plot of mean effect sizes (log odds ratios) and confidence intervals for results from studies by: 1) Lataster et al. 2006; 2) Kelleher et al. 2008; 3) Arsenault et al. 2010; 4) Schreier et al. 2009; 5) van Nierop et al. 2011; 6) Mackie et al. 2010; and 7) Nishida et al. 2008.

\section{Bullying and psychosis in clinical samples}

Only a limited number of studies have reported on the association between bullying and psychotic disorders (Bebbington et al. 2004; Sourander et al. 2007; Sourander et al. 2009; Luukkonen et al. 2010). Bebbington et al. (2004) focused specifically on the association between bullying and psychosis, but did not report the time-frame of bullying. The three other studies did not have this specific focus. Moreover, these studies report on different sample characteristics and outcome variables (e.g. psychotic disorders and the use of antipsychotics) and the results are, not surprisingly, inconclusive (see table 1).

In the study of Bebbington et al. (2004), respondents with a probable psychotic disorder were compared with respondents without a psychotic disorder. The psychosis group was about 4 times more likely to report a history of being bullied. However, after adjustment for other negative life events this effect disappeared. Sourander et al. (2007), using a sample overlapping with the sample of Sourander et al. (2009), found that the bully-victim status at age 8 years predicted psychotic disorders in early adulthood among men. However, when controlled for parental education and baseline general and behavioral symptomatology, this effect was no longer significant. Sourander et al. (2009) found an association between bullying and antipsychotic treatment in women. Antipsychotic treatment was arguably used 
as a proxy for an outcome measure of psychosis. However, the incidence of psychosis may well be discrepant from that of prescribed antipsychotic medication.

A recent study of Luukkonen et al. (2010) found that psychotic disorders were not significantly associated with bullying behavior compared with no bullying in adolescence.

\section{Discussion}

In this study we explored the literature on the association between childhood bullying and clinical psychotic disorder and non-clinical psychotic symptoms. The results of the population-based non-clinical studies support the role of bullying in the subsequent development of psychotic symptoms. Moreover, stronger associations are found with increased frequency, severity and persistence of bullying (Lataster et al. 2006; Schreier et al. 2009; Mackie et al. 2010). The evidence for a causal relation is strengthened by the consistency across studies. Of note, members from other humiliated groups are also at increased risk for psychotic disorders, for example, victims of sexual or physical abuse (Janssen et al. 2004; Shevlin et al. 2008) and migrants from developing countries experiencing discrimination (Selten \& Cantor-Graae, 2005).

The results of clinical studies, however, do not allow an unequivocal conclusion concerning the association between bullying and development of a psychotic disorder, which is not surprising given the heterogeneous methodological approaches.

\section{How to explain an association between childhood bullying and psychotic symptoms?}

There are several theories that could explain the possible association between childhood bullying and psychotic symptoms. First, a history of being bullied may be a developmental marker for the risk of psychosis, but not an aetiological factor in itself (Murray \& Fearon, 1999; Schreier et al. 2009). In some people with psychotic disorders, abnormalities in social adjustment and motor performance are present during childhood (Done et al. 1994). A study by Cannon et al. (1999), for example, found that children who later develop schizophrenia already perform worse than their peers in sports. Children who show deviant behaviour or perform poorly in sports are more vulnerable to bullying (Schreier et al. 2009). The experience of being bullied may result from poor social adjustment and is not necessarily a causal factor in the development of the disorder. It should be noted that other forms of trauma also increase the risk for the development of (non-clinical) psychotic symptoms. The issue of reverse causation applies here too (Lataster et al. 2006; Schreier et al. 2009). However, even if bullying was a consequence of social awkwardness consequent on a preexisting developmental risk for later psychosis, the additional impact of bullying may further contribute to risk of later symptoms and disorder. At present, the evidence does not allow these alternatives to be disentangled.

Second, the experience of being bullied may lead to the development of negative schemas of the self and the world (Gracie et al. 2007). Crittendon and Ainsworth (1989) argue that bullied children have a tendency to be hypervigilant to hostile cues in their environment. They may become suspicious of others' intentions, which in turn may predispose them to psychotic symptoms such as paranoia or ideas of reference (Morrison et al. 2003). 
Third, it has been hypothesized that traumatic events during childhood lead to a dysregulation of the hypothalamic-pituitary-adrenal (HPA) axis (Walker \& DiForio, 1997). Dysregulation of this HPA-axis may result in activation of dopaminergic circuits, which in turn, may lead to the emergence of psychotic symptoms (Kapur, 2003). One of the few studies investigating the relationship between childhood bullying and activity of the HPA-axis found hypersecretion of cortisol in boys and hyposecretion of cortisol in girls (Vaillancourt et al. 2008), but further research is needed to validate this hypothesis (Fisher \& Craig, 2008).

\section{4}

\section{Implications for prevention and treatment}

Although a causal relationship between a history of being bullied and the subsequent development of schizophrenia has not been established formally, there is sufficient reason to discuss methods to prevent children from being bullied and to treat the negative consequences.

It is important to note here that non-clinical psychotic symptoms are a risk factor for the subsequent development of psychotic disorder (Cougnard et al. 2007; Poulton et al. 2000). This highlights the importance of early school-based interventions, designed to stop bullying. It could also be of importance to evaluate children who have been bullied for possible psychotic symptoms, because these symptoms may be early markers of clinical psychotic symptoms and, at that stage, may be subject to effective intervention. Furthermore, negative appraisals about self and others may be important subjects for discussion in the class-room to change existing cognitive schema, and in helping children cope (Carney, 2008) even when there would be no relationship between bullying and psychotic symptoms.

For clinical purposes it is important to ask people with non-clinical psychotic symptoms whether they have experienced bullying (Read et al, 2005; Schreier et al. 2009), because psychological approaches may help reduce the complaints (Read et al. 2005) by changing the existing cognitive schema and thereby enabling individuals to cope with their traumatic responses to bullying. Research has suggested that early detection and intervention for emerging psychotic symptoms may have the potential to change the course of early psychopathology (Marshall et al. 2005).

\section{Methodological issues and future research}

Prospective designs are essential for studying possible causal directions. Good examples are studies of Schreier et al. (2009), Arsenault et al. (2010) and Mackie et al. (2010) showing that bullying experiences do play an important role in the development of non-clinical psychotic symptoms in later life. We recommend that future studies should assess bullying at an early age (e.g. primary school) to elucidate on time order in the causality of this association.

Furthermore, there is evidence that the mesolimbic dopamine system of psychotic patients is sensitized and that certain environmental factors (e.g. trauma) may cause this sensitization. Experimental social defeat in animals has been shown to cause dopamine sensitization in animals (Selten \& Cantor-Graae, 2005). Consequently, the case for bullying as a causal risk factor for psychotic disorder can be strengthened by showing that the mesolimbic dopamine system of bully victims is sensitized. 
With regard to distinguishing between genetic and environmental effects, it would be of interest to examine whether adopted children of biological parents with a psychotic disorder, are more likely to be bullied at school than other children. It is also of importance to establish a dose-response relationship between the severity of bullying experiences and the subsequent risk of developing psychosis.

The relationship between being bullied in childhood and the development of a psychotic disorder later in life is still equivocal. The research conducted so far is too sparse and may lack power to draw definitive conclusions. It is necessary to follow bullied and non-bullied children until early adulthood when the first expression of psychosis is expected to clarify the direction and strength of this association.

Finally, we suggest that research should also focus on protective factors, such as perceived-self effectiveness of coping (Crosby et al. 2010) and the extent of social support. Both factors may play a role in the association between being bullied and the development of psychotic symptoms.

\section{Strengths and limitations of this review}

This review assembles findings from a relatively large number of investigations on the relationship between psychotic symptoms and bullying in childhood. As the relationship between psychotic symptoms and bullying has not received much attention until recently, we conducted an extensive search and retained papers even when the term bullying was not carefully defined to ensure that all possible literature was included. Authors were contacted to ensure accuracy and completeness of data. Moreover, the additional narrative approach in addition to the straightforward quantitative summary gives an informative overview of more nuanced aspects adopted in some particular studies (such as those examining frequency of bullying or transient versus persistent symptoms).

One limitation is that the included studies varied widely in the type of population examined, type of measurement and duration of follow-up. A further limitation is the small number of pertinent studies. Consequently, it is difficult to draw a definitive conclusion about an association between bullying and psychotic symptomatology.

\section{Acknowledgements}

We thank J. Daarms for assisting with the database searches. We are supported by the European Union [European Community's Seventh Framework Program (grant agreement no. HEALTH-F2-2009-241909 (Project EU-GEI)]. 


\section{References}

1. Allison, S., Roeger, L., Reinfeld-Kirkman, N. (2009). Does school bullying affect adult health? Population survey of health-related quality of life and past victimization. Aust N Z J Psychiatry 43, 1163-1170.

2. Arsenault, L., Cannon, M., Fisher, H. L., Polanczyk, G., Moffit, T. E., Caspi, A. (2010). Childhood trauma and Children's Emerging Psychotic Symptoms: A genetically sensitive Longitudinal Cohort Study. Am J Psychiatry. Published online: 15 October 2010. doi: 10.1176/appi.ajp. 2010.10040567.

3. Bebbington, P. E., Bhugra, D., Brugha, T., Singleton, N., Farrel, M., Jenkins, R., Lewis, G., Meltzer, H. (2004). Psychosis, victimisation and childhood disadvantage: Evidence from the second British National Survey of Psychiatric Morbidity. Br J Psychiatry 185, 220-226.

4. Bechdolf, A., Thompson, A., Nelson, B., Cotton, S., Simmons, M. B., Amminger, G. P., Leicester, S., Francey, S. M., McNab, C., Krstev, H., Sidis, A., McGorry, P. D., Yung, A. R. (2010). Experience of trauma and conversion to psychosis in an ultra-highrisk (prodromal) group. Acta Psychiatr Scan 121, 377-384.

5. Bendall, S., Jackson, H. J., Hulbert, C. A., McGorry, P. D. (2008). Childhood Trauma and Psychotic Disorders: A Systematic, Critical review of the Evidence. Schizophr Bull 34, 568-579.

6. Bourque, F., van der Ven, E., Malla, A. (2011). A meta-analysis of the risk for psychotic disorders among first- and second-generation immigrants. Psychol Med 41, 897-910.

7. Campbell, M. L. C., Morrison, A. P. (2007). The relationship between bullying, psychotic-like experiences and appraisals in 14-16 year olds. Behav Res Ther 45, 1579-1591.

8. Cannon, M., Jones, P., Huttunen, M. O., Tanskanen, A., Huttunen, T., RabeHesketh, S., Murray, R. M. (1999). School Performance in Finish Children and Later development of Schizophrenia. A Population-Based Longitudinal Study. Arch Gen Psychiatry 56, 457-463.

9. Carney, J. L. V. (2008). Perceptions of Bullying and Associated Trauma During Adolescence. Prof School Counselling 11, 179-188.
10. Cougnard, A., Marcelis, M., MyinGermeys, I., de Graaf, R., Vollebergh, W., Krabbendam, L., Lieb, R., Wittchen, H., Henquet, C., Spauwen, J., van Os, J. (2007). Does normal developmental expression of psychosis combine with environmental risk to cause persistence of psychosis? A psychosis proneness-persistence model. Psychol Med 37, 513-527.

4

11. Craig, W. M., Harel, Y. (2004). Bullying, physicalfighting, and victimization. In Young people's health in context: International report from the HBSC 2001/02 survey. WHO Policy Series: Health policy for children and adolescents (ed. C. Currie, C. Roberts, A. Morgan, R. Smith, W. Settertobulte and O. Samdal et al.), pp. 133-144. World Health Organization Regional Office for Europe: Copenhagen.

12. Crittendon, P. M., Ainsworth, M. D. S. (1989). Child maltreatment and attachment theory. In Childhood Maltreatment: Theory and Research on the causes and Consequences of Child Abuse and Neglect (ed. D. Cicchetti and V. Carlson), pp. 432-463. Cambridge University Press: Cambridge.

13. Crosby,J. W., Oehler, J., Capaccioli, K. (2010). Relationship between peer victimization and post-traumatic stress symptomatology in a rural sample. Psychology in the Schools 47, 297-310.

14. De Loore, E., Drukker, M., Gunther, N., Feron, F., Deboutte, D., Sabbe, B., Mengelers, R., van Os, J., Myin-Germeys, I. (2007). Childhood negative experiences and subclinical psychosis in adolescence: A longitudinal general population Study. Early Interv Psychiatry 1, 201-207.

15. Done, D. J., Crow, T. J., Johnstone, E. C., Sacker, A. (1994). Childhood Antecedents Of Schizophrenia And Affective Illness: Social Adjustment At ages 7 And 11. BMC 309, 699-703.

16. Fisher, H., Craig, T. (2008). Childhood adversity and psychosis. In Society and Psychosis (ed. C. Morgan, K. McKenzie and P. Fearon), pp. 95-111. Cambridge University Press: Cambridge.

17. Frisén, A., Bjarnelind, S. (2010). Healthrelated quality of life and bullying in adolescence. Acta Paediatr 99, 597-603. 
18. Gracie, A., Freeman, D., Green, S., Garety, P. A., Kuipers, E., Hardy, A., Ray, K., Dunn, G., Bebbington, P., Fowler, D. (2007). The association between traumatic experience, paranoia and hallucinations: a test of the predictions of psychological models. Acta Psychiatr Scand 116, 280-289.

19. Hawker, D.S. J., Boulton, M. J. (2000). Twenty Tears' Research on Peer Victimization and Psychosocial Maladjustment: A Metaanalytic Review of Cross-sectional Studies. J Child Psychol Psychiatry 41, 441-455.

20. Janssen, I., Krabbendam, L., Bak, M., Hanssen, M., Vollebergh, W., de Graaf, R., van Os, J. (2004). Childhood abuse as a risk factor for psychotic experiences. Acta Psychiatr Scand 109, 38-45.

21. Kapur, S. (2003). Psychosis as a State of Aberrant Salience: A Framework Linking Biology, Phenomenology, and Pharmacology in Schizophrenia. Am J Psychiatry 160, 1323.

22. Kelleher, I., Harley, M., Lynch, F., Arsenault, L., Fitzpatrick, C., Cannon, M. (2008). Associations between childhood trauma, bullying and psychotic symptoms among a school based adolescent sample. $\mathrm{Br}$ J Psychiatry 193, 378-382.

23. Lardinois, M., Lataster, T., Mengelers, R., van Os, J., Myin-Germeys, I. (2011). Childhood trauma and increased stress sensitivity in psychosis. Acta Psychiatr Scand 123, 28-35.

24. Larkin, W., Read, J. (2008). Childhood trauma and psychosis: Evidence, pathways, and implications. J Postgrad Med 54, 287 293.

25. Lataster, T., van Os, J., Drukker, M., Henquest, C., Feron, F., Gunther, N., Myin-Germeys, I. (2006). Childhood victimisation and developmental expression of non-clinical delusional ideation and hallucinatory experiences. Soc Psychiatry Psychiatr Epidemiol 41, 423-428.

26. Luukkonen, A. H., Riala, K., Hakko, H., Räsänen, P. (2010). Bullying behaviour and substance abuse among underage psychiatric inpatients adolescents. Eur Psychiatry 25, 382-389.

27. Mackie, C. J., Castellanos-Ryan, N., Conrod, P. J. (2010). Developmental trajectories of psychotic-like experiences across adolescence: Impact of victimization and substance use. Psychol Med. Published online: 29 March 2010. doi: 10.1017/ S0033291710000449.

28. Marshall, M., Lewis, S., Lockwood, A., Drake, R., Jones, P., Croudace, T. (2005). Association Between Duration of Untreated Psychosis and Outcome in Cohorts of FirstEpisode Patients. A Systematic Review. Arch Gen Psychiatry 62, 975-983.

29. McGrath, J., Saha, S., Welham, J., El Saadi, O., MacCauley, C., Chant, D. (2004). A systematic review of the incidence of schizophrenia: The distribution of rates and the influence of sex, urbanicity, migrant status and methodology. BMC Medicine 2, 13.

30. Morgan,C., Fisher, H. (2007). Environmental Factors in Schizophrenia: Childhood Trauma - A Critical Review. Schizophr Bull 33, 3-10.

31. Morrison, A. P., Frame, L., Larkin, W. (2003). Relationships between trauma and psychosis: A review and integration. Br J Clin Psychiatry 42, 331-353.

32. Morrison, A.P., Petersen, T. (2003). Trauma, metacognition and predisposition to hallucinations in non-patients. Behav Cogn Psychother 31, 235-246.

33. Murray, R. M., Fearon, P. (1999). The developmental "risk factor" model of schizophrenia. J Psychiatr Res 33, 497-499.

34. Mynard, H., Joseph, S., Alexander, J. (2000). Peer-victimisation and posttraumatic stress in adolescents. Pers Individ Dif 29, 815-821.

35. Newman, M. L., Holden, G. W., Delville, Y. (2005). Isolation and the stress of being bullied. J Adolescence 28, 343-357.

36. Nierop van, M., van Os, J., Gunther, N., Myin-Germeys, I., Graaf de, R., ten Have, M, van Dorsselaer, S., Bak, M., van Winkel, R. (2011). Phenotypically Continuous With Clinical Psychosis, Discontinuous in Need for Care: Evidence for an Extended Psychosis Phenotype. Schizophr Bull. Published online: 9 September 2011. doi: 10.1093/ schbul/sbr129.

37. Nishida, A., Tanii, H., Nishimura, Y., Kajiki, N., Inoue, K., Okada, M., Sasaki, T., Okazaki, Y. (2008). Associations between psychotic-like experiences and mental health status and other psychopathologies among Japanese early teens. Schizophr Res 99, 125133. 
38. Olweus, D. (1996). Bullying at School: Knowledge Base and an Effective Intervention program. Ann N Y Acad Sci 794, 265-276.

39. Poulton, R., Caspi, A., Moffit, T.E ., Cannon, M., Murray, R., Harrington, H. (2000). Children's Self-Reported Psychotic Symptoms and Adult Schizophreniform Disorder: A 15-Year Longitudinal Study. Arch Gen Psychiatry 57, 1053-1058.

40. Read, J., van Os, J., Morrison, A. P., Ross, C. A. (2005). Childhood trauma, psychosis and schizophrenia: A literature review with theoretical and clinical implications. Acta Psychiatr Scand 112, 330-350.

41. Rosenberg, M. S., Adams, D. C., Gurevitch, J. (2000). MetaWin: Statistical Software for Meta-Analysis. Version 2. Sinauer Associates, Sunderland, Massachusetts.

42. Schreier, A., Wolke, D., Thomas, K., Horwood, J., Hollis, C., Gunnel, D., Lewis, G., Thompson, A., Zammit, S., Duffy, L., Salvi, G., Harrison, G. (2009). Prospective study of peer victimization in childhood and psychotic symptoms in a non-clinical population at age 12 years. Arch Gen Psychiatry 66, 527-536.

43. Selten, J. P., Cantor-Graae, E. (2005). Social defeat: risk factor for schizophrenia? Br J Psychiatry 187, 101-102.

44. Shevlin, M., Houston, J. E., Dorahy, M. J., Adamson, G. (2008). Cumulative Traumas and Psychosis: An Analysis of the National Comorbidity Survey and the British Psychiatric Morbidity Survey. Schizophr Bull 34, 193-199.

45. Sourander, A., Jensen, P., Rönning, J., Niemelä, S., Helenius, H., Sillanmäki, L., Kumpulainen, K., Piha, J., Tamminen, T., Moilanan, I., Almqvist, F. (2007). What Is the Early Adulthood Outcome of Boys Who Bully or Are Bullied in Childhood?
The Finnish "From a Boy to a Man" study. Pediatrics 120, 397-404.

46. Sourander, A., Rönning, J., BrunsteinKlomek, A., Gyllenberg, D., Kumpulainen, K., Niemelä, S., Helenius, H., Sillanmäki, L., Ristkari, T., Tamminen, T., Moilanan, I., Piha, J., Almqvist, F. (2009). Childhood Bullying Behavior and Later Psychiatric Hospital and Psychopharmacologic Treatment. Arch Gen Psychiatry 66, 10051012.

4

47. Spauwen, J., Krabbendam, L., Lieb, R., Wittchen, H., van Os, J. (2006). Impact of psychological trauma on the development of psychotic symptoms: relationship with psychosis proneness. Br J Psychiatry 188, 527-533.

48. Storch, E. A., Esposito, L. E. (2003). Peer victimization and posttraumatic stress among children. Child Study J 33, 91-98.

49. Thompson, J. L., Kelly, M., Kimhy, D., Harkavy-Friedman, J. M., Khan, S., Messinger, J. W., Schobel, S., Goetz, R., Malaspina, D., Corcoran, C. (2009). Childhood trauma and prodromal symptoms among individuals at clinical high risk for psychosis. Schizophr Res 108, 176-181.

50. Vaillancourt, T., Duku, E., Decatanzaro, D., Macmillan, H., Muir, C., Schmidt, L. A. (2008). Variation in Hypothalamic-PituitaryAdrenal Axis Activity Among Bullied and Non-bullied Children. Aggressive Behav 34, 294-305.

51. Walker, E. F., Diforio, D. (1997). Schizophrenia: A Neural Diathesis-Stress Model. Psychol Rev 104, 667-685.

52. Wilkins-Shurmer, A., O'Callaghan, M. J., Najman, J. M., Bor, W., Williams, G. M., Anderson, M. J. (2003). Association of bullying with adolescent health-related quality of life. J Paediatr Child Health 39, 436-441. 



\section{chapter FIVE}

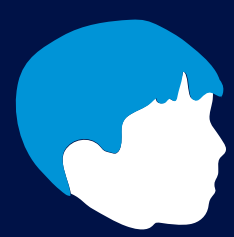

An incidence study of diagnosed autism-spectrum disorders among immigrants to the Netherlands

E. van der Ven,

F. Termorshuizen,

W. Laan,

E.J. Breetvelt,

J. van Os,

J.P. Selten

Acta Psychiatrica Scandinavica (2012), 128(1), 54-60. 


\begin{abstract}
Objective

To estimate the risk of developing autism-spectrum disorder (ASD) in children born to immigrants as compared to children of Dutch-born parents.
\end{abstract}

\title{
Method
}

Retrospective, population-based cohort study of all live births $(\mathrm{N}=106,953)$ between 1998 and 2007 in a circumscribed geographical region in the Netherlands. Cohort members were linked to the Psychiatric Case Register to identify diagnosed cases.

\section{Results}

A total of 518 cases of ASD were identified, including 150 children with autism and 368 children with Asperger syndrome or Pervasive Developmental Disorder Not Otherwise Specified (PDD-NOS). Children born to migrants from developing countries were at significantly lower risk of ASD (rate ratio $(\mathrm{RR})=0.6,95 \%(\mathrm{CI}) 0.5-0.9$ ) than children of Dutch-born parents. Within the ASD group, the risk for the subgroup with Asperger syndrome and PDD-NOS was reduced ( $R \mathrm{R}=0.4,95 \% \mathrm{CI} 0.3-0.6)$, whereas that for narrowly defined autism was non-significantly increased ( $R R=1.4,95 \%$ CI $0.9-2.4)$. Migrant groups did not differ in age at diagnosis.

\section{Conclusion}

The results echo Swedish findings indicating a reversal of risk gradient in children of parents from developing countries, specifically a decreased risk for high-functioning and increased risk for low-functioning autism. 


\section{Introduction}

The long-held axiom that autism is an almost exclusively heritable neurodevelopmental disorder has recently been challenged by a twin study showing that $55 \%$ of the liability to autism can be explained by the shared twin environment (Hallmayer et al. 2011). Parental immigration as a risk factor for ASD in the child is receiving renewed attention. In the UK, mothers born outside of Europe were found to have a significantly higher risk of having a child with ASD compared to native-born mothers, with the highest risk observed for the Caribbean group (Keen et al. 2010). Two recent Swedish studies (Haglund \& Källén, 2011; Magnusson et al. 2012) reported differential results contingent on level of functioning of the child. Maternal birth outside Northern Europe was associated with a reduced incidence of high functioning and an elevated incidence of low functioning subtypes of ASD. While most European findings point to increased rates (Hultman et al. 2002; Keen et al. 2010; Lauritsen et al. 2005), studies from the US have reported no differences or even decreased rates of ASD according to maternal migrant status or ethnic origin (Croen et al. 2002; Palmer et al. 2010; Zaroff \& Uhm, 2012). Variation in study results, as well as differences in diagnostic categorization, migrant group distribution, case ascertainment and confounding variables, challenge the interpretation of these findings (Rutter, 2011).

\section{Aims of the study}

The purpose of this study was to examine whether a history of parental migration influenced a child's risk of being diagnosed with ASD. We compared the risk in children of two Dutchborn parents to the risk in children with at least one parent born in Morocco, Turkey, Surinam, the Netherlands Antilles, or other countries with developing or developed economies. We also explored the effect of parental migration on the incidence of separate ASD subtypes, i.e., autistic disorder, Asperger syndrome and Pervasive Developmental Disorder Not Otherwise Specified (PDD-NOS).

\section{Material and methods}

\section{Study population and data extraction}

A retrospective cohort study was carried out using two data sources. The first source pertained to a birth cohort, with information on the parents, that was selected from the civil registry database of Statistics Netherlands (Centraal Bureau voor de Statistiek, CBS), consisting of all live births in the urban area of Utrecht and surrounding semi-rural municipalities between January $1^{\text {st }} 1998$ and December $31^{\text {st }} 2007$ ( $n=106,953$; hereafter: CBS-cohort). The CBS is responsible for collecting and processing all individual and population health care data in the Netherlands for the purpose of research by health authorities and academic institutions (CBS, 2011). Under Dutch privacy law, use of personal (healthcare) data for the purpose of scientific research is allowed, provided that data cannot be traced to the individual. For 514 individuals $(0.5 \%)$ the mother could not be identified, for 3735 (3.5\%) the father and for 378 individuals $(0.4 \%)$ neither the mother nor the father. 
The second source of the data originates from The Psychiatric Case Registry of the central part of the Netherlands (PCR-MN), which is in operation since 1999. It contains anonymized information on all patients who attended in- or outpatient facilities for mental health care until December $31^{\text {st }} 2009$, including date of birth, sex, postal code and at least one DSM-IV diagnosis (Smeets et al. 2011). The PCR-MN does not receive information from GPs, paediatricians or from the small number of psychiatrists working in private practice who rarely see patients with autism. Thus, it is likely that the vast majority of children referred to psychiatric services are recorded by PCR-MN.

Linkage between the PCR-MN and the CBS-cohort was based on date of birth of the child, sex and a part of the postal code. The postal codes included in the CBS-cohort are identical to those covered by the PCR-MN region. A unique match with a record in the CBS-cohort could be established in $89 \%$ of the patients registered in the PCR-MN with autistic disorder (DSM-IV code 299.00), Asperger syndrome (299.80) or PDD-NOS (299.80). Country of birth and parental country of birth are known for all children in the CBS-cohort, because it is part of the information provided at compulsory child registration after birth. In the PCR-MN, parental country of birth was incomplete for $27 \%$ of the children. However, we used the available information from the PCR-MN to verify whether ethnic minorities were disproportionally present among cases that could not be linked to the CBS-cohort. The proportions of children for whom successful record linkage was possible were $84 \%$ for the native Dutch children, $86 \%$ for the Moroccan, $83 \%$ for the Turkish, 100\% for the Surinamese and Dutch Antillean children and $91 \%$ for those from other countries of origin. Thus, in the cohort resulting from the merge between PCR-MN and CBS-cohort, the occurrence of diagnosed ASD may be slightly underestimated, but not differentially between immigrant or native-born children.

For children with a diagnosis of ASD, the period at risk ended at the time of diagnosis, i.e. at the age at diagnosis. For children without a diagnosis of ASD, the period at risk ended at emigration outside the catchment area, death or 31 December 2009, whichever came first. In addition, to evaluate whether any difference between migrants and non-migrants in rates of ASD or its subtypes may be explained by differences in time until diagnosis, age at diagnosis was estimated for each migrant group.

In line with the CBS definition of immigrant status, a Dutch-born subject with two Dutch-born parents was considered native Dutch. A Dutch-born subject with at least one foreign-born parent was classified according to the country of birth of that parent. When the parents were born in different foreign countries, the maternal country of birth was decisive for assignment to a particular group. In an effort to distinguish the effect of maternal from paternal migration, we consecutively reclassified children based on the country of birth of the mother only. Most migrants in the study area originated from Turkey, Morocco, Surinam and the Netherlands Antilles. The latter two groups of migrants from former Dutch colonies with relative geographical proximity were collapsed into a single group in the analyses. Migrants were categorized according to their source country's economic situation to capture the putative influence of discrepancy in level of development between source and host society. Using the United Nations Conference on Trade and Development (UNCTAD) classification for the year 2011 countries were divided into three categories: 1) developing 
economies, 2) transition economies (e.g., Croatia, Ukraine), and 3) developed economies (United Nations Conference on Trade and Development, 2011). UNCTAD group 2 including predominantly Eastern European countries was adjoined with group 3, reasoning that these countries mostly resemble countries with developed economies in terms of cultural and ethnic characteristics. This combined group is hereafter referred to as "developed countries". UNCTAD group 1 is referred to as "developing countries".

\section{Statistical analysis}

Group comparisons on demographic variables and age at diagnosis were performed using $t$ tests for independent groups. Incidence rates of any ASD, and separately for narrowly defined autism versus Asperger syndrome and PDD-NOS, were estimated for each migrant group. Multivariable Poisson regression analysis was used to estimate rate ratios (RR), adjusted for gender and paternal age. These variables were selected $a$ priori based on the reported association with the incidence of ASD (Reichenberg et al. 2006). We adjusted for advanced maternal age at birth, which has also been related to an increased risk for ASD (Sandin et al. 2012), in separate analyses to minimize the possible effect of collinearity with paternal age. RRs with a confidence interval (CI) not including unity were considered statistically significant. Time of observation was used as offset and the variance was scaled to take possible over-dispersion into account. The Poisson regression analysis was performed with the Generalized Linear Models (GLM) module of STATA, version 10.0 (Rabe-Hesketh \& Skrondal, 2005). The overall between-group differences in risk were tested with the Wald chi-square statistic.

We used the Kaplan-Meier method to estimate the cumulative incidence for a diagnosis of ASD at age 10 in the entire birth cohort. The age cut-off was set at a maximum of 10 years, because for an older age the majority of the cohort was not followed up through the period of risk. Because migrants tend to settle in urban areas and urbanicity has been associated with an increased risk for autism (Palmer et al. 2010), we performed subanalyses on a restricted urban sample of the inhabitants of the city of Utrecht only.

\section{Results}

\section{Cohort description}

During the 673,752 person-years at risk, 518 children developed ASD of whom 150 were diagnosed with an autistic disorder and 368 with Asperger syndrome or PDD-NOS. This corresponded to a cumulative incidence at age 10 of $1.0 \%$ (CI 95\% 0.9-1.1) for any ASD, or $0.2 \%$ (CI 95\% 0.1-0.3) for autism and $0.8 \%$ (CI 95\% 0.7-0.9) for Asperger syndrome and PDD-NOS.

Loss to follow-up occurred mostly due to individuals moving out of the catchment area (13.8\% of total cohort), which was less common in families with a child diagnosed with ASD. Individuals diagnosed with ASD were predominantly male. About one fourth of the children had one or two foreign-born parents. There was no large or significant difference in paternal or maternal age at birth between children with and without ASD (Table 1). Age at diagnosis was significantly lower for children with an autistic disorder compared to those with Asperger syndrome and PDD-NOS $(\mathrm{t}=10.3, \mathrm{p}<0.01)$, also when grouped by parental 
Table 1. Basic demographic characteristics of denominator and numerator populations

\begin{tabular}{|c|c|c|c|c|}
\hline Denominator Population & $\begin{array}{l}\text { Population } \\
\text { at } \text { risk }^{\mathrm{a}} \\
(\mathrm{n}=106,953)\end{array}$ & $\begin{array}{l}\text { Any ASD } \\
(n=518)\end{array}$ & $\begin{array}{l}\text { Asperger syndrome } \\
\text { \& PDD-NOS } \\
(n=368)\end{array}$ & $\begin{array}{l}\text { Autistic } \\
\text { disorder } \\
(n=150)\end{array}$ \\
\hline \multicolumn{5}{|l|}{ Sex, n (\%) } \\
\hline Male & $54,774(51.0)$ & $443(85.5)$ & $310(84.2)$ & $133(88.7)$ \\
\hline Female & $52,179(49.0)$ & $75(14.5)$ & $58(15.8)$ & $17(11.3)$ \\
\hline \multicolumn{5}{|l|}{ Parental country of birth ${ }^{\mathrm{b}}, \mathrm{n}(\%)$} \\
\hline Netherlands ${ }^{c}$ & $80,354(75.1)$ & $420(81.1)$ & $320(87.0)$ & $100(66.7)$ \\
\hline Developed countries $^{\mathrm{d}}$ & $6,651(6.2)$ & $29(5.6)$ & $16(4.3)$ & $13(8.7)$ \\
\hline Developing countries & $19,948(18.7)$ & $69(13.3)$ & $32(8.7)$ & $37(24.7)$ \\
\hline Paternal age at birth, mean (sd) & $34.4(5.2)$ & $34.1(5.2)$ & $33.8(5.2)$ & $34.6(6.0)$ \\
\hline Maternal age at birth, mean (sd) & $31.5(4.6)$ & $31.2(4.6)$ & $31.2(4.6)$ & $31.2(4.7)$ \\
\hline Age at diagnosis, mean (sd) & NA & $6.2(2.3)$ & $6.8(2.1)$ & $4.7(2.1)$ \\
\hline
\end{tabular}

${ }^{\text {a }}$ total population at risk per study year

${ }^{\mathrm{b}}$ divided according the United Nations Conference on Trade and Development (UNCTAD) classification of economic development. "Developed countries" include countries with economies in transition and developed economies; "Developing countries" include those with developing economies.

${ }^{\mathrm{c}}$ Born in the Netherlands and both parents born in the Netherlands

${ }^{\mathrm{d}}$ European countries (except for Turkey), Japan, US, Canada, Australia, New Zealand

country of birth in native Dutch, developed or developing countries (Table 2). There were no significant differences between migrant groups and native Dutch in terms of duration of follow-up or number of cases lost to follow-up, sex distribution or mean age at diagnosis.

\section{Incidence of ASD by parental country of birth}

Incidence rates and rate ratios (RRs) grouped by parental country of birth are displayed in Table 3. There were no major differences between crude RRs, RRs adjusted for gender and paternal age, and RRs adjusted for gender and maternal age. Parental birth in a developing country was associated with a significantly decreased risk of ASD (RR: 0.6, 95\% CI 0.5-0.9). Children born to Moroccan immigrants were at a very low risk $(\mathrm{RR}=0.3,95 \% \mathrm{CI} 0.2-0.6)$, whereas the risk for children from developed countries was similar to that of native Dutch.

\section{Incidence of ASD subtypes by parental country of birth}

Second-generation migrants were at decreased risk of Asperger syndrome or PDD-NOS. This finding was significant for children from developing countries ( $R \mathrm{R}=0.4$, CI 95\% 0.3-0.6). A reversed pattern was observed for a diagnosis of autism, for which a non-significantly increased risk was observed of 1.6 (CI 95\% 0.8-3.4) and 1.4 (CI 95\% 0.9-2.4) for the developed and developing group, respectively.

Children of Moroccan-born parents were at significantly lower risk of receiving a diagnosis of Asperger syndrome or PDD-NOS, but not of autistic disorder. The group of children from developing countries other than Morocco, Turkey, Surinam or Netherlands Antilles was at significantly decreased risk of Asperger syndrome or PDD-NOS (RR=0.3, CI $95 \%$ 0.2-0.7), but at significantly increased risk for autistic disorder ( $\mathrm{RR}=2.3, \mathrm{CI} 95 \%$ 1.1-4.8). 

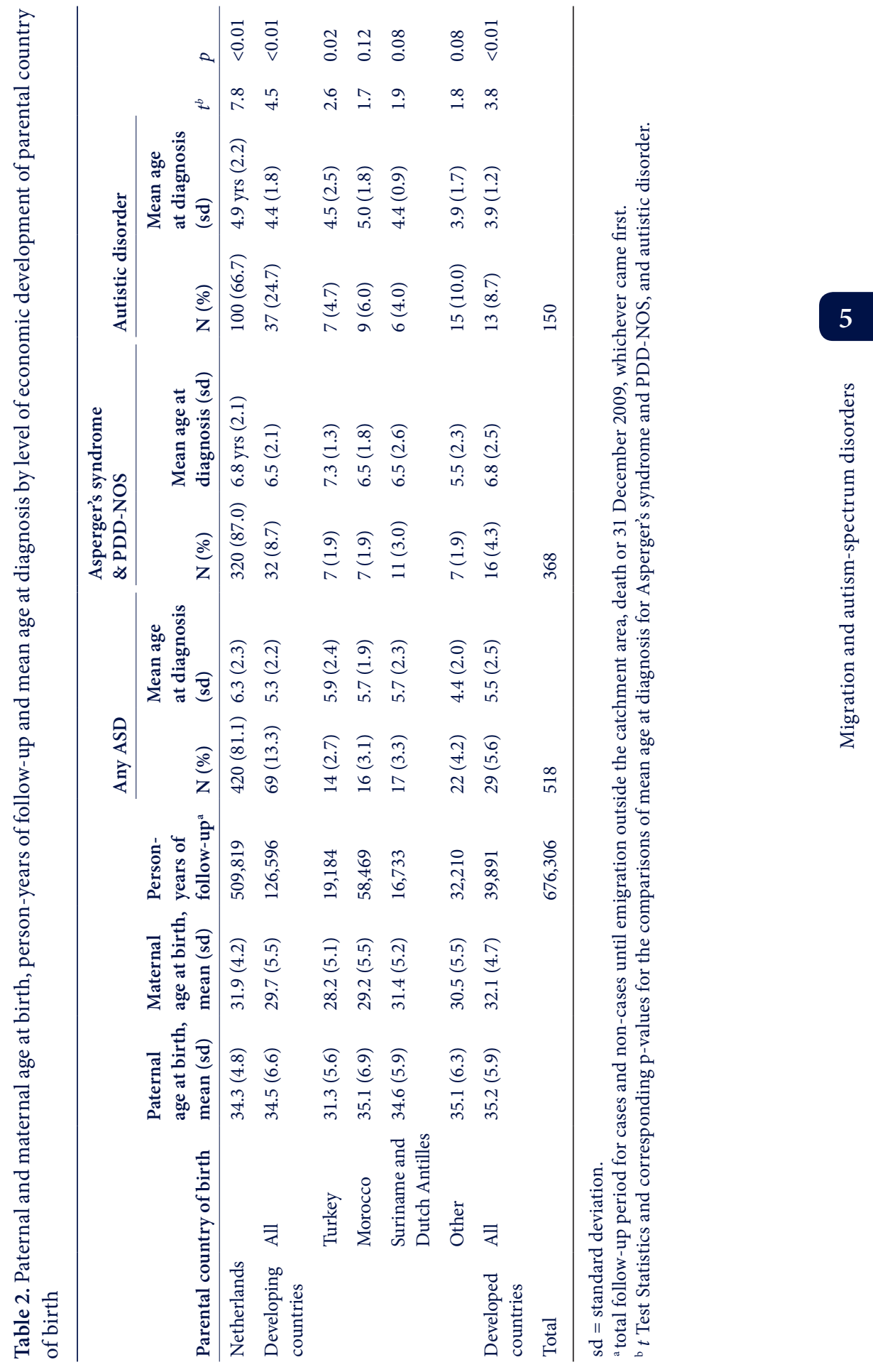
Table 3. Incidence rates and rate ratios (RRs) of ASD and its subtypes in Utrecht and surroundings by level of economic development of parental country of birth

\begin{tabular}{|c|c|c|c|c|c|c|c|}
\hline & & \multicolumn{2}{|l|}{ Any ASD } & \multicolumn{2}{|c|}{$\begin{array}{l}\text { Asperger's syndrome } \\
\text { \& PDD-NOS }\end{array}$} & \multicolumn{2}{|c|}{ Autistic disorder } \\
\hline \multicolumn{2}{|c|}{$\begin{array}{l}\text { Parental country of } \\
\text { birth }\end{array}$} & $\begin{array}{l}\text { Rate per } \\
10,000 \text { py } \\
(\mathrm{CI})\end{array}$ & $\begin{array}{l}\mathrm{RR} \\
(95 \% \mathrm{CI})^{\mathrm{a}}\end{array}$ & $\begin{array}{l}\text { Rate per } \\
10,000 \text { py } \\
(\mathrm{CI})\end{array}$ & $\begin{array}{l}\mathrm{RR} \\
(95 \% \mathrm{CI})^{\mathrm{a}}\end{array}$ & $\begin{array}{l}\text { Rate per } \\
10,000 \text { py } \\
(\mathrm{CI})\end{array}$ & $\begin{array}{l}\mathrm{RR} \\
(95 \% \mathrm{CI})^{\mathrm{a}}\end{array}$ \\
\hline Netherlands & & $8.2(7.4-9.0)$ & 1.0 & $6.2(5.6-7.0)$ & 1.0 & $1.9(1.6-2.3)$ & 1.0 \\
\hline \multirow[t]{5}{*}{$\begin{array}{l}\text { Developing } \\
\text { countries }\end{array}$} & All & $5.4(4.2-6.9)$ & $0.6(0.5-0.9)$ & $2.5(1.7-3.5)$ & $0.4(0.3-0.6)$ & $2.9(2.0-4.0)$ & $1.4(0.9-2.4)$ \\
\hline & Turkey & $7.3(3.9-12.2)$ & $0.8(0.5-1.5)$ & $3.6(1.4-7.5)$ & $0.5(0.2-1.2)$ & $3.6(1.4-7.5)$ & $1.8(0.6-4.9)$ \\
\hline & Morocco & $2.7(1.5-4.4)$ & $0.3(0.2-0.6)$ & $1.2(0.4-2.4)$ & $0.2(0.1-0.4)$ & $1.5(0.7-2.9)$ & $0.8(0.3-1.9)$ \\
\hline & $\begin{array}{l}\text { Suriname } \\
\text { and Dutch } \\
\text { Antilles }\end{array}$ & $\begin{array}{l}10.1(5.9- \\
16.2)\end{array}$ & $1.2(0.7-2.1)$ & $\begin{array}{l}6.5(3.2- \\
11.7)\end{array}$ & $1.0(0.5-1.9)$ & $3.5(1.3-7.8)$ & $1.8(0.6-5.4)$ \\
\hline & Other & $6.8(4.2-10.3)$ & $0.8(0.5-1.3)$ & $2.1(0.8-4.4)$ & $0.3(0.2-0.7)$ & $4.6(2.6-7.6)$ & $2.3(1.1-4.8)$ \\
\hline \multirow{2}{*}{$\begin{array}{l}\text { Developed } \\
\text { countries }\end{array}$} & All & $7.2(4.8-10.4)$ & $0.9(0.6-1.3)$ & $4.0(2.2-6.5)$ & $0.6(0.4-1.1)$ & $3.2(1.7-5.5)$ & $1.6(0.8-3.5)$ \\
\hline & & & $\begin{array}{l}\mathrm{p}<0.01 \\
(\mathrm{df}=5)^{\mathrm{b}} \\
\mathrm{p}=0.09 \\
(\mathrm{df}=2)^{\mathrm{c}}\end{array}$ & & $\begin{array}{l}\mathrm{p}<0.01 \\
(\mathrm{df}=5)^{\mathrm{b}} \\
\mathrm{p}<0.01 \\
(\mathrm{df}=2)^{\mathrm{c}}\end{array}$ & & $\begin{array}{l}\mathrm{p}=0.14 \\
(\mathrm{df}=5)^{\mathrm{b}} \\
\mathrm{p}=0.22 \\
(\mathrm{df}=2)^{\mathrm{c}}\end{array}$ \\
\hline
\end{tabular}

$\mathrm{ASD}=$ Autistic Spectrum Disorder; py= person-years; RR = Rate Ratio; CI = Confidence Interval; $\mathrm{df}=$ degrees of freedom.

a Adjusted for gender and paternal age.

${ }^{\mathrm{b}}$ Significance level of between-group differences in estimated RRs, excluding the combined category "developing countries, all".

'Significance level of differences in estimated RRs between three groups of parental country of birth: the Netherlands, developing countries and developed countries.

Migrant groups from developing countries, especially those from Turkey ( $R \mathrm{R}=1.0, \mathrm{CI}$ 95\% 0.5-1.9) and Suriname and Dutch Antilles ( $\mathrm{RR}=1.8$, CI 95\% 0.8-3.7) were at a slightly higher risk of ASD in the strictly urban subsample compared to the total sample. However, differences in risk between Asperger syndrome or PDD-NOS and autistic disorder remained present in all immigrant groups (see table 4).

\section{Incidence of ASD and its subtypes by maternal and paternal country of birth separately}

When reclassifying the sample based on birth country of the mother only, there was a minor decrease in estimated risk of ASD among children with a mother from a developed country $(\mathrm{RR}=0.5$, CI 95\% 0.3-1.0) and among those with a Surinamese or Dutch Antillean mother $(\mathrm{RR}=1.0$, CI 95\% 0.5-2.0). In other migrant groups the rate ratio for ASD, autistic disorder, and Asperger syndrome or PDD-NOS did not change more than 10\% for the reclassified 
Table 4. Rate ratios (RRs) of ASD and its subtypes in an exclusively urban study area (city of Utrecht) by level of economic development of parental country of birth

\begin{tabular}{|c|c|c|c|c|c|c|c|}
\hline \multirow{2}{*}{\multicolumn{2}{|c|}{ Parental country of birth }} & \multicolumn{2}{|c|}{ Any ASD } & \multicolumn{2}{|c|}{$\begin{array}{l}\text { Asperger's syndrome } \\
\text { \& PDD-NOS }\end{array}$} & \multicolumn{2}{|c|}{ Autistic disorder } \\
\hline & & $\mathrm{N}$ & $\mathrm{RR}(95 \% \mathrm{CI})^{\mathrm{a}}$ & $\mathbf{N}$ & $\mathrm{RR}(95 \% \mathrm{CI})^{\mathrm{a}}$ & $\mathbf{N}$ & $\mathrm{RR}(95 \% \mathrm{CI})^{\mathrm{a}}$ \\
\hline Netherlands & & 110 & 1.0 & 86 & 1.0 & 24 & 1.0 \\
\hline \multirow[t]{5}{*}{$\begin{array}{l}\text { Developing } \\
\text { countries }\end{array}$} & All & 46 & $0.6(0.4-1.0)$ & 23 & $0.5(0.3-0.8)$ & 23 & $1.2(0.6-2.5)$ \\
\hline & Turkey & 13 & $1.0(0.5-1.9)$ & 7 & $0.7(0.3-1.5)$ & 6 & $2.5(0.8-7.7)$ \\
\hline & Morocco & 13 & $0.4(0.2-0.8)$ & 6 & $0.2(0.1-0.5)$ & 7 & $1.0(0.4-2.9)$ \\
\hline & $\begin{array}{l}\text { Suriname } \\
\text { and Dutch } \\
\text { Antilles }\end{array}$ & 9 & $1.8(0.8-3.7)$ & $630 f)$ & $1.5(0.7-3.5)$ & 3 & $2.6(0.6-11.8)$ \\
\hline & Other & 11 & $1.0(0.5-1.9)$ & 4 & $0.5(0.2-1.3)$ & 7 & $2.8(1.0-8.1)$ \\
\hline \multirow{2}{*}{$\begin{array}{l}\text { Developed } \\
\text { countries }\end{array}$} & All & 9 & $0.7(0.3-1.4)$ & 4 & $0.4(0.1-1.1)$ & 5 & $1.7(0.5-5.7)$ \\
\hline & & & $\begin{array}{l}\mathrm{p}=0.03(\mathrm{df}=5)^{\mathrm{b}} \\
\mathrm{p}=0.09(\mathrm{df}=2)^{\mathrm{c}}\end{array}$ & & $\begin{array}{l}\mathrm{p}<0.01(\mathrm{df}=5)^{\mathrm{b}} \\
\mathrm{p}=0.04(\mathrm{df}=2)^{\mathrm{c}}\end{array}$ & & $\begin{array}{l}\mathrm{p}=0.27(\mathrm{df}=5)^{\mathrm{b}} \\
\mathrm{p}=0.64(\mathrm{df}=2)^{\mathrm{c}}\end{array}$ \\
\hline
\end{tabular}

$\mathrm{ASD}=$ Autistic Spectrum Disorder; RR = Rate Ratio; $\mathrm{CI}=$ Confidence Interval; $\mathrm{df}=$ degrees of freedom. ${ }^{\text {a }}$ Adjusted for gender and paternal age.

${ }^{\mathrm{b}}$ Significance level of between-group differences in estimated RRs, excluding the combined category "developing countries, all".

'Significance level of differences in estimated RRs between three groups of parental country of birth: the Netherlands, developing countries and developed countries.

sample. To study the effect of specifically paternal migrant status, children with a foreignborn father and a Dutch-born mother (ASD total $n=37$ ) were analysed as a separate group. The RR of ASD among children with a Dutch mother and a foreign father compared to native Dutch was 1.2 (CI 95\%, 0.8-1.8) with a lower risk of Asperger or PDD-NOS (RR=0.8, CI 95\% 0.5-1.3) and a significantly higher risk of autistic disorder ( $R R=2.6, C I$ 95\% 1.4-5.0).

\section{Discussion}

This is the first epidemiological study on the incidence of diagnosed ASD in the Netherlands. A decreased risk was found for ASD among second-generation immigrants from developing countries. A closer look at specific diagnostic categories revealed that this was attributable to a significantly lower relative risk for Asperger syndrome and PDD-NOS, but not for autistic disorder, which showed a trend in the opposite direction, albeit statistically inconclusive. The study may have lacked the power to reveal significant differences in the incidence of autistic disorders as a function of parental migrant status. The restricted number of cases also precluded in-depth analyses on other relevant factors, for example the timing of 
maternal migration. Asperger syndrome and PDD-NOS were registered under an identical DSM-IV code (299.80), hence we were unable to calculate incidence rates for each diagnostic group separately. The external validity of these findings may be limited for rural areas, since the study area comprised an urban and semi-rural area. However, it is unlikely that urbanicity acted as a confounder, because in a more homogeneous, strictly urban subsample the association between the risk of ASD and migrant status remained similar, as well as the risk difference between ASD subtypes. A major strength of the study is that PCR-MN covers both in- and outpatient psychiatric health care facilities in a large, well-defined study area. Because of the nature of the Dutch health care system, characterised by compulsory medical insurance and compulsory diagnostic registration in order to receive funding, the diagnostic registration of treated patients is particularly complete (Smeets et al. 2011). This is supported by our reported cumulative incidence of ASD of roughly $1 \%$, which is in accordance with two large-scale, prevalence studies using rigorous case finding methods (Baio, 2012; Idring et al. 2012).

It is uncertain to what degree the decreased risk of Asperger syndrome or PDD-NOS and the increased risk of autistic disorder among migrants from developing countries represent valid findings, or, alternatively, the result of various potential biases. The findings concur with two recent Swedish studies (Haglund \& Källén, 2011; Magnusson et al. 2012) showing a negative and a positive association between the risk for high and low functioning autism, respectively, and maternal birth outside Northern Europe. It was argued that the stressful circumstances of migration contribute to the increased risk for autism with co-morbid intellectual disability, in particular when operating in utero (Magnusson et al. 2012). Similar findings have been reported in the US (Croen et al. 2007), where black ethnicity was positively associated with autistic disorder ( $R R=2.6,95 \%$ CI 1.3-5.0), with apparent reversal of risk for PDD-NOS and Asperger syndrome ( $R R=0.5,95 \%$ CI 0.2-1.0). Dealberto (2011) suggested that maternal vitamin D insufficiency among migrant mothers may be responsible for increased rates of especially the strict definition of autism. Our findings did not uniformly support this hypothesis given that autistic disorder was not more common in migrant groups in the Netherlands known to have low serum vitamin D, e.g., those from Moroccan origin (van der Meer et al. 2011). In addition, we demonstrated that exclusively paternal foreign birth is also associated with a reverse risk gradient of ASD subtypes in the child, in particular a significantly increased risk for autistic disorder. This suggests that the effect of parental migration on ASD risk is not fully explained by maternal migration history, but may also be mediated by the migration history of the father.

The low risk of Asperger syndrome and PDD-NOS for second-generation migrants may also be due to a low detection rate. Underutilization of child psychiatric services has been reported for non-Dutch youth in the Hague (Boon et al. 2010). Parents originating from a different cultural background may not view the disturbed behaviour of their children as a medical problem or may be reluctant to seek help for fear of stigma (Fassaert et al. 2009; Thomas et al. 2007). This would leave cases of less severe forms of ASD, such as Asperger syndrome or PDD-NOS, particularly undetected. Children with autistic disorder, on the other hand, often have concurrent intellectual disabilities, decreasing their possibilities 
to complete a school education in the regular stream, increasing the probability of helpseeking behaviour (Yeargin-Allsopp et al. 2003). It is also possible that children with higher functioning forms of autism are not diagnosed at all, because clinicians may be inclined to attribute minor social and communicative problems to a child's ethnic background (Reijneveld et al. 2005). A study from the Netherlands found that paediatricians more often chose autism as the most likely diagnosis when judging clinical vignettes of European majority cases than vignettes including non-European minority cases (Moroccan or Turkish) (Begeer et al. 2009). However, our finding that age at diagnosis was similar across groups does not fit the notion that children born to immigrants are less likely to be diagnosed with ASD. Nevertheless, diagnosing minor behavioural problems among Dutch youth as Asperger syndrome and PDD-NOS can result in an overestimation of these disorders, leading to an artificially decreased observed incidence among immigrants.

\section{References}

1. Baio, J.(2012). Prevalence of autism spectrum disorders: Autism and Developmental Disabilities Monitoring Network, 14 sites, United States, 2008. MMWR Surveill Summ 61, 1-19.

2. Begeer, S., Bouk, S., Boussaid, W., Terwogt, M., Koot, H. (2009). Underdiagnosis and referral bias of autism in ethnic minorities. J Autism Dev Disord 39, 142-148.

3. Boon, A., de Haan, A., de Boer, S. (2010). Clients using the youth mental health services in The Hague are not an ethnic reflection of the youth of that city; bias not by social economic status but by ethnic origin. Tijdschr Psychiatr 52, 653-658.

4. CBS (2011). About statistics Netherlands. http://www.cbs.nl/en-GB/menu/organisatie/ default.htm. Accessed March 1, 2012.

5. Croen, L. A., Grether, J. K., Selvin, S. (2002). Descriptive epidemiology of autism in a California Population: who is at risk? J Autism Dev Disord 32, 217-224.

6. Croen, L. A., Najjar, D. V., Fireman, B., Grether, J. K. (2007). Maternal and paternal age and risk of autism spectrum disorders. Arch Pediatr Adolesc Med 161, 334-340.

7. Dealberto, M. J. (2011). Prevalence of autism according to maternal immigrant status and ethnic origin. Acta Psychiatr Scand 123, 339348.

8. Fassaert, T., de Wit, M., Tuinebreijer, W., Verhoeff, A., Beekman, A., Dekker, J. (2009). Perceived need for mental health care among

non-western labour migrants. Soc Psychiatry Psychiatr Epidemiol 44, 208-216.

9. Haglund, N. G. S., Källén, K. B. M. (2011). Risk factors for autism and Asperger syndrome. Autism 15, 163-183.

10. Hallmayer, J., Cleveland, S., Torres, A., Phillips, J., Cohen, B., Torigoe, T., Miller, J., Fedele, A., Collins, J., Smith, K., Lotspeich, L., Croen, L. A., Ozonoff, S., Lajonchere, C., Grether, J. K., Risch, N. (2011). Genetic heritability and shared environmental factors among twin pairs with autism. Arch Gen Psychiatry 68, 1095-1102.

11. Hultman, C., Sparen, P., Cnattingius, S. (2002). Perinatal risk factors for infantile autism. Epidemiology 13, 417-423.

12. Idring, S., Rai, D., Dal, H., Dalman, C., Sturm, H., Zander, E., Lee, B. K., Serlachius, E., Magnusson, C. (2012). Autism spectrum disorders in the Stockholm Youth Cohort: design, prevalence and validity. PLoS ONE 7, e41280.

13. Keen, D. V., Reid, F. D., Arnone, D. (2010). Autism, ethnicity and maternal immigration. Br J Psychiatry 196, 274-281.

14. Lauritsen, M. B., Pedersen, C. B., Mortensen, P. B. (2005). Effects of familial risk factors and place of birth on the risk of autism: a nationwide register-based study. J Child Psychol Psychiatry 46, 963-971.

15. Magnusson, C., Rai, D., Goodman, A., Lundberg, M., Idring, S., Svensson, A., Koupil, I., Serlachius, E., Dalman, C. (2012). Migration and autism-spectrum disorder: 
population-based study. Br J Psychiatry, (Epub ahead of print) doi: 10.1192/bjp. bp.111.095125.

16. Palmer, R. F., Walker, T., Mandell, D., Bayles, B., Miller, C. S. (2010). Explaining Low Rates of Autism Among Hispanic Schoolchildren in Texas. Am J Public Health 100, 270-272.

17. Rabe-Hesketh, S., Skrondal, A. (2005). Counts. In Multilevel and Longitudinal Modeling using Stata, pp. 181-216. STATA Press: Texas.

18. Reichenberg, A., Gross, R., Weiser, M., Bresnahan, M., Silverman, J., Harlap, S., Rabinowitz, J., Shulman, C., Malaspina, D., Lubin, G., Knobler, H. Y., Davidson, M., Susser, E. (2006). Advancing paternal age and autism. Arch Gen Psychiatry 63, 10261032.

19. Reijneveld, S. A., Harland, P., Brugman, E., Verhulst, F. C., Verloove-Vanhorick, S. P. (2005). Psychosocial problems among immigrant and non-immigrant children. Eur Child Adolesc Psychiatry 14, 145-152.

20. Rutter, M. (2011). Progress in understanding autism: 2007-2010. J Autism Dev Disord 41, 395-404.

21. Sandin, S., Hultman, C. M., Kolevzon, A., Gross, R., MacCabe, J. H., Reichenberg, A. (2012). Advancing maternal age is associated with increasing risk for autism: a review and meta-analysis. J Am Acad Child Adolesc Psychiatry 51, 477-486.

22. Smeets, H. M., Laan, W., Engelhard, I. M., Boks, M. P., Geerlings, M. I., de Wit, N. J. (2011). The psychiatric case register middle Netherlands. BMC. Psychiatry 11, 106.

23. Thomas, K., Ellis, A., McLaurin, C., Daniels, J., Morrissey, J. (2007). Access to care for autism-related services. J Autism Dev Disord 37, 1902-1912.

24. United Nations Conference on Trade and Development (2011). UNCTAD Handbook of Statistics 2011. United Nations: New York \& Geneva.

25. van der Meer, I. M., Middelkoop, B. J., Boeke, A. J., Lips, P. (2011). Prevalence of vitamin D deficiency among Turkish, Moroccan, Indian and sub-Sahara African populations in Europe and their countries of origin: an overview. Osteoporos Int 22, 1009-1021.

26. Yeargin-Allsopp, M., Rice, C., Karapurkar, T., Doernberg, N., Boyle, C., Murphy, C. (2003). Prevalence of autism in a US metropolitan area. JAMA 289, 49-55.

27. Zaroff, C., Uhm, S. (2012). Prevalence of autism spectrum disorders and influence of country of measurement and ethnicity. Soc Psychiatry Psychiatr Epidemiol 47, 395-398. 




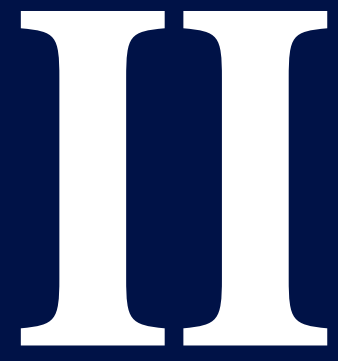

Examining hypotheses behind the epidemiology 



\section{chapter SIX}

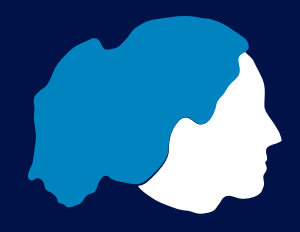

Comparing the clinical presentation of first-episode psychosis across different migrant and ethnic minority groups in Montreal, Quebec

E. van der Ven,

F. Bourque,

R. Joober,

J.P. Selten,

A. Malla 


\section{Abstract}

\section{Objective}

To explore differences in severity and nature of symptoms of first-episode psychosis (FEP) according to ethnic group and migrant status.

\section{Method}

We administered rating scales to assess positive and negative symptoms, as well as general psychopathology, to 301 consecutive patients presenting with a FEP within a defined catchment area in Montreal, Quebec, classified according to ethnicity and migrant status. Symptom scores of Euro-Canadian patients without a recent history of migration, that is, the reference group $(n=145)$, were compared with those of African and Afro-Caribbean $(n=39)$, Asian $(n=27)$, Central- and South-American $(n=15)$, Middle Eastern and North African $(n=24)$, and European and North American $(n=39)$ patients.

\section{Results}

Except for referral source, there were no significant differences between ethnic groups on any demographic variables. The African and Afro-Caribbean group had a higher level of negative symptoms (especially alogia), and general psychopathology scores on the Positive and Negative Syndrome Scale (especially, uncooperativeness, preoccupation and poor attention), compared with the reference group. Ethnic groups did not differ on the Scale for the Assessment of Positive Symptoms scores.

\section{Conclusions}

A comparison of FEP patients from different ethnic groups and native-born Euro-Canadians revealed no significant differences in the nature of positive symptoms at first presentation or in age at onset, suggesting that there was no evidence for the hypothesis that ethnic minorities are misdiagnosed as psychotic. Increased severity of negative symptoms and general psychopathology, specifically among the black ethnic minority group, may have implications for the role of ethnicity for the treatment and outcome of the initial episode of psychotic disorders. 


\section{Introduction}

There is now consistent evidence for an increased incidence of psychotic disorders in many migrant and ethnic minority groups across various countries (Cantor-Graae et al. 2003; Cantor-Graae et al. 2005; Coid et al. 2008; Fearon et al. 2006; Veling et al. 2006; Weiser et al. 2008). A recent meta-analysis has shown that the risk increase clearly persists in second generation migrants, with comparable effect sizes for both first and second migrant generations (Bourque et al. 2011). Importantly, the magnitude of risk varied significantly according to ethnicity, host country, and visible minority status. For instance, first- and second-generation migrants from countries where most of the population is black presented incidence rate ratios for first- and second-generation migrants of 4.0 (95\% CI 3.4-4.6) and 5.4 (95\% CI 3.2-8.8), respectively, compared with ratios of 1.8 (95\% CI 1.6-2.1) and 1.9 (95\% CI 1.2-3.0) for those from countries where most of the population is white. This betweengroup heterogeneity suggests that risk and/or protective factors for psychosis may operate differentially in diverse ethnic minority groups (Morgan et al. 2010).

Migration can be defined as a highly heterogeneous process of a person, alone or with others, moving from one cultural setting to another, mostly to improve their respective economical, political, or educational situation (Bhugra \& Jones, 2001). The literature commonly distinguishes first-generation immigrants, who are foreign-born, from secondgeneration immigrants born in the host country to one or two migrant parents. This variable can be referred to as 'migration status' and is one of the important facets defining a person's ethnic origin. Unlike the explicit definition of migration status, ethnicity is a complex concept loosely defined as a quality that refers to the group a person belongs to, based on shared group characteristics, such as cultural traditions, and geographical and ancestral origin (Bhopal, 2004). Indeed, generational differences may be relevant given that the migration process may have an impact on psychotic symptom expression, owing to the potential influence of factors, such as acculturation or trauma (Bhugra, 2004).

The clinical presentation of schizophrenia and psychotic disorders, in general, can comprise a widely diverse set of symptoms, which, depending on nature, content, and severity, shape a clinician's evaluation (Andreasen \& Carpenter, 1993). This has implications not only for the diagnostic process, but also for disposition and treatment decisions, including possibilities for pharmacological treatment, out- or inpatient care, and involuntary or voluntary hospital admission. Well-balanced clinical decisions may accelerate the pathway to appropriate psychiatric care, potentially leading to early intervention that, in turn, can positively impact long-term illness course (Marshall et al. 2005; McGorry et al. 2010). However, delays in the pathway and an increased likelihood of adversarial routes to mental health care, including police involvement and compulsory admissions, have been reported among ethnic minorities, specifically for Afro-Caribbean patients in the United Kingdom, and patients of Asian origin in Canada (Archie et al. 2010; Harrison et al. 1989; Burnett et al. 1999; Morgan et al. 2005a; Morgan et al. 2005b). By investigating symptom profiles across ethnic minority groups, we may better understand the reasons for disparities in accessing mental health care, which still remain poorly understood (Morgan et al. 2004). In addition, studying the nature and severity of 
individual or domains of symptoms may circumvent the arguable limitations of using diagnostic categories (Widiger \& Samuel, 2005).

To our knowledge, no study has investigated clinical presentation of FEP in different ethnic or migrant groups in Canada, despite its distinction as one of the most multicultural countries in the world, with an increasing influx of predominantly non-white migrants (Statistics Canada, 2011). So far, studies investigating differences in the constellations of psychotic symptoms between various ethnic groups have yielded inconsistent results. Several US-based studies examining psychotic symptoms among ethnic minority groups show generally more severe psychotic symptoms (Strakowski et al. 1996), higher levels of first-rank symptoms of schizophrenia (Arnold et al. 2004), and, specifically, higher ratings on suspiciousness and hallucinatory experience (Barrio et al. 2003) among African Americans compared with Euro-Americans. Further, Latin American patients have been documented to experience more somatic symptoms (Weisman et al. 2000) and generally more severe psychotic symptoms (Coelho et al. 1998; Vega \& Lewis-Fernandez, 2008), whereas other studies showed the opposite, that is, Latin Americans experiencing lower psychotic symptom levels (Weisman et al. 2000; Brekke \& Barrio, 1997). In the United Kingdom, several studies did not find any apparent differences between ethnic groups in symptom expression (Hutchinson et al. 1999; Harvey et al. 1990). Others reported higher rates of mania, religious and paranoid delusions in Afro-Caribbean patients (Ndetei, 1988; Littlewood \& Lipsedge, 1981; Demjaha et al. 2006), as well as increased rates for depressive psychosis among all ethnic minorities (Fearon et al. 2006). However, most of these studies concerned chronically ill patient populations, with symptom patterns that may have changed over time because of previous treatment and variations in treatment response. A first contact study from the Netherlands found that the Moroccan, but not the Turkish, Surinamese or other ethnic minority groups, presented with higher levels of general psychopathology, more negative symptoms, and more frequent paranoid delusions, compared with native Dutch patients with psychosis (Veling et al. 2007).

Here we report a comparative study of the clinical presentation of FEP in Canadian patients from European descent without a recent history of migration and patients from various ethnic minority populations, conducted in a defined catchment area. Our study had two aims: a) to explore variations in clinical presentation of FEP according to ethnicity and migration status; and b) to determine whether the severity of symptoms of migrants and ethnic minorities differ from that of the reference group.

\section{Method}

\section{Setting and participants}

Our study was carried out at the Prevention and Early Intervention Program for Psychosis in Montreal, Quebec. This program is a specialized early intervention program, providing comprehensive, phase-specific treatment to young people experiencing a previously untreated FEP. It serves a defined, urban catchment area in the southwest of Montreal, closely resembling an epidemiologic-treated incidence sample because there are no other 
specialized services for FEP offered within this sector, or any other psychiatric facility within the catchment area. Not only are all mental health services publicly funded, but there are virtually no private facilities available. There were four inclusion criteria for the treatment program as well as for our study: (a) living in the catchment area, (b) aged between 14 and 30 years, (c) diagnosed with a psychotic disorder according to the Diagnostic and Statistical Manual of Mental Disorders, $4^{\text {th }}$ edition (DSM-IV)(APA), and (d) no previous antipsychotic pharmacological treatment of a duration longer than 30 days. There were four exclusion criteria: (a) an IQ of lower than 70, (b) a history of organic brain syndrome, (c) a primary diagnosis of substance-induced psychosis, and (d) insufficient ability to speak English or French for symptoms to be accurately assessed. Approval was given by the Human Ethics Research Board of the Douglas Mental Health University Institute, and all participants signed an informed consent form.

\section{Ascertainment of ethnicity}

In June 2008, all available information on ethnicity, including birthplace, parental birthplace, and previous countries of residence, was retrospectively collected through chart reviews on the entire cohort that entered the program since January $1^{\text {st }} 2003$. This information had been collected systematically as part of the clinical interview. As of June 2008, these data were collected during face-to-face interviews with all newly admitted patients. Immigrant status was ascribed as either 'first-generation migrant' for foreignborn patients and as 'second-generation migrant' for Canadian-born patients with at least one foreign-born parent. All migrants were assigned to an ethnic migrant group based on their geographical area of origin, as per the 16 categories of the Statistics Canada 2006 census (Statistics Canada). In case both parents were born in different foreign countries, the country of birth of the mother determined the assigned ethnic migrant group, as per the procedure used in other migrant studies (Veling et al. 2006; Bourque et al. 2011). To enable comparability with sufficient sample sizes in each group, categories were collapsed into a reference group and the following five ethnic groups: (I) African and Afro-Caribbean, including sub-Saharan Africa and the West Indies; (II) Asian, including all Asian countries East of Iran; (III) Mexican, Central and South American; (IV) Middle Eastern and North African, including Arabic countries and super-Saharan Africa; and (V) European and North American (specifically, the United States). The reference group refers to white French or English Canadians of European descent without a recent history of migration (that is, no personal or parental migratory background). Given the inherent complexity of the ethnicity concept, any classification undermines considerable within-group heterogeneity (Bhopal, 2004). However, this important limitation was overlooked to enable comparisons that may elaborate on previous ethnicity-based findings (Archie et al. 2010).

\section{Diagnostic and symptom characteristics}

Within the first 3 months of entry into the program, the Structured Clinical Interview for DSM-IV (First et al. 2002) and the Circumstances of Onset and Relapse Schedule (CORS) were conducted, or, in case of service disengagement, reconstructed based on medical files (in $8.7 \%$ of cases). The CORS is an unpublished, shortened version of the Retrospective 
Assessment of Onset of Schizophrenia (IRAOS) and creates a timeline of the patient's life to determine mainly the onset of psychotic symptoms by means of a semi-structured interview (Häfner et al. 1992). Consensus regarding diagnosis, duration of untreated psychosis (DUP), and age at onset of psychosis was established by two senior psychiatrists (AM and RJ). To establish an inter-rater reliability for DUP estimates, three trained raters determined DUPs of 20 randomly selected cases, yielding a high intra-class correlation (ICC) varying from 0.86 to 0.98 .

Within three weeks of program admission, symptoms were assessed with a comprehensive evaluation, comprised of the Scale for the Assessment of Positive Symptoms (SAPS)(Andreasen, 1984), the Scale for the Assessment of Negative Symptoms (SANS) (Andreasen, 1983), and the Positive and Negative Symptom Scale (PANSS)(Kay, 1987). These scales were completed based on a single interview, which has been designed to cover items on all instruments. For the purpose of our study, we only used SAPS to estimate positive symptoms, SANS for negative symptoms and the general psychopathology subscale score of the PANSS for other psychopathology. Evaluations were conducted by extensively trained and supervised research assistants of mixed ethnic background, including those similar to the reference group in the sample. They were not involved in the treatment of patients. Each consecutive patient enrolling in the program was distributed to a symptom assessor at random. Inter-rater reliability was assessed by means of a videotaped interview, rated independently by all research assistants. Intra-class correlation coefficients were established at $0.75,0.75$ and 0.85 for the SAPS, SANS and PANSS, respectively.

\section{Statistical Analysis}

All analyses were performed on SPSS software version 18.0 (SPSS, 2009). For comparison of demographic variables, chi-square tests were employed for categorical and one-way ANOVAs for continuous variables. DUP was log-transformed first to correct for a positively skewed distribution. Total SAPS and SANS scores were calculated by summing up all individual item scores, with the exception of the attention score on the SANS, which is not listed as negative symptom in DSM-IV. Total general psychopathology was indicated by the PANSS total sum of items G1 to G16, which reflects the global psychopathology subscale (Kay et al. 1987). After verifying that mean scale scores were normally distributed (Kirkwood \& Sterne, 2003), we compared global scale scores using univariate ANCOVAs, with age and sex entered as covariates. We assured the homogeneity of regression slopes across groups by means of Levene's tests. To limit the amount of hypotheses tested and to avoid Type I errors, we only analyzed individual symptoms if there was a significant difference on total (sub)scale scores on SAPS, SANS, or PANSS. Individual symptoms were compared using age- and sex-controlled MANCOVAs with p-values adjusted for multiple testing according to Bonferroni correction. These analyses were completed separately for the comparison of the reference group to other ethnicities, and for comparing the reference group to first- and second-generation migrants. 
Table 1. Demographic characteristics of the FEP sample by ethnic group

\begin{tabular}{|c|c|c|c|c|c|c|c|}
\hline \multirow[b]{2}{*}{$\begin{array}{l}\text { Demographic } \\
\text { characteristic }\end{array}$} & \multirow[b]{2}{*}{$\begin{array}{l}\text { Reference } \\
\text { group, } \\
\mathrm{n}=145\end{array}$} & \multicolumn{6}{|c|}{ Ethnic group } \\
\hline & & $\begin{array}{l}\text { African \& } \\
\text { Afro- } \\
\text { Caribbean, } \\
\mathrm{n}=39\end{array}$ & $\begin{array}{l}\text { Asian, } \\
\mathrm{n}=27\end{array}$ & $\begin{array}{l}\text { Central } \\
\text { \& South } \\
\text { American, } \\
\mathrm{n}=15\end{array}$ & $\begin{array}{l}\text { Middle } \\
\text { Eastern } \\
\text { \& North } \\
\text { African, } \\
\mathrm{n}=24\end{array}$ & $\begin{array}{l}\text { European } \\
\text { \& North } \\
\text { American, } \\
\mathrm{n}=39\end{array}$ & $\begin{array}{l}\text { Chi-square, } \\
\text { Kruskall } \\
\text { Wallis Test } \\
\text { and ANOVAs } \\
\text { with p-values }\end{array}$ \\
\hline \multicolumn{8}{|l|}{$\begin{array}{l}\text { Age at entry into } \\
\text { program }\end{array}$} \\
\hline Mean years $(\mathrm{SD})$ & $23.4(4.0)$ & $22.8(4.3)$ & $21.3(5.0)$ & $22.1(3.6)$ & $22.3(3.1)$ & $22.9(3.8)$ & $\begin{array}{l}F=1.435 \\
d f=5 / 228 \\
p=0.21\end{array}$ \\
\hline \multicolumn{8}{|l|}{ Sex, n (\%) } \\
\hline Male & $103(71.0)$ & $28(71.8)$ & $17(63.0)$ & $12(80.0)$ & $17(70.8)$ & $23(59.0)$ & \multirow{2}{*}{$\begin{array}{l}\chi^{2}=3.609 \\
\mathrm{df}=5 \\
\mathrm{p}=0.61\end{array}$} \\
\hline Female & $42(29.0)$ & $11(28.2)$ & $10(37.0)$ & $3(20.0)$ & $7(29.2)$ & $16(41.0)$ & \\
\hline \multicolumn{8}{|l|}{$\begin{array}{l}\text { Level of education, } \\
\mathrm{n}(\%)\end{array}$} \\
\hline Less than high school & $71(50.4)$ & $21(55.3)$ & $14(56.0)$ & $6(42.9)$ & $8(33.3)$ & $19(50.0)$ & \multirow{2}{*}{$\begin{array}{l}\chi^{2}=3.726 \\
d f=5 \\
p=0.59\end{array}$} \\
\hline $\begin{array}{l}\text { High school and } \\
\text { higher }\end{array}$ & $70(49.6)$ & $17(44.7)$ & $11(44.0)$ & $8(57.1)$ & $16(66.7)$ & $19(50.0)$ & \\
\hline \multicolumn{8}{|l|}{$\begin{array}{l}\text { Primary diagnosis, } \\
\mathrm{n}(\%)\end{array}$} \\
\hline $\begin{array}{l}\text { Non-affective } \\
\text { psychosis }\end{array}$ & $106(73.1)$ & $32(82.1)$ & $18(66.7)$ & $12(80.0)$ & $18(78.3)$ & $27(69.2)$ & \multirow{2}{*}{$\begin{array}{l}\chi^{2}=3.085 \\
\mathrm{df}=5 \\
\mathrm{p}=0.69\end{array}$} \\
\hline Affective psychosis & $39(26.9)$ & $7(17.9)$ & $9(33.3)$ & $3(20.0)$ & $5(21.7)$ & $12(30.8)$ & \\
\hline \multicolumn{8}{|l|}{ Referral source, $\mathrm{n}(\%)^{*}$} \\
\hline ER/inpatient referral & $104(72.2)$ & $35(92.1)$ & $17(63.0)$ & $14(93.3)$ & $14(58.3)$ & $26(68.4)$ & \multirow{2}{*}{$\begin{array}{l}\chi^{2}=14.753 \\
d f=5 \\
p=0.01^{*}\end{array}$} \\
\hline Outpatient referral & $40(27.8)$ & $3(7.9)$ & $10(37.0)$ & $1(6.7)$ & $10(41.7)$ & $12(31.6)$ & \\
\hline \multicolumn{8}{|l|}{ DUP onsetb, c } \\
\hline Weeks, median (SD) & $14.9(119.8)$ & $17.5(88.2)$ & $24.1(60.4)$ & $11.0(57.7)$ & $16.4(64.7)$ & $17.9(56.2)$ & $\begin{array}{l}F=0.0305 \\
d f=5 / 272 \\
p=0.91\end{array}$ \\
\hline \multicolumn{8}{|l|}{$\begin{array}{l}\text { Age at onset of } \\
\text { psychosisa }\end{array}$} \\
\hline Mean age, yrs (SD) & $22.4(4.0)$ & $22.1(4.1)$ & $20.3(4.6)$ & $21.5(4.3)$ & $21.5(3.0)$ & $21.8(4.0)$ & $\begin{array}{l}F=1.402 \\
d f=5 / 282 \\
p=0.22\end{array}$ \\
\hline \multicolumn{8}{|l|}{ Migrant status, n (\%) } \\
\hline First generation & n.a. & $22(56.4)$ & $16(59.3)$ & $6(40.0)$ & $18(75.0)$ & $19(48.7)$ & \\
\hline $\begin{array}{l}\text { Second generation } \\
\text { a }<1 \% \text { of cases missing } \\
\text { b } 3.5 \% \text { of cases missing }\end{array}$ & n.a. & $17(43.6)$ & $11(40.7)$ & $9(60.0)$ & $6(25.0)$ & $20(51.3)$ & \\
\hline
\end{tabular}

${ }^{\mathrm{c}}$ Analyzed with Non-parametric Kruskal-Wallis test

* Significantly more ER/inpatient referrals among African and Afro-Caribbean group compared with Middle Eastern and North African group only n.a.= not applicable 


\section{Results}

Between January 2003 and January 2010, 301 patients met the inclusion criteria and completed informed consent for participation in the structured clinical evaluations. Patients of Aboriginal origin were excluded a priori due to the small sample size $(n=3)$. For five patients ethnic background could not be determined. Four patients withdrew from the treatment program before any structured assessments could be completed. Among the total cohort of 289 patients, 145 patients were white English or French Canadians with Canadianborn parents, hereafter referred to as the reference group, 81 first-generation migrants and 63 second-generation migrants. Demographic characteristics of the sample are displayed in table 1.

The African and Afro-Caribbean patients were more likely to be referred from the emergency department compared with patients from the Middle East and North Africa $\left(\chi^{2}=14.8, \mathrm{df}=5, \mathrm{p}=0.01\right)$, but not compared with the reference group. There were no differences between the reference and other ethnic groups in DUP, age at onset of psychotic disorder or any other demographic variables.

Comparing the total SAPS, SANS and PANSS general psychopathology subscale score of the reference group to the other ethnic groups showed higher mean total SANS and general psychopathology (PANSS subscale) scores only for the African and Afro-Caribbean group $(F[5,288]=2.817, p=0.02 ; F[5,288]=3.485, p=0.005$; respectively $)$. The Asian, Central and South American, Middle Eastern, and European and North American groups did not differ significantly from the reference group on any of the symptom rating scale scores. When dividing groups based on migrant status, no differences appeared between the reference group and the other ethnic groups on any symptoms rating scales. On the SAPS, there was no significant difference between any ethnic or migrant group compared with the reference group (table 2).

An overview of subscale SANS scores, as well as individual item psychopathology scores of the PANSS for the reference group compared with the African and Afro-Caribbean group are displayed in table 3 . The alogia subscale score of the SANS scores showed a higher mean for the African and Afro-Caribbean group compared with the reference group $(F[1,183]=7.671$, $p=0.006$ ). For the affective flattening and avolition-apathy subscales, significance was lost when Bonferroni adjustments were employed. On the PANSS general psychopathology items, the African and Afro-Caribbean group differed from the reference group on the uncooperativeness, poor attention and preoccupation items $(F[1,183]=8.909, p=0.003$; $F[1,183]=9.625, p=0.002 ; F[1,183]=12.065, p=0.001$; respectively) with a conservative $p$-value adjusted for multiple testing. No other differences in individual item scores were observed.

\section{Discussion}

Our study compared demographic and clinical characteristics, including symptom profile and severity of symptoms of patients with a FEP, grouped by migrant status and ethnic origin. Levels of psychopathology in Asian, South and Central American, Middle Eastern, and European and North American ethnic groups were similar to that in the reference group. 


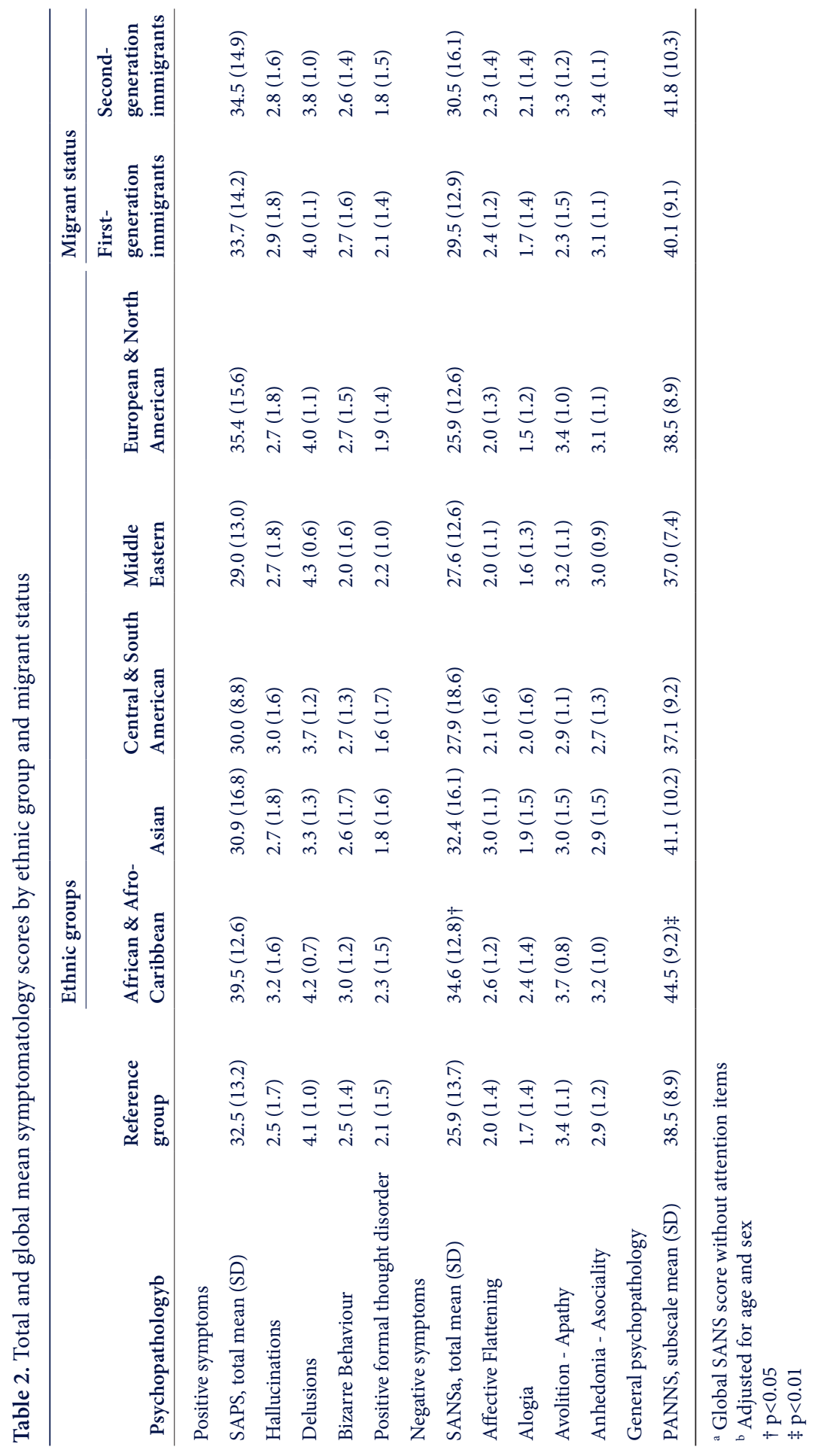

6

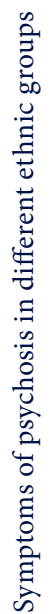


Table 3. Symptom domain scores for the reference group compared with the African and AfroCaribbean ethnic group

\begin{tabular}{llll}
\hline Global severity subscale scores, mean (SD) & Reference group & African \& Afro-Caribbean & p-value \\
\hline Negative symptoms (SANS) & & & \\
Affective Flattening & $2.0(1.4)$ & $2.6(1.2)$ & .028 \\
Alogia & $1.7(1.4)$ & $2.4(1.4) \dagger$ & .006 \\
Avolition - Apathy & $3.4(1.1)$ & $3.7(0.8)$ & .036 \\
Anhedonia - Asociality & $2.9(1.2)$ & $3.2(1.0)$ & .147 \\
General Psychopathology & & & \\
Somatic concern & $2.4(1.7)$ & $2.7(1.7)$ & .314 \\
Anxiety & $3.9(1.4)$ & $3.9(1.4)$ & .801 \\
Guilt feelings & $2.7(1.7)$ & $2.3(1.6)$ & .305 \\
Tension & $2.2(1.4)$ & $2.2(1.2)$ & .950 \\
Mannerisms and posturing & $1.3(0.7)$ & $1.6(0.9)$ & .026 \\
Depression & $3.4(1.8)$ & $3.5(1.7)$ & .747 \\
Motor retardation & $1.9(1.2)$ & $2.5(1.2)$ & .008 \\
Uncooperativeness & $2.0(1.4)$ & $2.9(1.8) \dagger$ & .003 \\
Unusual thought content & $3.8(1.2)$ & $4.1(1.1)$ & .089 \\
Disorientation & $1.6(1.0)$ & $1.6(0.9)$ & .640 \\
Poor attention & $1.8(1.1)$ & $2.5(1.3) \dagger$ & .002 \\
Lack of judgement and insight & $3.9(1.7)$ & $4.4(1.6)$ & .098 \\
Disturbance of volition & $1.5(0.9)$ & $2.0(1.2)$ & .005 \\
Poor impulse control & $2.3(1.5)$ & $2.9(1.6)$ & .028 \\
Preoccupation & $1.8(1.2)$ & $2.6(1.6) \dagger$ & .001 \\
Active social avoidance & $2.1(1.5)$ & $2.8(1.7)$ & .020 \\
\hline
\end{tabular}

${ }^{a}$ Corrected p-value according Bonferroni adjustment: $\mathrm{p}<0.0125(0.05 / 4)$

${ }^{\mathrm{b}}$ Corrected $\mathrm{p}$-value according Bonferroni adjustment: $\mathrm{p}<0.003(0.05 / 16)$

$\dagger$ Significant at adjusted p-level

However, African and Afro-Caribbean immigrants presenting with a previously untreated FEP exhibited more severe negative symptoms and general psychopathology than the reference group. More specifically, this group presented significantly higher ratings for the SANS alogia subscale and the PANSS symptom items for uncooperativeness, poor attention and preoccupation. No differences in symptom expression were found for the complete group of first- and second-generation immigrants compared with the reference group. No between-group differences emerged in any demographic variables, except the Africans and Afro-Caribbeans being more likely to be referred from a hospital inpatient or emergency facility, compared with Middle Eastern patients. Our findings showing only modest differences in symptom profiles of psychotic disorder between patients from various ethnic 
backgrounds echo those of previous studies from Europe and the US reporting similarities in core symptoms across ethnic groups (Barrio et al. 2003; Hutchinson et al. 1999; Harvey et al. 1990). As such, earlier studies highlighting increased first-rank symptoms, paranoia and unusual behaviour among black ethnicities (Arnold et al. 2004; Barrio et al. 2003; Ndetei, 1988) were not supported.

It is important to address the cultural environment within which these symptoms are experienced, as well as the potential cultural differences between users and providers of health care services (Bhui et al. 2003). A higher prevalence of misdiagnosis among ethnic minority groups has been hypothesized to account for the findings of increased incidence rates among these groups (Sashidharan, 1993; Zandi et al. 2010). For instance, it has been argued that Western-trained psychiatrists may incorrectly attribute some culturally appropriate beliefs or symptoms to the presence of a schizophrenia spectrum disorder. While current diagnostic categorisations may lack cross-cultural validity (Mezzich et al. 1999), we have attempted to minimize this limitation by investigating symptom profiles instead of diagnoses. Even though the exact incidence of psychosis among Afro-Caribbean immigrants to Canada is still unknown (Seeman, 2011), an increased chance of receiving a diagnosis of psychosis among black patients was also recently reported in a Montreal sample of psychiatric hospital admissions (Jarvis et al. 2011). Nevertheless, similarities in the nature and level of positive symptoms in our study across different ethnic groups do not support the idea that the disproportionate prevalence of diagnoses of psychosis in ethnic minorities is accounted for by selective misconstruing of clinical presentations as delusions or hallucinations.

An excess prevalence of affective symptoms misdiagnosed as nonaffective psychotic disorders in ethnic minorities has also been postulated as being responsible for increased rates of psychosis among ethnic minorities (Arnold et al. 2004). However, we did not find any differences in the ratings of the "depression" item of the PANSS $(F[1,183]=0.104, p=0.747)$, despite the increased general psychopathology scores in the black ethnic minority group. We cannot exclude the potential for cultural bias in interpreting our findings, as interviewers who rated the symptoms were not blind to the ethnicity of patients.

Similarities between ethnic groups extended beyond symptomatic phenomenology as groups were also comparable in terms of primary diagnosis of nonaffective versus affective psychosis, DUP, and age at onset of psychosis. This defies the idea that ethnicity has large pathoplastic influences on psychotic illness in this sample. Increased general psychopathology among the African and Afro-Caribbean ethnic group may represent preexisting, disadvantageous socioeconomic circumstances that ethnic minorities experience, such as fewer labour market possibilities and increased unemployment rates (Reitz, 2001).

The finding that African and Afro-Caribbean patients were more often referred from the emergency hospital service, compared with Middle Eastern and North African patients, supports other reports of ethnic variations in pathways to care. A previous study showed that Afro-Canadians were more likely to be brought to hospital by ambulance or police than were Euro-Canadians (Jarvis et al. 2005), which could be related to underuse of community mental health care services among this ethnic minority group (Kirmayer et al. 
2007). An adverse initial pathway to care, such as compulsory admission to hospital, may have a harmful impact on service engagement, satisfaction with services and future delay in help seeking. These factors are generally associated with poor clinical outcome in psychotic disorders (Anderson et al. 2010). A higher rating of uncooperativeness among African and Afro-Caribbean migrants may be a marker of a more severe psychotic illness and possibly related to an increased risk of involuntary commitment; conversely, uncooperativeness may also be fostered by adverse pathways to care and poor service engagement. In addition, it may explain higher ratings of alogia in this group, which is, after all, an observation on the part of the interviewer based on the amount of spontaneous speech.

Noteworthy limitations include, foremost, the complexity and controversy of ethnic classification, as available categories may undermine salient within-group differences. Also, owing to the limited sample size, we were unable to separate first- and second-generation migrants within each ethnic group. Thus, we could not disentangle the effects of migration from that of ethnicity and the experience as a visible minority in a society. Caution is warranted in the interpretation of the differences found in the African and Afro-Caribbean group, because this group represented the largest sample and, hence, had the most statistical power. The reverse could further explain why Central and South American patients did not differ on any symptom domains, which would be an interesting hypothesis for future investigation, with larger numbers of patients in each ethnic minority group. Also, no ethnicity-by-sex analysis was conducted because of the small sample size, which in previous research revealed higher first-rank symptoms among African-American men, specifically, compared with African-American women and Euro-American men (Arnold et al. 2004).

Our study was exploratory, and its generalisablity is largely limited by the specific sociopolitical context. We also need to address that there were no comparison groups from the place of origin of the different ethnic groups; for instance, it may be possible to address the influence of migration or an ethnic minority status in a society on symptom expression only by comparing the clinical presentation of Afro-Caribbeans in the Caribbean to those of Afro-Caribbeans in Canada. Further, it must also be acknowledged that symptoms were assessed following a mean of 2.9 weeks of antipsychotic medication and that this may conceal real differences at the time of the initial presentation for first treatment contact.

\section{Conclusions}

We examined symptom profiles of patients with psychosis from various ethnic origins in Montreal, Quebec. The results showed that native-born, Euro-Canadian patients with a FEP had a comparable age at onset and experienced similar levels of positive symptoms, compared with patients from various ethnic groups in Montreal. These similarities do not lend support for the hypothesis postulating that an increased prevalence of misdiagnosis among ethnic minorities accounts for the excess risk of psychosis observed in many migrant and ethnic minority groups (Cantor-Graae \& Selten, 2005; Bourque et al. 2011). The Afro-Caribbean and African patient group presented with increased severity of negative symptoms and general psychopathology, which calls for special attention towards treating these symptoms in the initial phase of psychosis. More extensive studies with larger sample sizes are needed 
to examine ethnic differences in pathways to care and clinical presentation. Conducting such studies among migrant and ethnic minority groups in a diversity of host society contexts may advance our understanding of the potential role of social factors in the development and persistence of psychotic symptoms, and their impact on service delivery.

\section{Acknowledgements}

The authors acknowledge the assistance of all the research staff and clinicians at the Prevention and Early Intervention Program for Psychosis, Montreal. We thank Veronique Pagé for giving advice on statistical analyses. This study was part of a larger study of FEP funded by a grant from the Canadian Institutions of Health Research (grant number 79505) to Dr Malla, who is also funded by the Canada Research Chairs program.

\section{References}

1. American Psychiatric Association (2003). Diagnostic and statistical manual of mental disorders: DSM-IV-TR. Washinton DC: American Psychiatric Association.

2. Anderson, K.K., Fuhrer, R., Malla A.K. (2010). The pathways to mental health care of first-episode psychosis patients: a systematic review. Psychol Med 40, 1585-1597.

3. Andreasen, N. C., Carpenter, W. T. (1993). Diagnosis and classification of schizophrenia. Schizophr Bull 19, 199-214.

4. Andreasen, N. C. (1984). The Scale for the Assessment of Positive Symptoms (SAPS). Iowa City: University of Iowa.

5. Andreasen, N. C. (1983). The Scale for the Assessment of Negative Symtpoms (SANS). Iowa City: University of Iowa.

6. Archie, S., Akhtar-Danesh, N., Norman, R., Malla, A., Roy, P., Zipursky, R. B. (2010). Ethnic diversity and pathways to care for a first episode of psychosis in Ontario. Schizophr Bull 36, 688-701.

7. Arnold, L. M., Keck, P. E., Collins, J., Wilson, R., Fleck, D. E., Corey, K. B., Amicone, J., Adebimpe, V. R., Strakowski, S. M. (2004). Ethnicity and first-rank symptoms in patients with psychosis. Schizophr Res 67, 207-212.

8. Barrio, C., Yamada, A. M., Atuel, H., Hough, R. L., Yee, S., Berthot, B., Russo, P. A. (2003). A tri-ethnic examination of symptom expression on the positive and negative syndrome scale in schizophrenia spectrum disorders. Schizophr Res 60, 259269.
9. Bhopal, R. (2004). Glossary of terms relating to ethnicity and race: for reflection and debate. J Epidemiol Community Health 58, 441-445.

10. Bhugra, D., Jones, P. (2001). Migration and mental illness. Adv Psychiatr Treat 7, 216222.

11. Bhugra, D. (2004). Migration and mental health. Acta Psychiatr Scand 109, 243-258.

12. Bhui, K., Stansfeld, S., Hull, S., Priebe, S., Mole, F., Feder, G. (2003). Ethnic variations in pathways to and use of specialist mental health services in the UK. Systematic review. Br J Psychiatry 182, 105-116.

13. Bourque, F., van der Ven, E., Malla A. (2011) A meta-analysis of the risk for psychotic disorders among first- and second-generation immigrants. Psychol Med 41, 897-910.

14. Brekke, J. S., Barrio, C. (1997). Cross-ethnic symptom differences in schizophrenia: the influence of culture and minority status. Schizophr Bull 23, 305-316.

15. Burnett, R., Mallett, R., Bhugra, D., Hutchinson, G., Der, G., Leff, J. (1999). The first contact of patients with schizophrenia with psychiatric services: social factors and pathways to care in a multi-ethnic population. Psychol Med 29, 475-483.

16. Cantor-Graae, E., Pedersen, C. B., McNeil, T. F., Mortensen, P. B. (2003). Migration as a risk factor for schizophrenia: a Danish population-based cohort study. $\mathrm{Br}$ J Psychiatry 182, 117-122.

17. Cantor-Graae, E., Selten, J. P. (2005). Schizophrenia and migration: a meta- 
analysis and review. Am J Psychiatry 162, 12-24.

18. Coelho, V. L., Strauss, M. E., Jenkins, J. H. (1998). Expression of symptomatic distress by Puerto Rican and Euro-American patients with depression and schizophrenia. J Nerv Ment Dis 186, 477-483.

19. Coid, J. W., Kirkbride, J. B., Barker, D., Cowden, F., Stamps, R., Yang, M., Jones, P. B. (2008). Raised incidence rates of all psychoses among migrant groups: findings from the East London first episode psychosis study. Arch Gen Psychiatry 65, 1250-1258.

20. Demjaha, K., Morgan K, Morgan C, Dazzan, P., Landau, S., Dean, K. (2006). Symptom dimensions and ethnicity in the AESOP first onset psychosis study. Schizophr Res 81, 233 233.

21. Fearon, P., Kirkbride, J. B., Morgan, C., Dazzan, P., Morgan, K., Lloyd, T., Hutchinson, G., Tarrant, J., Fung, W. L., Holloway, J., Mallett, R. (2006). Incidence of schizophrenia and other psychoses in ethnic minority groups: results from the MRC AESOP Study. Psychol Med 36, 1541-1550.

22. First, M. B., Spitzer, R. L., Gibbon, M., Williams, J. B. (1995). Structured clinical interview of DSM-IV axis I disorders. New York: Biometrics Research Department, New York State Psychiatric Institute.

23. Häfner, H., Riecher-Rössler, A., Hambrecht, M., Maurer, K., Meissner, S., Schmidtke, A., Fätkenheuer, B., Löffler, W., van der Heiden, W. (1992). IRAOS: an instrument for the assessment of onset and early course of schizophrenia. Schizophr Res 6, 209-223.

24. Harrison, G., Holton, A., Neilson, D., Owens, D., Boot, D., Cooper, J. (1989). Severe mental disorder in Afro-Caribbean patients: some social, demographic and service factors. Psychol Med 19, 683-696.

25. Hutchinson, G., Takei, N., Sham, P., Harvey, I., Murray, R. M. (1999). Factor analysis of symptoms in schizophrenia: differences between White and Caribbean patients in Camberwell. Psychol Med 29, 607-612.

26. Harvey, I., Williams, M., McGuffin, P., Toone, B. K. (1990). The functional psychoses in Afro-Caribbeans. Br J Psychiatry 157, 515 522.

27. Jarvis, G. E., Toniolo, I., Ryder, A. G., Sessa, F., Cremonese, C. (2011). High rates of psychosis for black inpatients in Padua and Montreal: different contexts, similar findings. Soc Psychiatry Psychiatr Epidemiol 46, 247-253.

28. Jarvis, G. E., Kirmayer, L. J., Jarvis, G. K., Whitley, R. (2005). The role of AfroCanadian status in police or ambulance referral to emergency psychiatric services. Psychiatr Serv 56, 705-710.

29. Kay, S. R., Fiszbein, A., Opler, L. A. (1987). The positive and negative syndrome scale (PANSS) for schizophrenia. Schizophr Bull 13, 261-276.

30. Kirkwood, B., Sterne, J. (2003). Medical Statistics. Malden, MA: Blackwell Science.

31. Kirmayer, L. J., Weinfeld, M., Burgos, G., du Fort, G. G. (2007). Use of health care service for psychological distress by immigrants in an urban multicutural milieu. Can J Psychiatry 52, 295-304.

32. Littlewood R, Lipsedge M. (1981). Some social and phenomenological characteristics of psychotic immigrants. Psychol Med 11, 289-302.

33. Marshall, M., Lewis, S., Lockwood, A., Drake, R., Jones, P., Croudace, T. (2005). Association between duration of untreated psychosis and outcome in cohorts of firstepisode patients: a systematic review. Arch Gen Psychiatry 62, 975-983.

34. McGorry, P., Johanessen, J. O., Lewis, S., Birchwood, M., Malla, A., Nordentoft, M., Addington, J., Yung, A. (2010). Early intervention in psychosis: keeping faith with evidence-based health care. Psychol Med 40, 399-404.

35. Mezzich, J. E., Kirmayer, L. J., Kleinman, A., Fabrega, H., Parron, D. L., Good, B. J., Lin, K. M., Manson, S. M. (1999). The place of culture in DSM-IV. J Nerv Ment Dis 187, 457-464.

36. Morgan, C., Mallett, R., Hutchinson, G., Bagalkote, H., Morgan, K., Fearon, P., Dazzan, P., Boydell, J., McKenzie, K., Harrison, G., Murray, R. (2005a). Pathways to care and ethnicity. 1: Sample characteristics and compulsory admission. Report from the AESOP study. Br J Psychiatry 186, 281-289.

37. Morgan, C., Mallett, R., Hutchinson, G., Bagalkote, H., Morgan, K., Fearon, P., Dazzan, P., Boydell, J., McKenzie, K., Harrison, G., Murray, R. (2005b). Pathways to care and ethnicity. 2: Source of referral and 
help-seeking. Report from the AESOP study. Br J Psychiatry 186, 290-296.

38. Morgan, C., Charalambides, M., Hutchinson, G., Murray, R. M. (2010). Migration, ethnicity, and psychosis: toward a sociodevelopmental model. Schizophr Bull $36,655-664$.

39. Morgan, C., Mallett, R., Hutchinson, G., Leff, J. (2004). Negative pathways to psychiatric care and ethnicity: the bridge between social science and psychiatry. Soc Sci Med 58, 739-752.

40. Ndetei, D. M. (1988). Psychiatric phenomenology across countries: constitutional, cultural, or environmental? Acta Psychiatr Scand Suppl 344, 33-44.

41. Reitz, J. G. (2001). Immigrant Success in the Knowledge Economy: Institutional Change and the Immigrant Experience in Canada, 1970-1995. J Soc Issues 57, 579-613.

42. Sashidharan, S, P. (1993). Afro-Caribbeans and Schizophrenia: The Ethnic Vulnerability Hypothesis Re-Examined. Int Rev Psychiatry 5, 129-144.

43. Seeman, M. V. (2011). Canada: psychosis in the immigrant Caribbean population. Int $\mathrm{J}$ Soc Psychiatry 57, 462-470.

44. SPSS for Windows, Rel. 18.0.0. (2009). Chicago, SPSS Inc.

45. Statistics Canada (2011). Migration. Available from: http://www.statcan.gc.ca/ daily-quotidien/100929/dq100929f-eng.htm.

46. Statistics Canada (2007). Immigration in Canada: a portrait of the foreign-born population, 2006 Census. Available from: http://www.statcan.gc.ca/bsolc/olc-cel/olccel?catno=97-557-xwe2006001\&lang=eng.

47. Strakowski, S. M., Flaum, M., Amador, X., Bracha, H. S., Pandurangi, A. K., Robinson,
D., Tohen, M. (1996). Racial differences in the diagnosis of psychosis. Schizophr Res 21, $117-124$.

48. Vega, W. A., Lewis-Fernandez, R. (2008). Ethnicity and variability of psychotic symptoms. Curr Psychiatry Rep 10, 223-228.

49. Veling, W., Selten, J. P., Mackenbach, J. P., Hoek, H. W. (2007). Symptoms at first contact for psychotic disorder: comparison between native Dutch and ethnic minorities. Schizophr Res 95, 30-38.

50. Veling, W., Selten, J. P., Veen, N., Laan, W., Blom, J. D., Hoek, H. W. (2006). Incidence of schizophrenia among ethnic minorities in the Netherlands: a four-year first-contact study. Schizophr Res 86, 189-193.

51. Weiser, M., Werbeloff, N., Vishna, T., Yoffe, R., Lubin, G., Shmushkevitch, M., Davidson, M. (2008). Elaboration on immigration and risk for schizophrenia. Psychol Med 38, 11131119.

52. Weisman, A. G., López, S. R., Ventura, J., Nuechterlein, K. H., Goldstein, M. J., Hwang, S. (2000). A comparison of psychiatric symptoms between AngloAmericans and Mexican-Americans with schizophrenia. Schizophr Bull 26, 817-824.

53. Widiger, T. A., Samuel, D. B. (2005). Diagnostic categories or dimensions? A question for the Diagnostic And Statistical Manual Of Mental Disorders - fifth edition. J Abnorm Psychol 114, 494-504.

54. Zandi, T., Havenaar, J. M., Smits, M., Limburg-Okken, A. G., Van Es, H., Cahn, W., Algra, A., Kahn, R. S., van den Brink, W. (2010). First contact incidence of psychotic disorders among native Dutch and Moroccan immigrants in the Netherlands: influence of diagnostic bias. Schizophr Res 119, 27-33.

6 



\section{chapter SEVEN}

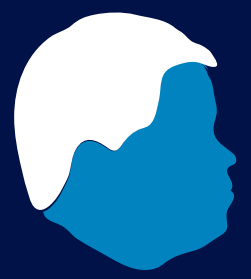

Testing Ødegaard's selective migration hypothesis: a longitudinal cohort study of risk factors for non-affective psychotic disorders among prospective emigrants

E. van der Ven,

C. Dalman,

S. Wicks,

P. Allebeck,

C. Magnusson,

J. van Os,

J.P. Selten 


\begin{abstract}
Background

The selection hypothesis posits that the increased rates of psychosis observed among migrants are due to selective migration of people who are predisposed to develop the disorder. To test this hypothesis, we examined whether risk factors for psychosis are more prevalent among future emigrants.
\end{abstract}

\title{
Methods
}

A cohort of 49321 Swedish military conscripts was assessed at age 18 on cannabis use, IQ, psychiatric diagnosis, social adjustment, history of trauma and urbanicity of place of upbringing. Through data linkage we examined whether these exposures predicted emigration out of Sweden. We also calculated the emigrants' hypothetical relative risk compared with non-emigrants for developing a non-affective psychotic disorder.

\section{Results}

Low IQ (odds ratio (OR) 0.5, 95\% confidence interval (95\% CI) 0.3-0.9) and 'poor social adjustment' (OR $0.4,95 \%$ CI $0.2-0.8$ ) were significantly less prevalent among prospective emigrants, whereas a history of urban upbringing (OR 2.3; 95\% CI 1.4-3.7) was significantly more common. Apart from a non-significant increase in cannabis use among emigrants (OR 1.6, 95\% CI 0.8-3.1), there were no major group differences in any other risk factors. Compared to non-emigrants, hypothetical relative risks for developing non-affective psychotic disorder were 0.7 (95\% CI 0.4-1.2) and 0.8 (95\% CI 0.7-1.0), respectively, for emigrants narrowly and broadly defined.

\section{Conclusions}

This study adds to an increasing body of evidence opposing the selection hypothesis. 


\section{Introduction}

The consistent observation of an increased incidence of non-affective psychotic disorder (NAPD) among immigrants (Bourque et al. 2011; Cantor-Graae \& Selten, 2005) has been attributed to the stress of adaptation to a new environment precipitating the disorder in those who are genetically at risk (van Os et al. 2010). Ødegaard proposed an alternative explanation (1932) based on his findings of an increased risk for schizophrenia among Norwegian-born immigrants in Minnesota. He suggested that this phenomenon was caused by negative selection, i.e. their disturbed personalities prevented them from efficiently integrating in their native country and encouraged them to emigrate.

However, Rosenthal and colleagues (1974) showed that adoptees born to a biological parent with a schizophrenia spectrum disorder were less likely to emigrate than adoptees without such a genetic predisposition. Using data from Danish national registries, Pedersen and coworkers (2011) found that a parental history of bipolar disorder (BD) was positively associated with a risk of future emigration from Denmark, whereas a parental history of schizophrenia or a personal history of mental illness was not. They further reported an association between emigration and the degree of urbanization of the place of birth, but this did not apply to Danes aged 17 to 26, the most relevant group for the selection hypothesis.

Another study demonstrated that the increased rates of schizophrenia among Surinamese immigrants in the Netherlands could not solely be explained by selective migration, considering that their relative risk remained increased compared to native Dutch presuming that the entire Surinamese population had emigrated, while in fact only one third did (Selten et al. 2002). Furthermore, a study in Uganda showed that aspirations regarding emigration, not active planning to emigrate, were associated with increased delusional ideation (Lundberg et al. 2007).

None of the above studies included information on an array of important factors associated with increased risk for NAPD, such as impaired social adjustment, low intellectual ability or cannabis use. We tested the hypothesis of selective migration by examining whether previously identified risk factors for psychotic disorders are more prevalent among Swedish men who emigrate later in life. Previous studies have found two-fold increased risks for schizophrenia in Swedish immigrants in New York State (Malzberg, 1962) and in Scandinavian migrants, including Swedes, in Denmark (Cantor-Graae et al. 2003).

Since emigrants are lost to follow-up, we also estimated their hypothetical relative risk for developing NAPD after emigration.

\section{Method}

\section{Subjects}

The study population consisted of 49321 Swedish males conscripted nationwide during one year 1969-1970 for compulsory military training. Over $98 \%$ of the cohort was between 18 and 20 years old. Two to three percent of the men were excused conscription owing to a severe physical or mental handicap. During this conscription year the conscripts filled out questionnaires on socio-demographic background, upbringing, school and work 
adjustment, psychiatric history, and on the use of alcohol, tobacco and drugs. Trained psychologists conducted structured interviews with all conscripts, and referred those suspected of a psychiatric disorder to a psychiatrist for diagnostic evaluation. Psychiatric diagnoses were coded according to the Nordic version of the International Classification of Diseases 8 (ICD-8) (World Health Organization, 1967). Thirty-two (0.1\%) subjects with a diagnosis of a psychotic disorder at conscription and 677 (1.4\%) foreign-born subjects were excluded from this study. Permission to perform the study was granted by the Stockholm Regional Ethical Review Board and the Swedish Data Inspection Board.

\section{Exposures}

First, we selected six exposures that have been reported to increase the risk for NAPD among members of this cohort: low IQ (David et al. 1997); 'poor social adjustment' (Malmberg et al. 1998); 'disturbed behavior' (Zammit et al. 2010); cannabis use (Andreasson et al. 1987; Zammit et al. 2002); non-psychotic psychiatric diagnosis at conscription (Lewis et al. 2000); and urban upbringing (Lewis et al. 1992). Secondly, since exposure to a trauma may be a cause of both emigration and psychotic symptomatology (Bhui et al. 2003), we added parental death and history of physical abuse to the list of exposures. We included parental history of a NAPD as well as BD as proxies of genetic liability, because of the partially shared genetic etiology of these disorders (Lichtenstein et al. 2009) and for comparability with results presented by Pedersen and colleagues (2011).

IQ was measured using verbal, visuo-spatial, general knowledge and mechanical reasoning tests. Total sum scores were set off against the scores of a conscript cohort of the previous year and standardized into a normal distribution with 9 bands $(<74,75-81,82-89$, 90-95, 96-104, 105-110, 111-118, 119-126, >126). 'Social adjustment' was measured using four Likert-type questions inquiring about friendships, presence of a steady girlfriend and sensitivity to others. There were four or five possible answers to each question. For example, answers to the question "do you think you are more sensitive than other people?" included "yes, much more", "yes, somewhat more", "about average", "no, somewhat less" or "no, much less". The first two answers were considered as presence of symptom, i.e. "more sensitive than other people" (Malmberg et al. 1998). A composite score of 'social adjustment' was calculated as the sum of the quantified variables (range 0-11). 'Disturbed behaviour' was measured using items on running away from home, misconduct at school, truancy and contact with police or social services. The selection of these items was based on a previously conducted factor analysis (Zammit et al. 2010). A composite score of 'disturbed behaviour' was similarly derived from the sum of the variables (range 0-9).

Information on cannabis use was based on replies to questions about the most commonly used drug and the frequency of use, recorded as: once, 2-4 times, 5-10 times, 11-50 times or $>50$ times. The psychiatric diagnoses recorded at conscription, which included personality and psychosomatic disorder, neurosis, alcohol and substance misuse, were subsumed under the heading of non-psychotic psychiatric disorder at conscription. Replies to the question "where did you live mostly while you were growing up?" were used to define the level of urbanicity of the place of upbringing. Possible responses included "Greater Stockholm, 
Göteborg, Malmö", "another town with more than 50.000 inhabitants", "another town with less than 50.000 inhabitants", "in the country" and "abroad" (Lewis et al. 1992). Childhood trauma was considered present in case of death of a parent before conscription or if the conscript reported physical abuse to have occurred sometimes or often. Links to the parents were obtained via the Multigenerational Register (Statistics Sweden, 2010) and information on the presence of a parental history of NAPD or BD was retrieved from the Swedish National Patient Register (Ludvigsson et al. 2011).

This register stores information on virtually all psychiatric admissions between 1973 and 2007. Diagnoses were coded according to the Swedish version of ICD: ICD-8 between 1973 and 1986, ICD-9 between 1987 and 1996, and ICD-10 between 1997 and 2007. NAPD was defined as schizophrenia or other non-affective psychoses (ICD-8: 295, 297, 298.20-298.99; ICD-9: 295, 297 and 298C-298X; ICD-10:F20-F29). Parental family history was classified as presence of schizophrenia or other non-affective psychoses (NAPD as described above) or bipolar disorders (ICD-8: 296.10-296.30; ICD-9: 296A, 296C-296E; ICD-10: F30-F31). Diagnoses of schizophrenia (Dalman et al. 2002; Ekholm et al. 2005; Kristjansson et al. 1987) and bipolar disorder (Sellgren et al. 2011) in the national patient register have shown to be of satisfactory validity for epidemiological studies.

\section{Outcome}

The main outcome was emigration. Statistics Sweden stores data on emigration and immigration from 1968. We had access to dates of emigration and immigration for each individual until the end of 2003 (Statistics Sweden, 2006). Emigration was a priori defined in two ways. The narrow definition included subjects who left the country after conscription and lived abroad for a period of at least two years before the age of 25. Since some men develop NAPD at a later age, we also included a broad definition referring to all individuals who lived abroad for at least 2 years during the period between conscription and the age of 40. Information about loss to follow-up due to death was obtained via the Cause of Death Register.

\section{Statistical methods}

We first calculated odds ratios (ORs) and their $95 \%$ confidence intervals (CIs) to measure the association between each exposure and future emigration. For ordinal exposures with more than two levels (IQ, urbanicity of place of upbringing and cannabis use) we examined doseresponse relationships by calculating chi-square statistics for linear-by-linear associations and corresponding $p$ values for trend. We conducted multivariate logistic regression to test whether variables were independently related to later emigration at 5\% significance level. Given the large number of exposures and the skewed distribution of ordinal data, we dichotomized exposures for the purpose of multivariate logistic regression analyses, adopting the same cut-off scores as used in previous studies (Zammit et al. 2010). Low IQ was defined as the lowest $33 \%$ of scores versus the rest, cannabis use as ever versus never used cannabis, urban upbringing as growing up in any of the three largest cities versus the rest of the country, 'poor social adjustment' as the lowest 30\% of scores and 'disturbed behaviour' as the highest $20 \%$ of scores on the composite variable (Zammit et al. 2010). 


\section{Hypothetical risk model}

In order to estimate the hypothetical relative risk for NAPD among emigrants, it is necessary to calculate the strength of the association between each exposure and the secondary outcome, i.e. risk of NAPD in non-emigrants. Presence of NAPD among conscripts was retrieved from the Swedish National Patient Register as described earlier. Using a multivariable logistic regression model we calculated the predictive value (beta) of each variable with the maximum likelihood method for developing NAPD. The final set of risk factors was selected based on backward elimination ( $\mathrm{P}<.05$ to retain) and verified using forward selection $(\mathrm{P}<.05$ to enter). Next, we composed a regression formula for emigrants and non-emigrants. According to this formula the beta weights are multiplied with the mean group prevalence of each exposure and the products added. To calculate a hypothetical relative risk (RR) for developing the disease among emigrants, the mean outcome $(\mathrm{Y})$ was transformed from the logit scale by using the formula: $\mathrm{p}=\mathrm{e}^{\mathrm{Y}} /\left(1+\mathrm{e}^{\mathrm{Y}}\right)$ and divided by the risk estimate $(\mathrm{p})$ for non-emigrants, i.e. the reference group. Confidence intervals were calculated based on the sample sizes in each group. All analyses were performed in SPSS version 20 (SPSS Inc., USA).

\section{Results}

\section{Cohort description}

Sixty-nine (0.1\%) of 48612 individuals emigrated before the age of 25 and stayed abroad for at least two years (narrow definition of emigration). Four hundred seventy-two individuals (1.0\%) emigrated before their $40^{\text {th }}$ birthday and did not return within the next two years (broad definition). In total, 1998 individuals (4.1\%) were lost to follow-up due to death.

\section{Risk factors for emigration}

The frequencies of each exposure and the corresponding odds ratios for emigration are presented in Table 1. IQ was negatively associated with emigration, whether narrowly or broadly defined. When categorized in three IQ bands for the narrow definition and in nine IQ bands for the broad definition, significant linear trends emerged between IQ and emigration $\left(\chi^{2}=11.043 ; \mathrm{p}<0.01\right.$ and $\chi^{2}=155.4 ; \mathrm{p}<0.001$, respectively). In addition, 'poor social adjustment' was less prevalent in the group of narrowly-defined emigrants $(\mathrm{OR}=0.4 ; 95 \% \mathrm{CI} 0.2-0.8)$, but not in the broadly defined group. There were no significant group differences on any of the individual social adjustment variables or in frequencies of reported 'disturbed behavior'. The prevalence of non-psychotic psychiatric disorder at the time of conscription was also similar in both groups. In contrast, emigrants were more likely to have been brought up in a city ( $\mathrm{OR}=2.3$; 95\% CI 1.4-3.7) with an increasing odds contingent on an increasing level of urbanicity of the main residence during upbringing $\left(\chi^{2}=13.9 ; \mathrm{p}\right.$-value $\left.<0.001\right)$. This association held when using the broad definition of emigration. Cannabis use was significantly increased among individuals emigrating before age 40 , but not among those emigrating before 25 , with a significant $\mathrm{p}$-value for linear trend (chi-square $=7.7$; $\mathrm{p}$-value $<0.01$ ). There were no significant group differences in the occurrence of parental death or physical abuse. Conscripts that emigrated were not 
Table 1. Prevalence of risk factors for non-affective psychotic disorder (NAPD) according to emigrant status, narrow and broad definition, corresponding crude odds ratios (ORs) and their 95\% confidence intervals $(95 \% \mathrm{CI})$.

\begin{tabular}{|c|c|c|c|c|c|}
\hline Exposure & $\begin{array}{l}\text { Non- } \\
\text { emigrant, } \\
\mathrm{N}\end{array}$ & $\begin{array}{l}\begin{array}{l}\text { Emigrant } \\
\text { (narrow }\end{array} \\
\text { definition), } \\
\mathrm{N}\end{array}$ & $\begin{array}{l}\text { Odds ratio } \\
\text { narrow } \\
\text { definition, } \\
\text { OR }(95 \% \mathrm{CI})\end{array}$ & $\begin{array}{l}\text { Emigrant } \\
\text { (broad } \\
\text { definition), } \\
\mathrm{N}\end{array}$ & $\begin{array}{l}\text { Odds ratio } \\
\text { broad } \\
\text { definition, } \\
\text { OR }(95 \% \mathrm{CI})\end{array}$ \\
\hline \multicolumn{6}{|l|}{ Lower IQ } \\
\hline Absent & 32275 & 56 & 1 (ref) & 397 & 1 (ref) \\
\hline Present & 16208 & 13 & $0.5(0.3-0.9)$ & 74 & $0.4(0.3-0.5)$ \\
\hline$>126$ & 3154 & $32^{\mathrm{a}}$ & 1 (ref) & 78 & 1 (ref) \\
\hline $119-126$ & 4977 & & & 99 & $0.8(0.6-0.7)$ \\
\hline $111-118$ & 7216 & & & 98 & $0.5(0.4-0.7)$ \\
\hline $105-110$ & 8578 & $24^{\mathrm{a}}$ & $0.7(0.4-1.2)$ & 61 & $0.3(0.2-0.4)$ \\
\hline $96-104$ & 8351 & & & 61 & $0.3(0.2-0.4)$ \\
\hline $90-95$ & 6914 & & & 38 & $0.2(0.1-0.3)$ \\
\hline $82-89$ & 4754 & $13^{\mathrm{a}}$ & $0.4(0.2-0.7)$ & 19 & $0.2(0.1-0.3)$ \\
\hline $75-81$ & 2591 & & & 14 & $0.3(0.2-0.5)$ \\
\hline$<74$ & 1935 & & & 3 & $0.1(0.0-0.4)$ \\
\hline \multicolumn{6}{|l|}{ Poor social adjustment } \\
\hline Absent & 34261 & 58 & 1 (ref) & 334 & 1 (ref) \\
\hline Present $^{\mathrm{b}}$ & 12846 & 8 & $0.4(0.2-0.8)$ & 121 & $1.0(0.8-1.2)$ \\
\hline Fewer than three close friends $s^{\mathrm{b}}$ & 3645 & 3 & $0.6(0.2-1.8)$ & 36 & $1.0(0.7-1.5)$ \\
\hline More sensitive than others ${ }^{b}$ & 6252 & 12 & $1.4(0.8-2.6)$ & 73 & $1.2(1.0-1.6)$ \\
\hline No steady girlfriend ${ }^{\mathrm{b}}$ & 27426 & 34 & $0.8(0.5-1.2)$ & 263 & $1.0(0.7-1.5)$ \\
\hline Prefers small groups ${ }^{\mathrm{b}}$ & 21841 & 32 & $1.1(0.7-1.8)$ & 216 & $1.1(0.9-1.3)$ \\
\hline \multicolumn{6}{|l|}{ Disturbed behaviour } \\
\hline Absent & 37612 & 54 & 1 (ref) & 358 & 1 (ref) \\
\hline Present & 8254 & 11 & $0.9(0.5-1.8)$ & 87 & $1.1(0.9-1.4)$ \\
\hline Ever ran away from home & 1633 & 5 & $2.3(0.9-5.7)$ & 20 & $1.3(0.8-2.0)$ \\
\hline Contact with police or social service & 13706 & 12 & $0.5(0.3-1.0)$ & 114 & $0.8(0.7-1.0)$ \\
\hline Misconduct at school & 11589 & 16 & $0.9(0.5-1.7)$ & 131 & $1.2(1.0-1.5)$ \\
\hline Truanted more than once/term & 20417 & 31 & $1.1(0.7-1.7)$ & 204 & $1.0(0.9-1.3)$ \\
\hline
\end{tabular}

Non-psychotic psychiatric disorder at conscription

$\begin{array}{llllll}\text { Absent } & 42445 & 60 & 1(\mathrm{ref}) & 419 & 1 \text { (ref) } \\ \text { Present (any disorder) } & 5230 & 7 & 0.9(0.4-2.1) & 42 & 0.8(0.6-1.1) \\ \text { Neurosis } & 2594 & & & 22 & 0.9(0.6-1.3) \\ \text { Personality disorder } & 1324 & & 6 & 0.5(0.2-1.1) \\ \text { Alcohol misuse } & 134 & & 1 & 0.7(0.1-5.4) \\ \text { Substance misuse } & 277 & & 5 & 1.8(0.8-4.5)\end{array}$


Table 1. Prevalence of risk factors for non-affective psychotic disorder (NAPD) according to emigrant status, narrow and broad definition, corresponding crude odds ratios (ORs) and their 95\% confidence intervals (95\% CI). (Continued)

\begin{tabular}{|c|c|c|c|c|c|}
\hline Exposure & $\begin{array}{l}\text { Non- } \\
\text { emigrant, } \\
\mathrm{N}\end{array}$ & $\begin{array}{l}\text { Emigrant } \\
\text { (narrow } \\
\text { definition), } \\
\mathrm{N}\end{array}$ & $\begin{array}{l}\text { Odds ratio } \\
\text { narrow } \\
\text { definition, } \\
\text { OR }(95 \% \mathrm{CI})\end{array}$ & $\begin{array}{l}\text { Emigrant } \\
\text { (broad } \\
\text { definition), } \\
\mathrm{N}\end{array}$ & $\begin{array}{l}\text { Odds ratio } \\
\text { broad } \\
\text { definition, } \\
\text { OR }(95 \% \mathrm{CI})\end{array}$ \\
\hline Psychosomatic disorder & 400 & & & 5 & $1.3(0.5-3.1)$ \\
\hline Other psychiatric disorder & 501 & & & 3 & $0.6(0.2-1.9)$ \\
\hline \multicolumn{6}{|l|}{ Cannabis use } \\
\hline Absent & 40065 & 53 & 1 (ref) & 374 & 1 (ref) \\
\hline Present (any use) & 5210 & 11 & $1.6(0.8-3.1)$ & 71 & $1.5(1.1-1.9)$ \\
\hline Once & 588 & & & 7 & $1.3(0.6-2.9)$ \\
\hline 2-4 times & 1359 & & & 15 & $1.2(0.7-2.1)$ \\
\hline 5-10 times & 793 & & & 13 & $1.9(1.1-3.3)$ \\
\hline 11-50 times & 672 & & & 8 & $1.4(0.7-2.7)$ \\
\hline$>50$ times & 722 & & & 11 & $1.7(0.9-3.2)$ \\
\hline \multicolumn{6}{|l|}{ Urban upbringing } \\
\hline Absent & 37480 & 41 & 1 (ref) & 301 & 1 (ref) \\
\hline Present & 10102 & 25 & $2.3(1.4-3.7)$ & 151 & $1.9(1.5-2.3)$ \\
\hline Countryside & 18535 & 14 & 1 (ref) & 111 & 1 (ref) \\
\hline$<50.000 \mathrm{inh}$ & 14120 & 20 & $1.9(0.9-3.7)$ & 138 & $1.6(1.3-2.1)$ \\
\hline$>50.000 \mathrm{inh}$ & 4825 & 7 & $1.9(0.8-4.8)$ & 52 & $1.8(1.3-2.5)$ \\
\hline Cities & 10102 & 25 & $3.3(1.7-6.3)$ & 151 & $2.5(2.0-3.2)$ \\
\hline Abroad & 109 & 1 & $12.1(1.6-93.2)$ & 6 & $9.6(4.1-22.3)$ \\
\hline \multicolumn{6}{|c|}{ Indicators of childhood trauma } \\
\hline Absent & 33871 & 53 & 1 (ref) & 373 & 1 (ref) \\
\hline Present & 8920 & 14 & $1.0(0.6-1.8)$ & 87 & $1.0(0.8-1.3)$ \\
\hline Loss of a parent & 3682 & 5 & $1.0(0.4-2.4)$ & 33 & $0.9(0.6-1.3)$ \\
\hline Physical abuse & 5715 & 10 & $1.3(0.7-2.5)$ & 57 & $1.0(0.8-1.4)$ \\
\hline \multicolumn{6}{|c|}{ Parental history of NAPD or BD } \\
\hline Absent & 44228 & 57 & 1 (ref) & 433 & 1 (ref) \\
\hline Present & 1931 & 4 & $1.6(0.6-4.4)$ & 18 & $1.0(0.6-1.9)$ \\
\hline Parental history of NAPD & 1324 & 3 & $1.8(0.5-5.6)$ & 14 & $1.1(0.6-1.9)$ \\
\hline Parental history of $\mathrm{BD}$ & 733 & 2 & $2.1(0.5-8.6)$ & 6 & $0.8(0.4-1.9)$ \\
\hline
\end{tabular}

Ref=reference, NAPD=non-affective psychotic disorder, $\mathrm{BD}=$ bipolar disorder;

${ }^{a}$ Due to small sample size in the group of narrowly-defined emigrants IQ was collapsed into 3 bands: $<90$, 90-110, >110.

${ }^{b}$ Discrepant results between the composite score of social adjustment and individual items are due to differences in the definitions (see Method section). 
significantly more likely to have been born to a parent with a NAPD or BD. Multivariate analysis (see Table 2) revealed that lower IQ was the strongest negative predictor for future emigration, broadly $(\mathrm{p}<0.001)$ or narrowly $(\mathrm{p}<0.05)$ defined.

\section{Hypothetical risk for developing NAPD}

Standardized beta weights for each exposure and the concurrent OR for NAPD are depicted in Table 2 . The final equation was $[-5.317+[0.728 \mathrm{X}$ lower IQ $]+[0.820 \mathrm{X}$ poor social adjustment $]+$ [0.872 X non-psychotic psychiatric disorder at conscription] + [0.235 X disturbed behaviour] $+[0.411 \mathrm{X}$ cannabis use $]+[0.213 \mathrm{X}$ urban upbringing $]+[0.895 \mathrm{X}$ parental history of NAPD or $\mathrm{BD}]+[0.212 \mathrm{X}$ childhood trauma $]$. Compared to non-emigrants, this regression formula yielded relative risks for developing NAPD of 0.7 (95\% CI 0.4-1.2) and 0.8 (95\% CI 0.7-1.0), respectively, for emigrants narrowly and broadly defined.

Table 2. Associations between exposures at conscription and prospective risk of treatment for non-affective psychotic disorder, emigration out of Sweden before age 25 (narrow definition) and before age 40 (broad definition)

\begin{tabular}{|c|c|c|c|c|c|c|}
\hline \multirow[b]{3}{*}{ Exposure } & \multicolumn{6}{|c|}{ Outcomes } \\
\hline & \multicolumn{2}{|c|}{ NAPD } & \multicolumn{2}{|c|}{$\begin{array}{l}\text { Emigration } \\
\text { (narrow definition) }\end{array}$} & \multicolumn{2}{|c|}{$\begin{array}{l}\text { Emigration } \\
\text { (broad definition) }\end{array}$} \\
\hline & $\beta$ & $\begin{array}{l}\text { Adjusted OR } \\
(95 \% \mathrm{CI})^{\mathrm{a}}\end{array}$ & $\beta$ & $\begin{array}{l}\text { Adjusted OR } \\
(95 \% \mathrm{CI})^{\mathrm{a}}\end{array}$ & $\beta$ & $\begin{array}{l}\text { Adjusted OR } \\
(95 \% \mathrm{CI})^{\mathrm{a}}\end{array}$ \\
\hline Lower IQ & 0.73 & $2.1(1.7-2.5)$ & -1.09 & $0.3(0.1-0.8)$ & -0.93 & $0.4(0.3-0.5)$ \\
\hline Poor social adjustment & 0.82 & $2.3(1.9-2.7)$ & -0.93 & $0.4(0.2-0.9)$ & -0.03 & $1.0(0.8-1.2)$ \\
\hline $\begin{array}{l}\text { Non-psychotic psychiatric } \\
\text { disorder at conscription }\end{array}$ & 0.86 & $2.4(1.9-2.9)$ & -0.75 & $0.5(0.1-2.0)$ & -0.34 & $0.7(0.5-1.1)$ \\
\hline Disturbed behavior & 0.24 & $1.3(1.0-1.6)$ & -0.21 & $0.8(0.3-1.9)$ & 0.07 & $1.1(0.8-1.4)$ \\
\hline Cannabis use & 0.41 & $1.5(1.2-1.9)$ & 0.39 & $1.5(0.7-3.3)$ & 0.26 & $1.3(1.0-1.8)$ \\
\hline Urban upbringing & 0.21 & $1.2(1.0-1.5)$ & 0.64 & $1.9(1.0-3.5)$ & 0.52 & $1.7(1.3-2.1)$ \\
\hline Childhood trauma & 0.20 & $1.2(1.0-1.5)$ & 0.03 & $1.0(0.5-2.2)$ & -0.04 & $1.0(0.7-1.3)$ \\
\hline Parental history of NAPD or BD & 0.89 & $2.4(1.8-3.3)$ & 0.52 & $1.7(0.5-5.4)$ & 0.07 & $1.1(0.6-1.8)$ \\
\hline
\end{tabular}

$\mathrm{NAPD}=$ non-affective psychotic disorder, $\mathrm{BD}=$ bipolar disorder, $\mathrm{OR}=$ odds ratio, $\beta$ (bèta $)=$ standardized regression coeffcient

${ }^{\text {a }}$ Adjusted for all other exposures in the regression model

\section{Discussion}

We tested the hypothesis that risk factors for NAPD are more prevalent among young Swedish males who emigrated. The results showed that a history of urban upbringing and cannabis use were more common. Although this may lend some support for the selection hypothesis, these findings were counterbalanced by the decreased prevalence of low IQ and 'poor social adjustment'. There were no major differences in the prevalence of other studied 
risk factors. The hypothetical risks for developing NAPD did not differ significantly between emigrants and non-emigrants.

There are some limitations that need to be addressed. First, our estimation of a hypothetical risk was restrained by the assumption that exposures remain stable over time, which in case of cannabis use and social adjustment may well be untrue. Nonetheless, IQ is considered to be relatively stable over time and emerged as the strongest predictor of emigrant status. Second, the selection mechanisms for emigration out of Sweden may differ from those related to migration from countries afflicted by poverty, unemployment, or political turmoil. Moreover, emigration rates and selection mechanisms may change over time. However, attachment to people in one's country of birth is a universal phenomenon and the present study does not support the hypothesis that emigration is prompted by an inability to establish social relationships. Thirdly, it is impossible to examine all psychosis risk factors for their potential to stimulate migration and we cannot rule out that other mechanisms operate before migration. Lastly, this study relied on self-report questionnaires for most exposures, which may have introduced errors that could result in bias, if differential.

In accordance with the study by Pedersen and colleagues (2011), we found that a personal history of mental illness does not predict emigration. Conversely, their finding of a parental history of bipolar disorder as risk factor for emigration, is not supported by this study. Also contrary to their results, we observed that Swedes who had been brought up in the city were more likely to emigrate before their mid-twenties (Pedersen et al. 2011). This is not surprising given that individuals in urban areas are more likely to be internationally oriented and may encounter more possibilities to move abroad, especially those with a higher IQ and level of education.

On the whole, in keeping with previous studies (Lundberg et al. 2007; Rosenthal et al. 1974; Selten et al. 2002) our findings do not support the selection hypothesis. Rosenthal and coworkers (1974) noted that the process of emigration involves a high level of mental perseverance and planning skills. The cognitive profile required for successful emigration seems inconsistent with premorbid cognitive deficits found in some individuals developing psychosis later in life (Cannon et al. 2000). In fact, our findings of a higher IQ among emigrants and a higher level of social adjustment among those emigrating before age 25 support the notion that the process of emigrating requires favourable environmental circumstances and certain individual qualities. In particular, our results are inconsistent with Ødegaard's characterization of most emigrants as socially maladjusted “loners".

\section{Acknowledgements}

This work was supported by the European Community's Seventh Framework Program under grant agreement No. HEALTH-F2-2009-241909 (Project EU-GEI). The authors thank Sofia Löving for preparing and matching the databases. Dr. Stanley Zammit has been an invaluable help in advising on definitions and categorizations of variables in the conscript database. We also thank Dr. Nan van Geloven for providing statistical guidance. Dr. Clifford Cassidy gave very useful comments to a preliminary version of this manuscript. 


\section{References}

1. Andreasson, S., Allebeck, P., Engstrom, A., Rydberg, U. (1987). Cannabis and schizophrenia. A longitudinal study of Swedish conscripts. Lancet 2, 1483-1486.

2. Bhui, K., Abdi, A., Abdi, M., Pereira, S., Dualeh, M., Robertson, D., Sathyamoorthy, G., Ismail, H. (2003). Traumatic events, migration characteristics and psychiatric symptoms among Somali refugees-preliminary communication. Soc Psychiatry Psychiatr Epidemiol 38, 35-43.

3. Bourque, F., van, d., V, Malla, A. (2011). A meta-analysis of the risk for psychotic disorders among first- and second-generation immigrants. Psychol Med 41, 897-910.

4. Cannon, T. D., Bearden, C. E., Hollister, J. M., Rosso, I. M., Sanchez, L. E., Hadley, T. (2000). Childhood Cognitive Functioning in Schizophrenia Patients and Their Unaffected Siblings: A Prospective Cohort Study. Schizophr Bull 26, 379-393.

5. Cantor-Graae, E., Pedersen, C. B., McNeil, T. F., Mortensen, P. B. (2003). Migration as a risk factor for schizophrenia: a Danish population-based cohort study. $\mathrm{Br} \mathrm{J}$ Psychiatry 182, 117-122.

6. Cantor-Graae, E., Selten, J. P. (2005). Schizophrenia and migration: a metaanalysis and review. Am J Psychiatry 162, 12-24.

7. Dalman, C., Broms, J., Cullberg, J., Allebeck, P. (2002). Young cases of schizophrenia identified in a national inpatient register--are the diagnoses valid? Soc Psychiatry Psychiatr Epidemiol 37, 527-531.

8. David, A. S., Malmberg, A., Brandt, L., Allebeck, P., Lewis, G. (1997). IQ and risk for schizophrenia: a population-based cohort study. Psychol Med 27, 1311-1323.

9. Ekholm, B., Ekholm, A., Adolfsson, R., Vares, M., Osby, U., Sedvall, G. C., Jonsson, E. G. (2005). Evaluation of diagnostic procedures in Swedish patients with schizophrenia and related psychoses. Nordic Journal of Psychiatry 59, 457-464.

10. Kristjansson, E., Allebeck, P., Wistedt, B. (1987). Validity of the diagnosis schizophrenia in a psychiatric inpatient register: A retrospective application of DSMIII criteria on ICD-8 diagnoses in Stockholm county. Nord J Psychiatry 41, 229-234.
11. Lewis, G., David, A., Andreasson, S., Allebeck, P. (1992). Schizophrenia and city life. Lancet 340, 137-140.

12. Lewis, G., David, A. S., Malmberg, A., Allebeck, P. (2000). Non-psychotic psychiatric disorder and subsequent risk of schizophrenia. Cohort study. Br J Psychiatry 177, 416-420.

13. Lichtenstein, P., Yip, B. H., Bjork, C., Pawitan, Y., Cannon, T. D., Sullivan, P. F., Hultman, C. M. (2009). Common genetic determinants of schizophrenia and bipolar disorder in Swedish families: a populationbased study. Lancet 373, 234-239.

14. Ludvigsson, J. F., Andersson, E., Ekbom, A., Feychting, M., Kim, J. L., Reuterwall, C., Heurgren, M., Olausson, P. O. (2011). External review and validation of the Swedish national inpatient register. BMC Public Health 11, 450.

15. Lundberg, P., Cantor-Graae, E., Kahima, M., Ostergren, P. O. (2007). Delusional ideation and manic symptoms in potential future emigrants in Uganda. Psychol Med 37, 505-512.

16. Malmberg, A., Lewis, G., David, A., Allebeck, P. (1998). Premorbid adjustment and personality in people with schizophrenia. Br J Psychiatry 172, 308-313.

17. Malzberg, B. (1962). Mental disease among Swedish-born and native-born of Swedish parentage in New York State, 1949-1951. Acta Psychiatr Scand 38, 79-107.

18. Ødegaard Ø (1932). Emigration and insanity. Acta Psychiatr Neurologica Scand Suppl 4, 1-206.

19. Pedersen, C. B., Mortensen, P. B., CantorGraae, E. (2011). Do risk factors for schizophrenia predispose to emigration? Schizophr Res 127, 229-234.

20. Rosenthal, D., Goldberg, I., Jacobsen, B., Wender, P. H., Kety, S. S., Schulsinger, F., Eldred, C. A. (1974). Migration, heredity, and schizophrenia. Psychiatry 37, 321-339.

21. Sellgren, C., Landen, M., Lichtenstein, P., Hultman, C. M., Langstrom, N. (2011). Validity of bipolar disorder hospital discharge diagnoses: file review and multiple register linkage in Sweden. Acta Psychiatr Scand 124, 447-453. 
22. Selten, J. P., Cantor-Graae, E., Slaets, J., Kahn, R. S. (2002). Odegaard's selection hypothesis revisited: schizophrenia in Surinamese immigrants to The Netherlands. Am J Psychiatry 159, 669-671.

23. Statistics Sweden (2006). Historic Population Register. Population and Welfare Statistics: Örebro.

24. Statistics Sweden (2010). Multi-generation register 2009: A description of contents and quality. Population and Welfare Statistics: Örebro.

25. van Os, J., Kenis, G., Rutten, B. P. F. (2010). The environment and schizophrenia. Nature 468, 203-212.
26. World Health Organization (1967). Manual of the International Statistical Classification of Diseases, injuries and Causes of Death, 1965 revision. WHO: Geneva.

27. Zammit, S., Lewis, G., Dalman, C., Allebeck, P. (2010). Examining interactions between risk factors for psychosis. Br J Psychiatry 197, 207-211.

28. Zammit, S., Allebeck, P., Andreasson, S., Lundberg, I., Lewis, G. (2002). Self reported cannabis use as a risk factor for schizophrenia in Swedish conscripts of 1969: historical cohort study. BMJ 325, 1199. 




\title{
chapter EIGHT
}

The social defeat hypothesis of schizophrenia: an update

\author{
J.P. Selten, \\ E. van der Ven, \\ B.P.F. Rutten, \\ E. Cantor-Graae
}

Schizophrenia Bulletin (2013), 39(6), 1180-1186. 


\begin{abstract}
According to the social defeat (SD) hypothesis, published in 2005, long-term exposure to the experience of SD may lead to sensitization of the mesolimbic dopamine (DA) system and thereby increase the risk for schizophrenia. The hypothesis posits that SD (i.e., the negative experience of being excluded from the majority group) is the common denominator of five major schizophrenia risk factors: urban upbringing, migration, childhood trauma, low intelligence and drug abuse. The purpose of this update of the literature since 2005 is to answer two questions: (i) What is the evidence that SD explains the association between schizophrenia and these risk factors? (ii) What is the evidence that SD leads to sensitization of the mesolimbic dopamine system? The evidence for SD as the mechanism underlying the increased risk was found to be strongest for migration and childhood trauma, while the evidence for urban upbringing, low intelligence and drug abuse is suggestive, but insufficient. Some other findings that may support the hypothesis are the association between risk for schizophrenia and African-American ethnicity, unemployment, single status, hearing impairment, autism, illiteracy, short stature, Klinefelter syndrome, and, possibly, sexual minority status. While the evidence that SD in humans leads to sensitization of the mesolimbic dopamine system is not sufficient, due to lack of studies, the evidence for this in animals is strong. The authors argue that the social defeat hypothesis provides a parsimonious and plausible explanation for a number of epidemiological findings that cannot be explained solely by genetic confounding.
\end{abstract}




\section{Introduction}

In 2005, following the principle of Occam's razor, we sought a common denominator for well-established risk factors for schizophrenia (migration, urban upbringing, low IQ, childhood trauma and illicit drug use) and hypothesised that long-term exposure to the experience of social defeat (SD) or social exclusion (SE) may lead to sensitization of the mesolimbic dopamine (DA) system (and/or increased baseline activity of this system) and thereby increase the risk for schizophrenia (Selten \& Cantor-Graae, 2005; Selten \& CantorGraae, 2007). Sensitization is a process whereby exposure to a given stimulus, such as a drug or a stressor, results in an enhanced response (here: DA response) to subsequent exposures. The purpose of this paper is to examine the current utility of the hypothesis. We review pertinent investigations published after 2005 and discuss some findings that have not been discussed within this context before 2005. We tried to answer the following questions: (i) What is the evidence that "long-term exposure to the experience of SD or SE" explains the association between schizophrenia and the above-mentioned five risk factors? Are there other epidemiological findings that support or refute the social defeat hypothesis? (ii) What is the evidence from studies in humans that SD leads to increased baseline activity and/or sensitization of the mesolimbic DA system? (iii) What is the evidence from animal studies that SD leads to dopaminergic abnormalities? (iv) Is SD a cause of schizophrenia?

\section{Conceptual issues}

Although SD and SE are different terms, we aim at one type of exposure, namely the negative experience of being excluded from the majority group. This experience is not a specific cause of schizophrenia, because many people exposed to it develop other psychiatric disorders, and it is unlikely to be a necessary or sufficient cause. How does the SD hypothesis relate to other hypotheses in the field? Collip et al. (2008) proposed that "environmental exposures induce psychological or physiological alterations that can be traced to a final common pathway of cognitive biases and/or altered DA neurotransmission, broadly referred to as "sensitization", facilitating the onset and persistence of psychotic symptoms". Morgan et al. (2008) suggested a role for cumulative social disadvantage and Hoffman (2007) formulated a social deafferentation hypothesis.

Firstly, because the sensitization hypothesis put forward by Collip et al. (2008) does not identify specific stressors, it concerns pathogenesis rather than aetiology. The SD hypothesis, in contrast, is about pathogenesis (i.e., sensitization of the mesolimbic DA system) and aetiology. Collip et al. (2008) understand by sensitization also progressively greater psychological responses to the same stimulus (e.g., irritation). Thus, the two hypotheses may complement each other.

Secondly, Morgan et al. (2008) proposed that cumulative social disadvantage in childhood and adulthood increases risk for schizophrenia. The authors identified indicators of social disadvantage in the domains of separation from (or death of) parents, education, employment, living arrangement, housing, relationships and social networks (Stilo et al. 2012). Thus, the concept of social disadvantage is essentially broader than that of SD and 
does not specify how social disadvantage translates into increased psychosis risk. In contrast, the SD hypothesis postulates that indicators of social disadvantage may act as proxies for SD, provided that the subject interprets the situation as defeating. This is important, because no evidence exists that populations in low-income countries are at increased risk, and low socio-economic status of the parents is generally not a risk factor for schizophrenia (Byrne et al. 2004).

Finally, Hoffman (2007) hypothesized that high levels of isolation prompt the social brain to produce spurious social meaning in the form of hallucinations and delusions representing other persons or agents. This social deafferentation hypothesis capitalizes on the principle that the brain, if deprived from input of information, will produce this information by itself. Thus, this hypothesis postulates that isolation is a risk factor by itself, while the SD hypothesis requires isolation to occur in a context of defeat.

\section{Measurement}

The experience of SD is difficult to measure, because humans use strategies to keep up appearances. For that reason the SD hypothesis is mainly based on epidemiological studies that compared defeated and non-defeated groups (not individuals). Alternative measurements include firstly the use of questionnaires such as the social comparison scale (Allan \& Gilbert, 1995), the defeat scale (Gilbert \& Allan, 1998) and the Brief Core Schema Scales (Fowler et al. 2006). Secondly, one can use momentary assessment techniques (MyinGermeys et al. 2009), or, since exclusion from the majority group will often lead to low selfesteem, tests for the measurement of implicit self-esteem (Greenwald \& Farnham, 2000). Thirdly, one can simulate SE or negative evaluation in a laboratory situation (Lederbogen et al. 2011), although the short duration of exposure is a drawback.

\section{Evidence that SD explains association with urban upbringing}

What is the evidence that higher levels of competition in urban areas, and correspondingly more frequent exposure to SD, explain the association between urban upbringing and risk for schizophrenia? A functional magnetic resonance imaging (fMRI) study examined the impact of urban upbringing and current city living on social evaluative stress processing in the brain (Lederbogen et al. 2011). The researchers subjected psychologically healthy participants to the Montreal Imaging Stress Task (MIST), which requires individuals to solve arithmetic tasks under pressure of time and negative feedback. The results showed that current city living was associated with increased amygdala activity, whereas urban upbringing affected the perigenual anterior cingulate cortex (pACC). No urbanicity effect was seen during control experiments invoking cognitive processing without stress. Interestingly, the results may provide a neural basis for the epidemiological finding that urban upbringing, rather than current city living, is associated with increased risk for schizophrenia and provide preliminary evidence for SD as the mechanism underlying the association with urban upbringing.

Zammit et al. (2010) examined whether individual, school or municipality characteristics predicted the psychosis risk for Swedish adolescents. School-level variables included the foreign-born average (proportion of children with one or two parents born 
abroad), the social fragmentation average (the proportion of children who migrated into Sweden, moved into a different municipality between ages 8 and 16 years, or were raised in single-parent households), the deprivation average (proportion of children with low socio-economic status) and the low grade average (proportion of children scoring low). Municipality variables included, among others, population density. Interestingly, the results showed strong evidence of interaction between certain variables at the individual level and the same variables at school level. For example, deprivation at the individual level increased psychosis risk when most children at school were not deprived. However, deprivation at the individual level protected against psychosis when the majority of most children at school were deprived. The same was true for the variables foreign birth and social fragmentation, but not for low grade. The authors concluded, in line with the SD hypothesis, that any characteristic that defines a person as different from his environment may increase his psychosis risk. In conclusion, the results of the Lederbogen et al. study (2011) suggest a role for SD in the aetiology of schizophrenia, but do not yet, of course, establish a causal relationship. The results of the Zammit et al. study (2010) suggest causality more strongly.

\section{Evidence that SD explains association with migration}

The SD hypothesis was prompted in part by a meta-analysis of migrant studies, which showed greater effect sizes for migrants from low-income countries and for migrants with black skin colour (Cantor-Graae \& Selten, 2005). Bourque et al. (2011) found that the increased risk persists into the second generation, suggesting that rather than adverse circumstances during the migration process per se, the minority position in the host society has a more determinant role.

One of the most striking findings in this area is the cross-over interaction with ethnic density. In The Hague and London it was demonstrated that living in a neighbourhood with a high proportion of residents of the own ethnic group is related to a lower risk for schizophrenia and low own-group ethnic density to a higher risk (Kirkbride et al. 2012; Veling et al. 2008). Das-Munshi et al. (2012) showed that potential markers of SD, such as discrimination, poor social support and chronic strains, mediated the relationship between low own-group ethnic density and presence of psychotic experiences. Zammit et al. (2010) showed that the ethnic density effect also operates at school level, as it similarly applies to children with Swedish parents attending schools with a high proportion of foreignborn children.

A longitudinal study from the Netherlands demonstrated that younger age at migration predicts a higher risk for psychotic disorders among non-Western immigrants, with the most elevated risk among children who migrated between ages 0 and 4 years (Veling et al. 2011). Remarkably, the risk for migrants arriving at age 20-24 or 25-29 was only modestly increased. Whether these findings support or contradict the SD hypothesis is uncertain. One could both predict a high risk for migrants who arrive in early adulthood and have to cope with difficulties at the labour market and also for migrants who are exposed to discrimination at a very young age. The results must, however, be interpreted with caution, 
because they could not be replicated using nationwide registry data from Denmark (Pedersen \& Cantor-Graae, 2012).

\section{Evidence that SD explains association with low IQ}

Low IQ is a well-established risk factor for schizophrenia and several studies attempted to identify common (poly)genetic components between the two phenotypes. Toulopoulou et al. $(2007 ; 2010)$ initially reported high $(-.75)$ to moderate $(-.38)$ phenotypic correlations between IQ and schizophrenia, respectively. However, the twin samples of these studies were not population-based and IQ was measured after the onset of psychosis. Fowler et al. (2012) avoided these sources of bias and found a weak correlation (-.11) and a shared genetic variance of only $7 \%$.

Goldberg et al. (2011) examined the influence of cognitive abilities and pre-morbid socioeconomic status (SES) on the risk of hospitalization for schizophrenia. Adolescents with low cognitive ability appeared to have an increased risk for schizophrenia, especially when they grew up in areas with a high SES. The authors argue that the increased risk may be partly conferred by the discrepancy between these high expectations and actual achievements. Nonetheless, the evidence supporting the role of SD in the association between low IQ and schizophrenia is as yet not sufficient.

\section{Evidence that SD explains association with childhood trauma}

Meta-analytic evidence demonstrates consistent patterns of increased incidence of psychotic disorder and subclinical psychotic symptoms in individuals who experienced several types of childhood trauma (Matheson et al. 2013; Varese et al. 2012). Despite the association being predominantly based on results from retrospective studies susceptible to recall bias, its validity has been strengthened by comparable findings from prospective studies that did not depend on personal recollection (Arseneault et al. 2011; Cutajar et al. 2010).

Childhood trauma encompasses a broad range of adverse experiences. Traumas that involve an intentional harm such as sexual, physical and psychological abuse, and bullying, putatively lead to SD. In other types of childhood trauma, such as accidents or parental loss, SD might not necessarily be as directly implicated. In a longitudinal twin study, risk for psychotic symptoms at age 12 was associated with previous maltreatment by an adult (relative risk $(R R)=3.2,95 \%$ CI $1.9-5.2)$ or bullying by peers $(R R=2.5,95 \%$ CI 1.7-3.5), but much less so with the experience of a lifetime accident ( $R R=1.47,95 \%$ CI 1.0-2.1)(Arseneault et al. 2011). In line with the SD hypothesis, the relationship between intentionally inflicted childhood trauma and risk of psychotic disorder stresses the putative pathogenic influence of the experience of (chronic) humiliation. Contrarily, parental separation and parental death are types of trauma associated with increased psychosis risk that do not necessarily involve an intention to harm (Stilo et al. 2012; Varese et al. 2012). However, it is unknown whether these events are causal factors per se or whether they represent markers for family conflicts or instability.

In conclusion, consistent with the SD hypothesis, an increasing body of evidence affirms a true association between childhood trauma and psychotic disorder. 


\section{Evidence that SD explains association with illicit drugs}

That people who use illicit drugs are at risk of developing schizophrenia is primarily due to a toxic effect of these substances. However, SD may contribute to the association between drug use and schizophrenia in at least two ways. Firstly, drug abuse often leads to SD. Secondly, SD may lead to drug abuse. Studies have shown a strong association between a history of childhood trauma and subsequent drug abuse (Simpson \& Miller, 2002) and between unemployment and drug abuse (Henkel, 2011).

\section{Other epidemiological findings}

Risk for schizophrenia is associated with single status. While there may be many reasons for being unmarried, this may act as a stressor. The same considerations apply to unemployment. There are reports of an increased risk for schizophrenia among people with a hearing impairment (van der Werf et al. 2011). Earlier reports of no association between autistic spectrum disorders and schizophrenia are now superseded by reports of an increased risk (Howlin, 2003). There is evidence that autism and schizophrenia share genes, but SD may contribute to the increased risk. Traumatic brain injury is associated with an increased risk for schizophrenia (Molloy et al. 2011). It would be interesting to examine whether psychosis develops especially in those patients who lose their status. Klinefelter syndrome, characterized by small genitals and infertility, is associated with an excessive risk for schizophrenia (Bruining et al. 2009). An investigation of the Danish psychiatric registry found no significantly increased risk for schizophrenia among people with a cleft palate, but this may have been due to insufficient power of the study (Christensen \& Mortensen, 2002). With reference to discriminated minorities, during the period 1935-1965 there have been consistent reports of an increased risk for schizophrenia among African-Americans (Selten \& Cantor-Graae, 2004). More recent studies seem to confirm the earlier findings of a two- to threefold elevated risk (Bresnahan et al. 2007; Minsky et al. 2003). One could argue that the low prevalence of schizophrenia among a religious minority in North-America, the Hutterites, argues against the hypothesis, but this group is known for its social cohesion (Nimgaonkar et al. 2000). As for sexual minorities, population surveys reported an increased risk of psychotic symptoms among people with a homosexual orientation (Gevonden et al. 2013) and there is preliminary evidence of an increased risk among people with a gender identity disorder (à Campo et al. 2003). Other findings include the high prevalence of schizophrenia among illiterates in China, who experience discrimination (Liu et al. 2013), and the negative association between tallness and risk for schizophrenia among Swedish recruits (Zammit et al. 2007).

\section{Evidence that SD in humans leads to sensitization of the mesolimbic DA system}

Positron Emission Tomography (PET) studies have shown that non-psychotic subjects who report a low level of maternal care in early life release more DA after exposure to the MIST (Pruessner et al. 2004; Soliman et al. 2008). Another PET-study using the MIST showed that neuroleptic-naive patients and clinical high-risk subjects also exhibit a sensitized dopaminergic response (Mizrahi et al. 2012). The negative feedback on performance, 
which characterizes the MIST, seems to be essential, because a mathematic stress-task without negative feed-back yielded negative results (Montgomery et al. 2006). There have been no studies of DA function in migrants, people raised in cities, people with low IQ, or traumatized people. To summarize, the association between low perceived maternal care and stress-related DA function and the importance of negative feedback as stressor support the SD hypothesis, but the evidence on a whole is insufficient.

\section{Evidence from animal studies that SD leads to sensitization of mesolimbic dopamine} system

Several lines of experimental research have shown that the psychosocial environment, and chronic stress in particular, can mediate changes in gene expression, the Hypothalamic Pituitary Adrenal (HPA) axis, mesolimbic DA neurotransmission and behaviour. Firstly, Meaney \& Szyf (2005) have shown that parental care during early life of rodents induces long-term behavioural and neurobiological alterations, with offspring of low-nurturing mothers showing more signs of anxiety and stronger corticosterone responses after stress exposure, while expressing lower levels of the glucocorticoid receptor in the hippocampus in adulthood. Additional experiments indicated that epigenetic mechanisms mediated these alterations, whereas further animal studies have shown intricate crosstalk between the HPA axis and mesolimbic dopaminergic transmission circuitries in relation to chronic stress (Lemos et al. 2012; Weaver et al. 2004).

With respect to chronic SD stress, several animal studies using resident-intruder paradigms for modeling the effects of SD stress exposure have found strong indications that SD leads to dopaminergic hyperactivity, particularly in the mesolimbic dopaminergic neurotransmission system (Tidey \& Miczek, 1996) and to behavioral sensitization (Covington III \& Miczek, 2001). Interestingly, the effects of SD on the dopaminergic system seem to depend on environmental circumstances after the defeat. For example, Isovich et al. (2001) found that SD-induced alterations in the binding capacity of the DA transporter depended on the housing conditions after the defeat experience; i.e. social isolation after the defeat amplified the alterations, whereas more social housing, i.e. return to the same group as before the defeat, mitigated the changes.

It is important to note that the severe physical and social stress to experimental mice cannot directly be compared to the SD experience as occurring in everyday life of humans. Nevertheless, experimental SD exposure in rodents has been shown to induce striking alterations in anxiety-like behaviour, prolonged elevations in corticosterone levels and a range of other molecular, cellular and behavioural changes (Krishnan et al. 2007), such as alterations in neurogenesis (Van Bokhoven et al. 2011), besides the above-mentioned effects on dopaminergic transmission and behavioural sensitization.

Accumulating evidence indicates that chronic SD paradigms elicit a striking differential susceptibility in social behaviour as well as in distinct neurobiological phenotypes of SD-exposed mice (Krishnan et al. 2007). At the behavioural level, one group of mice displays social avoidance after the SD experience (these mice are called "susceptible") and signs of anhedonia, while a second group of mice still shows social interaction rates that are comparable with the control 
group (and is therefore called "unsusceptible" or "resilient"). At the neurobiological level, the susceptible mice display increased firing rates of dopaminergic Ventral Tegmental Area (VTA) neurons (i.e. the mesolimbic system, particularly those projecting to the nucleus accumbens) (Chaudhury et al. 2013), connected to upregulated voltage-gated K+-channels and epigenetic aberrations of the Brain Derived Neurotrophic Factor (BDNF) gene, while unsusceptible mice displayed normal firing rate of dopaminergic VTA neurons (Krishnan et al. 2007).

Thus, findings from animal studies are providing strong and replicated evidence that SD increases baseline activity of the mesolimbic dopaminergic system and induces sensitization of DA-related behavioural, electrophysiological and neurochemical features, while the more recent studies also illustrate that animals may strongly differ in DA-related effects of SD exposure, that chronic stress-induced alterations of the HPA axis are connected to dopaminergic alteration and that the differential susceptibility to SD may be (at least in part) of epigenetic origin.

\section{Is $\mathrm{SD}$ a cause of schizophrenia?}

Before addressing this question, we will respond to the following criticisms: (i) the association between SD and schizophrenia is due to genetic confounding; (ii) SD is not a specific risk factor for schizophrenia.

An explanation in terms of genetic confounding assumes that people who are genetically predisposed to schizophrenia move to urban areas because they prefer to live in anonymity, emigrate because they fail to integrate in their home country, are victimized during childhood because of their poor social skills and use illicit drugs because they are unhappy. In other words, SD is the consequence, not the cause. This explanation meets with at least four challenges. Firstly, there is little supportive evidence (CantorGraae \& Selten, 2005; Varese et al. 2012). Secondly, the explanations do not allow for the possibility that causality operates in both directions. Individuals genetically predisposed to schizophrenia, for example, may be more likely to use illicit drugs, but this does not preclude a toxic effect of these drugs. Thirdly, some assumptions are contradictory: children who carry genes for schizophrenia are presumed to be socially vulnerable, but migrants are enterprising and constitute a positive selection in terms of physical health (MacMahon \& Trichopoulos, 1996). Finally, the genetic confounding hypothesis rests on too many unproven assumptions: certain genes cause schizophrenia and the same genes also cause their carriers to move to cities, to emigrate, to use drugs, to be bullied and to be victimized. As for the issue of specificity, risk factors are rarely specific for a particular psychiatric disorder (Weiser et al. 2005).

We conclude that the SD hypothesis provides a more parsimonious and therefore more plausible explanation for the schizophrenia risk pattern than an explanation solely in terms of genetic confounding. Moreover, it may explain why a large part of the genome is involved in aetiology, because any change in a gene that renders the carrier more prone to SD will influence his risk. Another corollary of the SD hypothesis is that the presence of any mental disorder will increase the patient's risk for schizophrenia, because having a mental disorder is usually associated with a degree of social exclusion. The literature provides support for this 


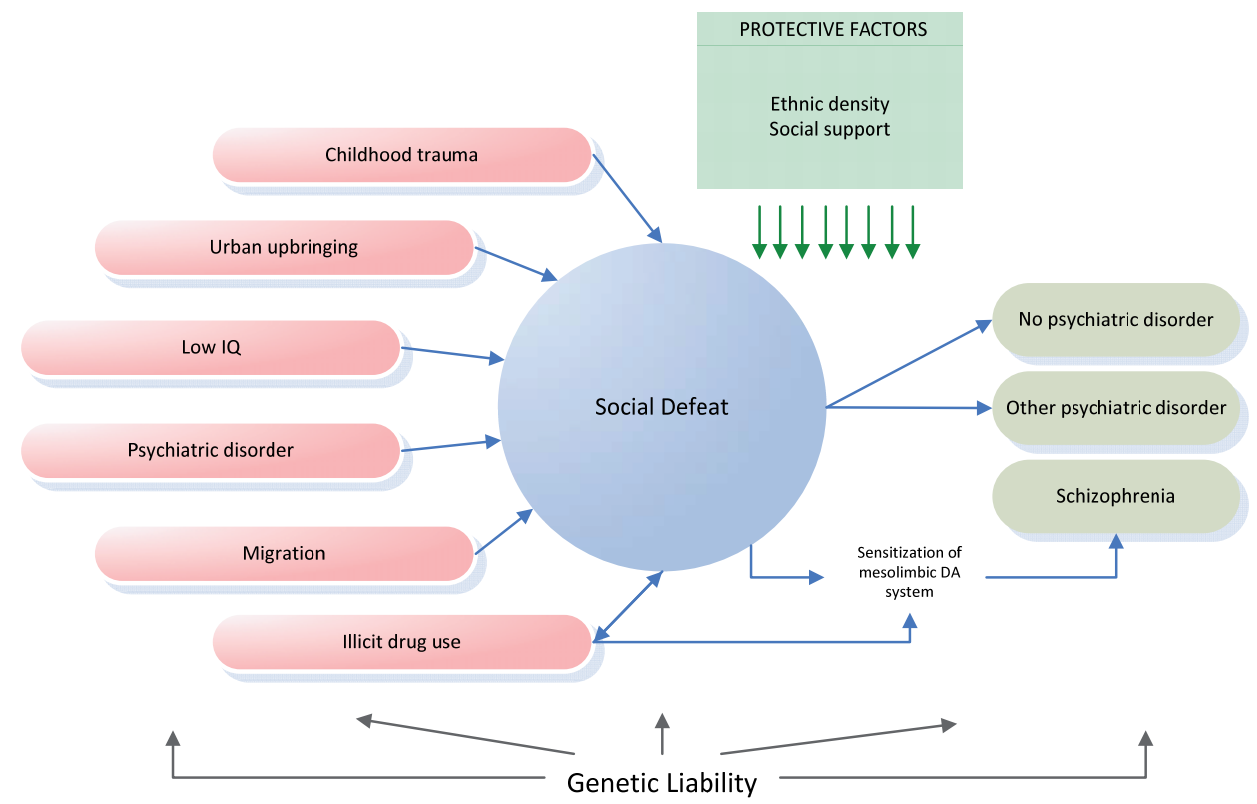

Figure 1. Schematic illustration of the experience of social defeat as the common mechanism underlying six major schizophrenia risk factors.

idea: mood, anxiety and substance use disorders are common precursors for schizophrenia (Tien \& Eaton, 1992; Wigman et al. 2012). See Figure 1 for a schematic illustration.

In sum, the evidence for the first part of the SD hypothesis (SD is the common denominator for the five major risk factors) is fairly strong and we contend that long-term exposure to SD is a cause of schizophrenia indeed. The evidence for the second part of the hypothesis (SD leads to DA dysregulation), however, is insufficient.

\section{Future studies}

Hypotheses should be evaluated by subjecting them to crucial tests. There are many possibilities. For example, our prediction that a study of ethnic subgroups within the Israeli population would find the highest risk for Ethiopian Jews was confirmed (Selten \& Cantor-Graae, 2005; Weiser et al. 2008). Future studies could examine whether people with a genetic risk for schizophrenia react differently to simulated social exclusion using fMRI and investigate which (epi)genetic profiles are associated with susceptibility to social defeat. Neuroreceptor imaging studies can examine DA response during stressful circumstances and DA function in high-risk groups. Thus, the SD hypothesis seems to provide many promising avenues for investigating epidemiological patterns that are still lacking a satisfactory explanation. 


\section{Acknowledgments}

We thank James Kirkbride for very useful comments. This work was supported by the European Community's Seventh Framework Programme under grant agreement No. HEALTH-F2-2010-241909 (Project EU-GEI).

\section{References}

1. à Campo, J., Nijman, H., Merckelbach, H., Evers, C. (2003). Psychiatric comorbidity of gender identity disorders: a survey among Dutch psychiatrists. Am J Psychiatry 160, 1332-1336.

2. Allan, S., Gilbert, P. (1995). A social comparison scale: Psychometric properties and relationship to psychopathology. Pers Individ Dif 19, 293-299.

3. Arseneault, L., Cannon, M., Fisher, H. L., Polanczyk, G., Moffitt, T. E., Caspi, A. (2011). Childhood trauma and children's emerging psychotic symptoms: A genetically sensitive longitudinal cohort study. Am J Psychiatry 168, 65-72.

4. Bourque, F., van der Ven, E., Malla, A. (2011). A meta-analysis of the risk for psychotic disorders among first- and secondgeneration immigrants. Psychol Med 41, 897910.

5. Bresnahan, M., Begg, M. D., Brown, A., Schaefer, C., Sohler, N., Insel, B., Vella, L., Susser, E. (2007). Race and risk of schizophrenia in a US birth cohort: another example of health disparity? Int J Epidemiol 36, 751-758.

6. Bruining, H., Swaab, H., Kas, M., van Engeland, H. (2009). Psychiatric characteristics in a self-selected sample of boys with Klinefelter syndrome. Pediatrics 123, e865-e870.

7. Byrne, M., Agerbo, E., Eaton, W. W., Mortensen, P. B. (2004). Parental socioeconomic status and risk of first admission with schizophrenia- a Danish national register based study. Soc Psychiatry Psychiatr Epidemiol 39, 87-96.

8. Cantor-Graae, E., Selten, J. P. (2005). Schizophrenia and migration: a metaanalysis and review. Am J Psychiatry 162, 12-24.

9. Chaudhury, D., Walsh, J. J., Friedman, A. K., Juarez, B., Ku, S. M., Koo, J. W., Ferguson, D., Tsai, H. C., Pomeranz, L., Christoffel, D.
J., Nectow, A. R., Ekstrand, M., Domingos, A., Mazei-Robison, M.S., Mouzon, E., Lobo, M. K., Neve, R. L., Friedman, J. M., Russo, S. J., Deisseroth, K., Nestler, E. J., Han, M. H. (2013). Rapid regulation of depressionrelated behaviours by control of midbrain dopamine neurons. Nature 493, 532-536.

10. Christensen, K., Mortensen, P. B. (2002). Facial clefting and psychiatric diseases: a follow-up of the Danish 1936-1987 Facial Cleft cohort. Cleft Palate Craniofac. J 39, 392-396.

11. Collip, D., Myin-Germeys, I., van Os, J. (2008). Does the concept of "sensitization" provide a plausible mechanism for the putative link between the environment and schizophrenia? Schizophr Bull 34, 220-225.

12. Covington III, H. E., Miczek, K. A. (2001). Repeated social-defeat stress, cocaine or morphine. Effects on behavioral sensitization and intravenous cocaine self-administration "binges". Psychopharmacol (Berl) 158, 388398.

13. Cutajar, M. C., Mullen, P. E., Ogloff, J. R., Thomas, S. D., Wells, D. L., Spataro, J. (2010). Schizophrenia and other psychotic disorders in a cohort of sexually abused children. Arch Gen Psychiatry 67, 1114-1119.

14. Das-Munshi, J., Becares, L., Boydell, J. E., Dewey, M. E., Morgan, C., Stansfeld, S. A., Prince, M. J. (2012). Ethnic density as a buffer for psychotic experiences: findings from a national survey (EMPIRIC). Br J Psychiatry 201, 282-290.

15. Fowler, D., Freeman, D., Smith, B., Kuipers, E., Bebbington, P., Bashforth, H., Coker, S., Hodgekins, J., Gracie, A., Dunn, G., Garety, P. (2006). The Brief Core Schema Scales (BCSS): psychometric properties and associations with paranoia and grandiosity in non-clinical and psychosis samples. Psychol Med 36, 749-759.

16. Fowler, T., Zammit, S., Owen, M. J., Rasmussen, F. (2012). A population-based

8 
study of shared genetic variation between premorbid IQ and psychosis among male twin pairs and sibling pairs from Sweden. Arch Gen Psychiatry 69, 460-466.

17. Gevonden, M. J., Selten, J. P., MyinGermeys, I., de Graaf, R., Ten Have, M., van Dorsselaer, S., van Os, J., Veling, W. (2014). Sexual minority status and psychotic symptoms: findings from the Netherlands Mental Health Survey and Incidence Studies (NEMESIS). Psychol Med 44, 421-433.

18. Gilbert, P., Allan, S. (1998). The role of defeat and entrapment (arrested flight) in depression: an exploration of an evolutionary view. Psychol Med 28, 585-598.

19. Goldberg, S., Fruchter, E., Davidson, M., Reichenberg, A., Yoffe, R., Weiser, M. (2011). The relationship between risk of hospitalization for schizophrenia, SES, and cognitive functioning. Schizophr Bull 37, 664-670.

20. Greenwald, A. G., Farnham, S. D. (2000). Using the implicit association test to measure self-esteem and self-concept. J Pers Soc Psychol 79, 1022-1038.

21. Henkel, D. (2011). Unemployment and substance use: a review of the literature (1990-2010). Curr Drug Abuse Rev 4, 4-27.

22. Hoffman, R. E. (2007). A social deafferentation hypothesis for induction of active schizophrenia. Schizophr Bull 33, 1066-1070.

23. Howlin, P. (2003). Outcome in highfunctioning adults with autism with and without early language delays: implications for the differentiation between autism and Asperger syndrome. J Autism Dev Disord 33, 3-13.

24. Isovich, E., Engelmann, M., Landgraf, R., Fuchs, E. (2001). Social isolation after a single defeat reduces striatal dopamine transporter binding in rats. Eur J Neurosci 13, 1254-1256.

25. Kirkbride, J. B., Jones, P. B., Ullrich, S., Coid, J. W. (2014). Social Deprivation, Inequality, and the Neighborhood-Level Incidence of Psychotic Syndromes in East London. Schizophr Bull 40, 169-180.

26. Krishnan, V., Han, M. H., Graham, D. L., Berton, O., Renthal, W., Russo, S. J., LaPlant, Q., Graham, A., Lutter, M., Lagace, D. C., Ghose, S., Reister, R., Tannous, P., Green, T. A., Neve, R. L., Chakravarty, S., Kumar, A.,
Eisch, A. J., Self, D. W., Lee, F. S., Tamminga, C. A., Cooper, D. C., Gershenfeld, H. K., Nestler, E. J. (2007). Molecular adaptations underlying susceptibility and resistance to social defeat in brain reward regions. Cell 131, 391-404.

27. Lederbogen, F., Kirsch, P., Haddad, L., Streit, F., Tost, H., Schuch, P., Wust, S., Pruessner, J. C., Rietschel, M., Deuschle, M., Meyer-Lindenberg, A. (2011). Cityliving and urban upbringing affect neural social stress processing in humans. Nature 474, 498-501.

28. Lemos, J. C., Wanat, M. J., Smith, J. S., Reyes, B. A., Hollon, N. G., Van Bockstaele, E. J., Chavkin, C., Phillips, P. E. (2012). Severe stress switches CRF action in the nucleus accumbens from appetitive to aversive. Nature 490, 402-406.

29. Liu, T., Song, X., Chen, G., Buka, S. L., Zhang, L., Pang, L., Zheng, X. (2013). Illiteracy and schizophrenia in China: a population-based survey. Soc Psychiatry Psychiatr Epidemiol 48, 455-464.

30. MacMahon, B., Trichopoulos, D. (1996). In Epidemiology. Principles and methods, pp. 148-154. Little, Brown and Company: Boston.

31. Matheson, S. L., Shepherd, A.M., Pinchbeck, R. M., Laurens, K. R., Carr, V. J. (2013). Childhood adversity in schizophrenia: a systematic meta-analysis. Psychol Med 43, 225-238

32. Meaney,M.J.,Szyf,M.(2005).Environmental programming of stress responses through DNA methylation: life at the interface between a dynamic environment and a fixed genome. Dialogues Clin Neurosci 7, 103-123.

33. Minsky, S., Vega, W., Miskimen, T., Gara, M., Escobar, J. (2003). Diagnostic patterns in Latino, African American, and European American psychiatric patients. Arch Gen Psychiatry 60, 637-644.

34. Mizrahi, R., Addington, J., Rusjan, P. M., Suridjan, I., Ng, A., Boileau, I., Pruessner, J. C., Remington, G., Houle, S., Wilson, A. A. (2012). Increased stress-induced dopamine release in psychosis. Biol Psychiatry 71, 561567.

35. Molloy, C., Conroy, R. M., Cotter, D. R., Cannon, M. (2011). Is traumatic brain injury a risk factor for schizophrenia? A metaanalysis of case-controlled population-based studies. Schizophr Bull 37, 1104-1110. 
36. Montgomery, A. J., Mehta, M. A., Grasby, P. M. (2006). Is psychological stress in man associated with increased striatal dopamine levels?: A [11C]raclopride PET study. Synapse 60, 124-131.

37. Morgan, C., Kirkbride, J., Hutchinson, G., Craig, T., Morgan, K., Dazzan, P., Boydell, J., Doody, G. A., Jones, P. B., Murray, R. M., Leff, J., Fearon, P. (2008). Cumulative social disadvantage, ethnicity and first-episode psychosis: a case-control study. Psychol Med 38, 1701-1715.

38. Myin-Germeys, I., Oorschot, M., Collip, D., Lataster, J., Delespaul, P., van Os, J. (2009). Experience sampling research in psychopathology: opening the black box of daily life. Psychol Med 39, 1533-1547.

39. Nimgaonkar, V. L., Fujiwara, T. M., Dutta, M., Wood, J., Gentry, K., Maendel, S., Morgan, K., Eaton, J. (2000). Low prevalence of psychoses among the Hutterites, an isolated religious community. Am J Psychiatry 157, 1065-1070.

40. Pedersen, C. B., Cantor-Graae, E. (2012). Age at migration and risk of schizophrenia among immigrants in Denmark: a 25-year incidence study. Am J Psychiatry 169, 11171118.

41. Pruessner, J. C., Champagne, F., Meaney, M. J., Dagher, A. (2004). Dopamine release in response to a psychological stress in humans and its relationship to early life maternal care: a positron emission tomography study using [11C]raclopride. J Neurosci 24, 2825-2831.

42. Selten, J. P., Cantor-Graae, E. (2004). Schizophrenia and Migration Vol. V. In Search for the causes of schizophrenia, (ed. W. Gattaz and H. Häfner), pp. 3-25. Steinkopff/Springer: Dermstadt.

43. Selten, J. P., Cantor-Graae, E. (2005). Social defeat: risk factor for schizophrenia? Br J Psychiatry 187, 101-102.

44. Selten, J. P., Cantor-Graae, E. (2007). Hypothesis: social defeat is a risk factor for schizophrenia? Br J Psychiatry Suppl 51, s912.

45. Simpson, T. L., Miller, W. R. (2002). Concomitance between childhood sexual and physical abuse and substance use problems. A review. Clin Psychol Rev 22, 27 77.

46. Soliman, A., O’Driscoll, G. A., Pruessner, J., Holahan, A. L., Boileau, I., Gagnon,
D., Dagher, A. (2008). Stress-induced dopamine release in humans at risk of psychosis: a [11C]raclopride PET study. Neuropsychopharmacology 33, 2033-2041.

47. Stilo, S. A., Di Forti, M., Mondelli, V., Falcone, A. M., Russo, M., O'Connor, J., Palmer, E., Paparelli, A., Kolliakou, A., Sirianni, M., Taylor, H., Handley, R., Dazzan, P., Pariante, C., Marques, T. R., Zoccali, R., David, A., Murray, R. M., Morgan, C. (2013). Social Disadvantage: Cause or Consequence of Impending Psychosis? Schizophr Bull 39, 1288-1295.

48. Tidey, J. W., Miczek, K. A. (1996). Socialdefeat stress selectively alters mesocorticolimbic dopamine release: an in vivo microdialysis study. Brain Res 721, 140-149.

49. Tien, A. Y., Eaton, W. W. (1992). Psychopathologic precursors and sociodemographic risk factors for the schizophrenia syndrome. Arch Gen Psychiatry 49, 37-46.

50. Toulopoulou, T., Goldberg, T. E., Mesa, I. R., Picchioni, M., Rijsdijk, F., Stahl, D., Cherny, S. S., Sham, P., Faraone, S. V., Tsuang, M., Weinberger, D. R., Seidman, L. J., Murray, R. M. (2010). Impaired intellect and memory: a missing link between genetic risk and schizophrenia? Arch Gen Psychiatry 67, 905-913.

51. Toulopoulou, T., Picchioni, M., Rijsdijk, F., Hua-Hall, M., Ettinger, U., Sham, P., Murray, R. (2007). Substantial genetic overlap between neurocognition and schizophrenia: genetic modeling in twin samples. Arch Gen Psychiatry 64, 1348-1355.

52. Van Bokhoven, P., Oomen, C. A., Hoogendijk, W. J., Smit, A. B., Lucassen, P. J., Spijker, S. (2011). Reduction in hippocampal neurogenesis after social defeat is longlasting and responsive to late antidepressant treatment. Eur J Neurosci 33, 1833-1840.

53. van der Werf, M., Thewissen, V., Dominguez, M. D., Lieb, R., Wittchen, H., van Os, J. (2011). Adolescent development of psychosis as an outcome of hearing impairment: a 10-year longitudinal study. Psychol Med 41, 477-485.

54. Varese, F., Smeets, F., Drukker, M., Lieverse, R., Lataster, T., Viechtbauer, W., Read, J., van Os, J., Bentall, R. P. (2012). Childhood adversities increase the risk of psychosis: a meta-analysis of patient-control,

\section{8}


prospective- and cross-sectional cohort studies. Schizophr Bull 38, 661-671.

55. Veling, W., Hoek, H. W., Selten, J. P., Susser, E. (2011). Age at migration and future risk of psychotic disorders among immigrants in the Netherlands: a 7-year incidence study. Am J Psychiatry 168, 1278-1285.

56. Veling, W., Susser, E., van Os, J., Mackenbach, J. P., Selten, J. P., Hoek, H. W. (2008). Ethnic density of neighborhoods and incidence of psychotic disorders among immigrants. Am J Psychiatry 165, 66-73.

57. Weaver, I. C., Cervoni, N., Champagne, F. A., D'Alessio, A. C., Sharma, S., Seckl, J. R., Dymov, S., Szyf, M., Meaney, M. J. (2004). Epigenetic programming by maternal behavior. Nature Neurosci 7, 847-854.

58. Weiser, M., van Os, J., Davidson, M. (2005). Time for a shift in focus in schizophrenia: from narrow phenotypes to broad endophenotypes. Br J Psychiatry 187, 203 205.

59. Weiser, M., Werbeloff, N., Vishna, T., Yoffe, R., Lubin, G., Shmushkevitch, M., Davidson,
M. (2008). Elaboration on immigration and risk for schizophrenia. Psychol Med 38, 11131119.

60. Wigman, J. T., van Nierop, M., Vollebergh, W. A., Lieb, R., Beesdo-Baum, K., Wittchen, H. U., van Os., J. (2012). Evidence that psychotic symptoms are prevalent in disorders of anxiety and depression, impacting on illness onset, risk, and severity--implications for diagnosis and ultra-high risk research. Schizophr Bull 38, 247-257.

61. Zammit, S., Lewis, G., Rasbash, J., Dalman, C., Gustafsson, J. E., Allebeck, P. (2010). Individuals, schools, and neighborhood: a multilevel longitudinal study of variation in incidence of psychotic disorders. Arch Gen Psychiatry 67, 914-922.

62. Zammit, S., Rasmussen, F., Farahmand, B., Gunnell, D., Lewis, G., Tynelius, P., Brobert, G. P. (2007). Height and body mass index in young adulthood and risk of schizophrenia: a longitudinal study of 1347520 Swedish men. Acta Psychiatr Scand 116, 378-385. 




\section{chapter NINE}

General discussion 



\section{The surprisingly rich contours of psychiatric epidemiology}

The first aim of this thesis was to examine the incidence of psychiatric disorder in minority groups by focusing on various study populations and different psychiatric outcomes (chapters 2, 3, 4 and 5).

Using meta-analytical techniques, we demonstrated that the risk for non-affective psychotic disorders does not only affect first-generation migrants with a personal migration history, but persists in second-generation migrants who are born in the host country to one or two migrant parents. In line with previous studies (Cantor-Graae \& Selten, 2005; Fearon et al. 2006), there was significant risk variation associated with visible minority status with the highest risk estimates among migrants from countries where the majority of the population is black (chapter 2). Although there were no global differences in risk elevation between male and female immigrants, we found strong evidence of a very high male-tofemale ratio for the incidence and prevalence of psychotic disorder, as well as subclinical psychotic symptoms, among North African immigrants in Europe, foremost among the Moroccan-Dutch population (chapter 3). Members from other socially excluded groups, for instance children that are victims of bullying, were also more likely to develop psychotic symptoms later in life (chapter 4 ).

Minority status emerged as risk moderator in the administrative incidence for autismspectrum disorders. Among second-generation immigrants from developing countries in the Netherlands, there was a reversal of risk gradient, with a decreased risk for highfunctioning and increased risk for low-functioning autism (chapter 5).

Revisiting the first aim of this thesis, we found disparities in incidence of psychotic symptoms, psychotic disorder, and autism-spectrum disorders between minority and majority groups. From a quantitative perspective, we found mean-weighted incidence rate ratios (IRRs) of psychotic disorder for first-generation and second-generation immigrants of 2.3 (95\% CI 2.0-2.7) and 2.1 (95\% CI 1.8-2.5), respectively. The odds ratio for bullied children to experience non-clinical psychotic symptoms was 2.3 (95\% CI 1.5-3.4) compared to those who were never bullied. These risk magnitudes fall in the same range as those associated with certain well-established risk factors, including cannabis use, severe malnutrition, and urbanicity (Tandon et al. 2008). In the Netherlands, the risk ratio (RR) for PDD-NOS and Asperger's syndrome among children born to parents from developing countries was very low $(\mathrm{RR}=0.4,95 \% \mathrm{CI} 0.3-0.6)$, while that for narrowly defined autism was modestly increased ( $\mathrm{RR}=1.4,95 \% \mathrm{CI} 0.9-2.4)$.

In the analysis of epidemiological data, we did not only observe risk differences between majority and minority groups, but also within minority populations. For instance, North African males in Europe are five times more likely to develop a non-affective psychotic disorder than their female counterparts, a sex divergence that is not present in other migrants or non-migrant Europeans. Furthermore, immigrants from host countries where the majority of the population have a black skin colour were at four- to five-fold increased risk for developing a psychotic disorder, in contrast with about a two-fold risk increase among other migrants. The host society, or a proxy measure operating herein, may also mediate the risk, as shown by significantly higher psychosis rates in second-generation immigrants 
in the Netherlands and the UK, as compared to Scandinavia or Israel. This suggests that the risk is not only conveyed by characteristics of migrated individuals, but also by those of the host society, and by the interaction of the two. The nature of the migration, and the extent to which migrants diverge from the host population in culture and appearance may be crucial. In the case of migration to Israel, Jewish immigrants may not feel as much like outsiders, as compared to migrants to other host countries. In fact, by moving to a Jewish state, they may even be moving away from a minority position, escaping from the cooccurring discrimination and other sources of social stress, to a more comfortable majority position (Corcoran et al. 2009).

As elegantly set forth by McGrath (2007), our findings indicate that the landscape of psychiatric epidemiology has surprisingly rich contours and cannot be characterized as a "flat and featureless horizon". Consequently, we continue to drift further away from the theory of uniformity, to be confronted instead with differences in incidence of psychiatric disorder between groups, which appear to be as diverse as the expression of psychiatric disorder between individuals.

\section{Misdiagnosis, selective migration and social defeat}

In the second part of this thesis, we investigated different hypotheses proposed to explain the increased risk of psychotic disorders in ethnic and other minority populations. To examine whether disproportional misdiagnosis can account for these findings, we compared the clinical presentation of psychotic disorder among ethnic minorities in Montreal, Canada, with that of the ethnic majority group (chapter 6). The results revealed that there were no differences between ethnic groups in the nature of positive symptoms at first presentation, age at onset, or duration of untreated psychosis (DUP). Although ethnic background may colour the content of thoughts and experiences of individuals, we did not find evidence supporting the idea that ethnicity has a large pathoplastic influence on core features of psychotic illness. Our findings, therefore, add to an increasing body of evidence that renders diagnostic bias an implausible explanation for the increased rates of psychosis among ethnic minorities.

Ødegaard's selection hypothesis (1932) posits that the high rates in migrants can be explained by selective migration of people with a high predisposition to develop a psychotic disorder (chapter 7). To test this hypothesis, we examined whether previously identified risk factor for psychosis, such as impaired social adjustment, low intellectual ability and cannabis use, are more prevalent among Swedish men who emigrate later in life. The results showed that a history of urban upbringing and cannabis use were more prevalent, while low IQ and poor social adjustment were less common among prospective emigrants. There were no differences between emigrants and non-migrants in the prevalence of other psychosis risk factors. Overall, in keeping with previous studies, our results do not support the selection hypothesis.

In Chapter 8 we investigated whether the social defeat hypothesis is compatible with contemporary, empirical evidence. According this hypothesis the "long-term exposure to the experience of being excluded from the majority group may lead to sensitization of 
the mesolimbic dopamine (DA) system and thereby increase the risk for schizophrenia". Following the principle of Occam's razor, we found evidence that the experience of social defeat is a common denominator for well-established psychosis risk factors, including migration, urban upbringing, low IQ, childhood trauma and illicit drug use. In rodents, the evidence that social defeat leads to DA dysregulation is strong. In humans, however, the evidence for this is preliminary (Gevonden et al. 2014).

\section{Taking stock from risk patterns and investigating hypotheses}

The work described in this dissertation has improved our ability to take stock from the existing diversity of theories on why immigrants and other minority populations have an increased risk for developing psychosis. The existing hypotheses can be categorized in roughly three categories. First, those that attribute risk differences to methodological artefacts, such as selection bias, genetic confounding and diagnostic bias. The second group consists of biological theories addressing antenatal conditions, such as obstetric complications, as well as hypovitaminosis D and cannabis use. The third category includes hypotheses that emphasize the potentially pathological influence of the social environment.

\section{Methodological considerations}

The headline of a Dutch newspaper on February $5^{\text {th }} 2014$ read that Moroccans in the Netherlands are too quickly diagnosed with schizophrenia (Vermeulen, 2014). Based on a study population of twenty-six Moroccan-Dutch, and thirty-seven Dutch patients, Zandi and colleagues (2010) concluded that the risk for developing schizophrenia is not increased among the Moroccan-Dutch if clinicians use culture sensitive diagnostic instruments. The researchers omitted, however, to involve family members in the diagnostic process, and based their conclusions on a very small sample. They also downplayed their finding that the risk for any psychotic disorder was increased more than four times amongst the Moroccan-Dutch group. Given the limited validity of specific diagnoses within the larger DSM-category of psychotic disorders (Kapur et al. 2012), it is questionable whether this distinction has clinical value. Furthermore, over the past decades, methods of migrant studies have become more rigorous in terms of diagnostic procedures, reliability of denominator data and case finding. In summary, research to date, supplemented by the work in this dissertation, provides ample evidence that the increased risk of psychosis in migrants is a valid and consistent finding that cannot be explained by diagnostic, hospital or age bias.

Reverse causality or genetic confounding is another methodological issue that has been proposed to account for variation in psychosis incidence, assuming that people who are genetically at risk are more likely to emigrate, because they do not ground well in their home country (Pedersen et al. 2011) or are bullied in childhood because of poor social skills (Susser \& Widom, 2012). We demonstrated that prospective emigrant men in Sweden are not a negative selection and have not more psychosis risk factors than their non-migrant counterparts, which blends in with the notion that migrants are enterprising, and on average in better physical health than the general population. In the case of childhood bullying, it may well be that causality acts in both directions, meaning that exposure to this trauma is both a cause and an effect of (a vulnerability for) psychotic disorder. 
Kelleher and colleagues (2013) not only found a dose-response relationship between severity of childhood trauma and risk for psychotic experiences, but they also provided the first evidence that it is reversible, i.e. cessation of childhood trauma was predictive of a reduced incidence of psychotic experiences. It is therefore unlikely that the association between childhood bullying and development of psychotic symptoms can be solely explained by genetic confounding.

Vitamins, infections and cannabis

Migrant studies have been instrumental in the discovery of childhood as an important risk period implicated in multiple sclerosis (MS). The well-known north-south gradient of MS, with an increasing risk contingent on increasing latitude of the place of residence, applies to migrants who migrated after age fifteen. Those who migrated before age fifteen tend to retain the MS risk in their country of birth. As a result, hypovitaminosis D and viral infections have been identified as childhood environmental risk factors for MS (Handel et al. 2010). Similarly, exposures to vitamin D deficiency and Toxoplasmosa gondii in early life have been hypothesized to account for the migrant effect observed in the incidence of psychotic disorder (McGrath, 2011; Mortensen et al. 2007). However, as mentioned in the introduction, these putatively pathological exposures cannot account for increased psychosis risk among immigrants moving to similar, or even warmer countries. We further demonstrated in our meta-analysis on the incidence of psychotic disorder in first- and second-generation immigrants, that the intergenerational risk pattern differs from that of MS, given that migrants from countries with a warm climate do not seem to retain the low psychosis risk of their country of origin. Overall, the risk increased similarly in first- and second-generation migrants of various ethnic backgrounds. Our finding of a disproportional male-to-female ratio in psychosis risk among the Moroccan-Dutch also contradicts a purely biological explanation, because Moroccan men are not more exposed to any of the candidate biological factors. In fact, a reversal of the risk pattern would be expected, if vitamin $\mathrm{D}$ were an important risk factor, given that Moroccan females who are often veiled and spend more time indoors, are less exposed to sunlight, resulting in low serum vitamin D levels (van der Meer et al. 2011).

An exception to this rule applies to biological factors that are associated with risk behaviours, such as cannabis and other illicit drug use. Di Forti and colleagues (2015) found a population attributable fraction of first episode psychosis for cannabis use of $24 \%$ (95\% CI 17-31) in the ethnically diverse area of South London. They stress that the ready availability of high-potency cannabis may have increased the proportion of new psychosis cases attributable to cannabis use. It is therefore possible that drug abuse contributes to the excessive male-to-female ratio in psychosis risk among the Moroccan-Dutch. Indeed, Moroccan-Dutch men are disproportionally more likely to be treated for drug abuse compared to their female counterparts (Selten et al. 2007). However, there is no evidence that the rates of illicit drug use are increased among Moroccan-Dutch males with a first psychotic episode (Veen et al. 2002).

Reporting and selection bias are common methodological issues of studies depending on self-report measures of drug use, which makes reliable measurement of exposures 
extremely difficult (Selten et al. 2002). The bi-directionality of minority stress and drug use also challenges the interpretation of findings.

In conclusion, although we cannot exclude any influence of vitamin D or infectious agents whatsoever, the pattern of incidence findings does not suggest these factors play a large part in psychosis aetiology. Cannabis use may well contribute to, but not solely explain, the higher risk of psychotic disorder among minority populations.

The social context

The findings in this dissertation support previous lines of evidence, supporting the role of the social environment, more so than any explanation in terms of methodological artefacts or biological factors. In our review on the social defeat hypothesis, we concluded that this hypothesis is compatible with the accumulated findings that those aspects of the social environment pushing individuals into a stressful, minority position increase the risk for developing psychotic symptoms. This is supported by evidence of higher rates among individuals with an acquired hearing impairment (van der Werf et al. 2011), among sexual minorities (Gevonden et al. 2013) and among those who were victim of trauma in childhood (Varese et al. 2012). A central aspect concerns the subjective experience of social defeat or exclusion. Another attempt to explain increased risks as a consequence of psychosocial stressors is the sociodevelopmental model of Morgan and colleagues (2010). The authors of this model emphasize the role of individual-level indicators of social disadvantage, including parental separation, unemployment, poor housing, living alone and low education. Compared to the white British population, a cumulative pattern of social disadvantage was more prevalent among the African-Caribbean population in the UK, a migrant group with very high psychosis incidence (Morgan et al. 2008). However, immigrants of South Asian origin have a similar psychosis risk as their white British counterparts (Coid et al. 2008; Fearon et al. 2006; King et al. 1994), even though they live in comparable socio-economic conditions as the African-Caribbeans. A higher prevalence of potential protective factors, such as strong family ties and higher employment rates among South Asians in the UK, may account for these differences in psychosis incidence. This coincides with the social defeat hypothesis, positing that poor housing conditions, unemployment or low education only confer increased psychosis risk when it is experienced as humiliating or defeating (Selten \& Cantor-Graae, 2005). The relevance of the distinction between social disadvantage and social defeat can also be illustrated by examining different types of childhood adversities. Varese and colleagues (2012) performed an extensive meta-analysis and found that bullying and neglect, as well as emotional, sexual and physical abuse, were associated with an odds for psychosis of about 2.4 (95\% CI 2.0-2.9) to 3.4 (95\% CI 2.0-5.6). In contrast, parental death was not associated with a significantly increased risk estimate (OR=1.7, 95\% CI $0.8-3.5)$ for psychosis. This may indicate that the extent to which a trauma is subjectively experienced as humiliating, defines its pathogenic impact.

One could raise the important question as to whether individuals are always consciously aware of their subordinate or outsider position. In clinical practice, many patients with a psychotic disorder do not speak about events that would be interpreted by most people as defeating. Regardless of whether this is due to keeping up appearances or to the use 
of a defence mechanism like denial, it constitutes a challenge to the measurement of the experience of social defeat.

From a neurobiological perspective, there have been some recent advances in demonstrating that minority stress can have a reaction to brain mechanisms associated with the pathology of psychotic disorder. For instance, to test whether the mesolimbic dopamine system among excluded individuals is sensitized, Gevonden and colleagues (2014) compared the dexamphetamine-induced dopamine release in young adults with a severe hearing impairment and normal hearing controls using single-photon emission computed tomography (SPECT). They found a greater amphetamine-induced striatal dopamine release among people with severe hearing impairment, which is preliminary evidence of dopamine sensitization in a socially excluded group. Since this is a promising result, there is a strong need for further research to link increased psychosis susceptibility in ethnic minority populations to dopamine sensitization.

\section{Clinical implications and future studies}

Although there is accumulating evidence pointing at the role of the social context in the aetiology of psychotic disorder, many questions remain. It goes without saying that 'ethnicity' is not a risk factor in itself, but rather a proxy measure for other factors that have the potential to modify disease risk. Yet which specific aspects of the social environment increase psychosis risk by causing chronic minority stress? Does disease risk decrease or increase over time concomitant with changes in social status of an ethnic minority group? What is the effect of targeting minority stress as part of the treatment of individuals with psychotic disorder? Given the uncertainties across the board, research connecting epidemiological, neurobiological and genetic levels is needed to improve prevention and intervention strategies.

On epidemiological level there are many possibilities for future research. Although the increased risk of psychotic disorders in various ethnic minority groups, foremost among Moroccan immigrants in the Netherlands and African-Caribbeans in the UK, is a wellestablished finding, many risk patterns are still unknown. The example of Israel, where psychosis incidence among Ethiopian, but not Western Jews is significantly increased, shows that the studied association is highly context-specific (Corcoran et al. 2009; Weiser et al. 2008). Research on migrant groups with similar psychosis rates as the native population, could provide clues about resilience and protective factors that may counterbalance stressors. Departing from the social defeat hypothesis, one would expect that risk patterns change over time, parallel with the level of successful integration into the host society. Investigating intergenerational risk patterns could be instrumental. For instance, the intergenerational risk increase among Turkish migrants in the Netherlands generated the hypothesis that the strength of their social network may decline over time, therefore weakening protective influences (Veling et al. 2006). We also demonstrated a disproportional male-to-female risk pattern in a specific ethnic group, i.e. the Moroccan-Dutch, while an excessive femaleto-male risk has previously been reported among Asian immigrants in London (Coid et al. 2008). Identifying intergenerational and sex differences between and within ethnic groups 
may further aid our understanding of the nature of minority stress, which has implications for existing hypotheses on psychosis aetiology, as well as public health policies.

Despite the robust evidence of high psychosis rates in immigrants, there is very little recognition at the political level of what has been coined a "public health tragedy" (Morgan \& Hutchinson, 2010) and "the denial of a psychosis epidemic" (Selten \& Cantor-Graae, 2010). In times where the Islamic state and other Muslim-extremist groups dominate the news of the day, anti-Islamic political views have become increasingly popular in European society. Sadly, while the scientific evidence reveals an urgent need to strengthen the position of ethnic minorities in order to prevent the onset of new psychosis cases, the implementation of public health strategies is lagging behind. In an ideal world, based on the research so far, initiatives from within ethnic minority communities would promote education and general societal participation, while maintaining strong ties within the ethnic group. High-risk individuals should be identified early on and receive support to facilitate a healthy social development. Finally, anti-discrimination campaigns and other strategies to fight stigma should be in place to stimulate a more inclusive attitude at the receiving end of society.

The mounting evidence pointing to negative social experiences in psychosis aetiology may have implications for psychological treatments too. Fortunately, there has been a shift in the approach of psychosis treatment paradigms. Whereas a decade ago, few psychotic patients were treated for trauma for fear of causing relapse or disorganization in the person's life, there is now evidence that trauma therapy in psychotic patients has an alleviating effect on trauma-related distress, as well as psychotic symptoms (van den Berg et al. 2015). While most patients will receive therapy for specific, delimited traumas, it would be interesting to investigate whether treatment targeting the chronic exposure to social defeat is effective as well.

\section{Conclusion}

Overall, the research presented in this thesis provides strong evidence of an elevated risk for developing psychotic symptoms and psychotic disorder among various ethnic and other minority groups. Furthermore, ethnicity may modify the risk for autism-spectrum disorder, but the evidence of this is still thin. Misdiagnosis, selective migration and other methodological artefacts are implausible explanations for the findings on psychotic disorder. Instead, we propose that 'social defeat', defined as the chronic experience of being excluded from the majority group, may increase the risk for psychotic disorder by sensitizing the mesolimbic dopamine system. Future challenges lie in connecting the underlying biological mechanisms to behavioural expression in socially excluded groups, as well as in bridging the gap with the clinical field and the wider society by stimulating the implementation of strategies that strengthen the position of minority populations. 


\section{References}

1. Cantor-Graae, E., Selten, J. P. (2005). Schizophrenia and migration: a metaanalysis and review. Am J Psychiatry 162, 12-24.

2. Coid, J. W., Kirkbride, J. B., Barker, D., Cowden, F., Stamps, R., Yang, M., Jones, P. B. (2008). Raised incidence rates of all psychoses among migrant groups: findings from the East London first episode psychosis study. Arch Gen Psychiatry 65, 1250-1258.

3. Corcoran, C., Perrin, M., Harlap, S., Deutsch, L., Fennig, S., Manor, O., Nahon, D., Kimhy, D., Malaspina, D., Susser, E. (2009). Incidence of schizophrenia among second-generation immigrants in the Jerusalem perinatal cohort. Schizophr Bull 35, 596-602.

4. Di Forti, M., Marconi, A., Carra, E., Fraietta, S., Trotta, A., Bonomo, M., Bianconi, F., Gardner-Sood, P., O’Connor, J., Russo, M. (2015). Proportion of patients in south London with first-episode psychosis attributable to use of high potency cannabis: a case-control study. Lancet Psychiatry 2, 233-238.

5. Fearon, P., Kirkbride, J. B., Morgan, C., Dazzan, P., Morgan, K., Lloyd, T., Hutchinson, G., Tarrant, J., Fung, W. L., Holloway, J., Mallett, R., Harrison, G., Leff, J., Jones, P. B., Murray, R. M. (2006). Incidence of schizophrenia and other psychoses in ethnic minority groups: results from the MRC AESOP Study. Psychol Med 36, 1541-1550.

6. Gevonden, M., Booij, J., van den Brink, W., Heijtel, D., Van Os, J., Selten, J. P. (2014). Increased release of dopamine in the striata of young adults with hearing impairment and its relevance for the social defeat hypothesis of schizophrenia. JAMA Psychiatry 71, 13641372.

7. Gevonden, M. J., Selten, J. P., MyinGermeys, I., de Graaf, R., Ten Have, M., van Dorsselaer, S., van Os, J., Veling, W. (2013). Sexual minority status and psychotic symptoms: findings from the Netherlands Mental Health Survey and Incidence Studies (NEMESIS). Psychol Med, 1-13.

8. Handel, A. E., Giovannoni, G., Ebers, G. C., Ramagopalan, S. V. (2010). Environmental factors and their timing in adult-onset multiple sclerosis. Nat Rev Neurol 6, 156-166.
9. Kapur, S., Phillips, A. G., Insel, T. R. (2012). Why has it taken so long for biological psychiatry to develop clinical tests and what to do about it. Mol Psychiatry 17, 1174-1179.

10. Kelleher, I., Keeley, H., Corcoran, P., Ramsay, H., Wasserman, C., Carli, V., Sarchiapone, M., Hoven, C., Wasserman, D., Cannon, M. (2013). Childhood trauma and psychosis in a prospective cohort study: cause, effect, and directionality. Am J Psychiatry 170, 734-741.

11. King, M., Coker, E., Leavey, G., Hoare, A., Johnson-Sabine, E. (1994). Incidence of psychotic illness in London: comparison of ethnic groups. BMJ 309, 1115-1119.

12. McGrath, J. (2011). Migrant status, vitamin D and risk of schizophrenia. Psychol Med 41, 892-893.

13. McGrath, J. J. (2007). The surprisingly rich contours of schizophrenia epidemiology. Arch Gen Psychiatry 64, 14-16.

14. Morgan, C., Charalambides, M., Hutchinson, G., Murray, R. M. (2010). Migration, ethnicity, and psychosis: toward a sociodevelopmental model. Schizophr Bull 36, 655-664.

15. Morgan, C., Hutchinson, G. (2010). The social determinants of psychosis in migrant and ethnic minority populations: a public health tragedy. Psychol Med 40, 705-709.

16. Morgan, C., Kirkbride, J., Hutchinson, G., Craig, T., Morgan, K., Dazzan, P., Boydell, J., Doody, G. A., Jones, P. B., Murray, R. M., Leff, J., Fearon, P. (2008). Cumulative social disadvantage, ethnicity and first-episode psychosis: a case-control study. Psychol Med 38, 1701-1715.

17. Mortensen, P. B., Norgaard-Pedersen, B., Waltoft, B. L., Sorensen, T. L., Hougaard, D., Torrey, E. F., Yolken, R. H. (2007). Toxoplasma gondii as a Risk Factor for EarlyOnset Schizophrenia: Analysis of Filter Paper Blood Samples Obtained at Birth. Biol Psychiatry 61, 688-693.

18. Ødegaard, Ø. (1932). Emigration and insanity: a study of mental disease among Norwegian-born population in Minnesota. Acta Psychiatr Neurol Scan Suppl 4, 1-206.

19. Pedersen, C. B., Mortensen, P. B., CantorGraae, E. (2011). Do risk factors for 
schizophrenia predispose to emigration? Schizophr Res 127, 229-234.

20. Selten, J. P., Bosman, I. J., de, B. D., Veen, N. D., van der Graaf, Y., Maes, R. A., Kahn, R. S. (2002). Hair analysis for cannabinoids and amphetamines in a psychosis incidence study. Eur. Neuropsychopharmacol. 12, 27 30.

21. Selten, J. P., Cantor-Graae, E. (2005). Social defeat: risk factor for schizophrenia? Br J Psychiatry 187, 101-102.

22. Selten, J. P., Cantor-Graae, E. (2010). The denial of a psychosis epidemic. Psychol Med 40, 731-733.

23. Selten, J. P., Wierdsma, A., Mulder, N., Burger, H. (2007). Treatment seeking for alcohol and drug use disorders by immigrants to the Netherlands: retrospective, populationbased, cohort study. Soc Psychiatry Psychiatr Epidemiol 42, 301-306.

24. Susser, E., Widom, C. S. (2012). Still searching for lost truths about the bitter sorrows of childhood. Schizophr Bull 38, 672-675.

25. Tandon, R., Keshavan, M. S., Nasrallah, H. A. (2008). Schizophrenia, just the facts what we know in 2008. 2. Epidemiology and etiology. Schizophr Res 102, 1-18.

26. van den Berg, D. P., de Bont, P. A., van der Vleugel, B. M., de Roos, C., de Jongh, A., Van Minnen, A., van der Gaag, M. (2015). Prolonged Exposure vs Eye Movement Desensitization and Reprocessing vs Waiting List for Posttraumatic Stress Disorder in Patients With a Psychotic Disorder A Randomized Clinical Trial. JAMA Psychiatry 72, 259-267.

27. van der Meer, I. M., Middelkoop, B. J., Boeke, A. J., Lips, P. (2011). Prevalence of vitamin D deficiency among Turkish, Moroccan, Indian and sub-Sahara African populations in Europe and their countries of origin: an overview. Osteoporos Int 22, 1009-1021.

28. vander Werf, M., Thewissen, V., Dominguez, M. D., Lieb, R., Wittchen, H., van Os, J. (2011). Adolescent development of psychosis as an outcome of hearing impairment: a 10-year longitudinal study. Psychol Med 41, 477-485.

29. Varese, F., Smeets, F., Drukker, M., Lieverse, R., Lataster, T., Viechtbauer, W., Read, J., van Os, J., Bentall, R. P. (2012). Childhood adversities increase the risk of psychosis: a meta-analysis of patient-control, prospective- and cross-sectional cohort studies. Schizophr Bull 38, 661-671.

30. Veen, N., Selten, J. P., Hoek, H. W., Feller, W., van der Graaf, Y., Kahn, R. (2002). Use of illicit substances in a psychosis incidence cohort: a comparison among different ethnic groups in the Netherlands. Acta Psychiatr Scand 105, 440-443.

31. Veling, W., Selten, J. P., Veen, N., Laan, W., Blom, J. D., Hoek, H. W. (2006). Incidence of schizophrenia among ethnic minorities in the Netherlands: a four-year first-contact study. Schizophr Res 86, 189-193.

32. Vermeulen, M. (2014, February 5). Marokkaan krijgt te snel diagnose schizofrenie [Moroccan-Dutch is diagnosed with schizophrenia too quickly]. De Volkskrant. Retrieved from: https://www. volkskrant.nl.

33. Weiser, M., Werbeloff, N., Vishna, T., Yoffe, R., Lubin, G., Shmushkevitch, M., Davidson, M. (2008). Elaboration on immigration and risk for schizophrenia. Psychol Med 38, 11131119.

34. Zandi, T., Havenaar, J. M., Smits, M., Limburg-Okken, A. G., van Es, H., Cahn, W., Algra, A., Kahn, R. S., van den Brink, W. (2010). First contact incidence of psychotic disorders among native Dutch and Moroccan immigrants in the Netherlands: influence of diagnostic bias. Schizophr Res 119, 27-33.

\section{9}





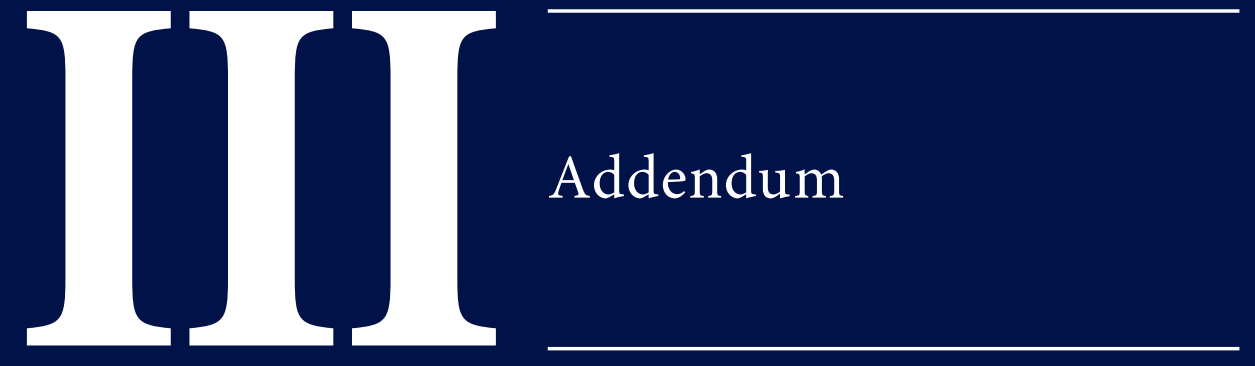





\section{Valorisation}

"Valorisation is the process of creating value from knowledge, by making this knowledge available and suitable for economic and social exploitation and to translate this knowledge into products, services, processes and new business." (Maastricht Valorisation Center, Maastricht University)

So valorisation is essentially the question why we study what we study. What is the practical use? Why is it important? Maastricht University emphasizes that PhD students ought to be self-critical and reflect on how their research counts, both within and outside the scientific community. In my discussion, I have already touched upon the importance of this thesis for understanding psychosis aetiology and how this may have implications for clinical treatment. Our findings further demonstrate a need for strengthening the position of ethnic minorities. In this addendum, I take the opportunity to discuss another way in which this thesis may add practical value.

While more than a million, mostly Syrian and Afghani refugees crossed into Europe in 2015, the largest influx of non-European immigrants in modern history (UNHCR, 2015), it is clear that studying the mental health of (ethnic) minority populations is relevant. It is part of our present reality, but it will possibly be even more so in the future. So what are the implications of our findings for this situation? To answer this question, we need to know more about what is happening.

Most refugees escape hunger, war and extreme poverty. There is not much time to plan the migration. They only leave with a bag of belongings and a little bit of money. For some there might already be family in Europe, others leave with the goal to cross to any Western European country where they can settle. All their money is spent on this one shot to make it across. The migration is tough; the journey by boat is dangerous and traumatic. Once on European soil, the circumstances are poor, lodging is insufficient, women feel unsafe, basic needs are not met. With a dream of a welcoming promise land in mind refugees keep on going, walking incredible distances while weather conditions are challenging.

A fortunate group makes it to Germany or Sweden, the most wanted destinations because of their flexible asylum policies, but Austria, Hungary, Belgium and the Netherlands are also popular (Eurostat, 2015). In the country where asylum is sought, people are registered and placed in temporary camps, ranging from military tents to school gymnasiums. There are volunteers from the Red Cross distributing clothes and food, and there is shelter. The accommodation is improvised and there is not much privacy. Volunteers teach the basics of the local language and some sports activities are in place. However, activities are insufficient to fill up a day and people are bored. The registration process takes up a lot of time and there are many uncertainties. Refugees do not know when their case will be handled, when they will have more information on their status and whether they are allowed to stay. Many families have been separated in the process and people are in desperate need of having information on the whereabouts of their loved ones. Unlike their expectations, they learn that family reunification can take up to years. 
In Europe, we are preoccupied with the consequences of the migration waves for our safety, our economy, for our living conditions. By doing so, we fail to put in perspective the detrimental effect this crisis may have for the people who are actually experiencing it.

In this thesis, we show that immigrants from the Middle East have a twofold risk increase for psychosis compared to the local population, which persists in the second generation. A similar risk increase was found for refugees in Sweden (Leao et al., 2006), one of the countries considered to have the most favourable circumstances for refugees. Importantly, these figures may represent a too optimistic view as they relate to refugees who obtained a legal status in Europe.

We demonstrated that factors leading to social exclusion might stir up psychosis risk. The majority of asylum seekers in Europe are forbidden to work and they may experience a lack of access to health care services, language barriers, long asylum procedures and family separations. They are excluded from European society.

In line with our findings showing that circumstances after migration are more important for psychosis risk than the migration process itself, the same might be true for psychopathology at large. Porter and Haslam (2005) found that living in institutional accommodation and restricted economic opportunities were predictive of psychopathology, while having a private home was a protective factor. Although socioeconomic status and education are positively associated with mental health, refugees who were more educated and had a higher socioeconomic status before migration had worse outcomes. The authors conclude that: "the sociopolitical context of the refugee experience is associated with refugee mental health. Humanitarian efforts that improve these conditions are likely to have positive impacts."

I am painfully aware that I am not providing any solutions here, however, acknowledging the high-risk situation that these people are in, may hopefully lead to a somewhat less selfcentred attitude in some.

\section{References}

1. Eurostat (2015). First quarter 2015: Eurostat news release 112/2015 18 June 2015. Retrieved from http://ec.europa.eu/eurostat/ documents/2995521/6887997/3-18062015CP-EN.pdf/4457b050-26f9-4cf1-bf279ffb73ff8c7b. Accessed Feb 13, 2016.

2. Leão, T.S., Sundquist, J., Frank, G., Johansson, L. M., Johansson, S. E., \& Sundquist, K. (2006). Incidence of schizophrenia or other psychoses in first-and second-generation immigrants: a national cohort study. J Nerv Ment Dis 194, 27-33.
3. Porter, M., \& Haslam, N. (2005). Predisplacement and postdisplacement factors associated with mental health of refugees and internally displaced persons: a meta-analysis. JAMA 294, 602-612.

4. UNHCR (2015). UNHCR Mid-Year Trends 2015. United Nations High Commissioner for Refugees, Geneva. Retrieved from http:// www.unhcr.org/56701b969.html. Accessed Feb 13, 2016. 


\section{Nederlandse samenvatting}

\section{Inleiding}

Dit proefschrift gaat over het risico op psychotische en autismespectrumstoornissen onder eerste- en tweedegeneratie migranten vergeleken met autochtonen. We gaan tevens op zoek naar verklaringen waarom het risico voor het ontwikkelen van psychotische stoornissen onder etnische en andere minderheidsgroepen verhoogd is. Migrantenonderzoek kan een uniek inzicht geven in het ontstaan van ziektebeelden door de frequentie van een ziekte te bepalen bij een verandering in omgeving. Door de kans op een bepaalde ziekte onder migranten te vergelijken met die van de thuisblijvers en de autochtone bevolking kunnen we beschermende en risicofactoren voor het ontwikkelen van die ziekte identificeren (NolenHoeksema, 1987).

We gebruiken hier meerdere definities voor het beschrijven en categoriseren van migrantengroepen. Migrantenonderzoek betreft grotendeels eerstegeneratiemigranten die in het buitenland geboren en zelf geëmigreerd zijn. Ook hun kinderen, tweedegeneratiemigranten, zullen aan bod komen die geen persoonlijke migratiegeschiedenis hebben. In tegenstelling tot hun ouders zijn zij niet blootgesteld aan de stressvolle omstandigheden voor en tijdens het migratieproces, maar zij delen wel de omstandigheden na migratie en groeien op in een minderheidspositie. Een onderverdeling van migranten naar etniciteit geeft weer met welke groep een persoon zich identificeert op grond van factoren, zoals geboorteregio, taal, dieet, geloof en lichamelijke eigenschappen.

\section{Psychotische en autismespectrumstoornissen}

Voordat ik overga op de belangrijkste bevindingen van dit proefschrift wil ik enkele termen nader toelichten. Met psychotische symptomen refereert men gebruikelijk naar zogeheten positieve symptomen, waaronder hallucinaties en waanideeën. Ongeveer $7 \%$ van de bevolking rapporteert deze ervaringen en ze zijn in $75 \%$ van de gevallen van voorbijgaande aard (van Os et al. 2009). Deze cijfers komen voort uit populatiestudies; onderzoek onder nietklinische steekproeven, d.w.z. willekeurige groepen mensen uit de (overwegend westerse) bevolking die niet in zorg zijn vanwege een psychose. Wanneer psychotische symptomen frequent aanwezig zijn, langer dan een week aanhouden en het functioneren van de persoon aantasten, spreken we van een (klinische) psychose of een psychotische stoornis. Als een psychose niet in het kader van een somatische aandoening, na gebruik of onttrekking van een psychoactief middel, of tijdens een ernstige depressie of manie ontstaat, kan bij een duur van meer dan zes maanden de diagnose schizofrenie gesteld worden.

In dit proefschrift is ook een onderzoek naar autismespectrumstoornissen (ASS) opgenomen. Er bestaat overlap tussen psychotische verschijnselen en symptomen die passen bij ASS, waaronder problemen in de sociale interactie en in het cognitief functioneren. Er zijn echter ook wezenlijke verschillen tussen deze syndromen. Zo zijn ASS ontwikkelingsstoornissen wat betekent dat ze in de vroege kindertijd aanwezig zijn, in de meeste gevallen al vóór het tweede levensjaar. Psychotische stoornissen ontwikkelen zich daarentegen vaak in de jonge volwassenheid. In ons onderzoek maakten wij een onderscheid tussen 'klassiek' autisme, de meest ernstige variant, het syndroom van Asperger en PDD-NOS 
('Pervasive Developmental Disorder Not Otherwise Specified'). Bij Asperger ontbreekt de vertraagde taalontwikkeling die bij autisme aanwezig is, en de diagnose PDD-NOS is een restcategorie die wordt gebruikt voor kinderen met sociale en communicatieve problemen, zoals bij autisme, maar in onvoldoende mate om aan de diagnose van autisme te voldoen.

\section{Psychose en autisme onder minderheidsgroepen}

Het eerste doel van dit proefschrift was om het vóórkomen van psychotische en austismespectrumstoornissen onder verschillende minderheidsgroepen te onderzoeken (hoofdstukken $2 \mathrm{t} / \mathrm{m}$ 5). In hoofdstuk 2 tonen wij aan dat het verhoogd risico voor psychotische stoornissen niet alleen geldt voor migranten van de eerste generatie met een persoonlijke migratiegeschiedenis, maar ook voor de tweede generatie die geboren is in het gastland als kind van één of twee gemigreerde ouders. De migratie zelf maakt dus niet het verschil, maar het lidmaatschap van een etnische minderheid. Bovendien vonden we dat huidskleur een rol speelt. Migranten met een donkere huidskleur hebben een vijfmaal verhoogd risico en migranten met een blanke huidskleur een tweemaal verhoogd risico vergeleken met autochtonen. Ook maakt het uit in welk gastland migranten geboren worden. Zo vonden wij dat het risico op psychose onder tweedegeneratiemigranten in Groot-Brittannië en Nederland hoger was dan in Scandinavië of Israël. Een belangrijke kanttekening is dat migrantengroepen zeer heterogeen zijn en dat de bevindingen niet van toepassing zijn op elk individu die tot een bepaalde etnische groep behoort.

Psychose komt ongeveer tweemaal vaker voor bij mannen dan bij vrouwen (Aleman et al. 2003). Onderzoek onder migranten laat zien dat het risico op het ontwikkelen van een psychotische stoornis voor zowel mannen als vrouwen vergeleken met autochtonen van hetzelfde geslacht ongeveer tweevoudig verhoogd is. Onder Noord-Afrikaanse immigranten lijken de geslachtsverschillen in psychoserisico echter buiten proportie met veel hogere cijfers voor mannen dan vrouwen. In hoofdstuk 3 hebben we systematisch onderzocht of dit daadwerkelijk het geval is en of deze observatie betrouwbaar is. Als we het onderzoek tot op heden samenvatten, blijkt dat in Europa, Noord-Afrikaanse mannen een vijfmaal hoger risico hebben op het ontwikkelen van psychose dan Noord-Afrikaanse vrouwen. Het overgrote deel van het bewijs is gestoeld op onderzoek onder Marokkaanse Nederlanders. Het geslachtsverschil was ook zichtbaar als we de aanwezigheid van psychotische symptomen onder een steekproef van Marokkaanse Nederlanders onderzochten. Andere migrantengroepen in Europa, afkomstig uit onder meer Zuid-Amerika en ten zuiden van de Sahara in Afrika, hadden ook verhoogde psychoserisico's, maar bij hen vonden we niet een dergelijk disproportioneel geslachtsverschil. Een definitieve verklaring voor deze opvallende bevinding hebben we niet. Een daling in sociale status na migratie, een kloof tussen verwachting en daadwerkelijk succes, of een hoger percentage druggebruik onder Marokkaans-Nederlandse mannen behoren tot onze hypothesen.

In hoofdstuk 4 staat een andere minderheidsgroep centraal, namelijk kinderen die slachtoffer zijn van pesten. Het overkomt ongeveer 1 op de 10 kinderen. In de afgelopen decennia zijn er verschillende klinische en algemene populatiestudies verricht naar de associatie tussen pesten en psychose. Klinische studies onder patiënten met een psychotische 
stoornis lieten over het algemeen gemengde resultaten zien. Populatiestudies toonden echter consistent bewijs dat pesten op school geassocieerd is met het ontwikkelen van nietklinische, psychotische symptomen. Kinderen die slachtoffer zijn van pesten hebben een ruim tweemaal verhoogd risico op het ontwikkelen van psychotische symptomen. Deze associatie bleek sterker naarmate de frequentie, de duur en de ernst van het pesten toeneemt.

In hoofdstuk 5 hebben we onderzocht of autisme-spectrumstoornissen net als psychotische stoornissen vaker voorkomen onder tweedegeneratie migranten in Nederland. Met behulp van het Psychiatrisch Casus Register van Midden-Nederland waren we in staat om ruim 100.000 pasgeborenen in Utrecht en omgeving te volgen. Van deze kinderen kwamen ruim 500 in zorg vanwege een ASS wat gelijk staat aan 1 op de 100 kinderen op 10 -jarige leeftijd. Hiervan kreeg $20 \%$ de diagnose autisme en $80 \%$ de diagnose PDD-NOS of Asperger. Over het algemeen hadden kinderen van ouders die geëmigreerd waren uit ontwikkelingslanden een lager risico de diagnose ASS te krijgen dan autochtone kinderen. Wanneer we de diagnostische groepen echter nader opsplitsten, bleek dat het risico voor PDD-NOS en Asperger significant lager was, terwijl het risico voor autisme onder deze kinderen juist hoger was. Deze bevinding wordt ondersteund door onderzoek uit Scandinavië waarin eenzelfde risicopatroon gevonden werd (Magnusson et al. 2012). Nader onderzoek moet aantonen of allochtone kinderen daadwerkelijk een verhoogd dan wel verlaagd risico voor ASS hebben. Het is ook mogelijk dat allochtone kinderen met ASS de weg naar de GGZ minder vaak bewandelen.

Samengevat vonden wij dat het van belang is of iemand tot een minderheid behoort voor het risico in zorg te komen vanwege een psychotische of autismespectrumstoornis. Voor psychotische stoornissen lijkt te gelden dat hoe meer iemand in deze minderheidspositie gedrukt wordt, hoe groter het risico dat psychotische symptomen zich ontwikkelen.

\section{Misdiagnose, selectieve migratie en 'social defeat'}

In het tweede deel van dit proefschrift hebben we verschillende hypothesen getoetst die opgevoerd zijn als verklaringen voor het verhoogde risico van psychotische stoornissen onder etnische en andere minderheidsgroepen. Zandi en collega's veronderstellen dat het verhoogd risico te verklaren valt door structurele misdiagnostiek van etnische minderheidsgroepen. Zij beweren dat westerse clinici met hun westerse diagnostische instrumenten en wellicht een wat bevooroordeelde klinische blik, de neiging hebben om ervaringen die passen binnen de cultuur ten onrechte te bestempelen als psychotische symptomen (Zandi et al. 2011). Om deze hypothese te toetsen hebben wij onderzocht of de klinische presentatie van etnische minderheden in Montreal, Canada, verschilt van die van de meerderheidsgroep, d.w.z. blanke Canadezen. Op basis van etniciteit bleken er geen verschillen te zijn in de ernst van de positieve symptomen, de leeftijd waarop de psychose zich had ontwikkeld of in de duur van de periode dat de psychose onbehandeld bleef. Wel vonden wij aanwijzingen dat de route om in zorg te komen voor patiënten van Caribische en Afrikaanse afkomst vaker onprettig en via een opname verloopt. Ondanks dat de etnische achtergrond van een persoon de inhoud van psychotische ervaringen zeker kan kleuren, concludeerden wij dat de kernkenmerken van psychose niet beïnvloed worden door etniciteit. Met dit onderzoek leveren we aanvullend 
bewijs dat misdiagnostiek geen sluitende verklaring vormt voor de hoge psychoserisico's onder etnische minderheden.

Een andere hypothese is die van selectieve migratie. Ødegaard liet al in 1932 zien dat het aantal ziekenhuisopnames voor psychose onder Noorse immigranten in de Verenigde Staten tweemaal hoger was dan onder autochtone Amerikanen en onder Noren in Noorwegen. Hij meende dat mensen met een aanleg voor psychose hun geluk vaker elders zoeken, omdat ze door hun kwetsbaarheid geen aansluiting vinden in hun geboorteland (Ødegaard, 1932). Wij onderzochten Ødegaard's selectiehypothese met behulp van gegevens van vijftigduizend Zweedse mannen. Bij hun keuring voor militaire dienst werden ze onder meer geëvalueerd op zaken waarvan we weten dat ze het risico op psychose vergroten, zoals een laag IQ, aanwezigheid van een psychotische stoornis bij vader of moeder, vroegkinderlijk trauma, slecht sociaal functioneren, opgroeien in een stad en cannabisgebruik. Daarna zochten we uit welke van deze mannen later geëmigreerd zijn. De mannen die Zweden hadden verlaten waren vaker opgegroeid in de stad en hadden voor emigratie meer cannabis gebruikt. Ze hadden daarentegen juist een hoger IQ en een beter sociaal functioneren dan de thuisblijvers. Er waren geen verschillen tussen de groepen in de andere risicofactoren. Samenvattend vonden wij geen ondersteunend bewijs voor de selectiehypothese en de bevindingen pleiten tegen Ødegaard's profielschets van migranten als onaangepaste einzelgängers.

Tenslotte hebben wij in hoofdstuk 8 onderzocht of de 'social defeat' hypothese een verenigbare verklaring geeft voor vijf belangrijke omgevingsfactoren die een rol spelen bij het ontstaan van psychose. Deze factoren zijn: opgroeien in een stedelijke omgeving, een laag IQ, traumatische ervaringen, druggebruik en een voorgeschiedenis van migratie. Volgens de 'social defeat' hypothese kan de subjectieve ervaring dat iemand zich een buitenstaander voelt de dopaminehuishouding in het brein ontregelen, waardoor het psychoserisico toeneemt. Dopamine is de stof in het brein die als belangrijkste kandidaat geassocieerd is met psychotische symptomen. Uit dieronderzoek is tevens gebleken dat van een rat die herhaaldelijk verslagen wordt door een soortgenoot het dopaminesysteem ontregelt (Covington, III and Miczek, 2001). Alhoewel dit aantoont dat 'social defeat' tot ontregeling van dopamine in het rattenbrein kan leiden, is het bewijs voor eenzelfde soort mechanisme in mensen nog dun (Gevonden et al. 2014). Ten aanzien van de omgevingsfactoren menen wij dat de 'social defeat'-hypothese een spaarzame verklaring biedt, omdat urbanisatie, migratie, laag IQ, druggebruik en trauma de kans vergroten dat iemand in een positie als buitenstaander terecht komt, wat voorts zou kunnen leiden tot een verhoogd risico op het ontwikkelen van een psychose.

Op basis van de 'social defeat' hypothese kunnen we veronderstellen dat jongeren die zich buitengesloten voelen, kwetsbaar zijn voor het ontwikkelen van psychotische symptomen. Een groep Turkse professionals schreef hierover in de Volkskrant van 10 januari 2011:

"Al met al is er een groeiende groep jongeren aan het ontstaan die zich ontheemd voelen. Ze voelen zich niet welkom in de Nederlandse samenleving. Sommigen trekken zich terug in de eigen (religieuze) gemeenschap, anderen zonderen zich af en dreigen te vereenzamen, ernstige psychische klachten te ontwikkelen of vatbaar te worden voor de verleidingen van radicalisme of criminaliteit. Dat zou niet alleen dramatisch zijn voor deze jongeren, maar voor de hele Nederlandse samenleving." 
Concluderend laten wij zien dat er robuust wetenschappelijke bewijs is voor een verhoogd risico op psychotische stoornissen onder verscheidene etnische en andere minderheidsgroepen. Mogelijk zijn er op basis van etniciteit ook verschillen in de behandelde incidentie van autismespectrumstoornissen, maar dit vergt meer onderzoek. Misdiagnose, selectieve migratie en andere methodologische vertekeningen bieden geen sluitende verklaring voor de verhoogde psychoserisico's in minderheidsgroepen. Wij beweren daarentegen dat het pathologische effect van de ervaring als buitenstaander ten grondslag ligt aan onze bevindingen. Uitdagingen voor de toekomst liggen in het verbinden van de biologische mechanismen aan de ervaringen van sociaal buitengesloten groepen. Want hoe sterker het bewijs, hoe nadrukkelijker het belang van het implementeren van strategieën die de positie van etnische minderheden versterken.

\section{References}

1. Aleman, A., Kahn, R. S., Selten, J. P. (2003). Sex differences in the risk of schizophrenia: evidence from meta-analysis. Arch Gen Psychiatry 60, 565-571.

2. Covington, H. E., III \& Miczek, K. A. (2001). Repeated social-defeat stress, cocaine or morphine. Effects on behavioral sensitization and intravenous cocaine self-administration "binges". Psychopharmacology (Berl) 158, 388-398.

3. Gevonden, M., Booij, J., van den Brink, W., Heijtel, D., van Os, J., Selten, J. P. (2014). Increased release of dopamine in the striata of young adults with hearing impairment and its relevance for the social defeat hypothesis of schizophrenia. JAMA Psychiatry 71, 13641372.

4. Magnusson, C., Rai, D., Goodman, A., Lundberg, M., Idring, S., Svensson, A., Koupil, I., Serlachius, E., Dalman, C. (2012). Migration and autism spectrum disorder: population-based study. Br J Psychiatry 201, 109-115.

5. Nolen-Hoeksema, S. (1987). Sex differences in unipolar depression: evidence and theory. Psychol Bull 101, 259-282.

6. Ødegaard, Ø. (1932). Emigration and insanity: a study of mental disease among Norwegian-born population in Minnesota. Acta Psychiatr Neurol Scand Suppl 4, 1-206.

7. van Os, J., Linscott, R. J., Myin-Germeys, I., Delespaul, P., Krabbendam, L. (2009). A systematic review and meta-analysis of the psychosis continuum: evidence for a psychosis proneness-persistenceimpairment model of psychotic disorder. Psychol Med 39, 179-195.

8. Zandi, T., Havenaar, J. M., Laan, W., Kahn, R. S., van den Brink, W. (2011). Predictive validity of a culturally informed diagnosis of schizophrenia: a 30 month follow-up study with first episode psychosis. Schizophr Res 133, 29-35.

\section{\&}





\section{List of publications}

\section{Peer-reviewed journal articles}

Van der Ven, E., Dalman, C., Wicks, S., Allebeck, P., van Os, J., Magnusson, C., Selten, J.P. (2015) Testing Ødegaard's Selective Migration hypothesis: a longitudinal cohort study of risk factors for non-affective psychotic disorders among prospective emigrants. Psychological Medicine, 45(4): 727-734.

Selten, J.P., van der Ven, E., Rutten, B., Cantor-Graae, E. (2013) The social defeat hypothesis of schizophrenia: an update. Schizophrenia Bulletin, 39(6): 1180-1186.

Van der Ven, E., Termorshuizen, F., Laan, W., Breetvelt, E.J., van Os, J., Selten, J.P. (2012) An incidence study of diagnosed autism-spectrum disorders among immigrants to the Netherlands. Acta Psychiatrica Scandinavica, 128(1):54-60.

Van Dam, D.S., van der Ven, E., Velthorst, E., Selten, J.P., Morgan, C., de Haan, L. (2012) Childhood bullying and the association with psychosis in non-clinical and clinical samples: a review and meta-analysis. Psychological Medicine, 42(12): 2463-2474.

Van der Ven, E., Bourque, F., Joober, R., Selten, J.P., Malla, A. (2012) Comparing the clinical presentation of first episode psychosis across different migrant and ethnic minority groups in Montreal, Quebec. Canadian Journal of Psychiatry, 57(5): 300-308.

Bourque, F., van der Ven, E., Fusar-Poli, P., Malla, A. (2012) Immigration, social environment and onset of psychotic disorders. Current Pharmaceutical Design, 18(4): 518-526.

Bourque, F., van der Ven, E., Malla, A. (2011) A meta-analysis of the risk for psychotic disorders among first-and second generation immigrants. Psychological Medicine, 41(5): 897-910.

\section{Under review}

Van der Ven, E., Veling, W., Tortelli, A., Tarricone, I., Berardi, D., Bourque, F., Selten, J.P. Evidence of an excessive male-to-female ratio among North African immigrants with a psychotic disorder in Europe: a systematic review and meta-analysis.

\section{Book chapters}

Van der Ven, E., Laban, C.J., Selten, J.P. (2013) Sociaal-maatschappelijke oorzaken van psychiatrische stoornissen bij migranten en vluchtelingen. In C. van der Feltz-Cornelis \& N. Mulder (redactie), Handboek Sociale Psychiatrie. Utrecht: De Tijdstroom. 


\section{Online contributions}

Van der Ven, E., Selten, J. (2012) Naar erkenning van een epidemie van psychosen onder migranten in Europa. Cultuur, Migratie en Gezondheid, www.mikadonet.nl.

\section{Refereed conference proceedings and invited lectures}

Van der Ven, E., Veling, W., Tortelli, A., Tarricone, I., Berardi, D., Bourque, F., Selten, J.P. Het mysterie van de excessieve man-vrouwratio in psychoserisico onder Noord-Afrikaanse immigranten in Europa. Gepresenteerd op het NVvP Voorjaarscongres, Maastricht, april 2015.

Van der Ven, E., Dalman, C., Wicks, S., Allebeck, P., van Os, J., Magnusson, C., Selten, J.P. Odegaard's selectiehypothese getoetst: longitudinaal cohortonderzoek naar risicofactoren voor psychotische stoornissen in emigranten. Gepresenteerd op het NVvP Voorjaarscongres, Maastricht, april 2014.

Van der Ven, E., van Dam, D.S., van der Meer, F.J., Velthorst, E., Messchaert, E., Sweep, F., de Haan, L., Selten, J.P. Plasma Oxytocin and Testosterone Levels in Patients with psychotic Disorder, their Unaffected Siblings and Healthy Controls: Results from the EU-GEI Project. Presented at the European Congress of Psychiatry (EPA), Munich, Germany, March 2014.

Van der Ven, E., Dalman, C., Wicks, S., Allebeck, P., van Os, J., Magnusson, C., Selten, J.P. Testing alternative hypotheses for the increased rate of psychotic disorder in immigrants. Presented at the European Congress of Psychiatry (EPA), Munich, Germany, March 2014.

Van der Ven, E., Bourque, F., Joober, R., Selten, J.P., Malla, A. The clinical presentation of first-episode psychosis across different migrant and ethnic minority groups in Montreal, Quebec. Presented at PEPP $10^{\text {th }}$ anniversary conference, Montreal, Canada, May 2013.

Van der Ven, E., Termorshuizen, F., Laan, W., Breetvelt, E.J., van Os, J., Selten, J.P. An incidence study of diagnosed autism-spectrum disorders among immigrants to the Netherlands. Presented at European Congress of Psychiatry (EPA), Nice, France, April 2013. (awarded with a travel grant).

Van der Ven, E., Termorshuizen, F., Laan, W., Breetvelt, E.J., van Os, J., Selten, J.P. Een cohortstudie van autismespectrumstoornissen onder kinderen van allochtone afkomst. Gepresenteerd op het NVvP Voorjaarscongres, Maastricht, april 2012. 


\section{Dankwoord}

Op een ijskoude ochtend in januari 2008 loop ik net buiten het psychiatrisch ziekenhuis in Montreal, Canada, door de meterhoge sneeuw te ploeteren, uitgestapt bij het verkeerde busstation, aan de compleet andere kant van het immense complex, uiteraard een tikkeltje aan de late kant. Met verkleumde voeten struikel ik zenuwachtig, in een spoor van brokjes sneeuw, de psychosekliniek van het ziekenhuis binnen.

Daar komt een glimlachende Indiër op me af gelopen. Dr. Malla, thanks for having faith in this newly arrived, inexperienced Dutchie. You have introduced me to the clinical world of psychiatry, specifically psychosis, for which I am extremely thankful. Your vision and optimism regarding recovery in young people with mental illness were the ingredients for wanting to pursue my career in this field. Thanks Vidya and Dr. Joober, for standing by me while I was getting acquainted with scientific research.

On my first working day, I walked into a large meeting room filled with an overwhelming variety of new faces. I still get nervous thinking about the moment having to read the word "tangentiality" out loud. Thanks dear PEPP-ers, you added so much to making my years in Montreal a blast! Francois, you are a walking PR sign for studying the mental health of migrants and I would have never believed that one day I would thank you for convincing me to come along your meta-analytic ride. I would love to keep on working with you in the future. Heleentje, van een blind date op Rue Mont Royal tot mijn canadese BFF, ik blijf je nog heel lang in Montreal stalken.

Ma famille et mes amis québécois, Marcel, Claire, Claude, Jacinthe, Lou-Jeanne, Émi, Rosie, MC, San, Aida, Annie et tous les autres, merci de m'avoir accueillie les bras ouverts dès mon arrivée à Montréal.

Op een warme zomerdag, in juni 2010, besloot ik in een impulsieve bui een email te sturen naar de Nederlandse expert op het gebied van psychotische stoornissen onder migranten. Gewoon, om mijn bestaan eens aan te kondigen. Na een paar e-mails en een Skypegesprek, was ik opeens een ongeplande remigratie en een promotieplek verder.

Prof. Selten, Jean-Paul, a.k.a. de betrokken promotor en de frontaalkwab van dit proefschrift, toen ik eens teleurgesteld bij je aankwam met in mijn ogen wat onverwachte resultaten, zei je: “Nee joh, geweldig, dit is juist het mooie van wetenschap!" Je enthousiasme werkt aanstekelijk en omdat je oprecht begaan was met mijn onderzoek, bleef mijn motivatie overeind. Ik zie het mede als jouw verdienste dat ik nog lang geen afscheid van de wetenschap wil nemen.

Toen kreeg ik nog een tweede promotor toegewezen, wat een luxe. Prof. van Os, Jim, a.k.a. the cool professor, die zelfs vanuit Marokko of tijdens een WK-wedstrijd met een aanmoedigende quote op een email reageert. Naast je wetenschappelijk talent, bewonder ik je strijdvaardigheid en ik ga graag naast je op de barricade staan voor een nieuwe GGZ waarin we beter voor mensen met psychiatrische klachten zorgen. Leden van de leescommissie, Professoren Therese en Inez, alsook de voor mij nog onbekende Professoren Ormel en 
Mulder, hartelijk dank voor het beoordelen van mijn proefschrift. Dr. Veling, Wim, toen in Canada jouw paper over het beschermende effect van etnische dichtheid op het ontwikkelen van psychose werd gepresenteerd, had ik mijn eigen eureka-momentje: dáár wil ik onderzoek naar doen. Je werk bleef een belangrijke inspiratiebron voor dit proefschrift, dus ik vind het een eer dat je komt opponeren.

$\mathrm{Na}$ de eerste ontmoetingen met mijn promotores, kon het avontuur beginnen. Elles, El, a.k.a. partner in crime van het eerste uur, samen hebben we 100 patiënten, meer dan 100 controlepersonen en 50 broers en zussen voor het EU-GEI onderzoek gezien. Van een manische deelnemer die besloot zijn medepatiënten mee te nemen voor een rondje racen op de GGZ-parkeerplaats, tot ons insectenkantoor in Oegstgeest, huisbezoeken in smoezelige woonkamers en doorgelekte speekselbuizen in de brievenbus, we kunnen een bloemlezing over onze avonturen schrijven. Het waren de meest rare en hilarische momenten; wat een feest dat ik ze samen met jou kon beleven! Al snel kwam ik in contact met Martin, ons andere team JP-lid. Ik denk dat mensen die in de put zitten geen CGT, maar Mart-therapie moeten krijgen; een maatje die je laat zien dat álles mogelijk is, altijd en overal, ook als dat ongelofelijk onwaarschijnlijk lijkt. Het protocol noemen we dan "Optimisme voor gevorderden, een praktijkvoorbeeld". Wat was ik bovendien trots om naast je te staan toen je 'the odd one out' als een koning verdedigde. Dr-to-be Jonas, ons aspirant-lid die er meteen tussen paste, ik hoop nog lang met je samen te werken. Dat geldt ook voor jou, Fabian, je statistische en epidemiologische kennis is jaloersmakend.

Gouda was het beloofde land waar ik mijn patiënten, hun broers en zussen en controle proefpersonen zou gaan werven. Dat brengt mij gelijk bij een enorme dankbetuiging aan de ruggengraat van klinisch onderzoek, namelijk de deelnemers; mensen die urenlang geduldig vragen beantwoorden, zich aan saaie computertaakjes laten onderwerpen en lijstjes invullen. Een aantal deelnemers weigerden zelfs de kleine financiële bijdrage die ze voor deelname kregen en vroegen mij om het ten goede te laten komen aan de patiënten. Sindsdien heeft de opname-afdeling in Gouda waarschijnlijk de meest toegeruste knutselkast van de regio. Dr. Luteijn, Bert, je inspanning voor het onderzoek was goud waard. Hopelijk zetten we onze samenwerking voort, evenals de Firenze-traditie. Asjen, je maakte altijd tijd voor mij om de lijst met nieuwe aanmeldingen door te nemen, ook wanneer het leek alsof je die tijd eigenlijk niet had. Van onschatbare waarde voor dataverzameling en -invoer waren de stagiaires, Marjolein, Lisa en Sophia, en vrijwilligers, Henk en Wieteke; driewerf dank!

Eens per jaar mochten we ergens in Europa naar een EU-GEI vergadering, wat een straf. Een diner bij de barones in Palermo of tapas eten op een binnenplaats in Barcelona, het zijn geweldige herinneringen. A special thank you to all EU-GEI researchers and to my EU-GEI co-authors, Ilaria, Craig and Andrea, it is great working with you.

Onder de vleugels van Rivierduinen waren mijn werkplekken in Leiden en Gouda, maar er was ook een gastplek georganiseerd in het AMC (dank, Prof. de Haan!). Ik begon daar 
met een prikcursus, wat wil zeggen, drie keer in een plastic arm prikken op de plek waar je voorganger een vrij zichtbaar gaatje gemaakt heeft, en vervolgens gewoon op de prikpoli beginnen met het echte werk. Mijn eerste slachtoffer greep zich uit (prik)angst aan de muur van het kamertje vast; gelukkig was ze niet op de hoogte van mijn 2-uur-durende prikervaring. Enfin, lieve collega's van het AMC, bedankt dat jullie mij opnamen als jullie adoptiekind. Misschien een beetje sadistisch, maar het voelt toch veel lekkerder als je samen vastzit in je statistische analyse of als je niet de enige bent die moet dealen met een kwal van een reviewer. Daan, je was een te gekke 'roomie' en ik hield van onze gesprekken die varieerden van de frustrerende wispelturigheid van professoren ("anders laat je die groep toch gewoon uit de (extreem ingewikkelde, tijdrovende) analyse?") tot Tinderdates en het Israel-Palestina-conflict. Floor, Lau en Tamar, fijne collega's en congresmaten, ik denk aan een rokerige club in Bologna, fietspech in Florence of een nachtelijk opstootje in Barcelona, en krijg spontaan een glimlach op mijn gezicht. Jetje, we ontdekten elkaar wat later, maar ik beleef graag nog heel veel toegiften met je. Lindy, kom je nog een keer mee varen? Frederikeje, zonder te overleggen thuis, had ik je opeens in huis gehaald, leve de impulsiviteit! Je bleek de liefste huisgenoot die een mens zich kan wensen, een inspiratie op het gebied van creativiteit en leverancier van kilo's van de allerbeste chocola. Nathalie, Eva, Carin, Karin, Marise, en alle andere AMC'ers, dank, ook jullie waren een wel eens een klankbord of een welkome afleiding tijdens mijn promotiejaren.

Voor een prachtige database met 50.000 gescreende, Zweedse militairen, mocht ik op uitwisseling naar Stockholm. Dear Susanne, Christina, Peter and Cecilia, thanks for welcoming me at the Karolinska Institutet. I was impressed by all the statistical knowledge at the department, as well as your big salmon with potatoe lunches!

Zo belangrijk als begeleiders, promotores en collega's zijn binnen het promotieveld, minstens zo belangrijk zijn de vrienden en familie daarbuiten. Wilhelmina, buddy, onze geschiedenis begon met een zachte $\mathrm{G}$ en paarse Brinta. Wie had ooit kunnen raden dat er tussen die meisjes met die suffe hoedjes zo een hechte vriendschap zou ontstaan, met gezien dat beeld, zoveel vlijmscherpe analyses? Corrie, sorry dat ik geen man voor ons groepje heb aangeleverd, gelukkig tel jij voor twee.

Lieve Rosa, paranimf, als je eenmaal door jouw schilletje bent, is daar een heel comfy plekje waar ik voor de rest van mijn leven lekker zit. Jij tilt loyaliteit naar een hoger niveau, de hoeveelheid adviezen in dit hele proces zijn daar getuige van.

San en Maaik, een baken van steun, liefheid en fijne dinertjes zijn jullie. Boys, a.k.a. dansschoenen en biermaten, ik moet deze lente een beetje afkicken van al die zomers festival-, kroeg- en terrasjolijt (en spijzen), maar in augustus maak ik mijn comeback, ik reken op jullie. Lieve Peet \& Pieter, jullie zijn in korte tijd opeens heel 'present' geworden in mijn leven en daar ben ik superduperblij mee. Rein, dank dat ik gebruik mocht maken van jouw creatief brein.

Hier missen nog heel veel mensen, vandaar deze shout-out naar alle lieve familie en vrienden die mijn leven vullen met gezelligheid, DANK! 
Met een kleine brok in mijn keel begin ik te schrijven aan een kort woord van dank gericht aan de family. In 1983 kwam ik als nakomertje in een groot gezin terecht, waar ik door broers, zussen en ouders, eindeloos verwend en geliefkoosd werd. Wees niet bang, geschwister, anekdotes over je weerloze, kleine zusje kietelen tot ze in haar broek piest of haar vertellen dat spoken bestaan en vervolgens met witte lakens over het hoofd, boe-roepend haar kamer binnensluipen, zal ik hier verder achterwege laten. Brie, je bent een perfect voorbeeld van een oudste zus en hebt mij altijd met verve verdedigd, opgevoed ('Peter Andre for life') en geadviseerd. Tommie, je bent een trouwe hond op wie ik altijd kan rekenen. Ireen, airienie, mijn 5-jaar oudere tweeling in hart en nieren. Eefie, niemand wordt zo blij van een dagje musical als jij, je bent een topper! Thijs, bruder, paranimf, ik ben blij dat je drie jaar op mij gewacht hebt om je examenfeestje te geven, want in die periode ontdekten wij onze kracht; van stressen en moeilijk doen is nog nooit iemand beter geworden. Dit gedeelde motto in combinatie met een flinke dosis humor en men heeft de formule voor een onvervangbare broer-zusrelatie. Lieve koude kant, hier volstaat te zeggen dat ik me zeer gelukkig prijs met de partnerselectie die bovengenoemden gemaakt hebben. Lieve neefjes en nichtjes, als jullie dit kunnen lezen en begrijpen, tante Elsje is trots op jullie!

Dan papa en mama, mijn trouwste fans. Naast producenten en regisseurs van het warmste nest dat een mens zich kan wensen, is jullie onvoorwaardelijkheid en betrokkenheid écht bijzonder. Een klein kind realiseert zich dat niet, een puber ontkent het misschien, maar door de tijd heen wordt die onvoorwaardelijke liefde en acceptatie zo vaak bevestigd dat ik alleen maar kan zeggen dat ik het me realiseer en het niet voor lief neem, dus: dank jullie wel!!

Lautje, mon amour pour toujours, two migrations, two new languages, six houses, we have done it all. And this is only the beginning... How exciting?!

Now let's celebrate! 


\section{Curriculum vitae}

Els van der Ven was born on April 29, 1983 in Nijmegen, the Netherlands. After completing high school at the Stedelijk Gymnasium Nijmegen, she studied Psychology at the University of Utrecht. She obtained her Bachelor degree in 2006. She continued her studies in Neuropsychology and fulfilled her clinical internship at the Zuwe Hofpoort Hospital and Regional Psychiatric Centre in Woerden. She graduated for her Master of Science degree in

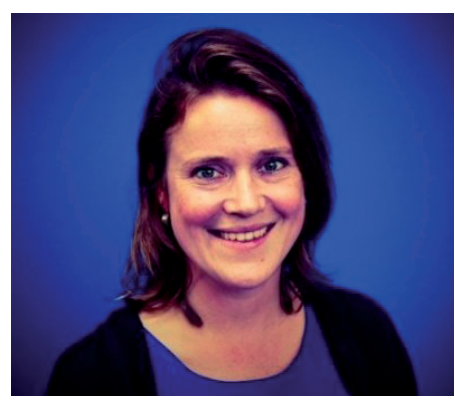
Neuropsychology in 2007.

From 2008 to 2010, she worked under supervision of Prof. dr. Ashok Malla as a symptom evaluator and research assistant at the Prevention and Early Intervention Program for Psychoses (PEPP) of the Douglas Mental Health University Institute, Montreal, Canada. $\mathrm{PEPP}$ is a specialized clinic for young people who are experiencing a first episode of psychosis. During this period, she enrolled as an external student in a postgraduate, international program in Epidemiology at the London School of Hygiene and Tropical Medicine, London, UK, and obtained her postgraduate epidemiology diploma in 2012.

After her return to the Netherlands, she joined the School for Mental Health and Neuroscience (MHeNs), Department of Psychiatry and Neuropsychology at Maastricht University, where she was employed as a PhD Candidate from 2011 to 2015 under supervision of Prof. dr. Jean-Paul Selten and Prof. dr. Jim van Os. She was involved in the EU-GEI (EUropean network of national schizophrenia networks studying Gene-Environment Interactions) project and conducted an incidence and case-control study at the Rivierduinen Mental Health Institute in Gouda. During her PhD-trajectory, she was a guest researcher at the AMC Early Psychosis department, Amsterdam, and at the department of Public Health Sciences of the Karolinska Institutet, Stockholm, Sweden.

In 2015 she started her two-year training as a healthcare psychologist (GZ-psycholoog) in a Flexible Assertive Community Treatment (FACT) team at the Rivierduinen Mental Health Institute in Zoetermeer. 
